\title{
ipen
}

INSTITUTO DE PESQUISAS ENERGÉTICAS E NUCLEARES

Autarquia associada à Universidade de São Paulo

\section{ASPECTOS HIDROBIOLÓGICOS DO COMPLEXO DE REPRESAS PARAIBUNA-PARAITINGA, SÃO PAULO, COM ÊNFASE NA COMUNIDADE FITOPLANCTÔNICA}

JANARA DE CAMARGO MATOS

Dissertação apresentada como parte dos requisitos para a obtenção do Grau de Mestre em Ciências na Área de Tecnologia Nuclear - Materiais.

Orientadora:

Prof. ${ }^{a}$ Dr. ${ }^{a}$ Maria Aparecida Faustino Pires

São Paulo 
Dedico este trabalho aos meus pais, Celso e Zaira, ao meu marido Luiz pela confiança e compreensão pelos momentos em que estive ausente. 


\section{AGRADECIMENTOS}

No desenvolvimento deste trabalho recebi, direta ou indiretamente, grandiosas contribuições, sem as quais, seria simplesmente impossível a conclusão do mesmo. Por isso, deixo aqui meus sinceros agradecimentos:

Primeiramente, à Deus, que sempre me acompanhou e me iluminou para que eu não fraquejasse perante os muitos obstáculos.

Aos meus pais, Celso e Zaira, a quem devo tudo que sou, agradeço pela preocupação constante com meu bem-estar e felicidade, pelo amor e pelo exemplo de honestidade e luta. Vocês são a base das minhas conquistas.

Ao meu marido, Luiz, pela força, paciência, alegria, incentivo e amor que sempre me deu. Obrigada por nunca me deixar desistir.

À minha orientadora Dra Maria Aparecida Faustino Pires pelo exemplo de pessoa e profissional competente, pela confiança, amizade, e apoio incondicional.

Ao Instituto de Pesquisas Energéticas e Nucleares (IPEN) pela infraestrutura oferecida e oportunidade de estudo.

Aos professores do programa de Pós-graduação do IPEN, pelo valiosos conhecimentos transmitidos, possibilitando meu crescimento intelectual e pessoal.

Ao Centro de Química e Meio Ambiente (CQMA) pela oportunidade de realização do projeto e análises.

À Companhia Energética de São Paulo (CESP) pela parceria e colaboração no projeto de pesquisa, em especial ao Biólogo Danilo Canepelle, pelo apoio incondicional nas coletas, ao Sr. Vicente, pela colaboração nas coletas e por nos guiar em segurança à bordo da embarcação.

Ao Instituto de Pesca de São Paulo, nas pessoas do Dro Antonio Olinto Ávila da Silva, pela confiança, e Dra Cacilda Thais Janson Mercante, pela confiança, pela disponibilização do microscópio invertido e pelo livre acesso que me proporcionou às dependências da instituição.

À Dra Marycel Elena Barbosa Cotrim por todo apoio ao projeto e por estar sempre pronta à ajudar. 
À $\operatorname{Dr}^{\mathrm{a}}$ Elizabeth Sonoda Keiko Dantas pelo apoio ao projeto e, principalmente, nas coletas em dias chuvosos.

Ao pessoal da Central do CQMA, Marta e Elias, pela ajuda com os laudos e coletas de campo.

À todos os funcionários do CQMA, pela amizade, pela realização das análises químicas, e pela presteza e cortesia com que sempre fui tratada.

À todos os colegas e amigos de pós-graduação e iniciação científica, aos quais tive o prazer de conhecer e conviver durante o período do mestrado: Lilian, Evelyn, Douglas, Júlia, Gabi, Carlos, Juliana Izidoro, em especial Viviane e Renata, amigas valiosas sempre prontas a ajudar, ouvir e contribuir nos momentos mais difíceis.

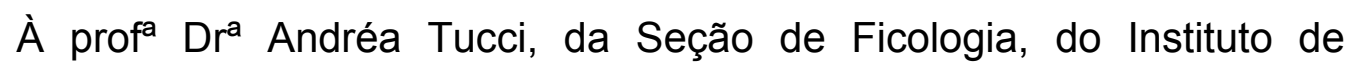
Botânica de São Paulo, pelo auxílio com as análises estatísticas e com a identificação dos táxons, pelo acesso à sua biblioteca particular, por ter me introduzido ao mundo do fitoplâncton e, principalmente, por sua valiosa amizade.

À Dra Silvana Audra Cutolo pela amizade, incentivo, por ter me apresentado o IPEN e, pela disponibilização de equipamentos e instalações.

Ao CNPq pelos 13 meses de auxílio financeiro por meio da bolsa de mestrado.

Às pessoas que não mencionei, mas que em algum momento torceram pelo meu sucesso. 
É melhor tentar e falhar, que preocupar-se e ver a vida passar. É melhor tentar, ainda que em vão que sentar-se, fazendo nada até o final. Eu prefiro na chuva caminhar, que em dias frios em casa me esconder. Prefiro ser feliz embora louco, que em conformidade viver. 


\title{
ASPECTOS HIDROBIOLÓGICOS DO COMPLEXO DE REPRESAS PARAIBUNA-PARAITINGA, SÃO PAULO, COM ÊNFASE NA COMUNIDADE FITOPLANCTÔNICA
}

\author{
Janara de Camargo Matos
}

\begin{abstract}
RESUMO
As águas continentais existem em menor quantidade na superfície terrestre e apresentam grande importância para a sobrevivência dos seres vivos, motivo pelo qual a preocupação com sua qualidade aumenta a cada dia. As represas de Paraibuna e Paraitinga, localizadas no município de Paraibuna, São Paulo, totalizam $224 \mathrm{~km}^{2}$ de extensão de espelho d'água, com função atual de geração de energia elétrica. Com o objetivo de analisar a qualidade da água destas represas, o presente trabalho apresenta um diagnóstico físico, químico, bem como biológico, no qual foi utilizada a comunidade fitoplanctônica e cálculos de índices de qualidade. Foram realizadas quatro coletas em nove pontos de amostragem distribuídos ao longo das represas. As análises físicas e químicas da água demonstraram baixas concentrações de nutrientes como nitrato (média 0,42 $\left.\pm 0,23 \mathrm{mg} \cdot \mathrm{L}^{-1}\right)$ e fosfato $\left(<0,05 \mathrm{mg} \cdot \mathrm{L}^{-1}\right)$. A maior parte dos metais e elementostraço analisados mostraram-se dentro dos limites estabelecidos pela legislação federal. O elemento fósforo apresentou valores acima (média 0,0293 $\pm 0,0153$ $\left.\mathrm{mg} \cdot \mathrm{L}^{-1}\right)$ do estabelecido pela resolução CONAMA 357/05 $\left(0,020 \mathrm{mg} \cdot \mathrm{L}^{-1}\right)$ em todos os pontos de amostragem no mês de maio, porém este fato pareceu não influenciar a densidade fitoplanctônica. Altos valores de oxigênio dissolvido e transparência, baixos valores de turbidez, condutividade e sólidos dissolvidos, $\mathrm{pH}$ próximo à neutralidade, em conjunto com altos índices de diversidade e baixos índices de dominância fitoplanctônica, com predomínio de clorofíceas, demonstraram que as represas estudadas ainda mantêm características de ambiente aquático preservado. Porém, a presença, ainda que em baixas densidades, de cianofíceas e a existência de atividades de monocultura e pecuária no entorno destas represas merecem especial atenção no que tange ao seu correto manejo para que não se tornem fatores prejudiciais à qualidade daquelas águas.
\end{abstract}




\title{
HYDROBIOLOGICAL ASPECTS OF PARAIBUNA AND PARAITINGA DAMS, SÃO PAULO, WITH EMPHASIS ON PHYTOPLANKTON COMMUNITY
}

\author{
Janara de Camargo Matos
}

\begin{abstract}
The inland waters are less on the Earth's surface and are extremely important for the survival of living things, why the concern for quality increases daily. The dams Paraibuna and Paraitinga, located in Paraibuna city, state of São Paulo, totaling $224 \mathrm{~km}^{2}$ of extension of water surface, with the current function of generating electricity. In order to analyze the water quality of these dams, this paper presents a diagnostic physical, chemical, and biological, which was used in the phytoplankton community and calculation of quality indexes. Four samples were taken at nine sampling points distributed along the dams. The physical and chemical analysis of water showed low concentrations of nutrients such as nitrate (mean 0,42 $\left.\pm 0,23 \mathrm{mg} \cdot \mathrm{L}^{-1}\right)$ and phosphate $\left(<0,05 \mathrm{mg} \cdot \mathrm{L}^{-1}\right)$. Most metals and trace elements analyzed were within the limit established by federal law. The element phosphorus (mean 0,0293 $\pm 0,0153 \mathrm{mg} \cdot \mathrm{L}^{-1}$ ) is presented above the values established by CONAMA Resolution 357/05 (0,020 mg. $\left.\mathrm{L}^{-1}\right)$ on all sampling points in the month of May, but this fact did not seem to influence the phytoplankton amount. High levels of dissolved oxygen and transparency, low levels of turbidity, conductivity and dissolved solids, $\mathrm{pH}$ close to neutrality, together with high diversity and low dominance of phytoplankton, with a predominance of green algae, showed that the dams still retain features of aquatic environment preserved, which suffer little influence of anthropogenic factors. However, the presence, even at low densities, of cyanobacteria and the existence of plantations and livestock activities in the borders of these dams deserve special attention in terms of their correct management to not become harmful factors to the quality of those waters.
\end{abstract}




\section{SUMÁRIO}

1. INTRODUÇÃO..............................................................................18

1.1. Impactos ambientais relacionados às usinas hidrelétricas ......................20

1.2. Metais e elementos-traço na água .............................................. 23

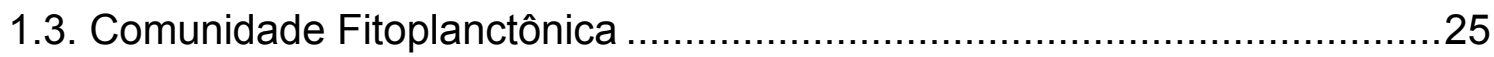

1.4. Qualidade de águas doces superficiais e legislação ............................32

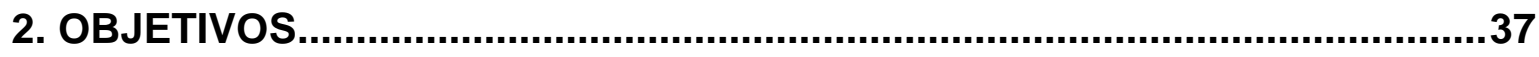

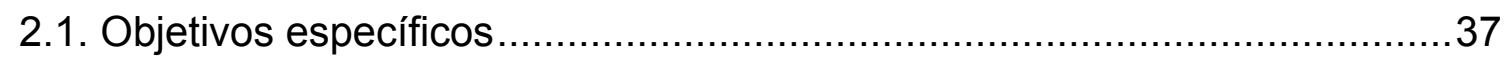

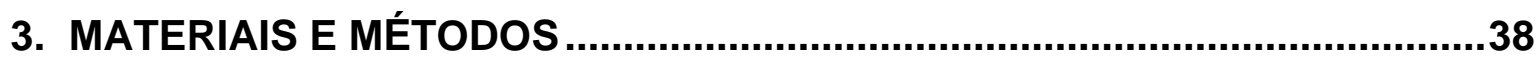

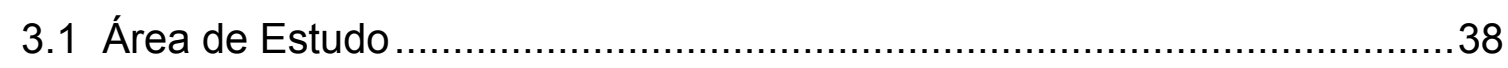

3.2 Periodicidade de amostragem e pontos de coleta ................................4 41

3.3 Dados Climatológicos ................................................................ 44

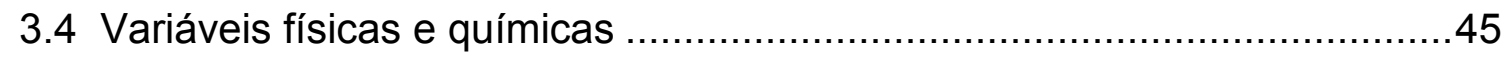

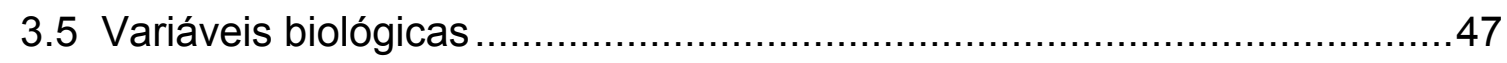

3.6 Aplicação de índices de qualidade ............................................... 51

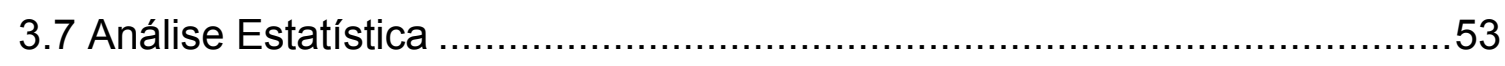

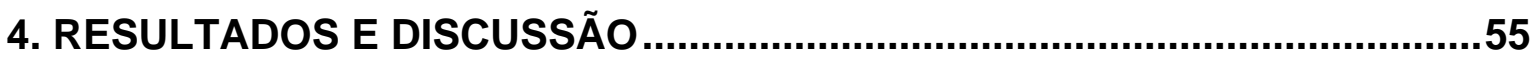

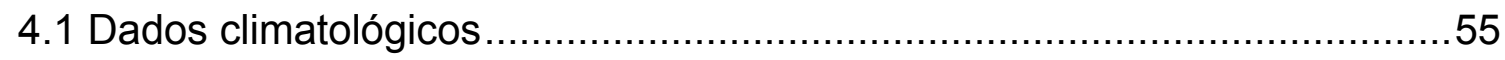

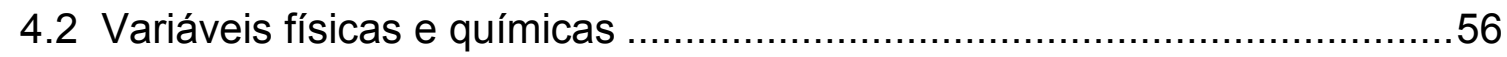

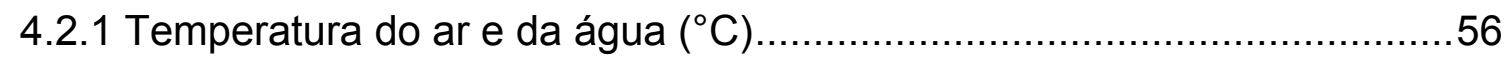

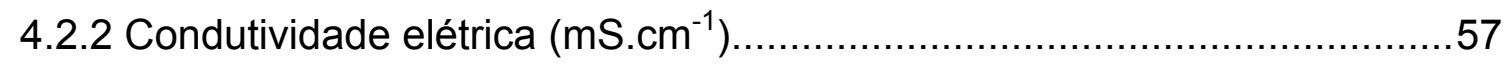

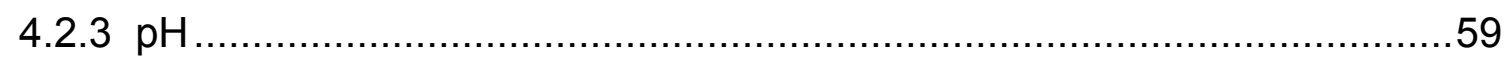

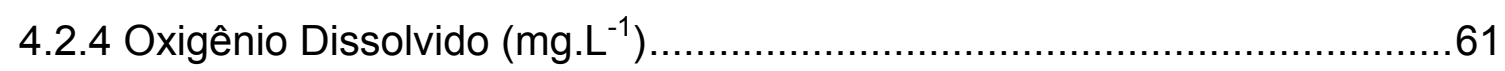

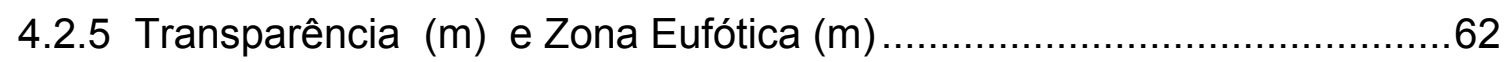

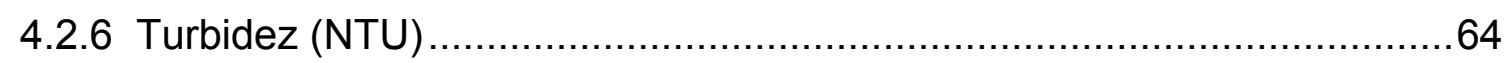

4.2.7 Ânions: Cloreto, Fluoreto, Nitrato, Sulfato e Fosfato $\left(\mathrm{mg} \cdot \mathrm{L}^{-1}\right)$................65

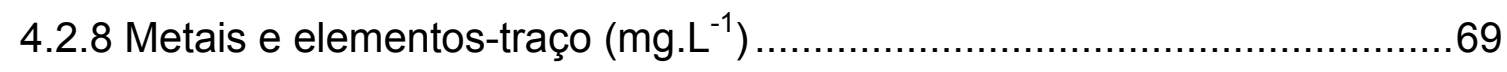

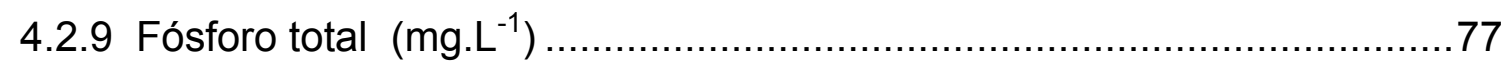

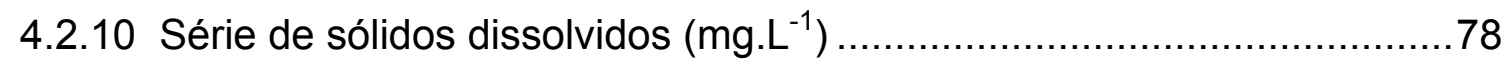

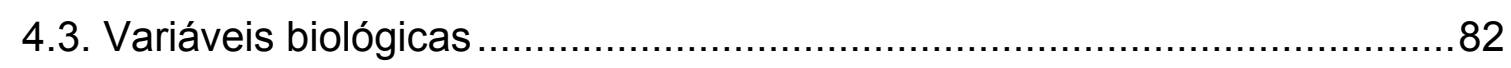

4.3.1 Análise qualitativa da comunidade fitoplanctônica ...............................82

4.3.2 Análise quantitativa da comunidade fitoplanctônica ...........................85 


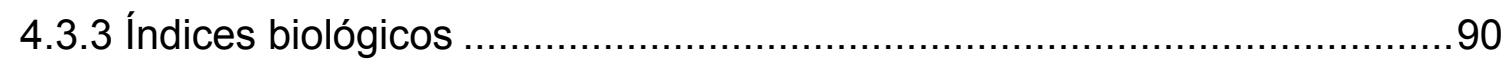

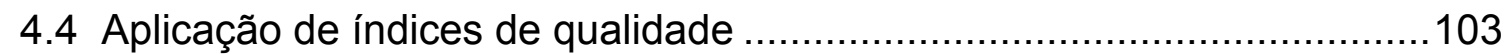

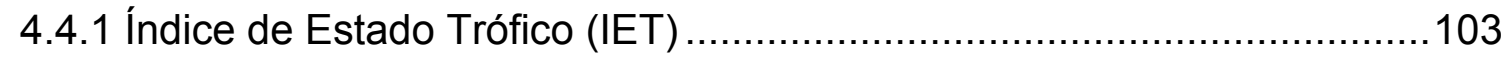

4.4.2 Índice da Comunidade Fitoplanctônica (ICF) .......................................105

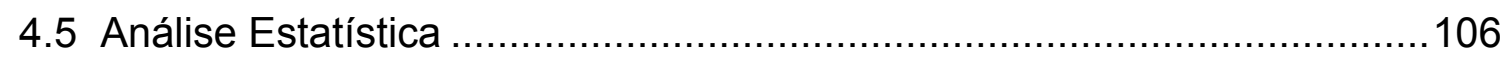

4.6 Análise dos resultados por pontos de amostragem ...............................110

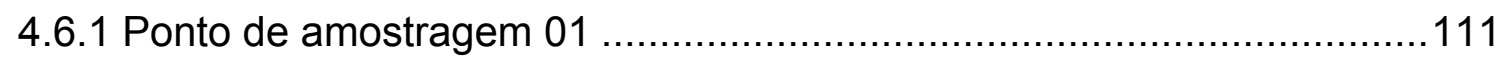

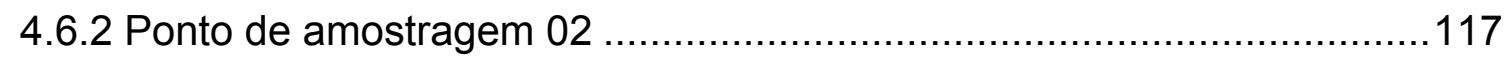

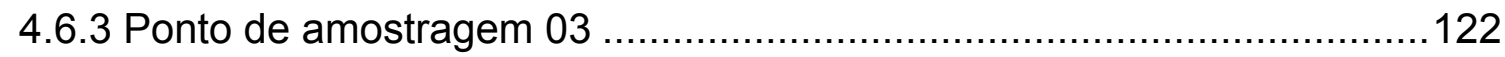

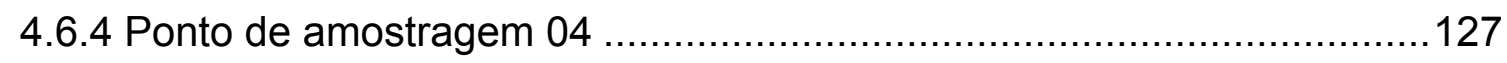

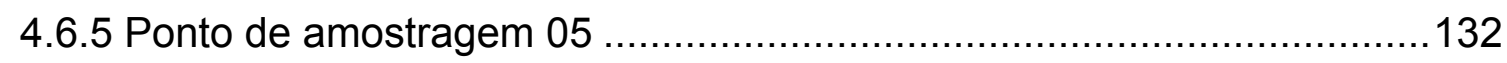

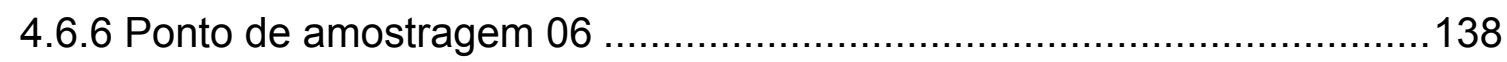

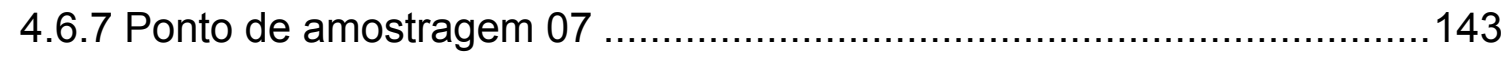

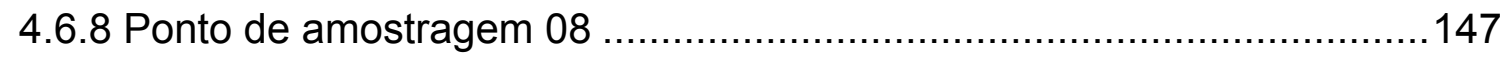

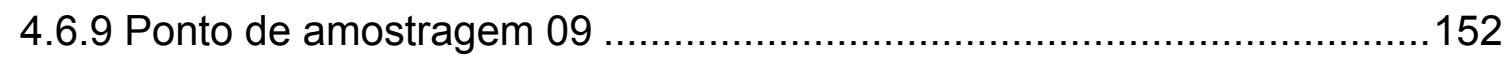

5. CONCLUSÕES

APÊNDICE A - Registro fotográfico do procedimento de coleta em campo...160

APÊNDICE B - Listagem dos táxons inventariados.....................................160

6. REFERÊNCIAS BIBLIOGRÁFICAS.........................................................179 


\section{LISTA DE TABELAS}

TABELA 1 - Classes de águas doces e usos preponderantes segundo resolução CONAMA 357/05

TABELA 2 - Parâmetros físicos e químicos analisados e seus valores limites dispostos na Resolução CONAMA 357/05, para águas doces de classe 2 . 35

TABELA 3 - Carga orgânica poluidora - origem doméstica 41

TABELA 4 - Coordenadas geográficas e descrição dos pontos amostrados .......44

TABELA 5 - Parâmetros físicos e químicos e métodos de análise. .46

TABELA 6 - Classificação do Estado Trófico, segundo Toledo (1990) …............52

TABELA 7 - Classificação do Índice da Comunidade Fitoplanctônica - ICF..........53

TABELA 8 - Dados de precipitação no município de Caraguatatuba .55

TABELA 9 - Média das concentrações dos elementos-traço e metais no período de estudo, desvio padrão (DP), mediana e intervalo de concentração ..................70 TABELA 10 - Concentrações de $\mathrm{Al}$ e Fe que ultrapassaram os valores da

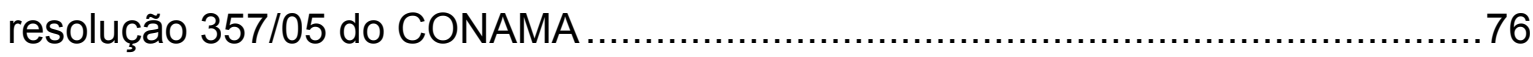

TABELA 11 - Contribuição do número de gêneros por classe taxonômica. .83 TABELA 12 - Espécies descritoras da comunidade fitoplanctônica com base na porcentagem de contribuição na densidade total .88

TABELA 13 - Valores de riqueza média, máxima, mínima, desvio padrão e coeficiente de variação nos meses de amostragem .90

TABELA 14 - Valores de diversidade média, máxima, mínima, desvio padrão e coeficiente de variação nos meses de amostragem

TABELA 15 - Valores de equitabilidade média, máxima, mínima, desvio padrão e coeficiente de variação nos meses de amostragem

TABELA 16 - Valores de dominância média, máxima, mínima, desvio padrão e coeficiente de variação nos meses de amostragem 96

TABELA 17 - Lista geral de táxons identificados, sua frequência de ocorrência (Freq.), classificação (Clas.: $\mathrm{R}=$ raro; $\mathrm{CM}=$ comum; $\mathrm{CT}=$ constante), espécies abundantes $\left(^{*}\right)$ nos meses de estudo.

TABELA 18 - Valores do Índice de Estado Trófico nos pontos de amostragem durante o período de estudo 103

TABELA 19 - Valores do Índice da Comunidade Fitoplanctônica nos pontos de amostragem durante o período de estudo 105 
TABELA 20 - Coeficientes de correlação de Pearson e Kendall entre as variáveis físicas e químicas da água e os dois primeiros eixos de ordenação para o período de estudo $(\mathrm{N}=31)$.

TABELA 21 - Coeficientes de correlação de Pearson e Kendall entre as espécies descritoras da comunidade fitoplanctônica e os dois primeiros eixos de ordenação para o período de estudo $(\mathrm{N}=31)$ 109

TABELA 22 - Parâmetros físicos e químicos e valores medidos no ponto de amostragem 01 em abril de 2008. 116

TABELA 23 - Valor médio, máximo e mínimo, desvio padrão e coeficiente de variação da densidade fitoplanctônica (org. $\mathrm{mL}^{-1}$ ) no ponto 02 durante o período de estudo

TABELA 24 - Valor médio, máximo e mínimo, desvio padrão e coeficiente de variação da densidade fitoplanctônica (org. $\mathrm{mL}^{-1}$ ) no ponto 03 durante o período de estudo 123

TABELA 25 - Valor médio, máximo e mínimo, desvio padrão e coeficiente de variação da densidade fitoplanctônica (org. $\mathrm{mL}^{-1}$ ) no ponto 04 durante o período de estudo

TABELA 26 - Valor médio, máximo e mínimo, desvio padrão e coeficiente de variação da densidade fitoplanctônica (org. $\mathrm{mL}^{-1}$ ) no ponto 05 durante o período de estudo 133

TABELA 27 - Valor médio, máximo e mínimo, desvio padrão e coeficiente de variação da densidade fitoplanctônica (org. $\mathrm{mL}^{-1}$ ) no ponto 06 durante o período de estudo

TABELA 28 - Valor médio, máximo e mínimo, desvio padrão e coeficiente de variação da densidade fitoplanctônica (org. $\mathrm{mL}^{-1}$ ) no ponto 07 durante o período de estudo 144

TABELA 29 - Valor médio, máximo e mínimo, desvio padrão e coeficiente de variação da densidade fitoplanctônica (org. $\mathrm{mL}^{-1}$ ) no ponto 08 durante o período de estudo 149

TABELA 30 - Valor médio, máximo e mínimo, desvio padrão e coeficiente de variação da densidade fitoplanctônica (org. $\mathrm{mL}^{-1}$ ) no ponto 09 durante o período de estudo 154 


\section{LISTA DE FIGURAS}

FIGURA 1 - Abordagens de gerenciamento da qualidade de água em reservatórios, conforme Straškraba e Tundisi (2000). .22

FIGURA 2 - Vista aérea da hidrelétrica do complexo Paraitinga-Paraibuna 40 FIGURA 3 - Localização da Bacia Hidrográfica do Paraíba do Sul e estações de amostragem nas represas Paraibuna e Paraitinga.

FIGURA 4 - a) Câmaras de sedimentação de Utermöhl; b) Microscópio invertido.

FIGURA 5 - Variação da tempertaura do ar e da água nos pontos de amostragem durante o período de estudo.

FIGURA 6 - Variação da condutividade elétrica da água nos pontos de amostragem durante o período de estudo. 58

FIGURA 7 - Variação do pH nos pontos de amostragem durante o período de estudo.

FIGURA 8 - Variação do oxigênio dissolvido nos pontos de amostragem durante o período de estudo.

FIGURA 9 - Variação da transparência e zona eufótica nos pontos de amostragem durante o período de estudo.

FIGURA 10 - Variação da turbidez nos pontos de amostragem durante o período de estudo.

FIGURA 11 - Variação da concentração dos ânions Cloreto, Fluoreto, Nitrato e Sulfato nos pontos de amostragem em abr/08, mai/08, nov/08 e fev/09.

FIGURA 12 - Variação da concentração de alumínio nos pontos de amostragem durante o período de estudo.

FIGURA 13 - Variação da concentração de bário nos pontos de amostragem durante o período de estudo .72

FIGURA 14 - Variação da concentração de ferro nos pontos de amostragem durante o período de estudo.

FIGURA 15 - Variação da concentração de lítio nos pontos de amostragem durante o período de estudo.

FIGURA 16 - Variação da concentração de manganês nos pontos de amostragem durante o período de estudo. 
FIGURA 17 - Variação da concentração de zinco nos pontos de amostragem durante o período de estudo.

FIGURA 18 - Variação da concentração de fósforo nos pontos de amostragem durante o período de estudo.

FIGURA 19 - Contribuição das concentrações de sólidos voláteis (SV) e sólidos fixos (SF) nos sólidos totais nos pontos de amostragem durante o período de estudo.

FIGURA 20 - Variação média de sólidos dissolvidos nos pontos de amostragem durante o período de estudo.

FIGURA 21 - Porcentagem de contribuição geral dos táxons em função das classes nos pontos de amostragem durante o período de estudo.

FIGURA 22 - Porcentagem de contribuição das classes fitoplanctônicas nos quatro meses de amostragem. 84

FIGURA 23 - Densidades totais da comunidade fitoplanctônica (org. $\mathrm{mL}^{-1}$ ). 86 FIGURA 24 - Contribuição das classes na densidade fitoplanctônica no período de estudo.

FIGURA 25 - Riqueza total ( $n^{\circ}$ de táxons) nos pontos de amostragem durante o período de estudo.

FIGURA 26 - Diversidade (bits.ind ${ }^{-1}$ ) nos pontos de amostragem durante o período de estudo.

FIGURA 27 - Equitabilidade (E') nos pontos de amostragem durante o período de estudo.

FIGURA 28 - Dominância (DS') nos pontos de amostragem durante o período de estudo.

FIGURA 29 - Porcentagens do IET, calculadas com base nos valores de fósforo total, nos meses de amostragem. 104

FIGURA 30 - Ordenação biplot, por ACP, das unidades amostrais (pontos de amostragem e meses) e das variáveis físicas e químicas analisadas. 108 FIGURA 31 - Ordenação biplot, por ACP, das unidades amostrais (pontos de amostragem e meses) e das espécies descritoras

FIGURA 32 - Massa de macrófitas aquáticas na represa Paraitinga.

FIGURA 33 - Detalhe Salvinea sp. da represa Paraitinga

FIGURA 34 - Fazenda Ponte Alta localizada próxima ao ponto de amostragem 02 
FIGURA 35 - Área de reflorestamento de eucaliptos localizada próxima ao ponto de amostragem 02.

FIGURA 36 - Densidades totais da comunidade fitoplanctônica (org. $\mathrm{mL}^{-1}$ ) no ponto de amostragem 02 .

FIGURA 37 - Composição da comunidade fitoplanctônica, do ponto de amostragem 02, durante o período de estudo.

FIGURA 38 - Valores de turbidez (NTU) e transparência (m) no ponto de amostragem 02.

FIGURA 39 - Valores de oxigênio dissolvido $\left(\mathrm{mg}^{\mathrm{L}} \mathrm{L}^{-1}\right)$ no ponto de amostragem 02.

FIGURA 40 - Concentração de nitrato, cloreto, sulfato e fluoreto (mg. $\mathrm{L}^{-1}$ ) no ponto de amostragem 02.

FIGURA 41 - Valores de série de sólidos dissolvidos, sólidos voláteis (SV) e sólidos fixos (SF) (mg. $\mathrm{L}^{-1}$ ) no ponto de amostragem 02 . 122 FIGURA 42 - Proporção das classificações do Índice de Estado Trófico (IET), no ponto de amostragem 02, durante o período de estudo.

FIGURA 43 - Área de reflorestamento de eucaliptos localizada próxima ao ponto de amostragem 03.

FIGURA 44 - Densidades totais da comunidade fitoplanctônica (org. $\mathrm{mL}^{-1}$ ) no ponto de amostragem 03.

FIGURA 45 - Valores de oxigênio dissolvido $\left(\mathrm{mg} \cdot \mathrm{L}^{-1}\right)$ no ponto de amostragem 03.

FIGURA 46 - Composição da comunidade fitoplanctônica, do ponto de amostragem 03, durante o período de estudo.

FIGURA 47 - Valores de turbidez (NTU) e transparência (m) no ponto de amostragem 03. 125

FIGURA 48 - Valores de série de sólidos dissolvidos, sólidos voláteis (SV) e sólidos fixos (SF) (mg. $\left.\mathrm{L}^{-1}\right)$ no ponto de amostragem 03. 126

FIGURA 49 - Concentração de nitrato, cloreto, sulfato e fluoreto (mg. $\mathrm{L}^{-1}$ ) no ponto de amostragem 03.

FIGURA 50 - Proporção das classificações do Índice de Estado Trófico (IET), no ponto de amostragem 03, durante o período de estudo.

FIGURA 51 - Área com erosão localizada próxima ao ponto de amostragem 04. 
FIGURA 52 - Densidades totais da comunidade fitoplanctônica (org. $\mathrm{mL}^{-1}$ ) no ponto de amostragem 04 .

FIGURA 53 - Valores de oxigênio dissolvido $\left(\mathrm{mg}^{\mathrm{L}} \mathrm{L}^{-1}\right)$ no ponto de amostragem 04.

FIGURA 54 - Composição da comunidade fitoplanctônica, do ponto de amostragem 04, durante o período de estudo. 130

FIGURA 55 - Valores de turbidez (NTU) e transparência (m) no ponto de amostragem 04.

FIGURA 56 - Valores de série de sólidos dissolvidos, sólidos voláteis (SV) e sólidos fixos (SF) (mg. $\left.\mathrm{L}^{-1}\right)$ no ponto de amostragem 04

FIGURA 57 - Concentração de nitrato, cloreto, sulfato e fluoreto $\left(\mathrm{mg}^{\mathrm{L}} \mathrm{L}^{-1}\right)$ no ponto de amostragem 04.

FIGURA 58 - Proporção das classificações do Índice de Estado Trófico (IET), no ponto de amostragem 04, durante o período de estudo.

FIGURA 59 - Barragem e equipamento de tomada de água da UHE Paraibuna.

FIGURA 60 - Densidades totais da comunidade fitoplanctônica (org. $\mathrm{mL}^{-1}$ ) no ponto de amostragem 05.

FIGURA 61 - Valores de oxigênio dissolvido $\left(\mathrm{mg}^{\mathrm{L}} \mathrm{L}^{-1}\right)$ no ponto de amostragem 05.

FIGURA 62 - Valores de turbidez (NTU) e transparência $(m)$ no ponto de amostragem 05 .

FIGURA 63 - Valores de série de sólidos dissolvidos, sólidos voláteis (SV) e sólidos fixos (SF) (mg. $\left.\mathrm{L}^{-1}\right)$ no ponto de amostragem 05 .

FIGURA 64 - Composição da comunidade fitoplanctônica, do ponto de amostragem 05, durante o período de estudo. 136

FIGURA 65 - Concentração de nitrato, cloreto, sulfato e fluoreto $\left(\mathrm{mg} \cdot \mathrm{L}^{-1}\right)$ no ponto de amostragem 05.

FIGURA 66 - Proporção das classificações do Índice de Estado Trófico (IET), no ponto de amostragem 05, durante o período de estudo.

FIGURA 67 - Área próxima ao ponto de amostragem 06, inexistência de mata ciliar 138

FIGURA 68 - Área próxima ao ponto de amostragem 06, balsa de travessia entre Paraibuna e Natividade da Serra. 
FIGURA 69 - Densidades totais da comunidade fitoplanctônica (org. $\mathrm{mL}^{-1}$ ) no ponto de amostragem 06 .

FIGURA 70 - Valores de oxigênio dissolvido $\left(\mathrm{mg}^{\mathrm{L}} \mathrm{L}^{-1}\right)$ no ponto de amostragem 06.

FIGURA 71 - Valores de turbidez (NTU) e transparência (m) no ponto de amostragem 06.

FIGURA 72 - Composição da comunidade fitoplanctônica, do ponto de amostragem 06, durante o período de estudo.

FIGURA 73 - Valores de série de sólidos dissolvidos, sólidos voláteis (SV) e sólidos fixos (SF) (mg. $\left.\mathrm{L}^{-1}\right)$ no ponto de amostragem 06.

FIGURA 74 - Concentração de nitrato, cloreto, sulfato e fluoreto $\left(\mathrm{mg}^{\mathrm{L}} \mathrm{L}^{-1}\right)$ no ponto de amostragem 06.

FIGURA 75 - Proporção das classificações do Índice de Estado Trófico (IET), no ponto de amostragem 06, durante o período de estudo.

FIGURA 76 - Área próxima ao ponto de amostragem 07, com pastagens e gado.

FIGURA 77 - Densidades totais da comunidade fitoplanctônica (org. $\mathrm{mL}^{-1}$ ) no ponto de amostragem 07.

FIGURA 78 - Valores de oxigênio dissolvido $\left(\mathrm{mg}^{\mathrm{L}} \mathrm{L}^{-1}\right)$ no ponto de amostragem144 07.

FIGURA 79 - Valores de turbidez (NTU) e transparência (m) no ponto de amostragem 07.

FIGURA 80 - Composição da comunidade fitoplanctônica, do ponto de amostragem 07, durante o período de estudo.

FIGURA 81 - Valores de série de sólidos dissolvidos, sólidos voláteis (SV) e sólidos fixos (SF) (mg. $\left.\mathrm{L}^{-1}\right)$ no ponto de amostragem 07 146

FIGURA 82 - Concentração de nitrato, cloreto, sulfato e fluoreto $\left(m g \cdot \mathrm{L}^{-1}\right)$ no ponto de amostragem 07.

FIGURA 83 - Proporção das classificações do Índice de Estado Trófico (IET), no ponto de amostragem 07 , durante o período de estudo.

FIGURA 84 - Área próxima ao ponto de amostragem 08, porto da CESP, estação a balsa para Natividade da Serra.

FIGURA 85 - Área próxima ao ponto de amostragem 08, porto da CESP, presença de pescadores 
FIGURA 86 - Densidades totais da comunidade fitoplanctônica (org. $\mathrm{mL}^{-1}$ ) no ponto de amostragem 08 .

FIGURA 87 - Valores de oxigênio dissolvido $\left(\mathrm{mg}^{\mathrm{L}} \mathrm{L}^{-1}\right)$ no ponto de amostragem 08.

FIGURA 88 - Composição da comunidade fitoplanctônica, do ponto de amostragem 08, durante o período de estudo. 150

FIGURA 89 - Valores de turbidez (NTU) e transparência (m) no ponto de amostragem 08.

FIGURA 90 - Valores de série de sólidos dissolvidos, sólidos voláteis (SV) e sólidos fixos (SF) (mg. $\left.\mathrm{L}^{-1}\right)$ no ponto de amostragem 08

FIGURA 91 - Concentração de nitrato, cloreto, sulfato e fluoreto $\left(\mathrm{mg}^{\mathrm{L}} \mathrm{L}^{-1}\right)$ no ponto de amostragem 08. 152 FIGURA 92 - Proporção das classificações do Índice de Estado Trófico (IET), no ponto de amostragem 08, durante o período de estudo. 152 FIGURA 93 - Área próxima ao ponto de amostragem 09, escassez de mata ciliar.

FIGURA 94 - Densidades totais da comunidade fitoplanctônica (org. $\mathrm{mL}^{-1}$ ) no ponto de amostragem 09. 154 FIGURA 95 - Valores de oxigênio dissolvido $\left(\mathrm{mg}^{\mathrm{L}} \mathrm{L}^{-1}\right)$ no ponto de amostragem 09. 154

FIGURA 96 - Valores de turbidez (NTU) e transparência $(m)$ no ponto de amostragem 09 155

FIGURA 97 - Composição da comunidade fitoplanctônica, do ponto de amostragem 09, durante o período de estudo. 155 FIGURA 98 - Valores de série de sólidos dissolvidos, sólidos voláteis (SV) e sólidos fixos (SF) (mg. $\left.\mathrm{L}^{-1}\right)$ no ponto de amostragem 09 156 FIGURA 99 - Concentração de nitrato, cloreto, sulfato e fluoreto $\left(m g \cdot \mathrm{L}^{-1}\right)$ no ponto de amostragem 09. 156 FIGURA 100 - Proporção das classificações do Índice de Estado Trófico (IET), no ponto de amostragem 09, durante o período de estudo. 


\section{INTRODUÇÃO}

A construção de reservatórios pelo homem é uma atividade que data de milhares de anos, desde a Antiga Mesopotâmia (Margalef, 1983) e, sempre esteve relacionada com o consumo humano, a irrigação de plantações e a biomassa pesqueira. Os reservatórios ou represas são sistemas artificiais construídos em diversas partes do mundo com condições e dimensões variáveis para atender as demandas da população humana.

Estas construções produzem várias modificações nos sistemas terrestres e aquáticos, envolvendo impactos geológicos, climáticos, hídricos, na flora e na fauna bem como sobre o homem e suas atividades (Espíndola, 2001). Tanto a localização da barragem, em relação ao curso do rio, como sua altura determinam diversas características hidrológicas importantes como: as vazões, tipos de relevo do vale, insolação, turbidez, luminosidade das águas e a química dos nutrientes que afetam sua biota (Carvalho, 2003).

No Brasil a construção de grandes reservatórios de água, principalmente para fins de hidroeletricidade e abastecimento público, atingiu seu máximo desenvolvimento nas décadas de 60 e 70 (Tundisi, 1999). As obras hidrelétricas, de uma forma geral, produzem grandes impactos sobre o meio ambiente, que são verificados ao longo do tempo de vida da usina, bem como após sua desativação. Os impactos mais significativos e complexos ocorrem nas fases de construção e de operação da usina, os quais poderão afetar até mesmo o andamento das próprias obras (Sousa, 2000).

A construção do reservatório envolve a diminuição da correnteza do rio, ou seja, a transformação de ambientes lóticos em lênticos. Este processo altera a dinâmica do ambiente aquático influenciando em diversos fatores tais como: o fluxo de deposição de sedimentos, a temperatura da água e a concentração do oxigênio e dos nutrientes (Sousa, 2000).

Além das interferências naturais do represamento, Minillo (2005) destaca que nas últimas décadas, muitos reservatórios no Brasil vêm sofrendo 
impactos antropogênicos como freqüentes despejos domésticos e industriais, principalmente nas regiões próximas aos grandes aglomerados urbanos. Nas demais regiões, o intenso desmatamento, associado à prática de monoculturas tem favorecido o carreamento de solos para o interior dos corpos d'água, juntamente com uma série de subprodutos oriundos de atividades agropecuárias. Em detrimento destas alterações, tem-se verificado o aumento da poluição orgânica, da eutrofização e da toxicidade dos reservatórios.

A eutrofização se caracteriza pelo enriquecimento do sistema aquático, sobretudo em razão do aporte contínuo de nutrientes como nitrogênio e fósforo (Krienitz et al., 1996). Como principal conseqüência ocorre o desenvolvimento acelerado das comunidades biológicas, principalmente das algas (Esteves, 1998; Wetzel, 1993).

As algas constituem um grupo polifiético onde os tipos e as combinações dos pigmentos, a natureza química dos produtos armazenados e as paredes das células são considerados essenciais em sua classificação. Algas livres flutuantes compõem a comunidade fitoplanctônica dos ecossistemas aquáticos, base da cadeia trófica desses ambientes (Pinto-Coelho et al., 2005).

Em estudos ecológico-sanitários, a comunidade fitoplanctônica é de importância fundamental como bioindicador (Beyruth, 1996), já que se encontra em quase todas as águas doces (Branco, 1986).

Segundo Carvalho (2003), o aporte de poluentes em reservatórios pode afetar as comunidades biológicas aquáticas devido ao desaparecimento de espécies sensíveis, ou sua substituição por espécies tolerantes ou oportunistas. Estudos florísticos e taxonômicos são importantes não apenas para pesquisas, mas também para a avaliação da qualidade da água, especialmente em abordagens de monitoramento que dependem de informações taxonômicas.

Medidas capazes de detectar alterações nessas comunidades, como índices de diversidade, índices bióticos e percentuais de organismos indicadores, têm sido ferramentas úteis ao diagnóstico precoce da qualidade dos habitats aquáticos (Warren, 1971; Sládecek, 1973).

A área de estudo do presente trabalho, as represas de Paraibuna e Paraitinga, situadas no estado de São Paulo, são utilizadas para geração de energia elétrica e, estão sob responsabilidade administrativa da Companhia Energética de São Paulo (CESP), juntas, estas represas, têm $224 \mathrm{~km}^{2}$ de 
extensão e volume total de $4.740 \times 10^{6} \mathrm{~m}^{3}$ (CESP, 2008). Estas represas foram enquadradas na classe 2 de águas doces, segundo Decreto Estadual 10.755 de 22/11/1997 (São Paulo, 1977).

Apesar de grande extensão destes corpos d'água, são escassos na literatura os trabalhos de avaliação da qualidade da água. Estas represas não estão inseridas no programa de monitoramento da qualidade de água realizado pela Companhia Ambiental do Estado de São Paulo (CETESB). O ponto de monitoramento da CETESB mais próximo fica no Reservatório de Santa Branca, situado no município de Santa Branca, distante 29 km do município de Paraibuna (Santa Branca, 2009). A CESP realiza monitoramento trimestral em quatro pontos de amostragem das represas, avaliando parâmetros físicos e químicos da água (temperatura, $\mathrm{pH}$, condutividade elétrica, turbidez e oxigênio dissolvido) in loco utilizando sonda Horiba. Foi realizada uma parceria entre a CESP e o IPEN para o desenvolvimento deste projeto, na qual a primeira disponibilizou funcionários, embarcação e equipamentos para realização das coletas, e a segunda procedeu com todas as análises e interpretação de resultados.

Sendo assim, este projeto visa o levantamento das características hidrobiológicas, com ênfase na composição da comunidade fitoplanctônica de corpos d'água ainda em estado conservado, para sua sustentável futura utilização, já que é provável o desenvolvimento da região de localização do complexo Paraibuna-Paraitinga. Existe ainda a possibilidade, em estudo, da utilização destas represas para abastecimento público.

Com os resultados gerados pretende-se obter um panorama geral das características estudadas no complexo Paraibuna-Paraitinga, gerando uma base de informações para futuros estudos e destacando áreas com problemas potenciais de contaminação.

\subsection{Impactos ambientais relacionados às usinas hidrelétricas}

A usina hidrelétrica é uma construção, em geral, maior que todas as demais construções existentes, equipada com máquinas e sistemas sofisticados e caros, para produzir eletricidade usando a energia dos rios (Seva, 2009).

O Brasil começou a utilizar a água dos rios para gerar energia elétrica em 1883, quando entrou em operação a usina hidrelétrica de Ribeirão do Inferno, 
em Diamantina (MG). Tratava-se de uma usina de pequeno porte, destinada ao abastecimento exclusivo de uma mineradora de diamantes. Após essa experiência bem-sucedida, uma série de hidrelétricas começaram a ser construídas no fim do século XIX e início do XX nas proximidades das regiões de maior concentração industrial e populacional. Desta maneira, as barragens que interromperam o curso dos rios e formaram lagos para mover as turbinas nas usinas marcaram época na história da energia no Brasil, país que hoje desponta entre os primeiros do mundo no uso dessa fonte de energia (Horizonte Geográfico, 2009).

Os empreendimentos hidrelétricos inserem-se dentro do interesse coletivo de uma sociedade por elevar, através da oferta de energia, a qualidade de vida da população. No entanto, além dos benefícios energéticos devem ser considerados os efeitos prejudiciais do empreendimento (Sousa, 2000).

Os efeitos negativos ambientais relacionam-se, entre outros, com a interferência do curso natural dos rios, o alagamento de grandes áreas de terras e matas nativas, a formação dos grandes lagos, a modificação nas características físicas e químicas da água e, a eliminação de espécies animais e vegetais.

Segundo Straškraba e Tundisi (2000), ainda ocorrem sobre o meio ambiente, em particular sobre os reservatórios, efeitos impactantes advindos de atividades humanas como desflorestamento, agricultura e agroindústria, irrigação, mineração, recreação, despejo de esgotos e outros dejetos, destruição de várzeas, introdução de espécies exóticas e exploração inadequada de biomassa.

Em contrapartida, as empresas hidrelétricas iniciaram a adoção de medidas, tanto para evitar danos quanto para recuperar o meio ambiente afetado por seus empreendimentos, implementando ações de recuperação de áreas degradadas, repovoamento da ictiofauna e avifauna e implementação de projetos de educação e turismo ambiental (AGEVAP, 2008).

O gerenciamento adequado de barragens é uma das prioridades essenciais na área de conservação, preservação e recuperação de ecossistemas. Implica em um conjunto de instrumentos de gestão que vão desde tecnologias apropriadas até a negociação com usuários das bacias hidrográficas e das barragens (ISA, 2008).

Para Straškraba e Tundisi (2000), há três tipos de abordagens temporais de gerenciamento da qualidade da água em reservatórios: 1) horizonte 
de curto prazo, com ações corretivas que visam melhorar as condições existentes, impedindo que elas piorem (gerenciamento corretivo); 2) horizonte de médio prazo, com gerenciamento dirigido para prevenção do aparecimento de problemas (gerenciamento preventivo); 3) maior horizonte possível, incluindo-se a disponibilidade para as gerações futuras (gerenciamento auto-sustentado) (FIG. $1)$;

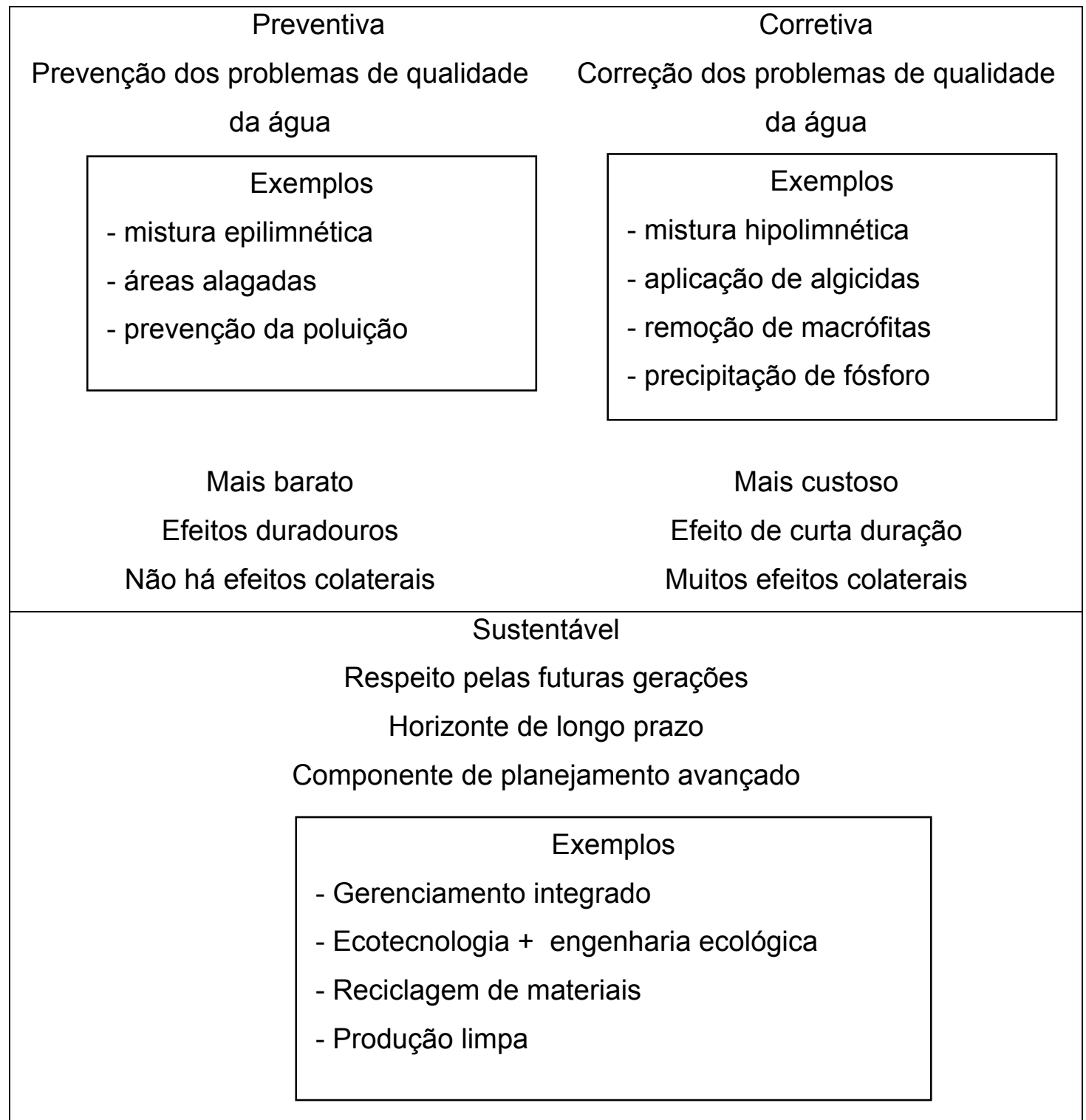

FIGURA 1 - Abordagens de gerenciamento da qualidade de água em reservatórios, conforme Straškraba e Tundisi (2000).

O monitoramento periódico das condições da água do reservatório é extremamente importante por permitir verificar a influência antrópica nas carcterísticas da água e identificar como a qualidade da água do reservatório 
afeta a vida das populações locais. O monitoramento periódico permite registrar modificações na qualidade da água e auxilia na compreensão dos processos físicos, químicos e biológicos no ambiente aquático. Esse conhecimento possibilita prever os efeitos das atividades antrópicas e pode contribuir para a elaboração de metas que visem minimizar seus danos (Figueiredo, 2002).

\subsection{Metais e elementos-traço na água}

A maioria dos elementos-traço faz parte, embora em pequenas concentrações, tanto da constituição da crosta terrestre como dos organismos. No entanto, com a industrialização do mundo moderno, a concentração destes elementos tem aumentado de maneira surpreendente, fazendo com que os elementos-traço, antes inofensivos ao homem, se tornassem uma das mais graves e temidas formas de poluição ambiental que se tem conhecimento (Esteves, 1998).

A presença de metais e outras substâncias inorgânicas tóxicas na água e no sedimento é atribuída aos processos naturais, como o intemperismo das rochas e o carreamento dos solos e aos processos antropogênicos (Primo, 2006). Mais recentemente estas fontes antropogênicas têm assumido grande importância: atividades industriais, através de afluentes sólidos que são lançados diretamente na atmosfera e líquidos que são lançados em pequenos córregos; atividades de mineração; efluentes domésticos e águas superficiais provenientes de áreas cultivadas com adubos químicos e defensivos agrícolas (Esteves, 1998).

A ação química dos metais tóxicos tem despertado grande interesse ambiental. Em geral, os metais, em grande concentração, merecem maior preocupação, especialmente por serem não degradáveis, permanecendo por longos períodos no ambiente, principalmente nos sedimentos. Isto determina que permaneçam em ciclos biogeoquímicos globais nos quais as águas naturais são seus principais meio de condução, podendo se acumular na biota aquática em níveis elevados (Cotta et al., 2006) (bioacumulação e biomagnificação), como por exemplo, se acumulando na gordura de peixes e crustáceos ou ainda em aves e outros animais terrestres, como no leite das vacas que utilizam a água de córregos e rios contaminados e, principalmente, em organismos do topo da 
cadeia trófica na qual o homem está inserido (Santos, 1999; Oliveira e Tornisielo, 2000).

Estudos de Milani (2004) demonstraram a biomagnificação do Al e As de fitoplâncton para zooplâncton, do As de zooplâncton para peixes onívoros e detrívoros e de $\mathrm{Cr}, \mathrm{Cu}, \mathrm{Zn}$ e As de peixes onívoros para detrívoros na Bacia do Taiaçupeba Açu, concluindo que a biomagnificação é relativa, dependente de inúmeros fatores sinérgicos ambientais e biológicos e, que o fitoplâncton demonstrou ser um potencial bioconcentrador de metais, podendo atuar como filtro biológico.

Primo (2006) analisou Ag, Al, As, Ba, Cd, Co, Cr, Fe, Mn, Ni, e Pb em água e sedimento em pontos a montante e a jusante do reservatório do Funil (RJ), formado pelo represamento do Rio Paraíba do Sul, no estado do Rio de Janeiro, concluindo que $\mathrm{As}, \mathrm{Ni}$ e $\mathrm{Pb}$ em todos os pontos de amostragem apresentaram concentrações em água acima do máximo permitido pela resolução do Conselho Nacional do Meio Ambiente (CONAMA) n 357/05.

Concentrações de $\mathrm{Ti}, \mathrm{Cr}, \mathrm{Mn}, \mathrm{Fe}, \mathrm{Cu}, \mathrm{Zn}, \mathrm{Rb}, \mathrm{Sr}, \mathrm{Ba}$, e Pb foram analisadas por Pereira et al. (2006) em amostras de superfície de sedimentos coletadas em estações ao longo do Rio Paraíba do Sul. Foi utilizado o critério internacional de contaminação de sedimento, segundo Long e Morgan (1990) apud Pereira et al. (2006), para analisar os resultados da fração residual (nível de efeito baixo, nível de efeito moderado e nível de efeito severo). A maioria das análises demonstrou níveis de efeitos moderados, porém alguns pontos demonstraram níveis de efeitos severos: Mn no Rio Bocaina; Mn e Zn na região de São José dos Campos; Fe em Volta Redonda; Fe e Mn no Rio Pomba. Os mais críticos estavam nas regiões de São José dos Campos e Volta Redonda, provavelmente devido às descargas de efluentes industriais e domésticos não tratados.

Nos ecossistemas aquáticos continentais, os elementos-traço podem estar sob a forma iônica, complexada (principalmente a moléculas orgânicas) e particulada (principalmente como componente dos detritos e da biomassa), formando complexos que se precipitam no sedimento. Estas também são as formas pelas quais estes elementos chegam aos corpos d'água (Esteves, 1998). As concentrações de metais nos sedimentos são, em geral, maiores que as concentrações dissolvidas na coluna d'água (Foster e Charlesworth, 1996). 
Embora os metais aderidos ao sedimento não estejam biodisponíveis, essa condição pode ser alterada devido às alterações químicas no ambiente. Os sedimentos contaminados por metais são potencialmente vulneráveis, uma vez que os metais anteriormente imobilizados podem ser liberados novamente para a coluna d'água, sob determinadas condições do ambiente, disponibilizando-os para o sistema (água e biota) (Leite, 2002).

Diversos estudos atuais têm sido desenvolvidos enfocando as concentrações de metais na água e no sedimento (Cotrim, 2006; Leite, 2002; Primo, 2006; Soares, 2006).

Cerca de doze metais e metalóides têm sido reconhecidos como potencialmente perigosos à saúde humana e a biota aquática, sendo incluídos na "Priority Polluants List (Black List)" por agências de controle ambiental em todo o mundo, incluindo os elementos antimônio, arsênio, berílio, cádmio, cobre, chumbo, mercúrio, níquel, selênio, prata, tálio e zinco (Cotrim, 2006).

No Brasil, metais considerados tóxicos têm seus padrões de concentrações máximas estabelecidas pela legislação ambiental vigente de acordo com o Conselho Nacional do Meio Ambiente (CONAMA) em sua resolução n 357/05 (Brasil, 2005) e na resolução n 397/08 (Brasil, 2008). O Ministério da Saúde (MS), por sua vez, na Portaria $n^{\circ}$ 518/04 (Brasil, 2004), estabelece valores máximos permitidos de metais para água de consumo humano e seu padrão de potabilidade.

\subsection{Comunidade Fitoplanctônica}

O plâncton é a comunidade que vive suspensa na água e se caracteriza por seu tamanho pequeno, variando desde alguns micrômetros até uns milímetros. Segundo sua natureza pode-se distinguir nas seguintes categorias: bacterioplâncton (bactérias), zooplâncton (copépoda, cladocera, rotíferos), fitoplâncton (algas) e protozooplâncton (protozoários) (Seto, 2007).

Fitoplâncton é a comunidade de organismos microscópicos fotossintetizantes que flutuam livremente nas diversas camadas dos corpos d’água e que é constituída principalmente por algas: clorofíceas, diatomáceas, euglenofíceas, crisofíceas, dinofíceas, xantofíceas e também cianobactérias ou cianofíceas (CETESB, 2005). 
O termo "alga" para designar uma entidade taxonômica, foi usado pela primeira vez por Linnaeus em 1753, em seu trabalho "Species Plantarum", quando assim designou a uma das quatro ordens propostas para as criptógamas. Porém, a maior parte do que Linnaeus denominou como "alga" inclui, na verdade, as hepáticas e os líquenes (Bicudo e Menezes, 2005).

Hoje, o termo "alga" como é compreendido, está desprovido de significado taxonômico e não corresponde, portanto a nenhuma categoria nomenclatural. É, simplesmente um termo coletivo para um grupo de plantas extremamente heterogêneo, e que torna difícil e problemática sua definição (Parra e Bicudo, 1996).

Com base em características morfológicas, fisiológicas e ecológicas, o fitoplâncton pode ser dividido em classes, que podem variar conforme seus autores: Bacillariophyceae, Chlorophyceae, Chrysophyceae, Cryptophyceae, Cyanophyceae, Dinophyceae, Euglenophyceae, Xanthophyceae, Zygnemaphyceae.

Bacillariophyceae, as diatomáceas, inclui organismos unicelulares, coloniais ou filamentosos, imóveis, que possuem clorofila 'a' e 'c'. Possuem parede celular conhecida como frústula, compostas de sílica polimerizada, consistindo em duas metades que se encaixam uma sobre a outra (valvas). Esta parede de sílica pode corresponder até $50 \%$ do seu peso (Esteves,1998). Possuem, dentre as demais classes, a maior taxa de sedimentação que está relacionada ao seu peso. As espécies de diatomáceas podem ser distinguidas pelas diferenças na ornamentação da frústula que pode apresentar estrias, depressões, poros ou canalículos (Raven, 2001), muitos deles visíveis apenas por meio de microscopia eletrônica.

Chlorophyceae, também denominadas, comumente, algas verdes, é o grupo com maior representatividade, em termos de número de táxons, em águas continentais brasileiras conforme mostram diversos estudos (Lopes, 2007; Marques, 2006; Nogueira e Leandro-Rodrigues, 1999; Taniguchi, 2002; Matsuzaki et al. 2004; Lira et al., 2007; Henry et al., 2006). Este grupo inclui mais de 17.000 espécies com estruturas e ciclo de vida diversificadas (Raven, 2001). Composto por organismos unicelulares, coloniais ou filamentosos, móveis ou não, possuem clorofila 'a' e 'b' e reserva energética em forma de amido. Fatores biológicos como tamanho, forma, e habilidade de locomoção, influenciam no potencial de resposta 
de crescimento dessas algas, além das interações com outros organismos (alelopatia, pastagem pelo zooplâncton e casos de parasitismo) (Tucci-Moura, 1996).

Chrysophyceae é composta, em sua maior parte, por organismos unicelulares, alguns coloniais, e raros filamentosos (Wetzel, 1993). Em sua maioria flagelados, fototróficos, alguns são incolores e outros apresentam clorofila 'a' e 'c' e reserva energética em forma de crisolaminarina (Wehr e Sheath, 2003). Também são conhecidas como algas douradas.

Cryptophyceae apresenta células isoladas, com pigmentos clorofila 'a' e 'c', e reserva energética em forma de amido. Com células geralmente assimétricas, portando dois flagelos desiguais, constituem um grupo relativamente pequeno nas águas doces (cerca de 100 espécies), mas, às vezes, de grande importância quantitativa (Esteves, 1998). São organismos encontrados praticamente em todos os ambientes aquáticos principalmente em lagos tropicais (Wehr \& Sheath, 2003).

Cyanophyceae, atualmente denominada, Cyanobacteria, é o grupo de seres procariontes, unicelulares, coloniais ou filamentosas, possuindo apenas clorofila 'a'. Algumas possuem vacúolos gasosos para flutuação, os aerótopos, células especializadas na fixação de nitrogênio, denominadas heterocitos, ou ainda, células que funcionam como esporos de resistência, denominadas acinetos. São organismos comuns em todos os ambientes aquáticos devido às suas diferentes estratégias adaptativas (Wehr e Sheath, 2003). Em águas continentais, as cianofíceas constituem-se no principal grupo responsável por problemas sanitários devido ao seu potencial de produção de toxinas (Werner, 2002).

Dinophyceae, conhecidos como dinoflagelados, é constituída por organismos unicelulares, tecados ou não, assimétricos, com dois flagelos diferentes na forma e função. Existem cerca de 230 espécies de água doce, distribuídos em 30 gêneros, sendo Peridinium e Gymnodinium as mais freqüentes nestas águas (Esteves, 1998). Possuem clorofila 'a' e 'c' e reserva energia em forma de amido. Preferem águas bem oxigenadas, com alta concentração de cálcio (água dura), com muita luz e temperatura mais elevada (Wehr e Sheath, 2003). 
Euglenophyceae inclui seres unicelulares flagelados, que possuem clorofila 'a' e 'b'. Aproximadamente $50 \%$ dos representantes realizam fotossíntese, sua reserva de energia está na forma de paramido. São freqüentemente encontradas em águas ricas em matéria orgânica, fósforo e nitrogênio (Alves-da-Silva e Laitano, 1994). O fato de poderem se movimentar é uma vantagem em ambientes túrbidos com relação a luz e permite, ainda, que estas algas possam utilizar nutrientes presentes em camadas mais profundas, podendo em seguida voltar para a região eufótica (Giani et al.,1999).

Xanthophyceae é um grupo composto por seres unicelulares, coloniais ou filamentosas, comumente encontram-se fixadas a um substrato (Wetzel, 1993). Apresentam clorofila 'a' e 'c', e xantofilas (anteroxantina, luteína e trolixantina) como pigmentos acessórios típicos deste grupo. A reserva é constituída de material graxo e crisolaminarina. Geralmente são dulcícolas (Parra e Bicudo, 1996).

Zygnemaphyceae, as desmídias, inclui organismos compostos de duas semicélulas iguais, seus cloroplastos ocupam quase todo o volume da célula, possuem pigmentos clorofila 'a' e 'b'. Comumente encontradas em águas ácidas, pobres em nutrientes, com baixa produtividade. Muitas desmídias ocorrem entre macrófitas e/ou frouxamente aderidas a elas (Wehr e Sheath, 2003).

A composição do fitoplâncton varia sazonalmente e é dependente das localização geográfica. A dependência geográfica é fruto não apenas de variáveis físicas como radiação e temperatura, mas também das inter-relaçoes bióticas dentro do corpo d'água (Straškraba e Tundisi, 2000).

A heterogeneidade da distribuição do fitoplâncton e sua abundância podem variar temporal e espacialmente. A escala de variação temporal está correlacionada aos fatores climáticos como radiação, temperatura da água e chuvas. A sazonalidade do plâncton é um dos mais estudados exemplos de sucessão, ou seja, ocorrem mudanças temporais na comunidade e no ecossistema, onde espécies mais bem adaptadas às novas condições do ambiente podem excluir as originais. A variação espacial é estreitamente relacionada aos influxos ambientais e estes podem regular a composição e densidade da flora ficológica (Henry et al., 1998).

No ambiente aquático, cada espécie de alga apresenta características inferiores e superiores que constituem os seus limites de tolerância, entretanto, a 
composição física e química da água de um reservatório apresenta variações que dependem da estação do ano, do período do dia, do local e da profundidade. O fósforo é o nutriente que potencialmente limita o crescimento do fitoplâncton e, a liberação de substâncias nos ecossistemas aquáticos produz uma variedade de respostas complexas nos organismos. A concentração de nutrientes disponíveis no meio é indispensáel ao metabolismo das algas (Xavier, 1979).

Dentre os bioindicadores aquáticos, as algas planctônicas são organismos amplamente empregados nos estudos da qualidade da água, pois possuem ecologia bem conhecida e apresentam respostas rápidas e bem marcadas às alterações dos ecossistemas.

O exame dos componentes do fitoplâncton, sua identificação e quantificação são de grande interesse para avaliar as condições ecológicas de um ecossistema aquático, prevenir ou controlar situações indesejáveis ou incompatíveis com a finalidade de utilização de um determinado manancial e, inclusive, para o desenvolvimento de culturas de interesse econômico, como a piscicultura (CETESB, 2005).

Em geral, águas limpas e pobres em nutrientes apresentam uma comunidade fitoplanctônica pouco abundante, com alta diversidade, enquanto que águas ricas em nutrientes apresentam grande número de organismos, pertencentes a poucas espécies (CETESB, 2005).

Se corretamente analisados, as modificações na comunidade fitoplanctônica podem adquirir caráter preditivo sobre as possíveis mudanças no meio onde ocorrem (Huszar, 1994).

Diversos estudos no Brasil, especialmente na região Sudeste, têm contribuído para o conhecimento da composição e variação da comunidade fitoplanctônica das águas continentais.

Matsuzaki (2002) acompanhou a variação sazonal do fitoplâncton num pesqueiro, localizado na Zona Sul da cidade de São Paulo, e sua relação com a qualidade de água. Foram realizadas quatro coletas em três pontos de amostragem. As análises demonstraram a ocorrência de 91 táxons distribuídos em 8 classes sendo Chlorophyceae (53\%) e Cyanophyceae (16,5\%) as mais representativas. Dentre as espécies de cianofíceas destacaram-se Microcystis paniformis, Cylindrospermopsis raciborskii e Anabaena spp., que apresentaram 
maior importância do ponto de vista sanitário devido ao seu potencial de produção de toxinas.

Os lagos Aníbal, Dom Helvético e o lago do Carvão com Azeite, localizados no Vale do Rio Doce, estado de Minas Gerais, foram estudados por Taniguchi (2002), que avaliou a estrutura, variação espacial e temporal da comunidade fitoplanctônica, concluindo que, maiores densidades fitoplanctônicas registradas no lago Aníbal foram relacionadas à maior concentração de nutrientes, principalmente, nitrogênio e fósforo e maiores densidades relativas e número de espécies de desmídias (Conjugatophyceae), no lago Dom Helvético, foram associadas às condições oligotróficas do mesmo.

Ferragut et al. (2005) analisaram a ficoflórula perifítica e planctônica do Lago do IAG, localizado no Parque Estadual das Fontes do Ipiranga (PEFI), município de São Paulo, considerado um reservatório oligotrófico raso. Foram identificados 198 táxons distribuídos em 13 classes. Dentre os táxons identificados, 93 foram encontrados exclusivamente no perifíton, 31 apenas no plâncton e 75 comuns aos dois hábitats. Cinco táxons foram referidos pioneiramente para o Brasil e 38 táxons para o $\mathrm{PEFI}$.

O Lago das Garças, também localizado no Parque Estadual das Fontes do Ipiranga (PEFI), município de São Paulo, foi estudado por Tucci et al. (2006), que contribuíram com os estudos florísticos já existentes sobre a comunidade fitoplanctônica daquele local. Foram identificados 265 táxons distribuídos em 12 classes, sendo 88 táxons novas ocorrências para o Lago das Garças. Destas, 29 pertencem às Chlorophyceae e 22 às Cyanobacteria, dentre elas, seis espécies potencialmente tóxicas.

Giani et al. (1999) descreveram 28 táxons de algas planctônicas pertencentes às divisões Euglenophyta, Chrysophyta, Pyrrophyta e Cyanobacteria, encontradas no reservatório da Pampulha, estado de Minas Gerais. Foram analisadas amostras no período de maio/1992 a fevereiro/1997. Euglenophyta foi a que apresentou maior número de espécies (13 espécies em uma família), seguidas de Cyanobacteria (oito espécies), Pyrrophyta (cinco espécies) e Chrysophyta (duas espécies). Vinte e três táxons foram as primeiras citações para o estado de Minas Gerais.

Apesar da relevância dos estudos limnológicos englobando fatores biológicos, como o fitoplâncton, sua composição, diversidade, distribuição e 
variação espacial e temporal, estas informações ainda são pouco exploradas, principalmente em ambientes preservados. No que se refere ao fitoplâncton das represas Paraibuna e Paraitinga, tais informações inexistem.

Nestas represas alguns trabalhos foram realizados, como o de Gianesella-Galvão (1986) que analisou a produtividade primária do fitoplâncton em três pontos da represa de Paraibuna utilizando o método do C-14 e clorofila-a, durante os meses de Março, Maio, Agosto e Dezembro do ano de 1979. Concluindo que, a produtividade fitoplanctônica, durante o período de estudo, sempre apresentou baixos valores $\left(0,8\right.$ - 5,8 $\left.\mathrm{mgC} \cdot \mathrm{m}^{2} \cdot \mathrm{hr}^{1}\right)$, sendo o fósforo o nutriente limitante desta produtividade.

Shimizu et al. (1990) estudaram as diferentes coberturas vegetais marginais da represa e a relação com a quantidade de alguns elementos como $P$, $\mathrm{Pb}, \mathrm{Cu}$ e Al na água, durante doze meses. Identificaram a ocorrência de mistura na coluna d'água no período mais frio. Devido ao escoamento superficial no período chuvoso, elementos como $\mathrm{P}, \mathrm{Pb}, \mathrm{Cu}$ e $\mathrm{Al}$ foram detectáveis somente neste período. Outros elementos como $\mathrm{Ca}$, Mg e Fe apresentaram maiores concentrações também no período chuvoso. A quantidade de elementos minerais na água da represa foi maior na região de margem com mata natural secundária, constatando-se que a qualidade química da água é dependente da cobertura vegetal marginal do sistema terrestre.

Cabe citar Brandimarte (1991), que analisou a macrofauna bentônica da zona litoral da represa Paraibuna sujeita à influência de quatro tipos de vegetação marginal, mata secundária residual, reflorestamentos, com sete e três anos de idade, e campo abandonado. Após as análises das doze amostras mensais, ficou constatado que a densidade das comunidades bentônicas litorais diminuiu no final do outono e durante o inverno, em função da queda da temperatura e da menor entrada de matéria orgânica de origem terrestre. Neste período, houve queda da equitatividade dos grupos taxonômicos, com conseqüente declínio da diversidade.

Cabianca (1991) avaliou a composição da comunidade zooplanctônica, em quatro diferentes locais da represa Paraibuna, com amostragens realizadas na zona litoral e limnética. A comunidade zooplanctônica apresentou riqueza de espécies considerável, mas densidades bastante reduzidas. Foi notada sazonalidade nítida, com a comunidade mais abundante nos meses quentes e 
chuvosos. Houve diferenciação porcentual de cada grupo zooplanctônico entre os pontos litoral e limnético, pois a medida que se afastou da margem, diminuíram os rotíferos e ganharam importância os ciclopóides cladóceros.

Kuhlmann (1993) caracterizou a comunidade bentônica da zona profunda da represa de Paraibuna através da análise de 15 amostras mensais do sedimento, em três profundidades, em quatro áreas com sistemas terrestres circundantes de coberturas vegetais distintas. As comunidades bentônicas mostraram homogeneidade espacial, com dominância principalmente de microcrustáceos. Não houve diferenças espaciais significativas no índice de diversidade. Pequenas variações espaciais populacionais foram detectadas, principalmente, em relação às abundâncias de Bryozoa, tendo sido relacionadas à disponibilidade de detrito grosseiro. Ao final da primavera, as quatro áreas exibiram as mais evidentes alterações estruturais de bentos profundal, quando o habitat passou a apresentar características sublitorâneas.

Dias et al. (2007) realizaram a caracterização das águas da represa Paraibuna utilizando dados hiperspectrais identificando boas condições tróficas desta represa. Os resultados indicaram também a ocorrência, em baixas concentrações, de sólidos em suspensão. Em três pontos de amostragem próximos à barragem foi identificada à presença de cianobactérias.

\subsection{Qualidade de águas doces superficiais e legislação}

O Brasil destaca-se mundialmente pela grande quantidade de água doce disponível em seu território, sendo responsável por $53 \%$ da produção de água doce do continente sul-americano e 12\% do total mundial (Rebouças, 1999).

A maior demanda por água no Brasil, como acontece em grande parte dos países, é a agricultura, sobretudo a irrigação, com cerca de $56 \%$ do total. 0 uso doméstico responde por $27 \%$ da demanda, em seguida está a indústria com $12 \%$ e, por útimo, a pecuária, para dessedentação de animais, com 5\% (ISA, 2008).

Em 1997, a Lei 9.433 instituiu a Política Nacional de Recursos Hídricos objetivando a criação de um Sistema Nacional de Gerenciamento de Recursos Hídricos, composto por Conselho Nacional de Recursos Hídricos, Agência Nacional de Águas, Conselhos de Recursos Hídricos dos Estados e do Distrito 
Federal, Comitês de Bacias Hidrográficas, órgãos dos poderes públicos federal, estaduais, do Distrito Federal e municipais, cujas competências se relacionem com a gestão de recursos hídricos e, as Agências de Água, que serão responsáveis pela gestão sistemática e integrada das águas doces brasileiras, com o intuito de assegurar, à atual e às futuras gerações, água em qualidade e quantidade suficientes através da utilização racional e integrada e da prevenção dos recursos hídricos.

O órgão brasileiro responsável pela regulamentação dos níveis de qualidade das águas doces, salobras e salinas é o CONAMA (Conselho Nacional de Meio Ambiente).

A Resolução CONAMA n 357/05 (Brasil, 2005) fornece os limites de padrões medidos em corpos d'água dentro de 5 classes de águas doces definidas pelos seus usos preponderantes (TAB. 1). Esta resolução dispõe sobre a classificação das águas doces, salinas e salobras e as diretrizes ambientais para o seu enquadramento, bem como estabelece as condições e padrões de lançamento de efluentes. 
TABELA 1 - Classes de águas doces e usos preponderantes segundo resolução CONAMA 357/05

\begin{tabular}{|c|c|}
\hline Classe & Uso preponderante \\
\hline Especial & $\begin{array}{l}\text { Abastecimento para consumo humano com desinfecção; } \\
\text { preservação do equilíbrio natural das comunidades aquáticas; } \\
\text { preservação dos ambientes aquáticos em unidades de } \\
\text { conservação de proteção integral. }\end{array}$ \\
\hline 1 & $\begin{array}{l}\text { Abastecimento para consumo humano após tratamento } \\
\text { simplificado; proteção das comunidades aquáticas; recreação } \\
\text { de contato primário, tais como natação, esqui aquático e } \\
\text { mergulho conforme Res. CONAMA 274/00; irrigação de } \\
\text { hortaliças que serão consumidas cruas, ou de frutas sem } \\
\text { remoção de película; proteção das comunidades aquáticas em } \\
\text { Terras Indígenas. }\end{array}$ \\
\hline 2 & $\begin{array}{l}\text { Abastecimento para consumo humano após tratamento } \\
\text { convencional; proteção das comunidades aquáticas; recreação } \\
\text { de contato primário, tais como natação, esqui aquático e } \\
\text { mergulho conforme Res. CONAMA 274/00; irrigação de } \\
\text { hortaliças, frutas frutíferas e de parques, jardins, campos de } \\
\text { esporte e lazer, com os quais o público possa vir a ter contato } \\
\text { direto; aqüicultura e à atividade de pesca. }\end{array}$ \\
\hline 3 & $\begin{array}{l}\text { Abastecimento para consumo humano após tratamento } \\
\text { convencional ou avançado; recreação de contato secundário; } \\
\text { irrigação de culturas arbóreas, cerealíferas e forrageiras; pesca } \\
\text { amadora e dessedentação de animais. }\end{array}$ \\
\hline 4 & Navegação e harmonia paisagística. \\
\hline
\end{tabular}

A preocupação com a qualidade das águas também está registrada na portaria $n^{\circ}$ 518/04 (Brasil, 2004), do Ministério da Saúde, que estabelece padrões de qualidade e potabilidade de água para consumo humano, dentre outros parâmetros, determinando níveis máximos permissíveis para densidade de cianobactérias e concentração de cianotoxinas.

O enquadramento dos corpos hídricos do estado de São Paulo foi dado pelo Decreto Estadual no 10.755 de 22/11/1977 (São Paulo, 1977). De acordo com este decreto os reservatórios de Paraibuna e de Paraitinga foram enquadrados na classe 2, que apresenta os valores limites dos parâmetros analisados no presente trabalho, dispostos na tabela abaixo (TAB. 2), segundo resolução CONAMA 357/05, para águas doces de classe 2. 
TABELA 2 - Parâmetros físicos e químicos analisados e seus valores limites dispostos na Resolução CONAMA 357/05, para águas doces de classe 2

\begin{tabular}{lc}
\hline \multicolumn{1}{c}{ Parâmetros } & Valores limites \\
\hline $\mathrm{pH}$ & $6,0 \mathrm{a} 9.0$ \\
Oxigênio Dissolvido (OD) & não inferior a $5,0 \mathrm{mg} \cdot \mathrm{L}^{-1}$ \\
Turbidez & $100 \mathrm{NTU}$ \\
Nitrato & $10 \mathrm{mg} \cdot \mathrm{L}^{-1}$ \\
Sulfato & $250 \mathrm{mg} \cdot \mathrm{L}^{-1}$ \\
Cloreto & $250 \mathrm{mg} \cdot \mathrm{L}^{-1}$ \\
Fluoreto & $1,4 \mathrm{mg} \cdot \mathrm{L}^{-1}$ \\
Sólidos dissolvidos totais & $500 \mathrm{mg} \cdot \mathrm{L}^{-1}$ \\
$\mathrm{Ag}$ & $0,01 \mathrm{mg} \cdot \mathrm{L}^{-1}$ \\
$\mathrm{Al}$ & $0,1 \mathrm{mg} \cdot \mathrm{L}^{-1}$ \\
$\mathrm{As}$ & $0,01 \mathrm{mg} \cdot \mathrm{L}^{-1}$ \\
$\mathrm{Ba}$ & $0,7 \mathrm{mg} \cdot \mathrm{L}^{-1}$ \\
$\mathrm{~B}$ & $0,5 \mathrm{mg} \cdot \mathrm{L}^{-1}$ \\
$\mathrm{Be}$ & $0,04 \mathrm{mg} \cdot \mathrm{L}^{-1}$ \\
$\mathrm{Cr}$ & $0,05 \mathrm{mg} \cdot \mathrm{L}^{-1}$ \\
$\mathrm{Co}$ & $0,05 \mathrm{mg} \cdot \mathrm{L}^{-1}$ \\
$\mathrm{Cu}$ & $0,009 \mathrm{mg} \cdot \mathrm{L}^{-1}$ \\
$\mathrm{Cd}$ & $0,001 \mathrm{mg} \cdot \mathrm{L}^{-1}$ \\
$\mathrm{Fe}$ & $0,3 \mathrm{mg} \cdot \mathrm{L}^{-1}$ \\
$\mathrm{Hg}$ & $0,0002 \mathrm{mg} \cdot \mathrm{L}^{-1}$ \\
$\mathrm{Li}$ & $2,5 \mathrm{mg} \cdot \mathrm{L}^{-1}$ \\
$\mathrm{Mn}$ & $0,1 \mathrm{mg} \cdot \mathrm{L}^{-1}$ \\
$\mathrm{Ni}$ & $0,025 \mathrm{mg} \cdot \mathrm{L}^{-1}$ \\
$\mathrm{P}$ & $0,02 \mathrm{mg} \cdot \mathrm{L}^{-1}$ \\
$\mathrm{~Pb}$ & $0,01 \mathrm{mg} \cdot \mathrm{L}^{-1}$ \\
$\mathrm{Sb}$ & $0,005 \mathrm{mg} \cdot \mathrm{L}^{-1}$ \\
$\mathrm{Se}$ & $0,01 \mathrm{mg} \cdot \mathrm{L}^{-1}$ \\
$\mathrm{Zn}$ & $0,1 \mathrm{mg} \cdot \mathrm{L}^{-1}$ \\
\hline
\end{tabular}


No Estado de São Paulo, a Lei n 9.866 de 1997 dispõe sobre diretrizes e normas para proteção e recuperação das bacias hidrográficas dos mananciais de interesse regional para abastecimento das populações, atuais e futuras, do Estado de São Paulo, assegurando compativelmente os demais usos múltiplos.

A lei, no entanto, não define quais são as áreas consideradas de interesse para o abastecimento público, ou seja, não cria efetivamente as Áreas de Proteção e Recuperação de Mananciais (APRM). Para que isso ocorra é necessário um complexo sistema de elaboração e aprovação, que se inicia com os Comitês de Bacia Hidrográfica, que deverão propor ao Conselho Estadual de Recursos Hídricos a criação de uma determinada APRM, que, se aprovar a proposta, e depois de ouvidos o CONSEMA e o Conselho de Desenvolvimento Regional - CDR, a encaminhará ao Poder Executivo para que este finalmente encaminhe um Projeto de Lei à Assembléia Legislativa propondo não só a criação de uma APRM, mas também a aprovação de uma lei específica que regulamente as atividades de gestão, preservação e recuperação ambiental na região protegida (Mananciais, 2009). 


\section{OBJETIVOS}

Avaliar a qualidade da água das represas Paraibuna e Paraitinga, São Paulo, em relação às variáveis limnológicas e a estrutura da comunidade fitoplanctônica, visando obter informações que demonstrem um panorama geral da área de estudo, e que possibilite sua futura utilização sustentável.

\subsection{Objetivos específicos}

- Apresentar as principais características hidrobiológicas das represas Paraibuna e Paraitinga.

- Analisar a estrutura da comunidade fitoplanctônica através da identificação das espécies, densidades, dominância, freqüência de ocorrência e índices biológicos, e verificar a influência das variáveis climatológicas, físicas e químicas sobre esta comunidade;

- Analisar a variação sazonal e espacial desta comunidade;

- Obter informações temporais e espaciais sobre a presença de metais e elementos-traço no reservatório da Usina Hidrelétrica de Paraibuna;

- Analisar o grau de trofia destes corpos d'água através do Índice de Estado Trófico (IET) e do Índice da Comunidade Fitoplanctônica (ICF). 


\section{MATERIAIS E MÉTODOS}

\section{1 Área de Estudo}

O Município de Paraibuna está situado no Vale do Paraíba, na escarpa da Serra do Mar, sub-região do Alto rio Paraíba, onde se forma o Rio Paraíba do Sul, com a confluência dos rios Paraibuna e Paraitinga.

O território do município de Paraibuna abrange uma área de aproximadamente $811,7 \mathrm{~km}^{2}$, dentre as quais $779,28 \mathrm{~km}^{2}$ são de área rural e $32,47 \mathrm{~km}^{2}$ são de área urbana $\left(3,25 \mathrm{~km}^{2}\right.$ são considerados área vazia) limitado ao norte com o município de Caraguatatuba, a leste com os de Redenção da Serra e Natividade da Serra e a oeste com os municípios de Santa Branca e Salesópolis (Instituto H \& H Fauser, 2009).

Com topografia acidentada (morraria), cerca de 15 mil hectares do território de Paraibuna foi ocupado por projetos de silvicultura abrindo espaço para a monocultura do eucalipto, voltada basicamente para o abastecimento da indústria de papel e celulose (Paraibuna, 2008).

O clima é classificado como mesotérmico ou CWA, segundo a classificação de Koppen. Seus verões são brandos e os invernos secos; a temperatura máxima é $32,35{ }^{\circ} \mathrm{C}$ e a mínima é $7,5^{\circ} \mathrm{C}$, sendo a temperatura média anual $20,4{ }^{\circ} \mathrm{C}$. Os ventos predominantes no verão vêm do norte e no inverno do sul. A precipitação anual varia entre $1300 \mathrm{~mm}$ e $1500 \mathrm{~mm}$; sendo o mês mais chuvoso dezembro e o mais seco agosto (Instituto H \& H Fauser, 2009).

O Rio Paraíba do Sul é formado pela junção dos rios Paraitinga e Paraibuna, na altura da cidade de Paraibuna (SP). As nascentes do Rio Paraitinga situam-se na Serra do Bocaina, a $1800 \mathrm{~m}$ de altitude, enquanto o Paraibuna nasce na Serra do Mar, na divisa entre o Rio de Janeiro e São Paulo, a 1600 m de altitude. O Rio Paraitinga corre de NE para SW e vence um desnível 
de 1180 m até encontrar o Paraibuna, que se desenvolve de NE para SW e de L para W (Paiva, 1982).

As represas de Paraibuna e Paraitinga, localizadas no município de Paraibuna, estão inseridas na bacia do Rio Paraíba do Sul. Esta bacia ocupa uma área de $55.400 \mathrm{~km}^{2}$, abrangendo parte dos Estados de São Paulo, Rio de Janeiro e Minas Gerais (Oliveira e Kacowicz, 1984 apud Brandimarte, 1991).

O limite ao norte da represa Paraitinga é o município de Redenção da Serra, ao Sul, Natividade da Serra e à oeste, Paraibuna. A nascente do Rio Paraitinga encontra-se no município de São José do Barreiro, percorre os municípios de Lagoinha e São Luiz do Paraitinga até ser represado em Paraibuna.

Já os limites da represa Paraibuna encontram-se ao norte, sul e oeste pelo município de Paraibuna e por Natividade da Serra ao leste. A nascente do Rio Paraibuna localiza-se em Cunha, suas águas percorrem os municípios de São Luiz do Paraitinga e Natividade da Serra chegando ao seu represamento em Paraibuna (IBGE, 2009).

As barragens de Paraibuna e Paraitinga, concluídas em 1977, estão entre as mais altas do Brasil, com $104 \mathrm{~m}$ de altura. A usina hidrelétrica de Paraibuna (UHE-Paraibuna), sob administração da Companhia Energética de São Paulo (CESP), tem potência para geração de energia elétrica total instalada de 85 MW e a área total do seu reservatório é de $224 \mathrm{~km}^{2}$, composta pelo reservatório de Paraibuna que tem $177 \mathrm{~km}^{2}$, o qual é interligado ao reservatório de Paraitinga, com $47 \mathrm{~km}^{2}$ (FIG.2), apresentando um volume hídrico útil de $2.636 \mathrm{~m}^{3} \times 10^{6}$ (CESP, 2008). 


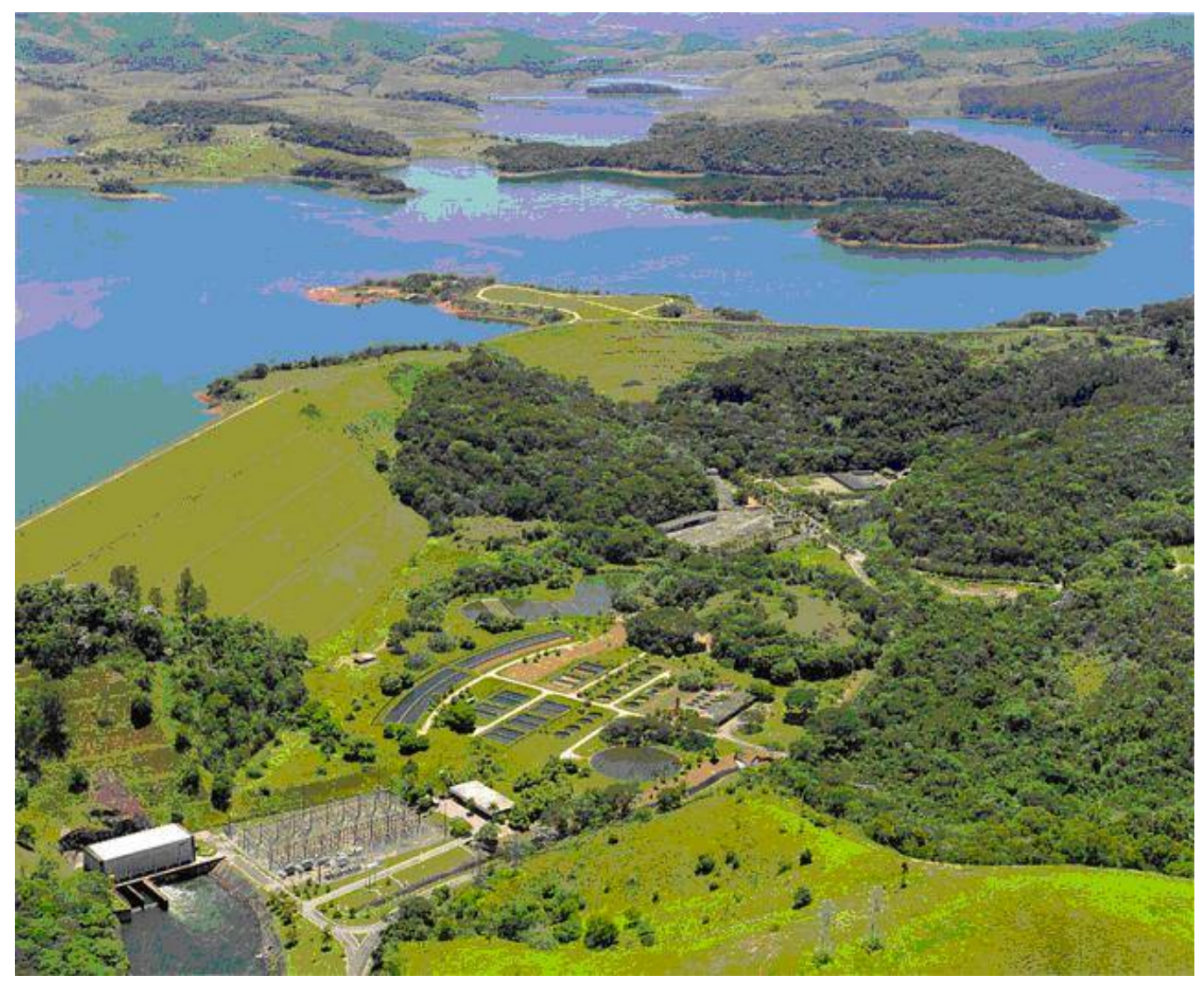

FIGURA 2 - Vista aérea da hidrelétrica do complexo Paraitinga-Paraibuna (Fonte: Prefeitura de Paraibuna).

Além de gerar energia, o reservatório da Usina Hidrelétrica de Paraibuna (UHE-Paraibuna) também tem por finalidade regular a vazão do rio Paraíba do Sul, principal responsável pelo fornecimento de água para várias cidades do Vale do Paraíba e do Estado do Rio de Janeiro (AGEVAP, 2008).

A porção mais profunda da represa de Paraibuna, a qual chega a atingir 98 metros de profundidade, abrange os dois braços inundados das antigas calhas dos rios Paraibuna e Paraitinga. Para a formação de um lago único, uma porção de relevo próxima à barragem que dividia as duas bacias foi dinamitada formando um canal de interligação. Esta represa possui um espelho d'água de $224 \mathrm{~km}^{2}$ quando com $100 \%$ de sua capacidade e as bacias de seus principais tributários ocupam uma área total de $4.078 \mathrm{~km}^{2}$ (Dias et al., 2007).

Ao longo de seus percursos o Rio Paraibuna e Paraitinga recebem contribuições de carga orgânica de origem doméstica, apresentadas na TAB. 3 (CETESB, 2006). 
TABELA 3 - Carga orgânica poluidora - origem doméstica

\begin{tabular}{|c|c|c|c|c|c|c|c|}
\hline \multirow{2}{*}{$\frac{\frac{0}{0}}{\frac{0}{\frac{O}{O}}}$} & \multirow{2}{*}{ 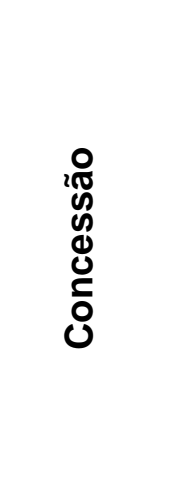 } & \multirow{2}{*}{ 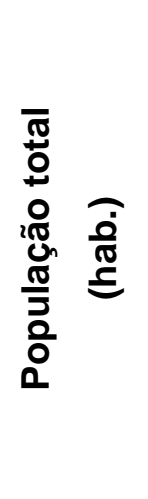 } & \multicolumn{2}{|c|}{ 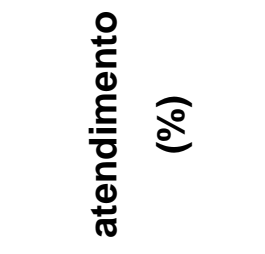 } & \multicolumn{2}{|c|}{ 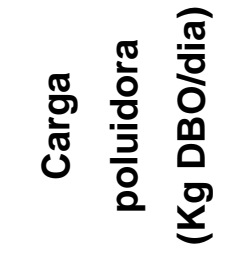 } & \multirow{2}{*}{ 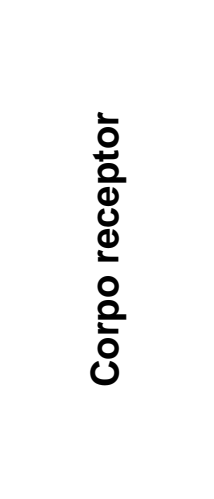 } \\
\hline & & & $\frac{\frac{\pi}{0}}{0}$ & 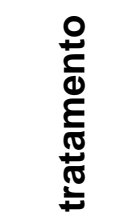 & $\begin{array}{l}\bar{\pi} \\
\frac{\pi}{0} \\
\frac{c}{0} \\
\stackrel{0}{0} \\
0\end{array}$ & 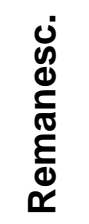 & \\
\hline $\begin{array}{l}\text { São Luiz do } \\
\text { Paraitinga }\end{array}$ & SABESP & 10.798 & 84 & 100 & 354 & 116 & $\begin{array}{c}\text { Rio } \\
\text { Paraitinga e } \\
\text { Chapéu }\end{array}$ \\
\hline $\begin{array}{l}\text { Natividade } \\
\text { da Serra }\end{array}$ & PM & 7.320 & 90 & 96 & 177 & 55 & $\begin{array}{c}\text { Res. } \\
\text { Paraibuna }\end{array}$ \\
\hline $\begin{array}{c}\text { Redenção da } \\
\text { Serra }\end{array}$ & SABESP & 4.103 & 59 & 100 & 92 & 49 & $\begin{array}{c}\text { Res. } \\
\text { Paraibuna }\end{array}$ \\
\hline Paraibuna & PM & 18.619 & 85 & 9 & 285 & 267 & $\begin{array}{c}\text { Rio } \\
\text { Paraibuna }\end{array}$ \\
\hline Lagoinha & SABESP & 5.073 & 100 & 100 & 163 & 33 & $\begin{array}{c}\text { Rib. } \\
\text { Botucatu }\end{array}$ \\
\hline
\end{tabular}

Fonte: CETESB, 2006.

\subsection{Periodicidade de amostragem e pontos de coleta}

As coletas foram realizadas no complexo de represas ParaibunaParaitinga, com o auxílio de embarcação a motor da CESP, em nove pontos distintos (FIG. 3), durante o período de seca em abril de 2008 (abr/08) e maio de 2008 (mai/08) e durante o período de chuva em novembro de 2008 (nov/08) e fevereiro de 2009 (fev/09), na superfície da água, distantes das margens, ocorrendo sempre no período matutino. Constam no APÊNDICE A representações fotográficas dos procedimentos de coleta.

Os nove pontos de amostragem, escolhidos ao longo das represas de Paraibuna e Paraitinga, foram georreferenciados com sistema de coordenadas geográficas (graus-minutos-decimais), por aparelho de Global Positioning System 
(GPS). O resumo das características e descrições de cada ponto encontram-se na TAB. 4.

A definição dos pontos de coleta foi realizada in-loco, em comum acordo com a equipe de controle sanitário da Companhia de Saneamento Básico do Estado de São Paulo (SABESP) e a equipe da CESP, de acordo com a facilidade de acesso e levando em consideração fatores críticos como os tributários contribuintes aos reservatórios, os pontos de captação de água superficial para abastecimento público (Redenção da Serra), fatores impactantes a montante e a jusante das cidades vizinhas e seus pontos de descarte de efluentes sanitários. 


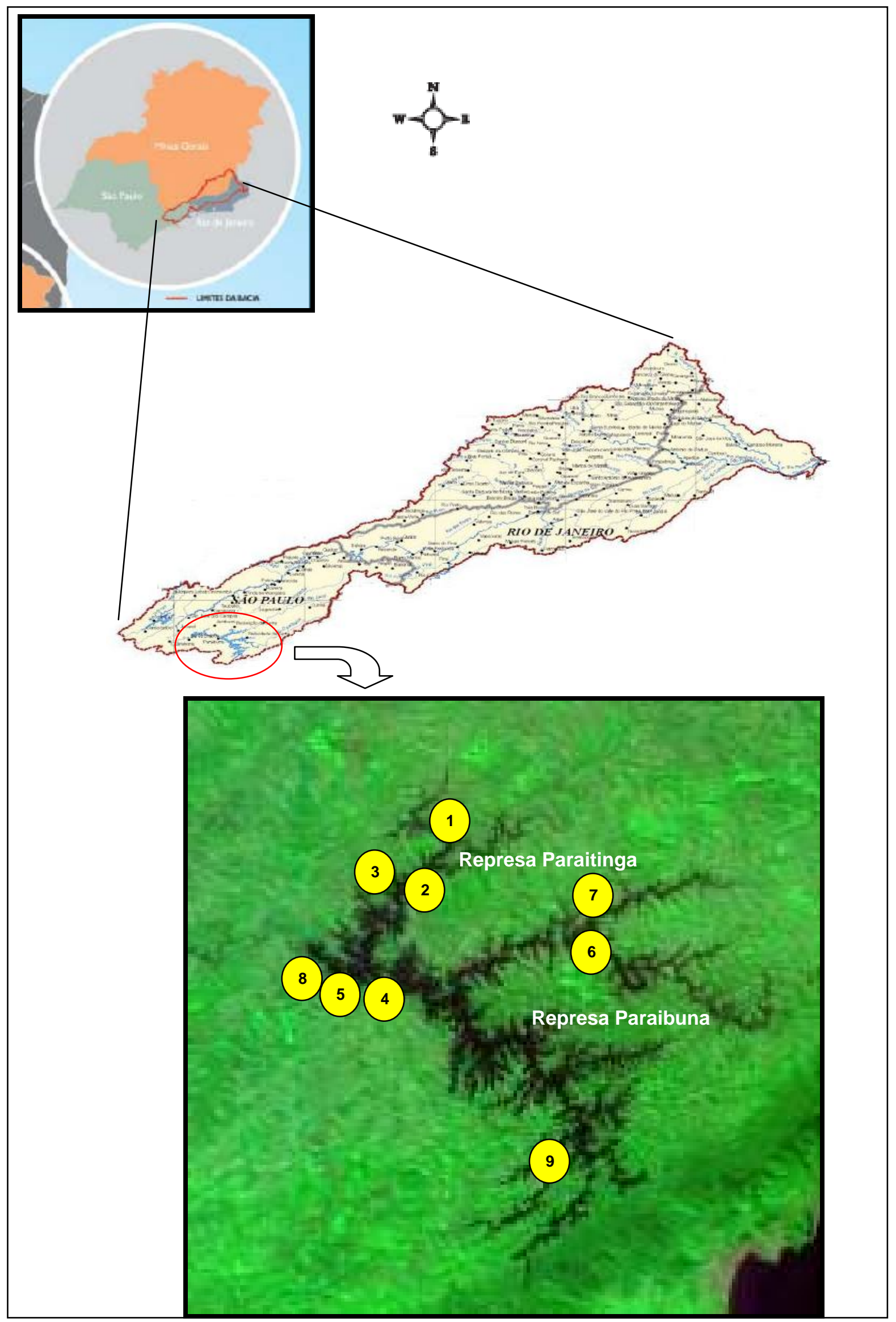

FIGURA 3 - Localização da Bacia Hidrográfica do Paraíba do Sul e estações de amostragem nas represas Paraibuna e Paraitinga (Foto satélite CBERS: www.inpe.br). 
TABELA 4 - Coordenadas geográficas e descrição dos pontos amostrados

\begin{tabular}{|c|c|c|}
\hline Ponto & Coordenada & Descrição \\
\hline 01 & S $23^{\circ} 19.564^{\prime} W 4^{\circ} 30.185^{\prime}$ & $\begin{array}{l}\text { Rio Paraitinga - próximo à ponte dos } \\
\text { Mineiros. Presença de gado e cavalos } \\
\text { próximos às margens. Grande massa } \\
\text { de macrófitas aquáticas. }\end{array}$ \\
\hline 02 & S $23^{\circ} 19.815^{\prime} W$ W $45^{\circ} 31.060^{\prime}$ & $\begin{array}{l}\text { Rio Paraitinga - próximo à Fazenda } \\
\text { Ponte Alta. }\end{array}$ \\
\hline 03 & S $23^{\circ} 19.967^{\prime}$ W $45^{\circ} 33.911^{\prime}$ & $\begin{array}{l}\text { Rio Paraitinga - margem voltada à } \\
\text { Redenção da Serra. Reflorestamento } \\
\text { de eucaliptos no entorno. }\end{array}$ \\
\hline 04 & $S 23^{\circ} 24.500^{\prime} W 4^{\circ} 35.178^{\prime}$ & $\begin{array}{l}\text { Rio Paraibuna - próximo à barragem } \\
\text { da hidrelétrica. Fazendas nas } \\
\text { proximidades. }\end{array}$ \\
\hline 05 & S $23^{\circ} 24.582^{\prime}$ W $45^{\circ} 35.924^{\prime}$ & $\begin{array}{l}\text { Rio Paraibuna - junto à barragem da } \\
\text { hidrelétrica. }\end{array}$ \\
\hline 06 & S $23^{\circ} 23.701^{\prime}$ W $45^{\circ} 27.953^{\prime}$ & $\begin{array}{l}\text { Junção do Rio do Peixe e Rio } \\
\text { Paaibuna - próximo à balsa de } \\
\text { Natividade da Serra. } \\
\text { Juncão do Rio do Peixe e Rio }\end{array}$ \\
\hline 07 & S $23^{\circ} 22.943^{\prime}$ W $45^{\circ} 27.681^{\prime}$ & $\begin{array}{l}\text { Paraibuna - próximo à Natividade da } \\
\text { Serra. }\end{array}$ \\
\hline 08 & S $23^{\circ} 23.399^{\prime}$ W $45^{\circ} 37.497^{\prime}$ & $\begin{array}{l}\text { Próximo à balsa para Paraitinga (porto) } \\
\text { e do Rio Lourenço Velho. }\end{array}$ \\
\hline 09 & S $23^{\circ} 31.282^{\prime}$ W $45^{\circ} 29.990^{\prime}$ & $\begin{array}{l}\text { Junção Rio Negro, Rio Pardo e Rio } \\
\text { Lourenço Velho. }\end{array}$ \\
\hline
\end{tabular}

\subsection{Dados Climatológicos}

Os dados de precipitação referentes as coletas realizadas nas represas de Paraibuna e Paraitinga foram obtidos no Banco de Dados Virtual do Centro Integrado de Informações Agrometeorológicas (CIIAGRO) consultadas no site http://ciiagro.iac.sp.gov.br. 


\subsection{Variáveis físicas e químicas}

Os parâmetros físicos e químicos analisados foram: temperatura do ar e da água, oxigênio dissolvido, $\mathrm{pH}$, condutividade elétrica, turbidez, transparência e zona eufótica, sólidos totais dissolvidos, juntamente com a análise química dos teores dos elementos dissolvidos prata, alumínio, boro, bário, berílio, cromo, cobalto, cobre, ferro, manganês, potássio, lítio, níquel, vanádio, zinco e fósforo total.

As temperaturas do ar e da água, $\mathrm{pH}$, oxigênio dissolvido e condutividade elétrica foram determinados in loco, na superfície da água utilizando sonda multiparamétrica HORIBA U-10.

A turbidez e a quantidade de sólidos totais dissolvidos foram determinados em laboratório para todas as amostras de água coletadas, utilizando turbímetro e a técnica de gravimetria, respectivamente.

Os teores de anions fluoreto, cloreto, sulfato, nitrato e fosfato foram analisados por cromatografia de íons no Laboratório de Cromatografia do CQMA/IPEN, no cromatógrafo de íons Dionex, DX-120.

Os 22 metais e elementos-traço analisados sofreram filtração prévia e adição de ácido nítrico, em seguida foram analisados por espectrometria de emissão com fonte de plasma induzido (ICP-OES), porém os elementos mercúrio, arsênio, selênio, antimônio, chumbo e cádmio foram analisados utilizando a técnica de espectrometria de absorção atômica (AA), forno de grafita e para o chumbo atomização por geração de vapor a frio (Cotrim, 2006).

Todas variáveis físicas e químicas, descritas na TAB. 5, foram avaliadas de acordo com Standard Methods for the Examination of Water and Wastewater, edição $21^{\circ}$, ano 2005, (APHA, 2005), e/ou adaptadas e validadas nos laboratórios do Centro de Química e Meio Ambiente do IPEN (Cotrim, 2006). 
TABELA 5 - Parâmetros físicos e químicos e métodos de análise

\begin{tabular}{|c|c|}
\hline Parâmetros & Técnicas/Métodos \\
\hline Temperatura do $\operatorname{ar}\left({ }^{\circ} \mathrm{C}\right)$ & Sonda Multiparamétrica Horiba \\
\hline Temperatura da água $\left({ }^{\circ} \mathrm{C}\right)$ & Sonda Multiparamétrica Horiba \\
\hline Condutividade $\left(\mathrm{mS} . \mathrm{cm}^{-1}\right)$ & Sonda Multiparamétrica Horiba \\
\hline $\mathrm{pH}$ & Sonda Multiparamétrica Horiba \\
\hline Oxigênio Dissolvido $\left(\mathrm{mg}^{-\mathrm{L}^{-1}}\right)$ & Sonda Multiparamétrica Horiba \\
\hline Transparência (m) & Disco de Secchi \\
\hline Zona eufótica $(\mathrm{m})$ & Segundo Cole (1975); Ishii (1987) \\
\hline Turbidez (NTU) & Turbidímetro \\
\hline $\begin{array}{l}\text { Fluoreto, cloreto, sulfato, fosfato e } \\
\text { nitrato }\left(\mathrm{mg}^{-1} \mathrm{~L}^{-1}\right)\end{array}$ & Cromatografia de íons \\
\hline 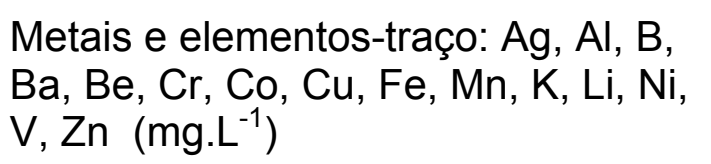 & $\begin{array}{l}\text { Espectrofotometria de emissão óptica com } \\
\text { Fonte de plasma de argônio induzido- } \\
\text { ICP-OES }\end{array}$ \\
\hline $\begin{array}{l}\text { Elementos } \mathrm{Hg}, \mathrm{As}, \mathrm{Cd}, \mathrm{Pb}, \mathrm{Sb} \text { e Se } \\
\left(\mathrm{mg} \cdot \mathrm{L}^{-1}\right)\end{array}$ & $\begin{array}{l}\text { Espectrometria de absorção atômica AA- } \\
\text { forno de grafita e geração de vapor frio } \\
\text { para o Ha }\end{array}$ \\
\hline Fósforo Total $\left(\mathrm{mg} \cdot \mathrm{L}^{-1}\right)$ & $\begin{array}{l}\text { Espectrofotometria de emissão óptica com } \\
\text { Fonte de plasma de argônio induzido- } \\
\text { ICP-OES }\end{array}$ \\
\hline Sólidos Totais Dissolvidos (mg. $\left.\mathrm{L}^{-1}\right)$ & Gravimetria \\
\hline Sólidos Fixos (mg. $\left.\mathrm{L}^{-1}\right)$ & Gravimetria \\
\hline Sólidos Voláteis (mg. $\mathrm{L}^{-1}$ ) & Gravimetria \\
\hline
\end{tabular}

Fonte: Apha, 2005; Cotrim, 2006. 


\subsection{Variáveis biológicas}

\subsubsection{Análise qualitativa da comunidade fitoplanctônica}

As coletas do fitoplâncton foram realizadas com o auxílio de uma rede de plâncton com abertura de malha de $20 \mu \mathrm{m}$. O volume de $100 \mathrm{~mL}$ foi armazenado em frasco de vidro e preservado com formol a $4 \%$, conforme metodologia descrita em diversos trabalhos (Taniguchi, 2002; Lopes, 2007; Gentil, 2007; Nishimura, 2008).

A análise foi realizada em microscópio óptico binocular modelo DMLS marca Leica, com câmara clara acoplada. Foram preparadas 5 lâminas, no mínimo, até cessar o surgimento de novas espécies para cada amostra.

A identificação foi realizada em nível genérico e infragenérico, analisando-se, sempre que possível as variações populacionais, baseada nas características morfométricas dos organismos, com o auxílio de artigos, dissertações e teses com ilustrações/descrições dos táxons. Na identificação, foram adotados os seguintes sistemas de classificação: Round (1971) para Chlorophyceae e Zygnemaphycae; Simonsen (1979) para Bacillariophyceae; Komárek e Anagnostidis (1986, 1989, 2005) e Anagnostidis e Komárek (1988, $1990)$ para Cyanobacteria; Bourrelly $(1981,1985)$ para as demais classes.

\subsubsection{Análise quantitativa da comunidade fitoplanctônica}

\subsubsection{Densidade total (org. $\mathrm{mL}^{-1}$ )}

As coletas foram realizadas pelo arrasto do frasco diretamente na superfície da água, e as amostras foram preservadas com lugol acético.

A contagem de fitoplâncton realizou-se segundo o método de Utermöhl (1958) que consiste na sedimentação em câmara de volume pré-definido e contagem de células, cenóbios ou filamentos através de microscópio invertido em aumento de 400 vezes (FIG. 4 a e $b$ ). O tempo de sedimentação das amostras foi de três horas para cada centímetro de altura da câmara (Lund et al., 1958). 


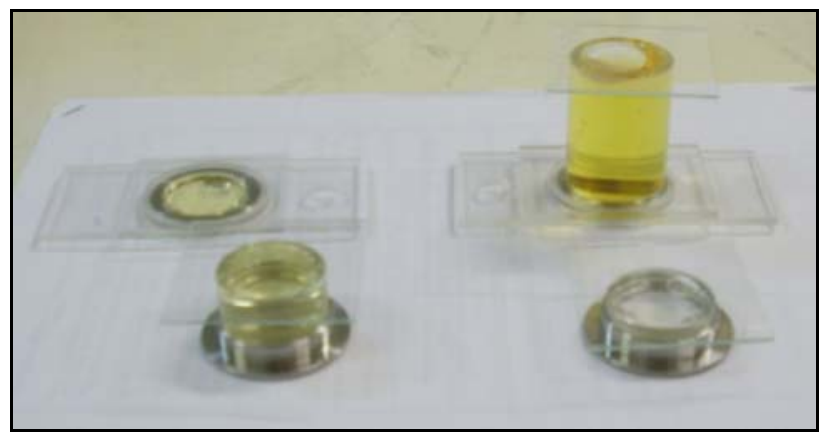

a

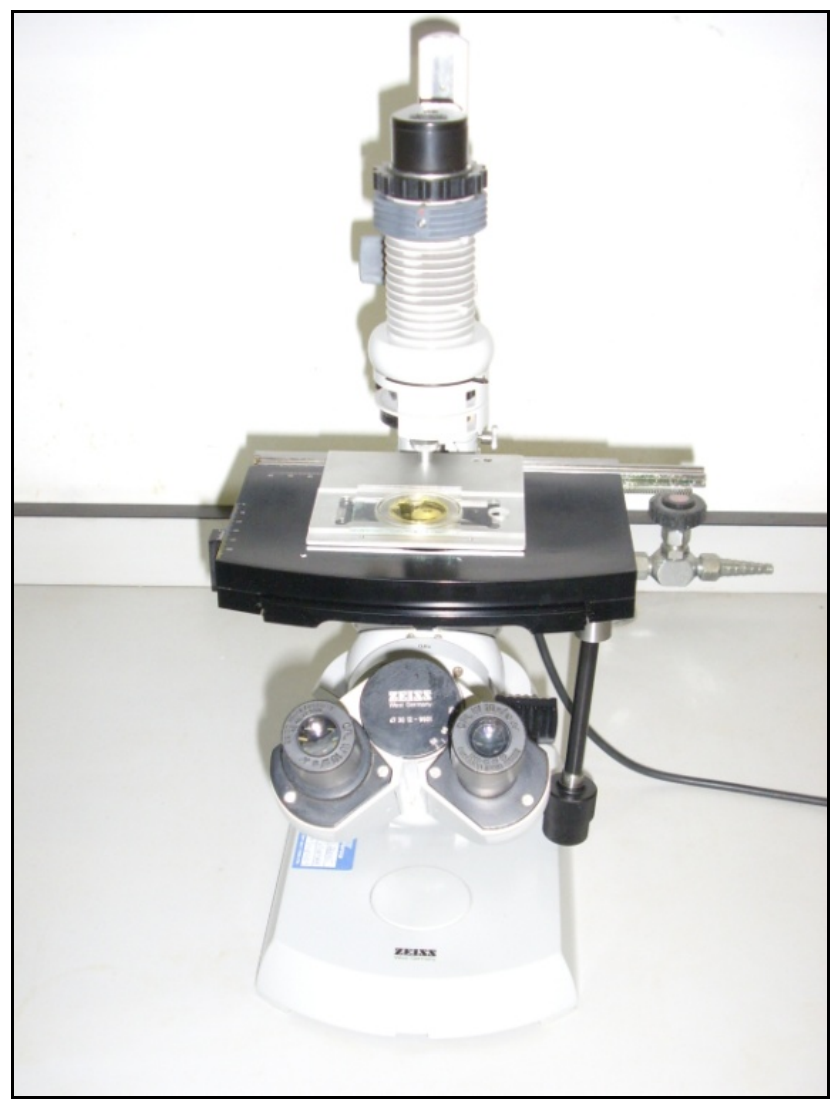

b

FIGURA 4 - a) Câmaras de sedimentação de Utermöhl; b) Microscópio invertido.

Foram seguidos transectos verticais e contados todos os indivíduos encontrados no campo, incluindo aqueles parcialmente visualizados.

O número mínimo de campos contados por câmara de sedimentação seguiu três critérios: a) estabilização do gráfico de riqueza da amostra, obtido a partir de novas espécies adicionadas pela contagem de campos e b) contagem de 100 indivíduos da espécie mais comum (Tucci, 2002) e no caso de "bloom", contagem de 100 indivíduos da segunda espécie mais comum; c) na escassez de organismos, impossibilitando os dois critérios anteriores, foram contados 100 campos. 
Foi considerado como indivíduo cada célula, colônia, cenóbio ou filamento. A densidade da comunidade fitoplanctônica foi calculada segundo a fórmula descrita em Weber (1973):

$$
\frac{\text { Organismos }}{\mathrm{mL}}=\frac{\mathrm{n}}{\mathrm{s} . \mathrm{C}} \cdot \frac{1}{\mathrm{~h}} \cdot \mathrm{F}
$$

onde: $\mathrm{n}=$ número de indivíduos contados;

$\mathrm{s}=$ área do campo em $\mathrm{mm}^{2}$ no aumento de $400 \mathrm{x}$;

$\mathrm{c}=$ número de campos contados;

$\mathrm{h}=$ altura da câmara de sedimentação em $\mathrm{mm}$;

$\mathrm{F}=$ fator de correção para $\mathrm{mL}\left(10^{3} \mathrm{~mm}^{3} / 1 \mathrm{~mL}\right)$.

O resultado desta análise foi apresentado em organismos por $\mathrm{mL}$ (org. $\left.\mathrm{mL}^{-1}\right)$.

\subsubsection{Espécies descritoras}

O critério utilizado para definir as espécies descritoras do sistema foi estabelecido de acordo com as características da comunidade encontrada. Assim, foram consideradas um nível de corte de $0,5 \%$ da densidade total da comunidade fitoplanctônica para todo o período de estudo. Este nível de corte consegue selecionar espécies que contribuíram com $70 \%$ ou mais para a biomassa total, de acordo com Sommer et al. (1993). Os táxons selecionados foram utilizados nas análises multivariadas.

\subsection{3 Índices biológicos}

\subsubsection{Riqueza (R)}

Este parâmetro refere-se ao número total de táxons encontrados por amostra.

\subsubsection{2 Índice de diversidade (H') $\left(\right.$ bits.ind $\left.^{-1}\right)$}

Calculado segundo os critérios de Shannon e Weaver (1963). O Índice de diversidade permite estabelecer diferenças que se relacionam com a riqueza, o número de espécies presentes e a uniformidade da distribuição das abundâncias 
relativas dos indivíduos dentro de cada espécie (Pielou, 1966 apud Branco, 1986; Carvalho 2003).

Seu valor mínimo ocorre quando todos os indivíduos pertencem à mesma espécie e o máximo quando cada indivíduo pertence a uma espécie diferente (ACIESP, 1997).

$$
H^{\prime}=-\sum_{i=1}^{n} \quad \text { pi } \quad \log _{2} \quad p i
$$

onde: $\quad H^{\prime}=$ índice de diversidade;

$\mathrm{pi}=\mathrm{ni} / \mathrm{n}$ probabilidade de que um indivíduo pertença à espécie $\mathrm{i}$;

$\mathrm{ni}=$ número total de indivíduos de cada táxon na amostra;

$\mathrm{n}=$ número total de indivíduos na amostra.

\subsubsection{3 Índice de equitabilidade (E')}

Calculado segundo os critérios de Lloyd e Ghelardi (1964). Os valores de equitabilidade variam entre zero e 1, sendo que a equitabilidade igual a 1 representa a condição em que as espécies estão igualmente distribuídas. A equitabilidade expressa a forma com que os indivíduos estão distribuídos entre os táxons e a riqueza de uma amostra equivale ao número total de táxons nela presente (Carvalho, 2003).

Quanto maior a equitabilidade de uma comunidade, menor a dominância.

$$
E^{\prime}=\underset{\log _{2} S}{H^{\prime}}
$$

onde: $\quad E^{\prime}=$ índice de equitabilidade;

$\mathrm{S}=$ número de táxons na amostra.

\subsubsection{4 Índice de dominância (DS'):}

Calculado segundo Simpson (1949). Este índice demonstra se há dominância de uma ou mais espécies sobre as outras, dentro de uma comunidade. 
$D^{\prime}=\frac{\sum n i(n i-1)}{n(n-1)}$

onde: $\quad$ DS' = índice de dominância;

ni = número total de indivíduos de cada

táxon na amostra;

$\mathrm{n}=$ número total de indivíduos na amostra.

\subsubsection{Freqüência de ocorrência (F) (\%)}

A frequência de ocorrência foi calculada de acordo com Lobo e Leighton (1986), para presença de cada espécie nas estações de amostragem.

$$
\mathrm{F}=\frac{\mathrm{Pa}}{\mathrm{P}} \cdot 100
$$

onde: $F=$ freqüência de ocorrência;

$\mathrm{Pa}=$ número de amostras em que a espécie "a" está presente;

$\mathrm{P}=$ número total de amostras analisadas.

Sendo classificadas como:

- Espécies Constantes: $\mathrm{F}>50 \%$

- Espécies Comuns: $20 \%<\mathrm{F}<50 \%$

- Espécies Raras: $\mathrm{F}<20 \%$

\subsubsection{Espécies dominantes e abundantes}

Segundo Lobo e Leighton (1986) espécies cuja densidade é superior ao valor da densidade média, em função do número total de indivíduos das espécies presentes na amostra são consideradas abundantes e espécies cuja densidade é superior a $50 \%$ do número total de indivíduos presentes na amostra são consideradas dominantes.

\subsection{Aplicação de índices de qualidade}

\subsection{1 Índice de Estado Trófico (IET)}


O Índice do Estado Trófico, é composto pelo Índice do Estado Trófico para o fósforo - IET(PT) e o Índice do Estado Trófico para a clorofila a - IET(CL), modificados por Lamparelli (2004), sendo estabelecidos para ambientes lênticos, segundo as equações:

$$
\begin{gathered}
\operatorname{IET}(C L)=10\{6-[(2,04-0,695 \ln \mathrm{CL}) / \ln 2]\} \\
\operatorname{IET}(P T)=10\{6-[\ln (80,32 / P) / \ln 2]\}
\end{gathered}
$$

onde:

PT: concentração de fósforo total medida à superfície da água, em $\mu \mathrm{g} \cdot \mathrm{L}^{-1}$;

CL: concentração de clorofila a medida à superfície da água, em $\mu \mathrm{g} \cdot \mathrm{L}^{-1}$;

In: logaritmo natural.

Quando ambas as variáveis estiverem disponíveis, o resultado apresentado nas tabelas do IET será a média aritmética simples dos índices relativos ao fósforo total e a clorofila a, segundo a equação:

$$
\mathrm{IET}=\frac{[\mathrm{IET}(\mathrm{CL})+\mathrm{IET}(\mathrm{PT})]}{2}
$$

Caso não seja possível a análise de uma das variáveis, o índice é calculado com o parâmetro disponível e considerando equivalente ao outro, devendo informar que apenas um dos parâmetros foi utilizado (CETESB, 2007).

A classificação dos corpos d'água de acordo com os diferentes graus de trofia para reservatórios, conforme Toledo (1990) apud Lamparelli (2004), encontra-se na TAB. 6.

TABELA 6 - Classificação do Estado Trófico, segundo Toledo (1990)

\begin{tabular}{ccccc}
\hline Critério & Estado Trófico & $\begin{array}{c}\text { Transparência } \\
(\mathrm{m})\end{array}$ & $\begin{array}{c}\text { Fósforo total } \\
-\mathrm{PT}\left(\mathrm{mg} \cdot \mathrm{L}^{-1}\right)\end{array}$ & $\begin{array}{c}\text { Clorofila } \mathrm{a}- \\
\mathrm{CL}\left(\mu \mathrm{g} \cdot \mathrm{L}^{-1}\right)\end{array}$ \\
\hline IET $\leq 24$ & Ultraoligotrófico & $\geq 7,8$ & $\leq 0,006$ & $\leq 0,51$ \\
$24<\mathrm{IET} \leq 44$ & Oligotrófico & $7,7-2,0$ & $0,007-0,026$ & $0,52-3,81$ \\
$44<$ IET $\leq 54$ & Mesotrófico & $1,9-1,0$ & $0,027-0,052$ & $3,82-10,34$ \\
$54<\mathrm{IET} \leq 74$ & Eutrófico & $0,9-0,3$ & $0,053-0,211$ & $10,35-76,06$ \\
$\mathrm{IET}>74$ & Hipereutrófico & $<0,3$ & $>0,211$ & $>76,06$ \\
\hline
\end{tabular}

Fonte: Lamparelli, 2004. 


\subsection{2 Índice da Comunidade Fitoplanctônica (ICF)}

Este índice utiliza a dominância dos grandes grupos que compõem o fitoplâncton, a densidade dos organismos e o Índice de Estado Trófico (IET), visando separar em categorias a qualidade da água. Com a alteração do IET, em 2005, foi estabelecida uma nova ponderação dessa variável, válida tanto para o índice para rios (ICFRIO) quanto para reservatórios (ICFRES), conforme CETESB (2007) (TAB. 7).

TABELA 7 - Classificação do Índice da Comunidade Fitoplanctônica - ICF

\begin{tabular}{|c|c|c|}
\hline Categoria & Ponderação & Níveis \\
\hline ÓTIMA & 1 & $\begin{array}{l}\text { Não há dominância entre os grupos } \\
\text { Densidade total }<1000 \text { org. } \mathrm{mL}^{-1} \\
\text { IET } \leq 52\end{array}$ \\
\hline BOA & 2 & $\begin{array}{l}\text { Dominância de Clorofíceas (Desmidiáceas) ou } \\
\text { Diatomáceas } \\
\text { Densidade total }>1000 \text { e }<5000 \text { org } \cdot \mathrm{mL}^{-1} \\
52<\text { IET } \leq 59\end{array}$ \\
\hline REGULAR & 3 & $\begin{array}{l}\text { Dominância de Clorofíceas (Chlorococcales) } \\
\text { Densidade total }>5000 \text { e }<10000 \text { org. } \mathrm{mL}^{-1} \\
59<\mathrm{IET} \leq 63\end{array}$ \\
\hline RUIM & 4 & $\begin{array}{l}\text { Dominância de Cianofíceas ou Euglenofíceas } \\
\text { Densidade total }>10000 \text { org. } \mathrm{mL}^{-1} \\
\text { IET > } 63\end{array}$ \\
\hline
\end{tabular}

\subsection{Análise Estatística}

Para estabelecer as correlações entre a comunidade fitoplanctônica e as variáveis físicas e químicas, foi utilizada a correlação de Pearson.

A avaliação dos resultados foi realizada por meio de análise multivariada dos dados. Para determinar a variabilidade dos dados ambientais e os dados biológicos (espécies descritoras) em relação às coletas e aos pontos de amostragem será realizada a Análise de Componentes Principais (ACP), utilizando o programa PC-ORD versão 3.1 para Windows. 
Foi utilizada a matriz de covariância, com transformação dos dados pela amplitude de variação de "ranging" ([(X-xmin) - (Xmax-Xmin)]) através do programa FITOPAC (Shepherd, 1996).

Foram consideradas as variáveis com correlação significativa aquelas que apresentaram $r>0,5$ com os eixos 1 e 2 da ordenação. 


\section{RESULTADOS E DISCUSSÃO}

Os resultados apresentados nos gráficos deste capítulo referem-se aos pontos de amostragens 02, 03, 04, 05, 06, 07, 08 e 09, descritos, anteriormente, na TAB.1 e FIG.1. O ponto 01, já na data da primeira coleta, encontrava-se com grande massa de macrófita aquática, pertencente ao gênero Salvinea sp. Nas datas das demais coletas, a massa de Salvinea sp. havia se intensificado, impedindo a passagem da embarcação e a coleta das amostras de água e fitoplâncton neste ponto de amostragem.

No mês de abril não houve coleta no ponto 09 devido a problemas técnicos com a embarcação e climatológicos.

\subsection{Dados climatológicos}

Os dados de precipitação foram obtidos no banco de dados virtual do Centro Integrado de Informações Agrometeorológicas (CIIAGRO, 2008), para o município de Caraguatatuba (localizado a $51,9 \mathrm{~km}$ de Paraibuna), e estão descritos na TAB. 8.

TABELA 8 - Dados de precipitação no município de Caraguatatuba

\begin{tabular}{ccc}
\hline Precipitação $(\mathbf{m m})$ & $\begin{array}{c}\text { Data da } \\
\text { Coleta }\end{array}$ & $\begin{array}{c}\text { Condições } \\
\text { Meteorológicas }\end{array}$ \\
\hline 11,2 & $29 / 04 / 2008$ & Ligeiramente Úmido \\
0 & $27 / 05 / 2008$ & Seco \\
87,9 & $17 / 11 / 2008$ & Úmido \\
40,5 & $27 / 02 / 2009$ & Úmido \\
\hline
\end{tabular}

Os dados de precipitação obtidos indicaram que os períodos estudados apresentaram menores precipitações nas coletas de abril e maio de 2008, e altas precipitações nas coletas realizadas em novembro de 2008 e fevereiro de 2009 , 
ampliando as possibilidades de análise dos dados por período seco e período chuvoso, respectivamente.

Altos valores de precipitação interferem nos ecossistemas aquáticos elevando a turbidez e diminuindo sua transparência em consequência da turbulência provocada pela chuva. A pluviosidade pode provocar drenagem superficial de solos com carreamento de sólidos para o interior do corpo d'água.

\subsection{Variáveis físicas e químicas}

\subsubsection{Temperatura do ar e da água $\left({ }^{\circ} \mathrm{C}\right)$}

Os valores da temperatura da água seguiram as oscilações da temperatura atmosférica (FIG. 5).

A temperatura atmosférica atingiu seu mínimo, $21,0^{\circ} \mathrm{C}$, no ponto $02 \mathrm{em}$ mai/08, e máximo, $28,8^{\circ} \mathrm{C}$, no ponto 06 em fev/09, com média de $25,2 \pm 2,3^{\circ} \mathrm{C}$.

A temperatura da água atingiu seu menor valor, de $20,7^{\circ} \mathrm{C}$, no ponto 02 em mai/08, e seu maior valor, de $28,9^{\circ} \mathrm{C}$, no ponto 03 em fev/09, com média de $24,6 \pm 2,5^{\circ} \mathrm{C}$.
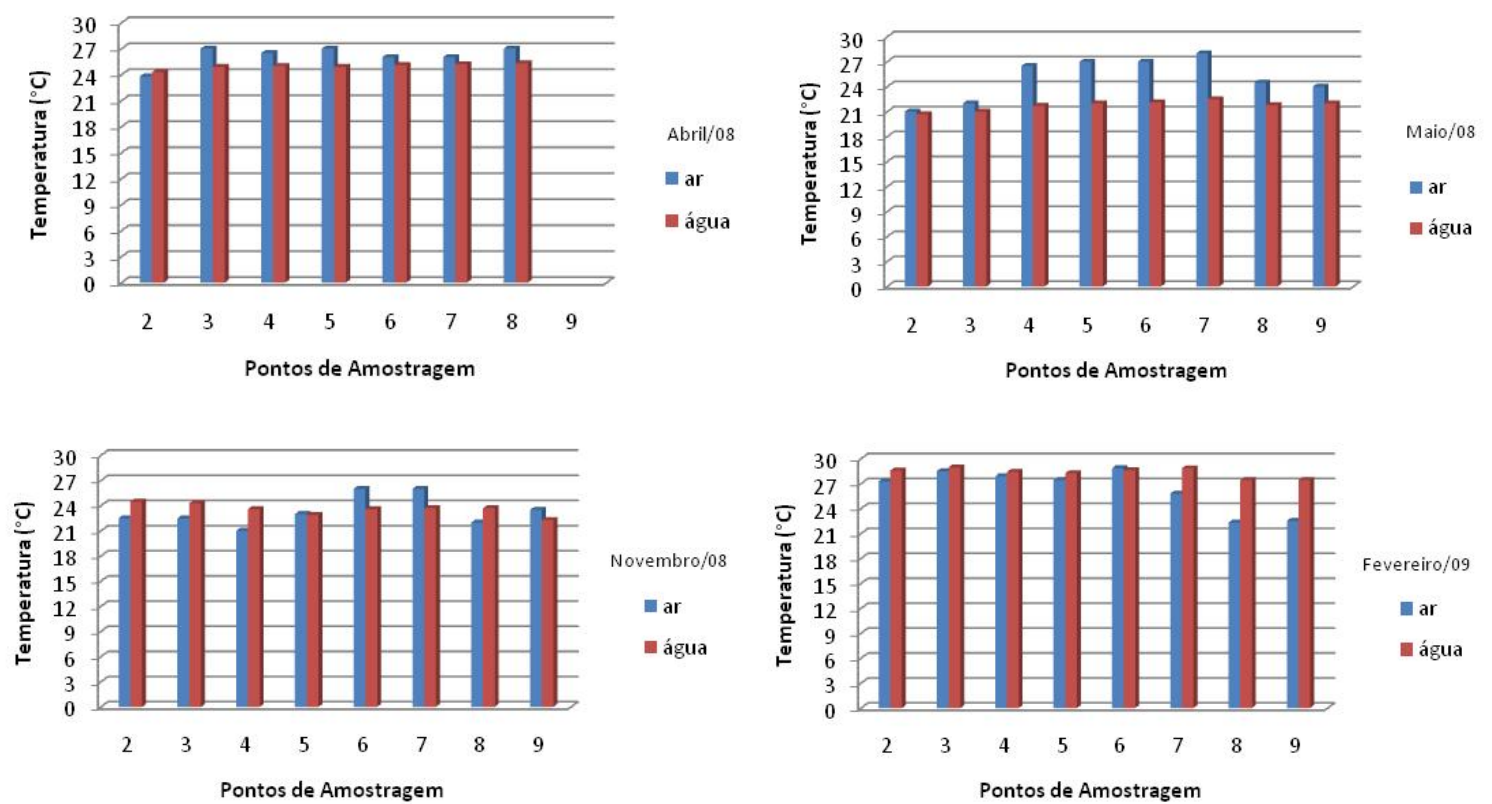

FIGURA 5 - Variação da tempertaura do ar e da água nos pontos de amostragem durante o período de estudo. 
Em decorrência do elevado calor específico da água, os ambientes aquáticos apresentam quase sempre amplitudes térmicas inferiores às obtidas na atmosfera (Liliamts, 2007).

A temperatura da água influencia nos processos biológicos, reações químicas e bioquímicas dos ecossistemas aquáticos podendo promover a circulação ou a estratificação da água, alterando assim a distribuição de gases $\left(\mathrm{CO}_{2}\right.$ e $\left.\mathrm{O}_{2}\right), \mathrm{pH}$, condutividade elétrica e a concentração de nutrientes (Esteves, 1998).

Wetzel (1993) enumera a temperatura, dentre outros fatores, como disponibilidade de luz e nutrientes, competição por recurso, e predação por outros organismos, como condições importantes para a regulação do desenvolvimento fitoplanctônico e seus estágios de sucessão. O autor ainda salienta que a temperatura modifica a densidade da água afetando a regulação da impulsão dos microrganismos, ou seja, meios utilizados para permanecer dentro da zona eufótica.

Observou-se a distribuição sazonal natural deste parâmetro, com baixas temperaturas no período seco e temperaturas um pouco mais elevadas no período chuvoso.

\subsubsection{Condutividade elétrica $\left(\mathrm{mS} \mathrm{cm}^{-1}\right)$}

Durante o período de estudo, o valor mínimo registrado para a condutividade elétrica foi de $0,017 \mathrm{mS} . \mathrm{cm}^{-1}$ no ponto $06 \mathrm{em}$ mai/08 e, o valor máximo registrado foi de $0,036 \mathrm{mS} . \mathrm{cm}^{-1}$ no ponto $02 \mathrm{em} \mathrm{mai/08}$ e fev/09, com média de $0,026 \pm 0,005 \mathrm{mS} . \mathrm{cm}^{-1}$. O ponto 02 foi o único que apresentou valores de condutividade elétrica acima de $0,030 \mathrm{mS} . \mathrm{cm}^{-1}$, em todos meses de amostragem.

Ocorreu um leve aumento nos valores de condutividade elétrica no mês fev/09, que pode estar associado ao período chuvoso no qual a elevação das temperaturas do ar e da água, aceleram o metabolismo dos organismos aquáticos e o aumento da degradação de matéria orgânica. 
Abril/08

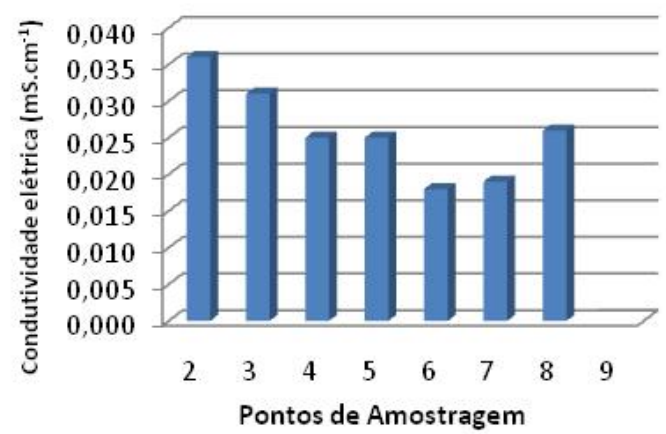

Novembro/08

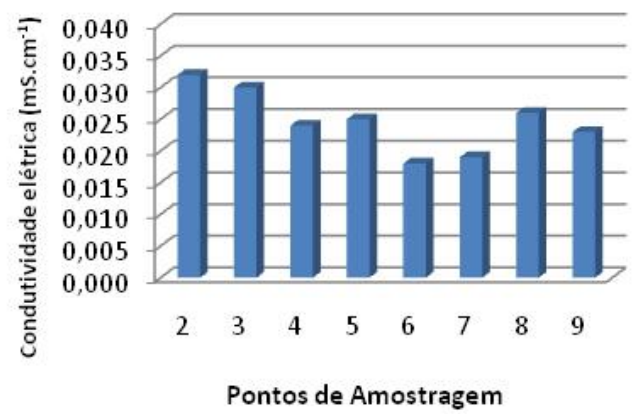

Maio/08

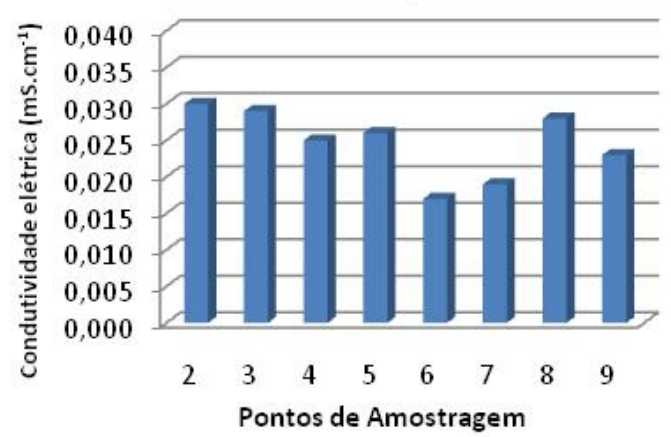

Fevereiro/09

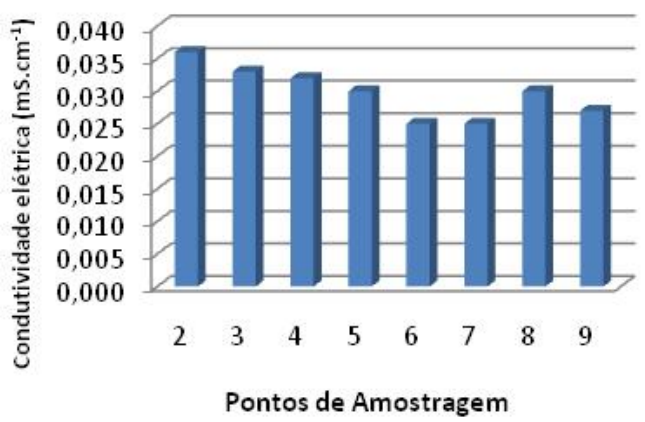

FIGURA 6 - Variação da condutividade elétrica da água nos pontos de amostragem durante o período de estudo.

A condutividade elétrica reflete o conteúdo de componentes minerais na forma iônica, podendo ser utilizado como um indicador das concentrações de sais minerais na água.

Segundo Esteves (1998), em regiões tropicais, os valores de condutividade nos ambientes aquáticos estão mais relacionados com as características geoquímicas da região onde se localizam e com as condições climáticas (estação de seca e de chuva), do que com o estado trófico do corpo d'água. Este parâmetro pode fornecer importantes informações, que possibilitam identificar as várias províncias geológicas, evidenciando, desta maneira, a interação entre o sistema aquático e o terrestre.

A variação da condutividade também fornece indicações sobre o processo de decomposição da matéria orgânica, pois geralmente se verifica um 
aumento de seus valores à medida que este processo é intensificado (Minillo, 2005).

Nishimura (2008) obteve valores de condutividade elétrica entre 0,204 mS. $\mathrm{cm}^{-1}$ e 0,250 mS.cm ${ }^{-1}$ no braço do Rio Grande, represa Billings (SP), classificado, segundo estado trófico, como oligo/mesotrófico, e no braço Taquacetuba da mesma represa, classificado como eu/supereutrófico, os valores de condutividade obtidos foram de $0,177 \mathrm{mS} \cdot \mathrm{cm}^{-1}$ a $0,222 \mathrm{mS} \cdot \mathrm{cm}^{-1}$.

Valores de condutividade semelhantes aos do presente estudo (FIG. 6), de $0,031 \mathrm{mS} . \mathrm{cm}^{-1}$ a $0,065 \mathrm{mS} . \mathrm{cm}^{-1}$, foram obtidos no Lago do IAG considerado um reservatório urbano oligotrófico (Vercellino e Bicudo, 2006).

\subsection{3 $\mathrm{pH}$}

Os valores de $\mathrm{pH}$ apresentaram pequena amplitude de variação de 5,57, ponto 02 em abr/08, a 8,58, ponto 05 em mai/08, com média de 7,3 $\pm 0,8$.

Os maiores valores de $\mathrm{pH}$ foram registrados na coleta de mai/08, fato que pode estar relacionado à baixa precipitação do período. Segundo Minillo (2005), normalmente os valores maiores de pH estão relacionados à redução da precipitação e à baixa presença de material alóctone (matéria orgânica). Os valores obtidos no presente estudo estão apresentados na FIG. 7. 

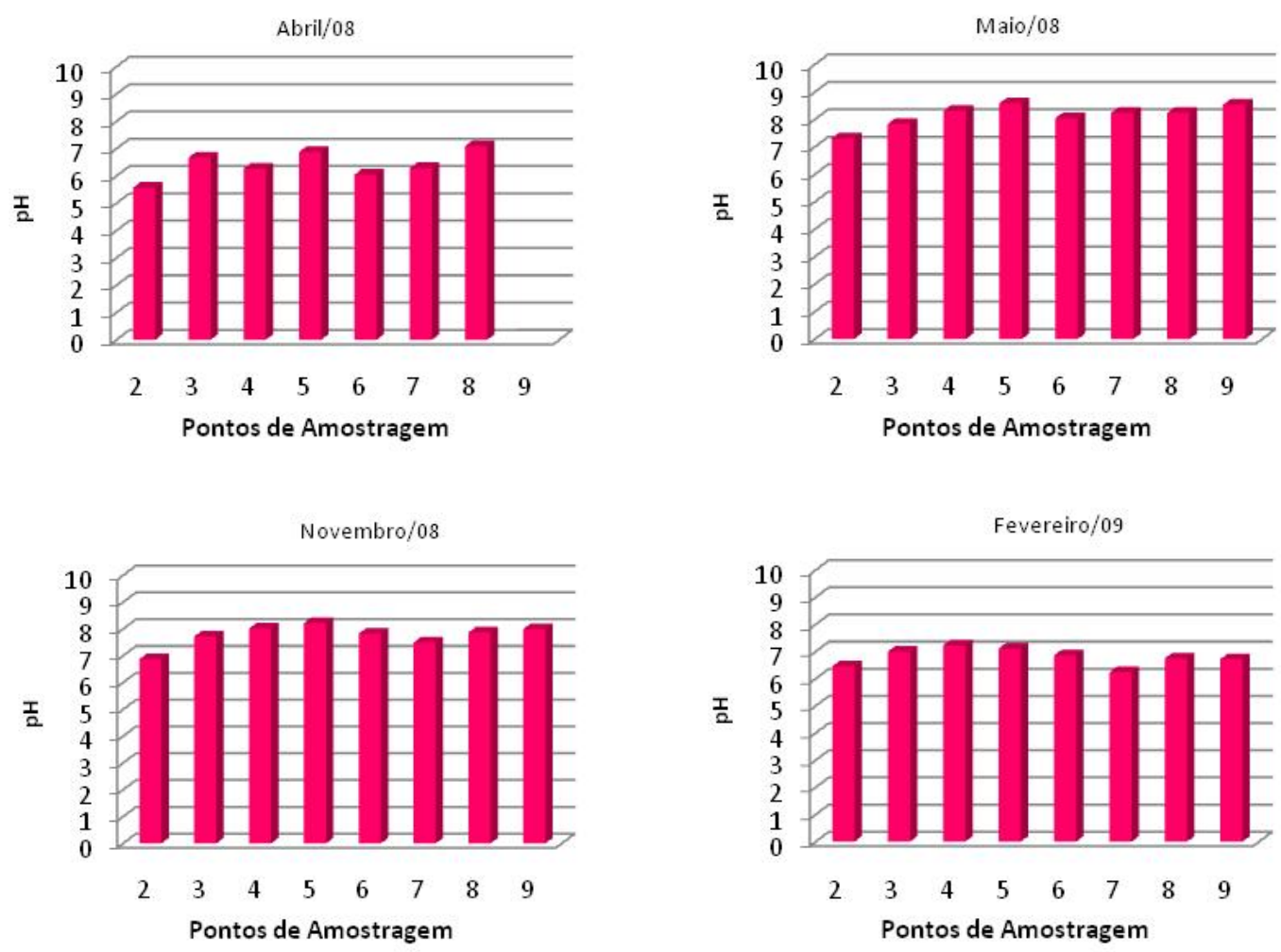

FIGURA 7 - Variação do $\mathrm{pH}$ nos pontos de amostragem durante o período de estudo.

O potencial hidrogeniônico de um ambiente aquático é influenciado, entre outros fatores, pela concentração de $\mathrm{CO}_{2}$ presente na água. Esta por sua vez é afetada pela temperatura da água, pressão parcial deste gás na atmosfera, taxa de respiração dos organismos aeróbicos aquáticos, pela taxa de fotossíntese e pela decomposição orgânica (Minillo, 2005).

Em água pura existe uma quantidade, embora pequena, de íons $\mathrm{H}^{+} \mathrm{e}$ $\mathrm{OH}^{-}$em equilíbrio com as moléculas da água. No ambiente natural, como esperado, não ocorre, via de regra, número igual de $\mathrm{H}^{+}$e $\mathrm{OH}^{-}$, mas suas concentrações são fortemente influenciadas por sais, ácidos, e bases presentes no meio (Esteves, 1998).

A influência do $\mathrm{pH}$ sobre os ecossistemas aquáticos naturais dá-se diretamente devido a seus efeitos sobre a fisiologia das diversas espécies. Também o efeito indireto é muito importante podendo, determinadas condições de $\mathrm{pH}$, contribuírem para a precipitação de elementos químicos tóxicos como alguns metais. Outras condições podem exercer efeitos sobre as solubilidades de nutrientes (CETESB, 2009). 
Desta forma, as restrições de faixas de pH são estabelecidas para as diversas classes de águas naturais, de acordo com a legislação federal, resolução CONAMA 357/05, a faixa de pH deve estar entre 6 e 9, para as classes 1, 2 e 3 de águas doces.

\subsubsection{Oxigênio Dissolvido (mg. $\left.\mathrm{L}^{-1}\right)$}

O maior valor de oxigênio dissolvido (OD) registrado foi de $8,60 \mathrm{mg} \cdot \mathrm{L}^{-1}$

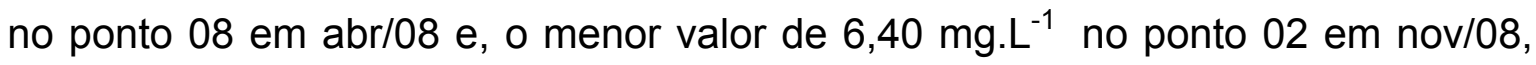
com média de 7,59 \pm 0,54 mg. $\mathrm{L}^{-1}$ Apenas os pontos 02, 03, 05 e 07 apresentaram alguns valores entre 6,40 e $7,00 \mathrm{mg} \cdot \mathrm{L}^{-1}$, os pontos $04,06,08$ e 09 , em todos os meses de amostragem, apresentaram concentrações de OD acima de 7,00 mg. ${ }^{-}$ ${ }^{1}$.(FIG. 8) .
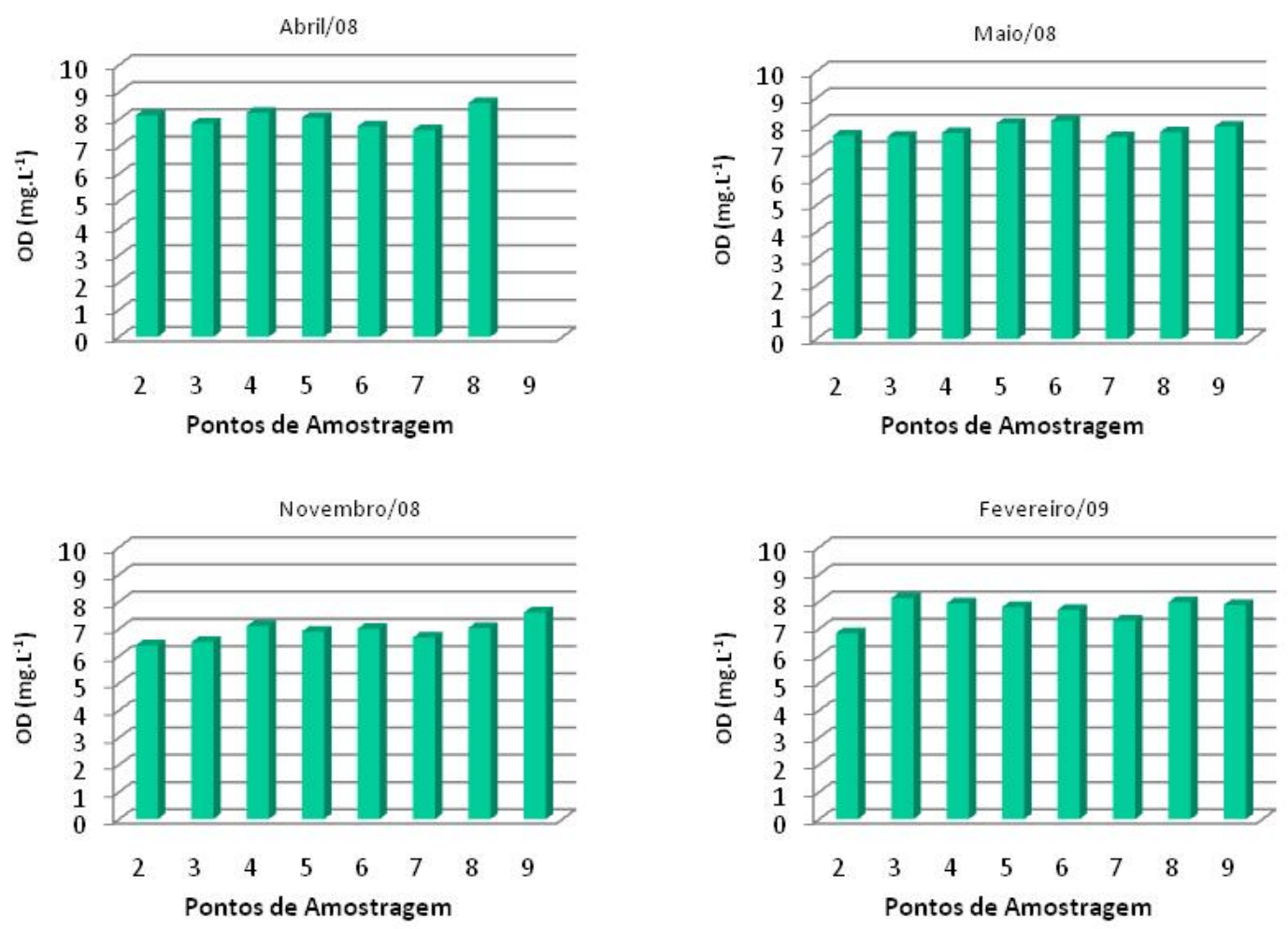

FIGURA 8 - Variação do oxigênio dissolvido nos pontos de amostragem durante o período de estudo.

Os valores obtidos de oxigênio dissolvido, em todos os pontos durante o período de estudo, sempre estiveram acima dos valores considerados próprios para manutenção da vida aquática, de acordo com a resolução CONAMA 357/05, que é de 5,0 mg.L ${ }^{-1}$ (Brasil, 2005). Este parâmetro é um dos mais importantes na 
dinâmica dos ecossistemas aquáticos, pois influencia a sobrevivência das comunidades aquáticas, além de participar de vários processos químicos (Esteves, 1998). As concentrações de OD são influenciadas pela temperatura, que afeta a solubilidade dos gases na água, como a do oxigênio que aumenta em baixas temperaturas.

Segundo Straškraba e Tundisi (2000), a concentração de oxigênio nas águas é função da relação entre a produção e utilização desse elemento. $\mathrm{Na}$ superfície do reservatório, concentrações baixas de oxigênio, menores que 2 $\mathrm{mg} \cdot \mathrm{L}^{-1}$, indicam poluição orgânica vinda do exterior, uma vez que a decomposição da matéria orgânica prevalece sobre a produção fotossintética. Altas concentrações de oxigênio durante os períodos frios e valores um pouco mais baixos durante os quentes sugerem a existência de um estado oligotrófico, ou seja, com elevadas concentrações de oxigênio no hipolímnio.

Godoi (2008) constatou correlação negativa moderada observada entre os valores de condutividade e oxigênio dissolvido, confirmando que quanto maior a concentração iônica maior a degradação da água superficial e maior o consumo de oxigênio no processo de oxidação dos compostos poluentes, ou seja, quanto maiores os valores de OD menores os valores de condutividade.

Correlação positiva ocorre entre valores de OD e transparência da água. A maior transparência e, consequentemente, maior profundidade de zona eufótica, indica o aumento de atividade fotossintética, responsável pelo incremento de oxigênio dissolvido na água (Szajubok, 2000).

\subsubsection{Transparência $(\mathrm{m})$ e Zona Eufótica (m)}

A transparência máxima registrada foi 4,82 metros no ponto 04 em nov/08 e mínima registrada foi 1,16 metros no ponto 02 do mesmo mês (FIG. 9), com média de 2,92 $\pm 1,01$ metros. 

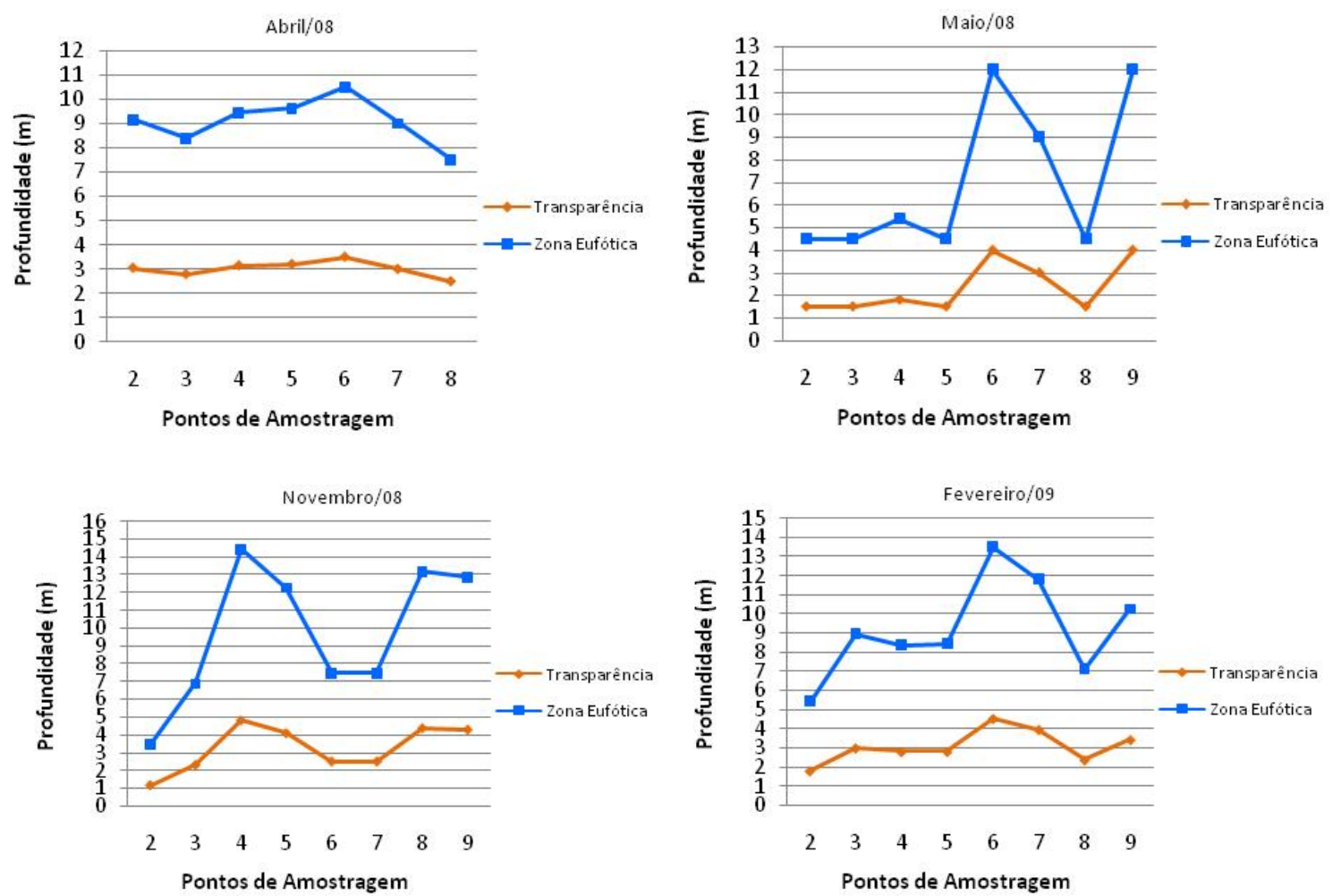

FIGURA 9 - Variação da transparência e zona eufótica nos pontos de amostragem durante o período de estudo.

De acordo com Wetzel (2001) apud Gentil (2007) a transparência ao disco de Secchi tem relação inversa com a quantidade de matéria orgânica dissolvida e em suspensão na água. Assim, quanto maior o valor de transparência, maior a penetração de luz adequada à atividade fotossintética dos organismos produtores que servem de alimento ao zooplâncton e aos peixes.

Barbosa (2002) constatou baixos valores de transparência da água, de $0,25 \mathrm{~m}$ a 1,0 $\mathrm{m}$ no açude Taperoá II, considerado um lago raso. Os valores apresentaram um padrão definido, menor nos meses chuvosos (março e abril) e maior nos meses secos (junho, julho, agosto e setembro), padrão não observado no presente trabalho.

A zona eufótica refere-se à porção iluminada da coluna d'água que pode variar desde alguns centrímetros até dezenas de metros, dependendo, principalmente, da capacidade do meio em atenuar a radiação subaquática (Esteves, 1998). A profundidade da zona eufótica pode ser reduzida, pela alta concentração de compostos dissolvidos, que atenua a penetração de luz na água. 
Valores altos de zona eufótica encontrados no complexo ParaibunaParaitinga demonstram a possibilidade da ocorrência de atividade fotossintética até cerca de $8 \mathrm{~m}$ (valor médio da zona eufótica) de profundidade.

\subsubsection{Turbidez (NTU)}

O menor valor de turbidez registrado foi de 0,74 NTU no ponto 06 em abr/08 e, o maior valor foi de 14,5 NTU no ponto 02 em nov/08, com média de $3,20 \pm 2,95$ NTU (FIG. 10). Estes valores mostraram-se muito abaixo dos valores estabelecidos pela resolução CONAMA 357/05, que é de até 100 NTU, para a classe 2 de águas doces.
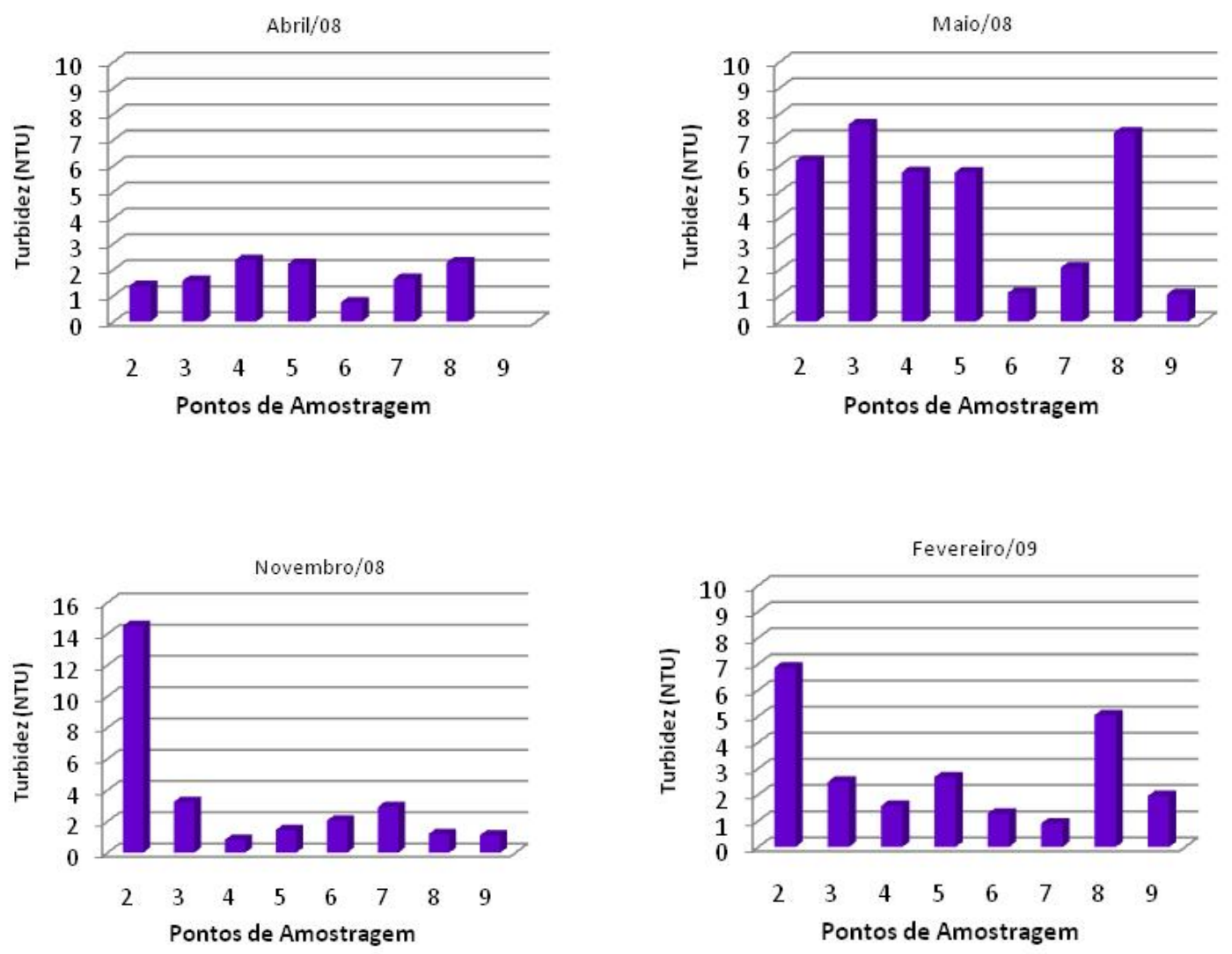

FIGURA 10 - Variação da turbidez nos pontos de amostragem durante o período de estudo.

A variável turbidez pode ser considerada o oposto da transparência (Esteves, 1998) e, resulta da presença de partículas em suspensão na água, tais como, bactérias, fitoplâncton, substâncias orgânicas e inorgânicas, estas 
advindas de processos erosivos do solo adjacente ou da ressuspensão do sedimento (Esteves, 1998; Wetzel, 2001). Considerando isto, os maiores valores de turbidez devem estar relacionados inversamento aos valores de transparência. Fato evidenciado, principalmente, nos pontos 06 e 07 nos meses de abr/08, mai/08 e fev/09, nos quais a transparência apresentou os maiores valores e a turbidez os menores valores.

A ocorrência de chuvas também é um fator elevador da turbidez, uma vez que, aumenta a concentração do material em suspensão, devido ao escoamento de material alóctone, bem como o aumento da contribuição fitoplanctônica, já que na época do verão sua densidade se eleva (Gentil, 2007).

A turbidez também pode induzir à sedimentação dos reservatórios e diminuir sua vida útil (Straškraba e Tundisi, 2000). Quando sedimentadas, estas partículas formam bancos de lodos onde a digestão anaeróbia leva à formação de gás metano e gás carbônico, principalmente, além de nitrogênio gasoso e gás sulfídrico (Piveli e Kato, 2006).

\subsection{7 Ânions: Cloreto, Fluoreto, Nitrato, Sulfato e Fosfato (mg.t $\left.{ }^{-1}\right)$}

As concentrações do ânion cloreto estiveram entre 1,33 mg.t ${ }^{-1}$ e 2,63 $\mathrm{mg} \cdot \mathrm{L}^{-1}$, com média de $1,84 \pm 0,35 \mathrm{mg} \cdot \mathrm{L}^{-1}$, valores considerados muito baixos se comparados ao permitido pela resolução CONAMA 357/05, que é de $250 \mathrm{mg} \cdot \mathrm{L}^{-1}$ e, aos valores geralmente encontrados em esgoto bruto, de $15 \mathrm{mg} \cdot \mathrm{L}^{-1}$ (CETESB, 2009).

Os valores obtidos para o ânion fluoreto apresentaram baixa oscilação, entre $0,030 \mathrm{mg} \cdot \mathrm{L}^{-1}$ e $0,050 \mathrm{mg} \cdot \mathrm{L}^{-1}$, com média de 0,041 $\pm 0,005 \mathrm{mg} \cdot \mathrm{L}^{-1}$, obedecendo o limite estabelecido pela legislação CONAMA 357/05, de 1,4 mg.t-1.

O mesmo comportamento foi verificado para o ânion nitrato, que apresentou baixa variação de concentração, entre $0,07 \mathrm{mg} \cdot \mathrm{L}^{-1}$ e $1,02 \mathrm{mg} \cdot \mathrm{L}^{-1}$, com média de 0,42 $\pm 0,23 \mathrm{mg} \cdot \mathrm{L}^{-1}$, obedecendo os valores limites CONAMA 357/05, de $10,0 \mathrm{mg} \cdot \mathrm{L}^{-1}$.

As concentrações do ânio sulfato estiveram entre $0,35 \mathrm{mg} \cdot \mathrm{L}^{-1}$ e 0,65 $\mathrm{mg} \cdot \mathrm{L}^{-1}$, com média de $0,52 \pm 0,06 \mathrm{mg} \cdot \mathrm{L}^{-1}$, valores muito menores do que é permitido pela mesma legislação, $250 \mathrm{mg} \cdot \mathrm{L}^{-1}$. 
Nas águas superficiais, as descargas de esgotos sanitários são fontes importantes de cloretos, sendo que cada pessoa expele através da urina cerca 6 $\mathrm{g}$ de cloreto por dia, o que faz com que os esgotos apresentem concentrações de cloreto que ultrapassam a 15 mg.L ${ }^{-1}$ (CETESB, 2009).

A fluoretação da água é um método reconhecido na prevenção da cárie dentária, quando utilizada na concentração ideal para cada região, segundo a temperatura média local. No entanto, é um fator de risco para fluorose dentária, quando a concentração de flúor ultrapassa os níveis recomendados (Ramires et al., 2004).

Na maioria das regiões brasileiras esta concentração é de $0,07 \mathrm{mg} \cdot \mathrm{L}^{-1}$, tolerando o mínimo de $0,6 \mathrm{mg} \cdot \mathrm{L}^{-1}$, concentração que garantiria os benefícios de redução de cárie, e o máximo de $0,8 \mathrm{mg} \cdot \mathrm{L}^{-1}$ para manter graus aceitáveis de fluorose dental (Catani, 2007). Altas concentrações de flúor são encontradas em águas naturais quando estas se encontram em locais onde existem minerais ricos em flúor, como próximos a montanhas altas ou áreas com depósitos geológicos de origem marinha, onde concentrações de até $10 \mathrm{mg} \cdot \mathrm{L}^{-1}$ ou mais são encontradas. Ou, fatores antrópicos como atividades industriais relacionadas à vidro e fios condutores de eletricidade também descarregam fluoreto nas águas naturais (CETESB, 2009).

O sulfato ocorre nas águas superficiais provenientes de descarga de esgotos domésticos e efluentes industriais como indústrias de celulose e papel, química e farmacêutica. Suas concentrações nestas águas variam em geral na faixa de 2 a 80 mg.t-1 (Piveli e Kato, 2006). Conforme resolução 357/05 do CONAMA, este parâmetro não deve ultrapassar $250 \mathrm{mg} \cdot \mathrm{L}^{-1}$ para todas as classes de águas doces.

Os nitratos são produzidos no solo pela nitrificação da amônia e do nitrogênio e, são facilmente liberados pelo solo, principalmente na ocorrência de fortes chuvas, quando a coesão dos grãos se torna menor. A redução dos nitratos dá origem a nitritos tóxicos. Na presença de compostos orgânicos nitrogenados, os nitritos podem tornar-se precursores de nitrosaminas carcinogênicas (Straškraba e Tundisi, 2000).

Henry et al. (1998) compararam as médias dos valores de nitrato entre os períodos chuvoso (início e pico) e seco, constatando que o início do período de precipitações funciona como um "gatilho", introduzindo N e P, proveniente da 
bacia de drenagem dos tributários principais do reservatório, porém este efeito fica limitado às estações próximas à desembocadura dos tributários.

O nitrato pode ser fator limitante da produção primária de ecossistemas aquáticos (Esteves, 1998), juntamente com o fósforo que é o elemento freqüentemente limitador da produtividade primária. A determinação das concentrações de fósforo nas camadas superficiais de um reservatório estão relacionadas às quantidades de clorofila a produzida no corpo d'água.

O fósforo encontra-se sob diversas formas na coluna d'água, sendo o fosfato solúvel reativo $\left(\mathrm{P}-\mathrm{PO}_{4}\right)$ a forma mais utilizada pelos organismos produtores do sistema, tornando-se um fator limitante para tais organismos em ambientes naturais. A temperatura elevada promove aceleração do metabolismo, contribuindo com maior consumo de $\mathrm{P}_{-} \mathrm{PO}_{4}$ pelas algas fitoplanctônicas presentes na zona eufótica da coluna d'água (Wetzel, 2001 apud Gentil, 2007 ).

As análises para o ânion fostato realizadas em todas as amostras coletadas indicaram que esse composto esteve abaixo do limite de detecção da técnica analítica utilizada que é de $0,05 \mathrm{mg} \cdot \mathrm{L}^{-1}$. Porém, esse valor econtra-se próximo daquele estabelecido na legislação CONAMA 357/05, para águas doces de classe 2, para o fósforo, que é de $0,02 \mathrm{mg} \cdot \mathrm{L}^{-1}$.

Os valores de cloreto, fluoreto, nitrato e sulfato, obtidos no presente estudo, estão apresentados na FIG. 11. 


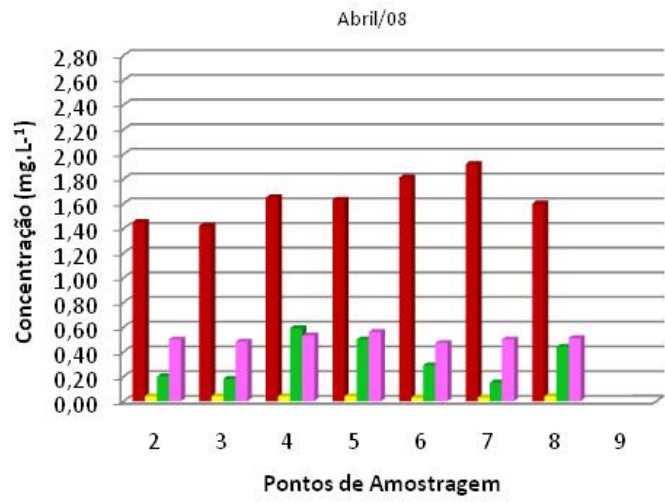

- Cloreto

Fluoreto

nitrato

- Sulfato

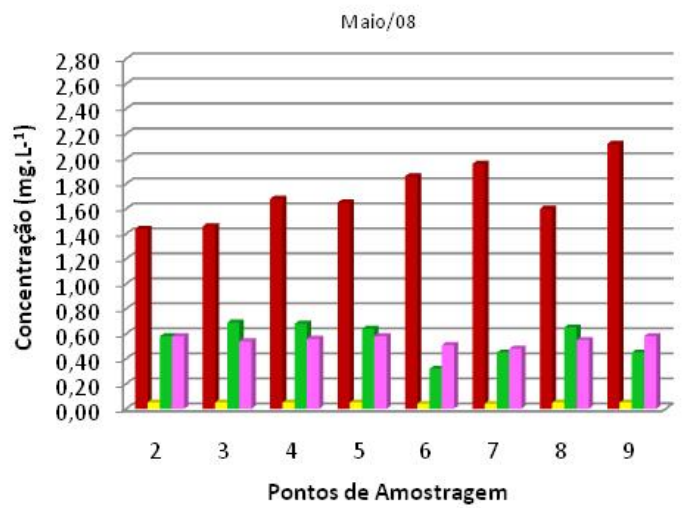

- Cloreto

Fluoreto

- Nitrato

- Sulfato

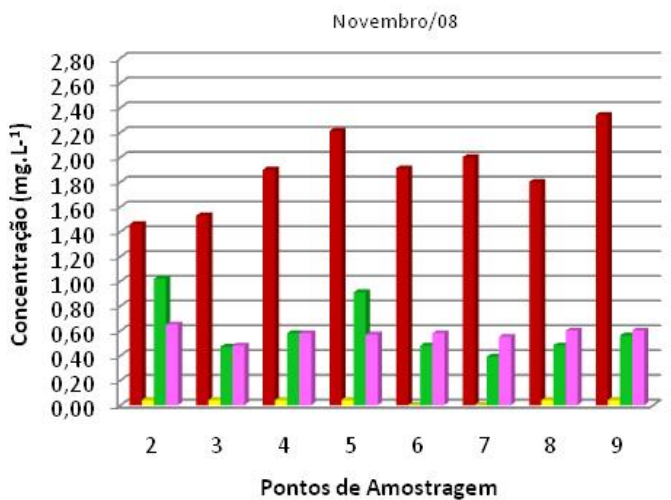

- Cloreto

Fluoreto

- Nitrato

Sulfato

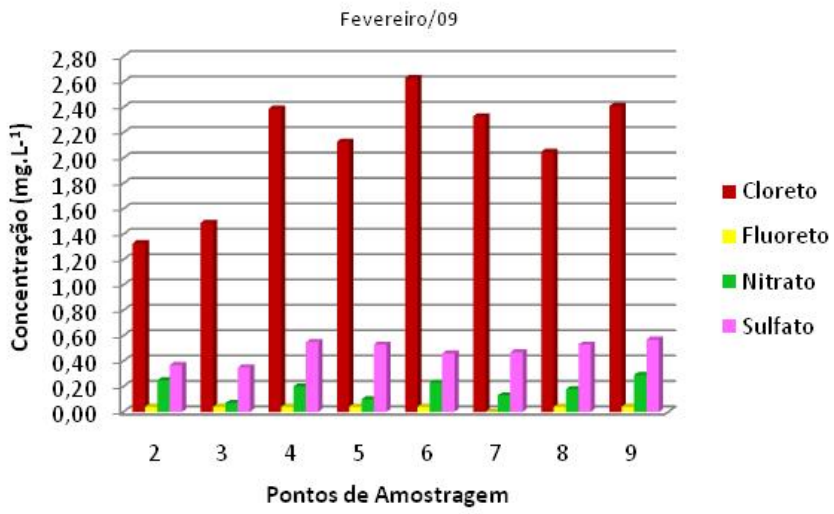

FIGURA 11 - Variação da concentração dos ânions Cloreto, Fluoreto, Nitrato e Sulfato nos pontos de amostragem em abr/08, mai/08, nov/08 e fev/09. 


\subsubsection{Metais e elementos-traço $\left(\mathrm{mg} \cdot \mathrm{L}^{-1}\right)$}

Todas as formas de vida são afetadas pela presença de metais dependendo da dose e da forma química. Muitos metais são essenciais, em baixas concentrações, para o crescimento de todos os tipos de organismos, desde as bactérias até mesmo o ser humano, mas podem causar danos aos sistemas biológicos (Nakano e Avila-Campos, 2008).

No ambiente aquático, são considerados como um dos contaminantes mais comuns e sua origem pode ser natural ou antrópica (Peláez-Rodríguez, 2001).

Branco (1986) lista em ordem descrescente os metais: $\mathrm{Hg}, \mathrm{Co}, \mathrm{Zn}, \mathrm{Cd}$, $\mathrm{Sn}, \mathrm{Al}, \mathrm{Ni}, \mathrm{Fe}, \mathrm{Ba}, \mathrm{Mn}, \mathrm{K}, \mathrm{Ca}, \mathrm{Mg}$ e $\mathrm{Na}$ que apresentam toxicidade nos peixes. Porém, podem ocorrer variações no grau de toxidez, relacionadas à natureza do ânion, além disso, pode haver efeitos de antagonismo e de sinergismo entre várias substâncias da água, o metal terá sua toxidez diminuída no primeiro caso, e aumentada no segundo pela presença de substâncias existentes.

As concentrações médias dos elementos $\mathrm{Ag}, \mathrm{Al}, \mathrm{B}, \mathrm{Ba}, \mathrm{Be}, \mathrm{Cr}, \mathrm{Co}, \mathrm{Cu}$, $\mathrm{Fe}, \mathrm{Mn}, \mathrm{Ni}, \mathrm{Li}, \mathrm{P}, \mathrm{Zn}, \mathrm{V}, \mathrm{Hg}, \mathrm{As}, \mathrm{Cd}, \mathrm{Pb}, \mathrm{Sb}$ e Se encontradas nas amostras analisadas estão apresentadas na TAB. 9.

Para alguns elementos, $\mathrm{As}, \mathrm{Be}, \mathrm{Cd}, \mathrm{Co}, \mathrm{Cr}, \mathrm{Cu}, \mathrm{Hg}, \mathrm{Ni}, \mathrm{Sb}$, não foi observada distribuição, sendo o limite de quantificação da metodologia analítica utilizada, o valor determinado. 
TABELA 9 - Média das concentrações dos elementos-traço e metais no período de estudo, desvio padrão (DP), mediana e intervalo de concentração

\begin{tabular}{|c|c|c|c|}
\hline Elemento & $\begin{array}{c}\text { Concentração } \\
\text { média }\left(m g . L^{-1}\right) \text { e } \\
\text { DP }\end{array}$ & Mediana & $\begin{array}{c}\text { Intervalo de } \\
\text { Concentração } \\
\left(m g . L^{-1}\right)\end{array}$ \\
\hline $\mathrm{Ag}$ & $0,0023 \pm 0,0005$ & 0,0026 & $0,0020-0,0032$ \\
\hline $\mathrm{Al}$ & $0,1210 \pm 0,1544$ & 0,0433 & $0,0010-0,5060$ \\
\hline B & $0,0145 \pm 0,0080$ & 0,0200 & $0,0040-0,0260$ \\
\hline $\mathrm{Ba}$ & $0,0098 \pm 0,0085$ & 0,0100 & $0,0010-0,0440$ \\
\hline $\mathrm{Fe}$ & $0,1397 \pm 0,1329$ & 0,0846 & $0,0100-0,4810$ \\
\hline $\mathrm{Mn}$ & $0,0021 \pm 0,0003$ & 0,0023 & $0,0020-0,0037$ \\
\hline $\mathrm{K}$ & $1,6363 \pm 0,4479$ & 1,6200 & $0,8222-2,3800$ \\
\hline $\mathrm{Li}$ & $0,0166 \pm 0,0009$ & 0,0169 & $0,0152-0,0177$ \\
\hline $\mathrm{P}$ & $0,0293 \pm 0,0153$ & 0,0410 & $0,0200-0,0863$ \\
\hline $\mathrm{Zn}$ & $0,0032 \pm 0,0036$ & 0,0025 & $0,0010-0,0207$ \\
\hline $\mathrm{Pb}$ & $0,0011 \pm 0,0003$ & 0,0013 & $0,0010-0,0023$ \\
\hline As & $<0,0010$ & - & - \\
\hline $\mathrm{Be}$ & $<0,0020$ & - & - \\
\hline $\mathrm{Cd}$ & $<0,0001$ & - & - \\
\hline Co & $<0,0100$ & - & - \\
\hline $\mathrm{Cr}$ & $<0,0100$ & - & - \\
\hline $\mathrm{Cu}$ & $<0,0200$ & - & - \\
\hline $\mathrm{Hg}$ & $<0,0008$ & - & - \\
\hline $\mathrm{Ni}$ & $<0,0100$ & - & - \\
\hline $\mathrm{Sb}$ & $<0,0010$ & - & - \\
\hline $\mathrm{Se}$ & $<0,0010$ & - & - \\
\hline V & $<0,0300$ & - & - \\
\hline
\end{tabular}

Elementos como $\mathrm{Co}, \mathrm{Pb}, \mathrm{Ni}$, Cu e $\mathrm{Zn}$ são compostos que se combinam com os ânions em solução, formando compostos de menor solubilidade, com tendência à deposição no sedimento (Godoi, 2008). Podendo este fator ter 
contribuído para a não quantificação, em determinados momentos, destes elementos na área de estudo.

Na FIG. 12 é apresentada a distribuição do elemento alumínio nos pontos de amostragem durante o período de estudo. Os valores deste elemento estiveram acima do limite estabelecido pela resolução CONAMA 357/05, que é de 0,100 mg. $\mathrm{L}^{-1}$, nos pontos 04 e 05 no mês de abr/08, nos pontos 02, 03, 04, 05, e 08 no mês de mai/08, no ponto 02 em nov/08 e nos pontos 02 e 03 em fev/09.

O Al é abundante em rochas e minerais, sendo considerado elemento de constituição. Nas águas doces e marinhas, entretanto, não se encontram concentrações elevadas de alumínio, sendo este fato decorrente da sua baixa solubilidade, precipitando-se ou sendo absorvido como hidróxido ou carbonato. Pode aparecer em águas de abastecimento, com resultado do processo de coagulação em que se emprega sulfato de alumínio (Piveli e Kato, 2006).

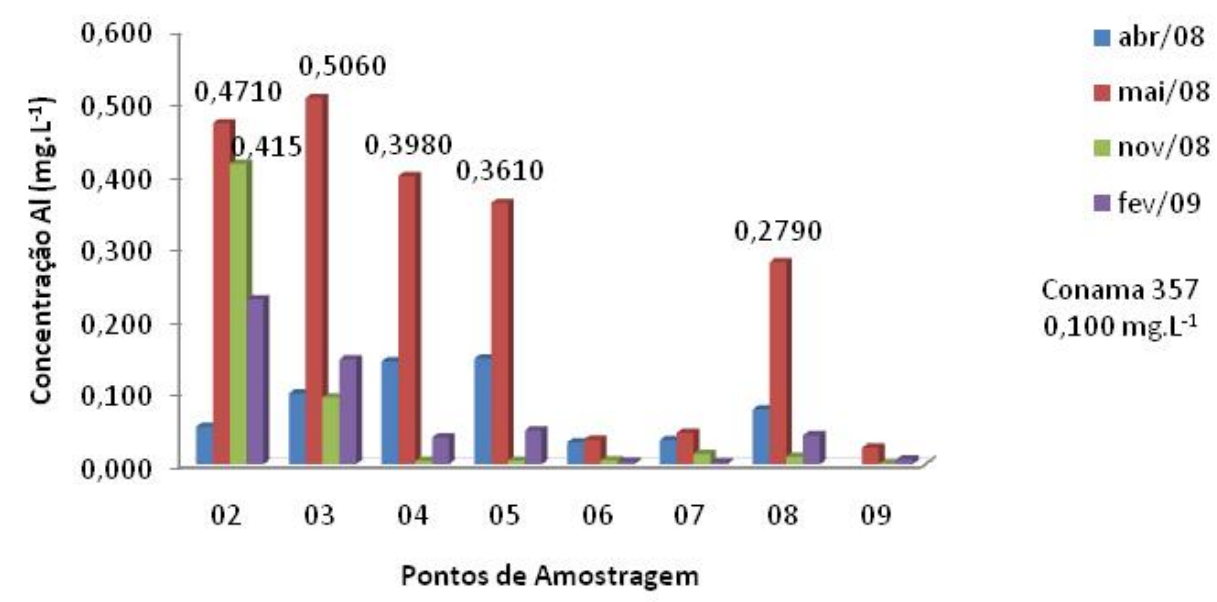

FIGURA 12 - Variação da concentração de alumínio nos pontos de amostragem durante o período de estudo.

Na FIG. 13 é apresentada a distribuição do elemento bário nos pontos de amostragem durante o período de estudo. Os valores deste elemento apresentaram distribuição homogênea em todos os pontos no mês de abr/08, sendo o limite de detecção da técnica analítica utilizada $\left(0,0010 \mathrm{mg} \cdot \mathrm{L}^{-1}\right)$ como valor observado, não representando, portanto, o valor real.

Todos os valores observados atenderam os limites da resolução CONAMA 357/05, sendo observado o valor máximo, de 0,0440 mg. $\mathrm{L}^{-1}$, no ponto 06 no mês de nov/08. 
O elemento $\mathrm{Ba}$ pode ocorrer naturalmente na água, na forma de carbonatos em algumas fontes minerais, mas pode decorrer de atividades industriais e da extração de bauxita (Piveli e Kato, 2006). Em geral, ocorre nas águas naturais em concentrações muito baixas, de $0,7 \mu \mathrm{g} \cdot \mathrm{L}^{-1}$ a $900 \mu \mathrm{g} \cdot \mathrm{L}^{-1}$ (CETESB, 2009).

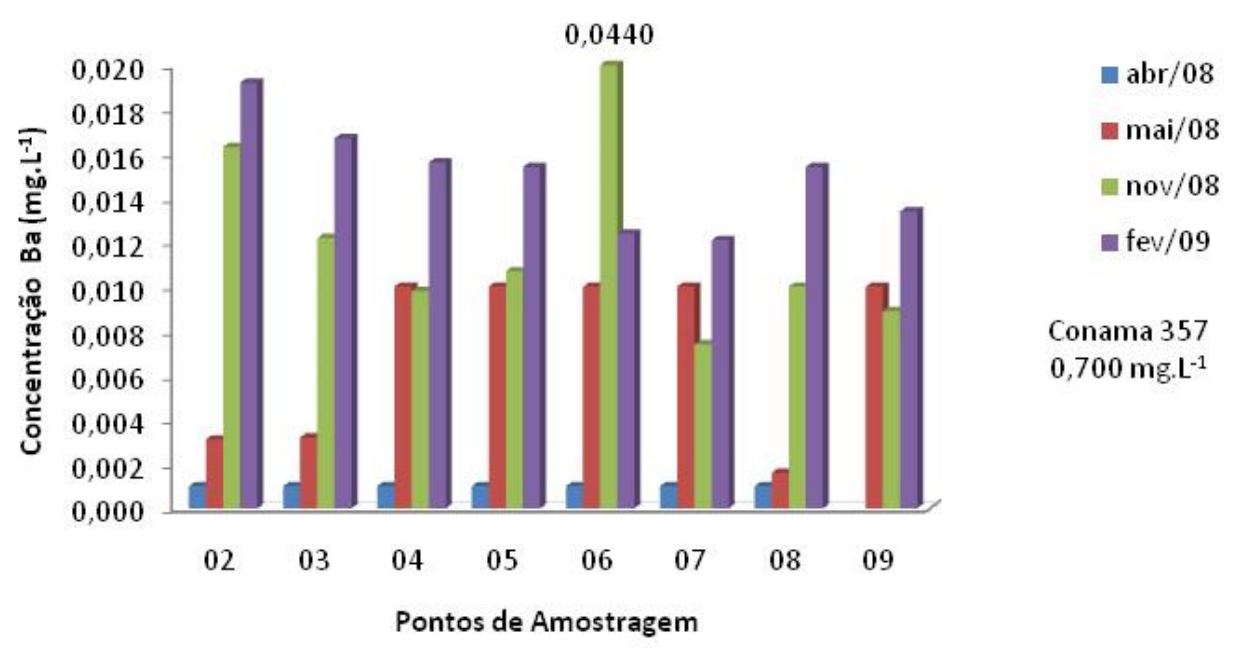

FIGURA 13 - Variação da concentração de bário nos pontos de amostragem durante o período de estudo.

A distribuição do elemento ferro nos pontos de amostragem durante 0 período de estudo é apresentada na FIG. 14. Os valores deste elemento estiveram acima do limite estabelecido pela resolução CONAMA 357/05, que é de $0,300 \mathrm{mg} \cdot \mathrm{L}^{-1}$, nos pontos 02 e 03 no mês de mai/08, no ponto 02 em nov/08 e no ponto 02 em fev/09.

Nas águas superficiais, o nível de ferro aumenta nas estações chuvosas devido ao carreamento de solos e a ocorrência de processos de erosão das margens. Também poderá ser importante a contribuição devida à efluentes industriais, pois muitas indústrias metalúrgicas desenvolvem atividades de remoção da camada oxidada (ferrugem) das peças antes de seu uso, processo conhecido por decapagem (CETESB, 2009).

Apesar de estar relacionada à erosão do solo nas margens, a concentração mais elevada, deste elemento, no ponto 02 não pode ser relacionada com este fato, já que há sivicultura de eucapliptos no entorno deste ponto e, segundo Vianna et al. (2009), ainda existem controvérsias a respeito dos impactos ambientais provocados por plantações de eucaliptos, relacionados ao 
esgotamento da umidade do solo, desestabilização do ciclo de nutrientes e aumento ou estabilidade da erosão, fazendo-se necessária a realização de estudos mais aprofundados.

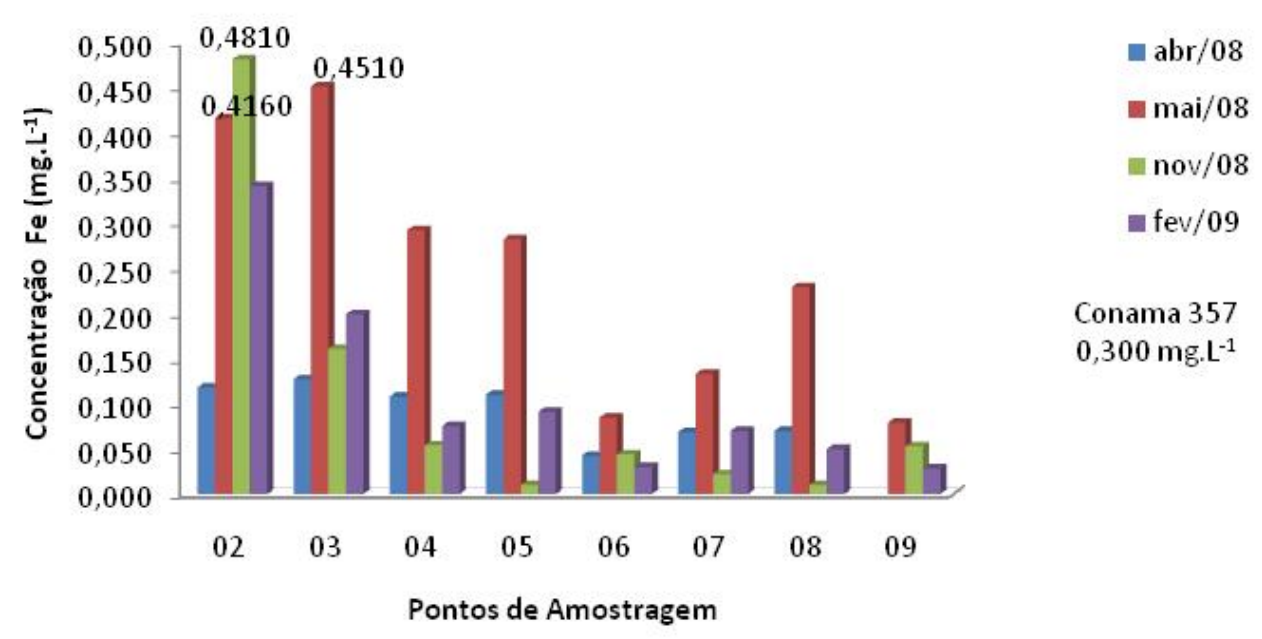

FIGURA 14 - Variação da concentração de ferro nos pontos de amostragem durante o período de estudo.

Na FIG. 15 é apresentada a distribuição do elemento lítio nos pontos de amostragem durante o período de estudo. Todos os valores observados atenderam os limites da resolução CONAMA 357/05, que é de 2,5 mg. $\mathrm{L}^{-1}$.

Os valores deste elemento apresentaram pouca variação na concentração em todos os pontos durante o período de estudo, sendo o valor mímino 0,0152 mg. $\mathrm{L}^{-1}$ nos pontos 02,03 e 05 no mês de fev/09, e o valor máximo de $0,0177 \mathrm{mg} \cdot \mathrm{L}^{-1}$ no ponto 07 no mês de abr/08.

Nordi et al. (2006) estudaram a propriedade do íon $\mathrm{Li}^{+}$de provocar desorganização estrutural da cápsula extracelular polissacarídica de algas como Ankistrodesmus gracilis. Esta estrutura também pode ser encontrada em muitas clorofíceas, cianofíceas e rodofíceas. Os autores concluíram que a partir da concentração de $\mathrm{LiCl}$ 1,0 M as cápsulas das algas são totalmente retiradas, resultando em células aglutinadas, e a partir desta foi constatada morte das células expostas. 


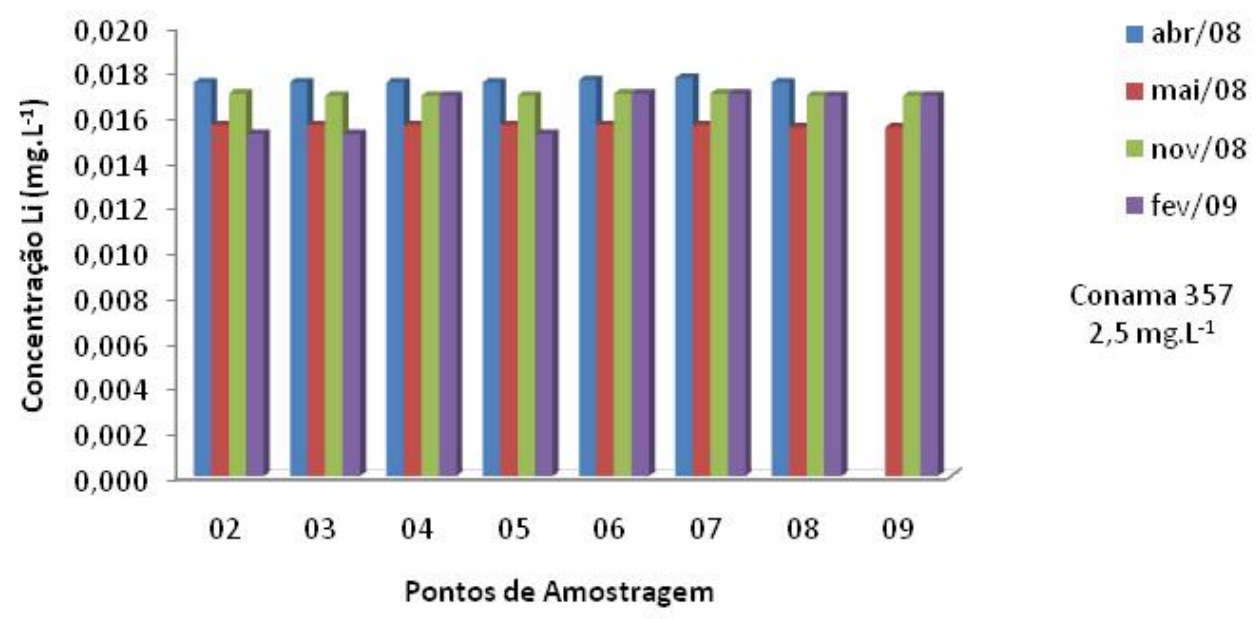

FIGURA 15 - Variação da concentração de lítio nos pontos de amostragem durante o período de estudo.

Na FIG. 16 é apresentada a distribuição do elemento manganês nos pontos de amostragem durante o período de estudo. Todos os valores observados mostraram-se bem abaixo dos limites estabelecidos na resolução CONAMA 357/05, que é de 0,100 mg. $\mathrm{L}^{-1}$.

Os valores deste elemento apresentaram distribuição homogênea em todos os pontos durante o período de estudo, mostrando-se, quase sempre, muito próximos ao valor do limite de deteç̧ão da técnica analítica utilizada que é de $0,002 \mathrm{mg} \cdot \mathrm{L}^{-1}$.

Segundo Piveli e Kato (2009) a concentração de manganês menor que $0,05 \mathrm{mg} \cdot \mathrm{L}^{-1}$ geralmente é aceitável em mananciais, devido ao fato de não ocorrerem, nesta faixa de concentração, manifestações de manchas negras ou depósitos de seu óxido nos sistemas de abastecimento de água.

Este elemento, raramente, atinge concentrações de 1,0 mg.L.-1 em águas superficiais naturais e, normalmente, está presente em quantidades de 0,2 $\mathrm{mg} \cdot \mathrm{L}^{-1}$ ou menos. É muito usado na indústria do aço, na fabricação de ligas metálicas e baterias e na indústria química em tintas, vernizes, fogos de artifícios e fertilizantes, entre outros (CETESB, 2009). 


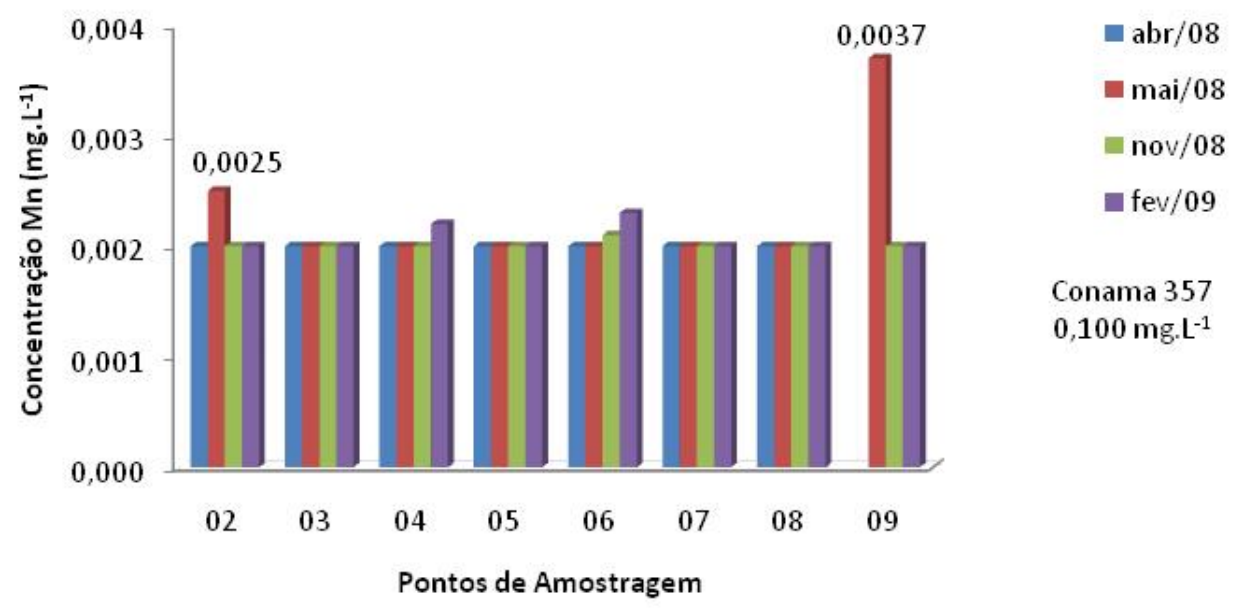

FIGURA 16 - Variação da concentração de manganês nos pontos de amostragem durante o período de estudo.

As concentrações do elemento zinco nos pontos de amostragem durante o período de estudo, são apresentadas na FIG. 17. Todos os valores observados mostraram-se distantes dos limites estabelecidos pela resolução CONAMA 357/05 $\left(0,180 \mathrm{mg} \cdot \mathrm{L}^{-1}\right)$. As concentrações deste elemento estiveram sempre abaixo de $0,007 \mathrm{mg} \cdot \mathrm{L}^{-1}$, sendo observado um pico (valor máximo), de $0,0207 \mathrm{mg} \cdot \mathrm{L}^{-1}$, no ponto 05 no mês de nov/08.

Corbi et al. (2006) puderam observar maiores valores dos elementos Co e $\mathrm{Zn}$, no sedimento de córregos, com áreas adjacentes de plantações de cana-de-açúcar, comparadas a áreas adjacentes de mata ciliar e pastagem. Relacionaram altos valores de $\mathrm{Zn}$ obtidos nestas áreas à atividade de queima da cana-de-açúcar, embora a retirada da mata ciliar e conseqüente lixiviação do solo não pudessem ser ignoradas. 


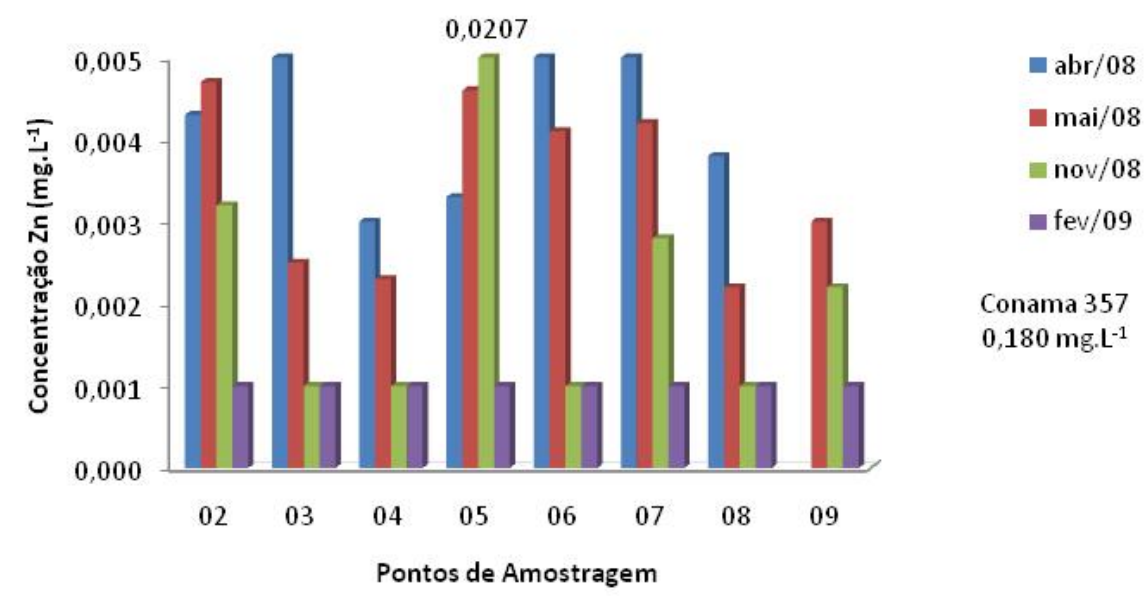

FIGURA 17 - Variação da concentração de zinco nos pontos de amostragem durante o período de estudo.

Avaliando-se os valores obtidos das concentrações dos 22 elementos, observa-se que a maioria dos valores estiveram abaixo dos parâmetros de qualidade da resolução CONAMA 357/05, exceto os elementos Al e $\mathrm{Fe}$ que apresentaram concentrações acima dos limites legais conforme apresentado na TAB. 10.

TABELA 10 - Concentrações de Al e Fe que ultrapassaram os valores da resolução 357/05 do CONAMA

\begin{tabular}{|c|c|c|c|c|}
\hline Elemento & Ponto & $\begin{array}{c}\text { Mês de } \\
\text { amostragem }\end{array}$ & $\begin{array}{c}\text { Concentração } \\
\left(m g \cdot L^{-1}\right)\end{array}$ & $\begin{array}{c}\text { Res. 357/05 } \\
\left.\text { (mg. } \mathrm{L}^{-1}\right)\end{array}$ \\
\hline \multirow{10}{*}{$\mathrm{Al}$} & & Maio/2008 & 0,4710 & \multirow{10}{*}{0,1} \\
\hline & 02 & Novembro/2008 & 0,4150 & \\
\hline & & Fevereiro/2009 & 0,2280 & \\
\hline & 03 & Maio/2008 & 0,5060 & \\
\hline & & Fevereiro/2009 & 0,1450 & \\
\hline & \multirow[t]{2}{*}{04} & Abril/2008 & 0,1420 & \\
\hline & & Maio/2008 & 0,3980 & \\
\hline & \multirow[t]{2}{*}{05} & Abril/2008 & 0,1460 & \\
\hline & & Maio/2008 & 0,3610 & \\
\hline & 08 & Maio/2008 & 0,2790 & \\
\hline \multirow{4}{*}{$\mathrm{Fe}$} & 02 & Maio/2008 & 0,4160 & \multirow{4}{*}{0,3} \\
\hline & & Novembro/2008 & 0,4810 & \\
\hline & & Fevereiro/2009 & 0,3410 & \\
\hline & 03 & Maio/2008 & 0,4510 & \\
\hline
\end{tabular}




\subsubsection{Fósforo total $\left(\mathrm{mg}^{\mathrm{L}} \mathrm{L}^{-1}\right)$}

Os valores de fósforo total analisados no período de estudo, variaram de $0,0200 \mathrm{mg} \cdot \mathrm{L}^{-1}$, em todos os pontos nos meses nov/08 e fev/09, a 0,0863 mg.L${ }^{1}$, no ponto 02 em mai/08 (FIG. 18), apresentando valor médio de 0,0293 $\pm 0,0153$ $\mathrm{mg} \cdot \mathrm{L}^{-1}$.

As amostras nos meses de abr/08 e mai/08, exceto a amostra do ponto 06 de mai/08, apresentaram concentração de fósforo total acima de $0,0200 \mathrm{mg} \cdot \mathrm{L}^{-}$ 1 , limite máximo estabelecido pelo CONAMA para águas lênticas de Classe 2, na sua resolução $n^{\circ} 357 / 05$.

Nos demais meses de estudo as concentrações estiveram próximas a $0,0200 \mathrm{mg} \cdot \mathrm{L}^{-1}$, valores considerados baixos, quando comparados com valores obtidos para outros ecossistemas eutróficos (Lopes, 2007; Carvalho, 2003).

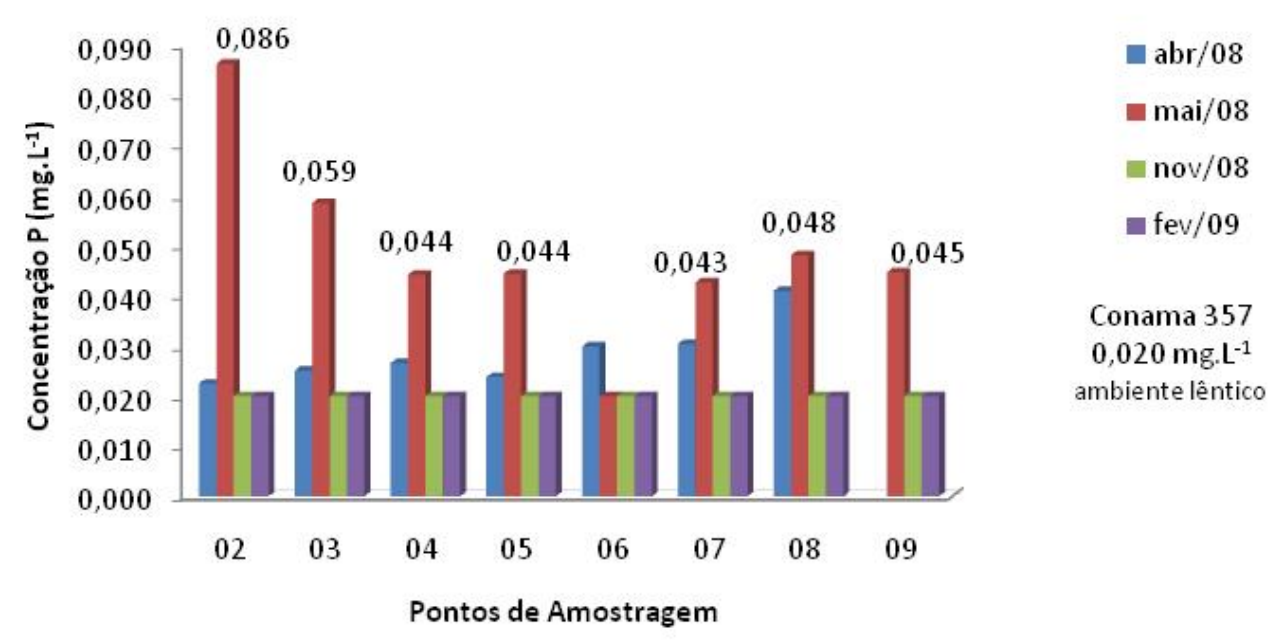

FIGURA 18 - Variação da concentração de fósforo nos pontos de amostragem durante o período de estudo.

No mês de mai/08, onde ocorreram os níveis mais altos deste elemento, pareceu ocorrer descarga orgânica extra nos corpos d'água estudados, já que, em águas naturais, este elemento aparece devido principalmente às descargas de esgotos sanitários, no qual os detergentes superfosfatados de cozinha constituem a principal fonte, além da própria matéria fecal.

Os meses de abril e maio são considerados secos, como verificado pelas baixas precipitações (TAB. 8), a estiagem pode ter levado à concentração 
deste elemento, onde a diminuição do volume de água leva à menor diluição das substâncias nela contida.

Lopes (2007) constatou valores mais altos de fósforo no período de seca (outono e inverno), sugerindo uma maior concentração de nutrientes neste período, devido à baixa renovação da água. Silva (2005) explica que no verão, podem ocorrer valores altos de fósforo devido à turbulência da água causada pelas chuvas e ressuspensão do sedimento contendo nutrientes. Para o córrego Pirajuçara, Godoi (2008) também correlacionou negativamente a quantidade de precipitação com a concentração de fósforo.

De modo que, este ponto de amostragem tem às suas margens monoculturas de eucaliptos e pastagens, estes podem ser fatores que causam aumento na concentração de fósforo, advindo do uso de fertilizantes e matéria orgânica residuária do metabolismo animal. Piveli e Kato (2006) assinalam que águas drenadas em áreas agrícolas e urbanas também podem provocar a presença excessiva de fósforo em águas naturais, por conta da aplicação de fertilizantes no solo.

Segundo Esteves (1998), na maioria das águas continentais, o fósforo é o principal fator limitante de sua produtividade. Além disso, tem sido apontado como o principal responsável pela eutrofização artificial destes ecossistemas.

\subsubsection{Série de sólidos dissolvidos $\left(\mathrm{mg}^{\mathrm{L}} \mathrm{L}^{-1}\right)$}

A amplitude dos valores de sólidos dissolvidos totais, durante o período de estudo, foi de 23,0 mg.t ${ }^{-1}$ (ponto $07 \mathrm{em} \mathrm{fev/09)} \mathrm{a} \mathrm{447,0} \mathrm{mg.L}{ }^{-1}$ (ponto $05 \mathrm{em}$ mai/08), com média de $65,0 \pm 74,0 \mathrm{mg} \cdot \mathrm{L}^{-1}$. A menor contribuição de sólidos voláteis, ou orgânicos, foi de $10,0 \mathrm{mg} \cdot \mathrm{L}^{-1}$ nos pontos $02 \mathrm{em} \mathrm{fev/09} \mathrm{e} 09$ em nov/08, e a maior foi de $263,0 \mathrm{mg} \cdot \mathrm{L}^{-1}$ no ponto $05 \mathrm{em} \mathrm{mai/08}$. Já a menor contribuição dos sólidos fixos, ou inorgânicos, foi de $4,0 \mathrm{mg} \cdot \mathrm{L}^{-1}$ no ponto $08 \mathrm{em}$ abr/08 e a maior foi de $184,0 \mathrm{mg} \cdot \mathrm{L}^{-1}$ no ponto $05 \mathrm{em}$ mai/08.

As concentrações de sólidos dissolvidos voláteis somadas às concentrações de sólidos dissolvidos fixos resultando nas concentrações de sólidos dissolvidos totais, estão apresentadas na FIG. 19. 

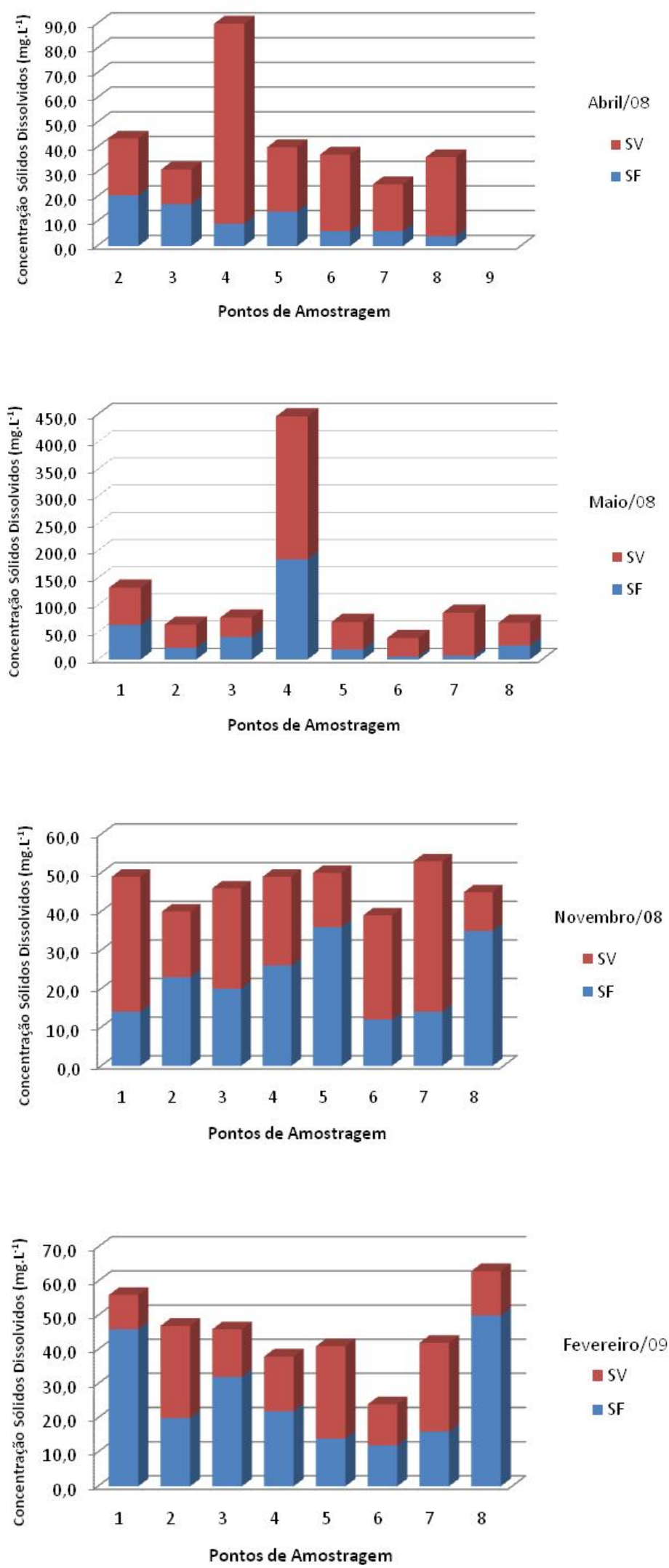

FIGURA 19 - Contribuição das concentrações de sólidos voláteis (SV) e sólidos fixos (SF) nos sólidos totais nos pontos de amostragem durante o período de estudo. 
Avaliando-se as medidas das concentrações de sólidos dissolvidos totais, observou-se que, a distribuição dos valores atenderam aos limites estabelecidos pela resolução CONAMA 357/05, para as Classes 1, 2 e 3 de enquadramento dos corpos de água doce (500 mg. $\left.\mathrm{L}^{-1}\right)$.

Os teores de sólidos dissolvidos de uma amostra de água afetam sua cor que está associada ao grau de redução de intensidade que a luz sofre ao atravessá-la, bem como a condutividade elétrica da amostra que tem relação diretamente proporcional à quantidade de sólidos dissolvidos (CETESB, 2009).

Nos estudos de controle de poluição das águas naturais, as determinações dos níveis de concentração das diversas frações de sólidos resultam em um quadro geral da distribuição das partículas com relação ao tamanho (sólidos em suspensão e dissolvidos) e com reação à natureza (fixos ou minerais e voláteis ou orgânicos). Deve-se destacar que embora a concentração de sólidos voláteis seja associado à presença de compostos orgânicos na água, não propicia qualquer informação sobre a natureza específica das diferentes moléculas orgânicas eventualmente presentes (Piveli e Kato, 2006).

Em tanques de piscicultura, Seto (2007) detectou sólidos totais dissolvidos e solúveis acima de $40 \mathrm{mg} \cdot \mathrm{L}^{-1}$ devido à alta biomassa fitoplanctônica e ao manejo alimentar, as concentrações mais elevadas, de $180 \mathrm{mg} \cdot \mathrm{L}^{-1}$, ocorreram no período de seca.

No lago artificial utilizado para abastecimento público do balneário de Jurerê Internacional, estado de Santa Catarina, os sólidos totais dissolvidos, analisados em coletas mensais apresentaram amplitude de $182,7 \mathrm{mg} \cdot \mathrm{L}^{-1}$ a 282 mg. $\mathrm{L}^{-1}$ (Vettorato, 2005).

As médias das concentrações de sólidos totais, por ponto de amostragem, demonstraram maior contribuição da fração volátil em relação à fração fixa (FIG. 20) na maioria dos pontos.

A maior contribuição da fração orgânica em relação à inorgânica, foi próxima dos resultados encontrados em outros estudos em reservatórios do Médio e Baixo Tietê (Minillo, 2005; Barbosa et al., 1999). Estudos realizados por Paranaguassu et al. (1988) apud Minillo (2005) no reservatório de Bariri constataram que a forte contribuição da fração orgânica na composição dos sólidos totais estava possivelmente associada ao lançamento de efluentes oriundos da indústria canavieira daquele local, bem como escoamento superficial 
ou subsuperficial das águas que percolam das áreas agriculturáveis nas quais são geralmente utilizados fertilizantes químicos e agrotóxicos. Este aspecto deve ser considerado, uma vez que, além da produção interna, outros fatores como o uso e ocupação do solo na área do entorno podem contribuir expressivamente para o aumento da quantidade de material em suspensão.

A maioria dos valores médios das frações voláteis acima das frações fixas, obtidos no presente estudo, podem estar relacionados com a existência de áreas de agropecuária no entorno dos pontos de amostragem.

Ponto 02

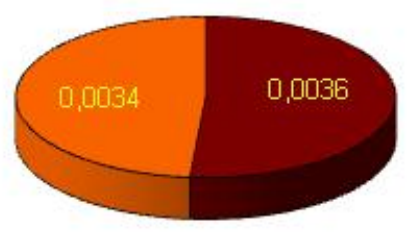

Ponto 03

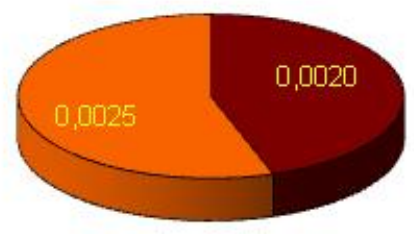

Ponto 04

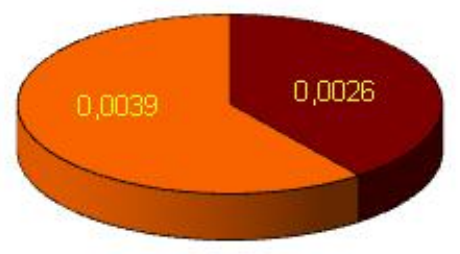

Ponto 05

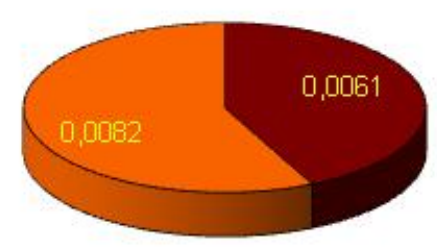

Ponto 06

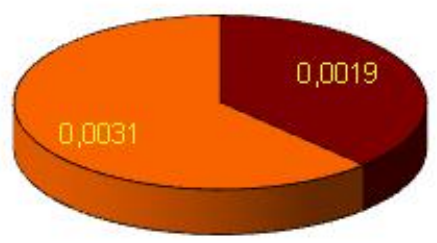

Ponto 07

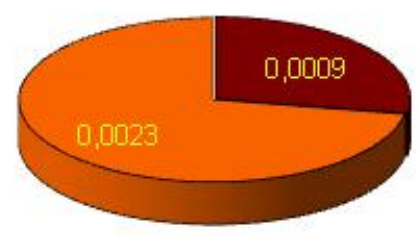

Ponto 08

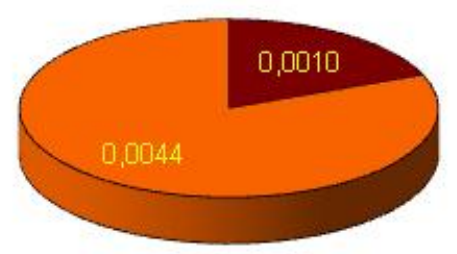

Ponto 09

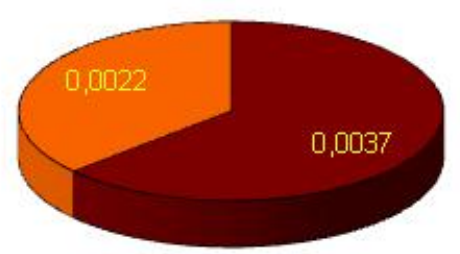

sólidos voláteis $\left(\mathrm{g} .100 \mathrm{~mL}^{-1}\right)$ sólidos fixos (g.100mL ${ }^{-1}$ )

FIGURA 20 - Variação média de sólidos dissolvidos nos pontos de amostragem durante o período de estudo. 


\subsection{Variáveis biológicas}

\subsubsection{Análise qualitativa da comunidade fitoplanctônica}

Foi totalizada a ocorrência de 92 táxons, distribuídos em 59 gêneros, pertencentes a 8 classes taxonômicas, nos oito pontos de amostragem estudados. A classe de maior representatividade foi Chlorophyceae (34\%), seguida por Cyanophyceae (26\%), Bacillariophyceae (11\%), Zygnemaphyceae (9\%), Euglenophyceae (9\%), Chrysophyceae (6\%), Dinophyceae (3\%), Cryptophyceae (2\%) (FIG. 21 e TAB. 11). A ordem qualitativamente melhor representada foi Chlorococcales (Chlorophyceae) com 29 táxons.
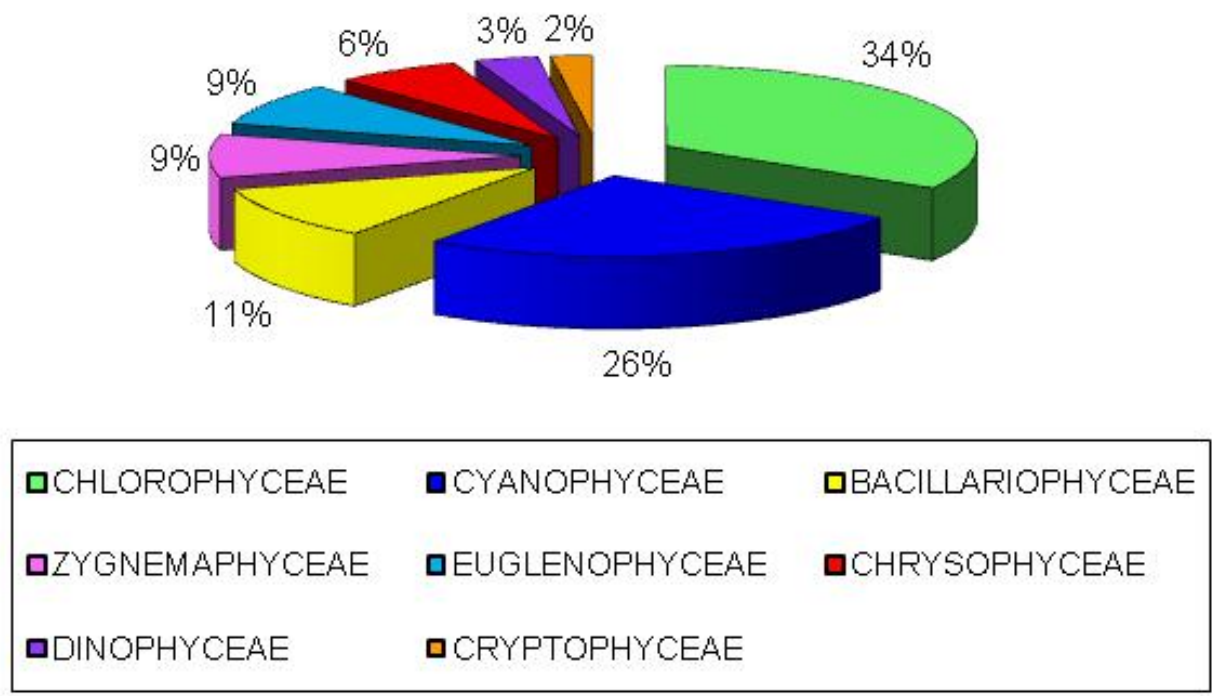

FIGURA 21 - Porcentagem de contribuição geral dos táxons em função das classes nos pontos de amostragem durante o período de estudo.

Chlorophyceae foi a classe mais representativa em termos de riqueza de espécies (29 táxons) . Este resultado obtido para as represas de Paraibuna e Paraitinga é confirmado para diferentes ecossistemas lacustres brasileiros, como represa Guarapiranga (Beyruth, 1996), Lago das Garças, em São Paulo (Sant'anna et al., 1989), lagos artificiais do Jardim Botânico Chico Mendes, em Goiás (Nogueira e Leandro-Rodrigues, 1999), demonstrando que as clorofíceas estão amplamente distribuídas nas águas continentais brasileiras e quase sempre é dominante em termos de número de táxons (Tucci et al., 2006). 
Dos 59 diferentes gêneros presentes nas represas Paraibuna e Paraitinga (TAB. 11) Chlorophyceae foi a classe que apresentou o maior número de gêneros (22), seguida de Cyanophyceae (13) e Bacillariophyceae (10).

TABELA 11 - Contribuição do número de gêneros por classe taxonômica

\begin{tabular}{lc}
\hline \multicolumn{1}{c}{ Classes } & Número de Gêneros \\
\hline CHLOROPHYCEAE & 22 \\
CYANOPHYCEAE & 13 \\
BACILLARIOPHYCEAE & 10 \\
ZYGNEMAPHYCEAE & 5 \\
CHRYSOPHYCEAE & 3 \\
EUGLENOPHYCEAE & 3 \\
CRYPTOPHYCEAE & 2 \\
DINOPHYCEAE & 1 \\
Total & 59 \\
\hline
\end{tabular}

A quantidade de gêneros encontrada foi próxima à quantidade detectada num estudo comparativo realizado entre nove lagos de regiões tropicais e subtropicais e sete lagos de regiões temperadas, no qual foi constatado que o número médio de gêneros para lagos tropicais (54 gêneros) é maior que os de regiões temperadas (37 gêneros) (Huszar, 1994 apud Barbosa, 2002).

Ao se comparar os quatros meses de amostragem separadamente, verificou-se que, tanto nos meses secos (abril e maio) quanto nos chuvosos (novembro e fevereiro), as porcentagens de contribuição das classes fitoplanctônicas foram muito semelhantes: Chlorophyceae foi a classe mais representativa, seguida por Cyanobacteria, Bacillariophyceae (exceto em abril, no qual Zygnemaphyceae ocupou esta posição), e as demais classes variando, em pequena amplitude, nas porcentagens de contribuição, como apresentado na FIG. 22. 

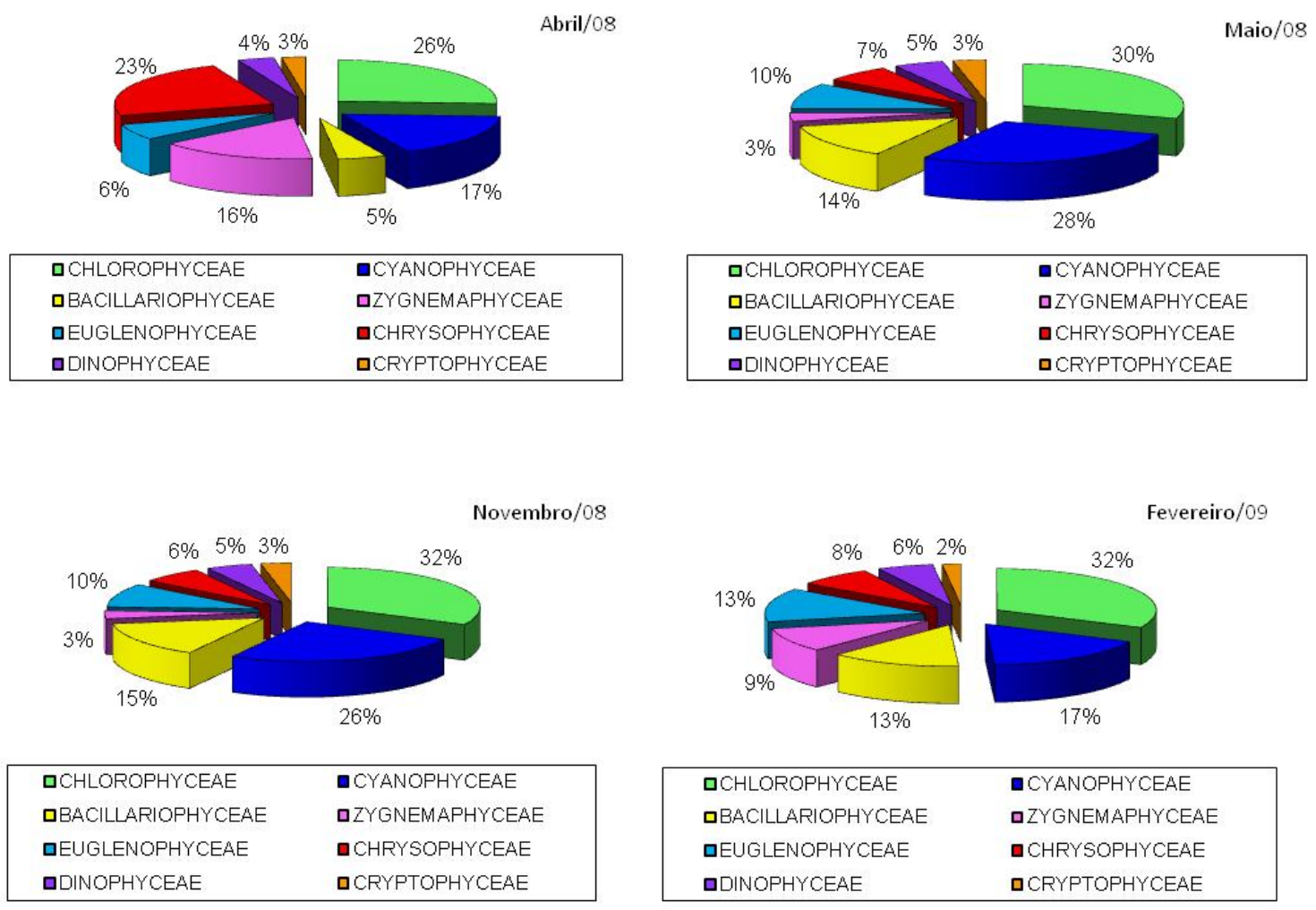

FIGURA 22 - Porcentagem de contribuição das classes fitoplanctônicas nos quatro meses de amostragem.

Conforme Wetzel (1993), o grupo denominado algas relaciona-se com um conjunto diversificado de organismos de vários grupos taxonômicos importantes, muitos deles, com necessidades fisiológicas distintas, mas que mesmo assim, coexistem num mesmo volume de água. A sistemática das algas é um assunto amplamente estudado, de forma detalhada, mas que está em constante revisão e aprimoramento.

O baixo número de características fenotípicas utilizadas na taxonomia do fitoplâncton leva a problemas de identificação. Atualmente, em conjunto com processos tradicionais de taxonomia, novas técnicas de biologia molecular, como sequenciamento do DNA, têm sido utilizadas para identificar e classificar estes organismos (Komárek, 2006; Bittencourt-Oliveira, 2009).

As análises das amostras de fitoplâncton coletadas nas represas Paraibuna e Paraitinga, demonstraram a presença de diversos táxons incluídos em grupos distintos. A descrição simplificada das características morfométricas dos táxons identificados encontram-se no APÊNDICE B. 


\subsubsection{Análise quantitativa da comunidade fitoplanctônica}

A análise quantitativa dos grupos de algas torna-se importante, pois permite conhecer as espécies dominantes do meio e relacioná-las as condições predominantes (Branco, 1986).

A presença de um número muito grande de organismos pertencentes a poucas espécies indica que o ambiente recebe uma carga poluente, se há muitas espécies com poucos organismos cada uma, é característica de ambiente natural (Odum, 1988).

\subsubsection{Densidade total (org. $\mathrm{mL}^{-1}$ )}

Durante o período de estudo, o valor máximo registrado foi 4.360 org. $\mathrm{mL}^{-1}$ no ponto $07 \mathrm{em}$ fev/09 e o mínimo foi de $38 \mathrm{org} \cdot \mathrm{mL}^{-1}$ no ponto $06 \mathrm{em}$ maio/08.

$\mathrm{Na}$ primeira coleta, realizada em abr/08 a densidade variou entre 47 org. $\mathrm{mL}^{-1}$ no ponto 08 a 258 org. $\mathrm{mL}^{-1}$ no ponto 05 . Em maio/08 a densidade de organismos variou entre 38 org. $\mathrm{mL}^{-1}$ no ponto 06 a 475 org. $\mathrm{mL}^{-1}$ no ponto 07 . Em nov/08 a densidade variou de 371 org. $\mathrm{mL}^{-1}$ no ponto 02 a 3.007 org. $\mathrm{mL}^{-1}$ no ponto 07. Em fev/09 a densidade esteve entre 325 org. $\mathrm{mL}^{-1}$ no ponto 03 e 4.360 org. $\mathrm{mL}^{-1}$ no ponto 07 (FIG. 23).

Os valores encontrados no presente estudo apresentam-se muito abaixo de valores de densidades encontrados em reservatórios eutróficos. Lopes (2007) encontrou densidades mínimas de 1.301 org. $\mathrm{mL}^{-1}$ e máximas de 34.510 org. $\mathrm{mL}^{-1}$ no Lago das Garças (SP). No reservatório Billings, Carvalho (2003) observou variação da densidade de $11.198 \mathrm{org} \cdot \mathrm{mL}^{-1}$ a $127.941 \mathrm{org} \cdot \mathrm{mL}^{-1}$, a partir de cinco coletas trimestrais. Nishimura (2008) estudando este mesmo reservatório explica que houve variação pronunciada da densidade fitoplanctônica, com maiores densidades no mês de fevereiro e menores densidades no mês de novembro (ambos no período quente-chuvoso).

Apesar dos valores de fósforo se mostrarem altos nos meses de abril e maio, este fato não pareceu influenciar positivamente a densidade fitoplanctônica que apresentou nestes meses menores densidades. As baixas temperaturas que 
ocorreram neste período podem ser citadas como influenciadoras da reprodução algácea.
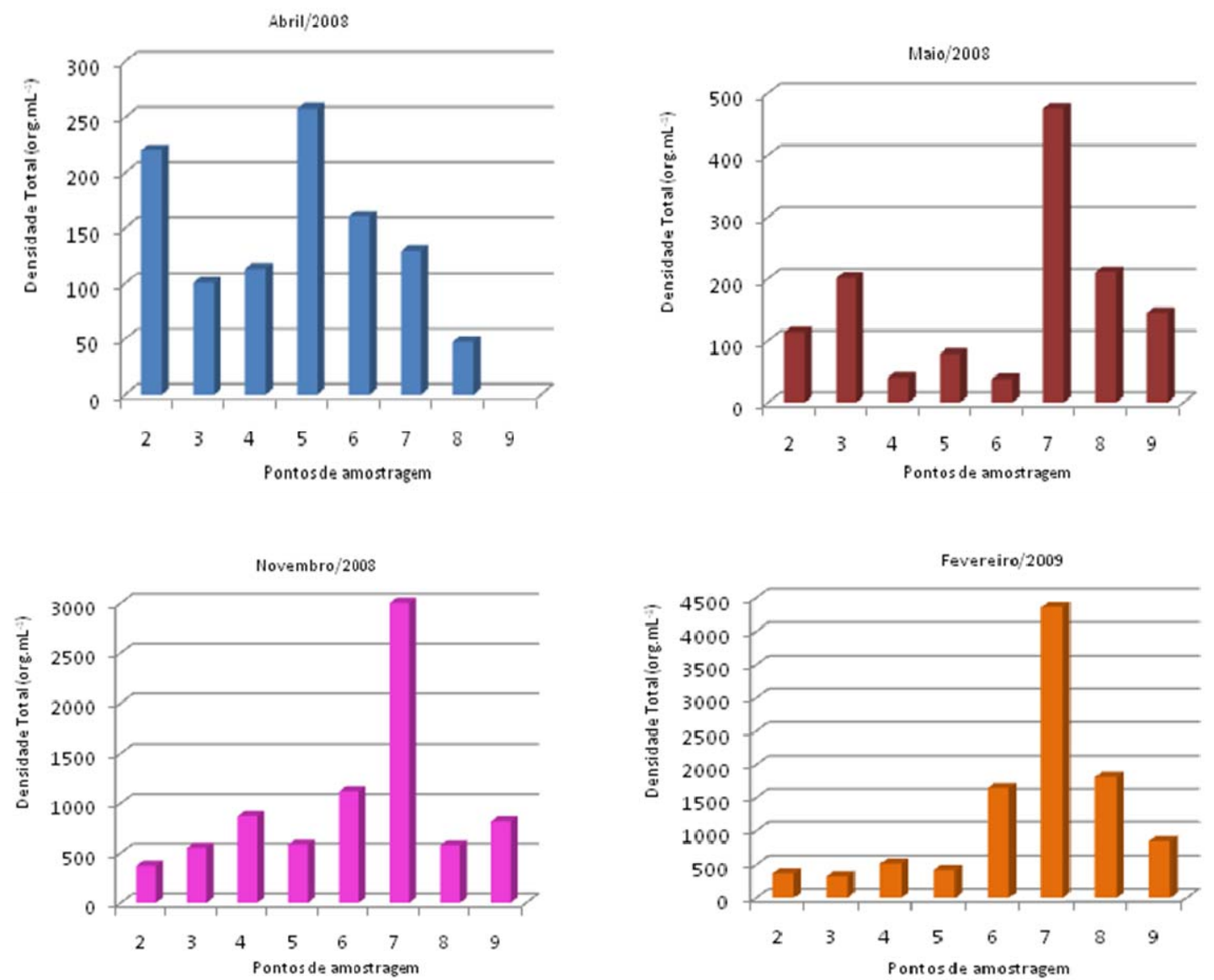

FIGURA 23 - Densidades totais da comunidade fitoplanctônica (org. $\mathrm{mL}^{-1}$ ).

Com relação às contribuições das classes às densidades, Cyanobacteria contribuiu com as maiores porcentagens nas amostras de abr/08, nov/08 e fev/09. Na amostra de mai/08 a classe Bacillariophyceae predominou (FIG.24). Para possibilitar a comparação dos dados obtidos à legislação pertinente, seria necessário a conversão da contagem realizada em organismos por mililitro (org. $\mathrm{mL}^{-1}$ ) para células por mililitro (cél. $\mathrm{mL}^{-1}$ ), já que a resolução CONAMA 357/05 estabelece a densidade máxima de cianobactérias de até 20.000 cél. $\mathrm{mL}^{-1}$ para águas doces de classe 1 , e de até 50.000 cél. $\mathrm{mL}^{-1}$ para águas doces de classe 2 . 


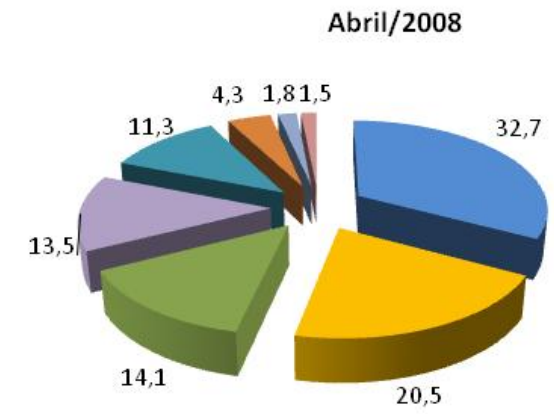

Novembro/2008
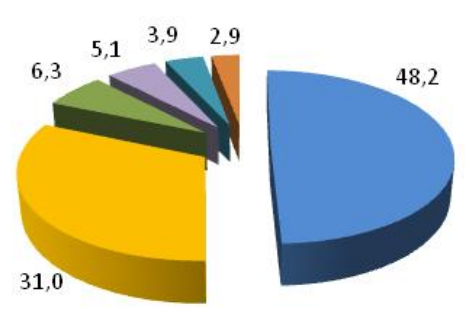

- Cyano

a Chloro

$\square$ Dino

- Crypto

- Bacillario

ETáxon

aryso

- Eugleno

Maio/2008
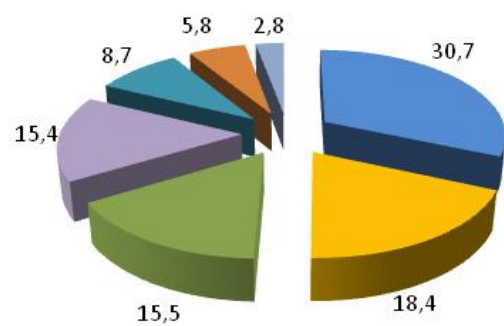

Eacillario

Crypto

In Cyano

a Chloro

= Cryso

= Dino

- Eugleno

Fevereiro/2009

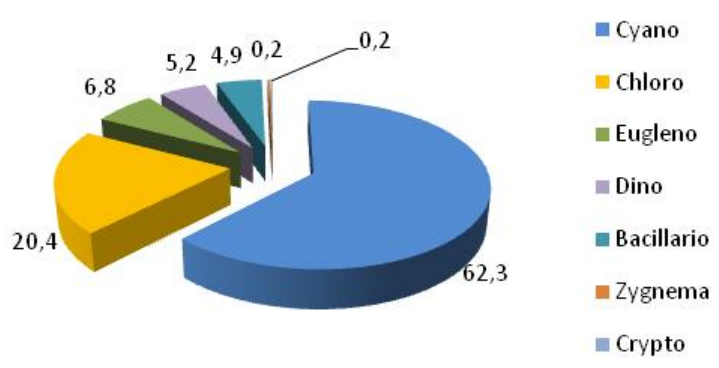

FIGURA 24 - Contribuição das classes na densidade fitoplanctônica no período de estudo.

\subsubsection{Espécies descritoras}

Dos 92 táxons identificados, 27 espécies foram consideradas descritoras da comunidade, contribuindo com 95,4\% da densidade total, através de um nível de corte de 0,5\% (TAB. 12). Destas, 10 espécies descritoras pertencem à Classe Chlorophyceae (23,3\%), 7 pertencem à classe Cyanobacteria (52,6\%), 2 à classe Cryptophyceae (3,3\%), 2 à classe Dinophyceae $(3,4 \%), 3$ à classe Bacillariophyceae (5,9\%), e 2 à classe Chrysophyceae $(1,9 \%)$ e um táxon não identificado $(4,6 \%)$. 
TABELA 12 - Espécies descritoras da comunidade fitoplanctônica com base na porcentagem de contribuição na densidade total

\begin{tabular}{|c|c|}
\hline Espécies Descritoras & Contribuição (\%) \\
\hline Cyanobacteria & 52,6 \\
\hline Chroococcus minimus & 18,3 \\
\hline Merismopedia glauca & 14,4 \\
\hline Myxobaktron sp. & 8,2 \\
\hline Chroococcus sp.1 & 7,0 \\
\hline Rabdoderma cf. sancti-pauli & 3,4 \\
\hline Aphanocapsa elachista & 0,7 \\
\hline Chroococcus sp. 2 & 0,6 \\
\hline Chlorophyceae & 23,3 \\
\hline Chlorella vulgaris & 6,9 \\
\hline Eutetramorus fottii & 7,3 \\
\hline Monoraphidium sp. 3 & 1,6 \\
\hline Monoraphidium sp. 2 & 1,8 \\
\hline Monoraphidium dybowskii & 1,7 \\
\hline Coelastrum reticulatum & 1,0 \\
\hline Radiococcus planktonicus & 0,8 \\
\hline Monoraphidium irregulari & 1,2 \\
\hline Elakatothrix gelatinosa & 0,5 \\
\hline Chlorococcum sp. & 0,5 \\
\hline Cryptophyceae & 3,3 \\
\hline Cryptomonas brasiliensis & 0,9 \\
\hline Cryptomonas marsonii & 2,4 \\
\hline Dinophyceae & 3,4 \\
\hline Peridinium cf. volzii & 1,9 \\
\hline Peridinium cf. pusillum & 1,5 \\
\hline Bacillariophyceae & 5,9 \\
\hline Aulacoseira sp. & 3,4 \\
\hline Cyclotella sp. & 2,0 \\
\hline Synedra sp. & 0,5 \\
\hline Chrysophyceae & 1,9 \\
\hline Mallomonas cf. mirabilis & 1,3 \\
\hline Trachelomonas volvocina & 0,6 \\
\hline Táxon não identificado & 4,6 \\
\hline
\end{tabular}


Do total de espécies descritoras a maior contribuição foi dada pela classe de Cyanobacteria, cujas espécies que mais se destacaram foram Chroococcus minimus (18,3\%), Merismopedia glauca (14,4\%) e Myxobaktron sp. $(8,2 \%)$ seguida pela classe Chlorophyceae, destacando espécies como Eutetramorus fottii $(7,3 \%)$ e Chlorella vulgaris $(6,9 \%)$.

Em águas continentais, as cianofíceas, ou cianobactérias, constituemse no principal grupo responsável por problemas sanitários devido ao seu potencial de produção de toxinas (Werner, 2002).

Gêneros potencialmente tóxicos podem produzir hepatotoxinas ou neurotoxinas que são responsáveis por causa letal ou intoxicações aguda e crônica em animais selvagens, domésticos, aquáticos e humanos (Carmichael, 2001).

Dentre as espécies de cianobactérias produtoras de toxinas que formam florações estão: Anabaena flos-aquae, Microcystis aeruginosa, Aphanizomenon flos-aquae, Oscillatoria agardhii e Nodularia spumigena (Carmichael, 1989), Microcystis protocystis, Anabaena planctonica (Carvalho et al. 2007).

Sant'anna et al. (2008) ainda cita como espécies tóxicas ocorrentes no Brasil: Synechocystis aquatilis, Gleiterinema amphibium, Pseudoanabaena limnetica, Anabaena circinalis, entre outras. Porém, Sant'anna et al. (2006) lembra que, a princípio, todas as espécies de cianobactérias são consideradas potencialmente tóxicas, e ocorrências de florações comprovadamente bioativas e suas conseqüentes intoxicações agudas em seres humanos e animais têm sido descritas em diversos países como Austrália, Portugal, Canadá, Estados Unidos e Brasil.

As espécies descritoras, da classe Chlorophyceae, que mais contribuíram para a densidade total foram Chlorella vulgaris e Eutetramorus fotti.

Chlorella vulgaris apresenta ampla distribuição em diferentes tipos de ambientes, águas paradas ou quase, lagos ou reservatórios, ambientes subáereos e no solo (Bicudo e Menezes, 2005). Sua ocorrência é comum no Brasil demonstrada em vários trabalhos taxonômicos (Barbosa, 2002; Seto, 2007; Gentil, 2007; Nogueira et al., 2008). 
Eutetramorus fotti apresenta controvérsia em sua taxonomia, alguns autores até duvidam de sua existência, acreditando que as espécies nele classificadas sejam estádios de vida de Sphaerocystis (Bicudo e Menezes, 2005). Este gênero apresenta distribuição cosmopolita, pois já foi coletado em ambientes lacustres praticamente do mundo inteiro.

\subsection{3 Índices biológicos}

Uma comunidade, conjunto de espécies (populações) que ocorre conjuntamente no tempo e no espaço (Begon et al., 1990), exibe certos atributos mensuráveis, como densidade, diversidade, entre outros, que podem dar a idéia do comportamento da comunidade estudada num determinado momento.

\subsubsection{Riqueza (R)}

A riqueza total da comunidade fitoplanctônica variou de 3 táxons nos ponto 03 em abr/08 a 28 táxons no ponto 03 em nov/08 (TAB. 13 e FIG. 25).

Em abr/08 a riqueza variou entre 3 táxons no ponto 03 e 13 táxons no ponto 06 . Em mai/08 a riqueza variou entre 6 táxons no ponto 05 e 18 táxons no ponto 07 . No mês de nov/08, a riqueza variou entre 12 táxons no ponto 02 e 24 táxons no ponto 03. E, em fev/09 a riqueza variou entre 10 táxons no ponto $09 \mathrm{e}$ 19 táxons no ponto 07 .

TABELA 13 - Valores de riqueza média, máxima, mínima, desvio padrão e coeficiente de variação nos meses de amostragem

\begin{tabular}{ccccc}
\hline & abr/08 & mai/08 & nov/08 & fev/09 \\
\hline Média & 7 & 11 & 18 & 16 \\
Máx. & 13 & 18 & 24 & 19 \\
Mín. & 3 & 6 & 12 & 10 \\
Desvio Padrão & 3,21 & 4,87 & 4,06 & 2,88 \\
Coef. Var. (\%) & 45,9 & 46,4 & 22,9 & 18,4 \\
\hline
\end{tabular}



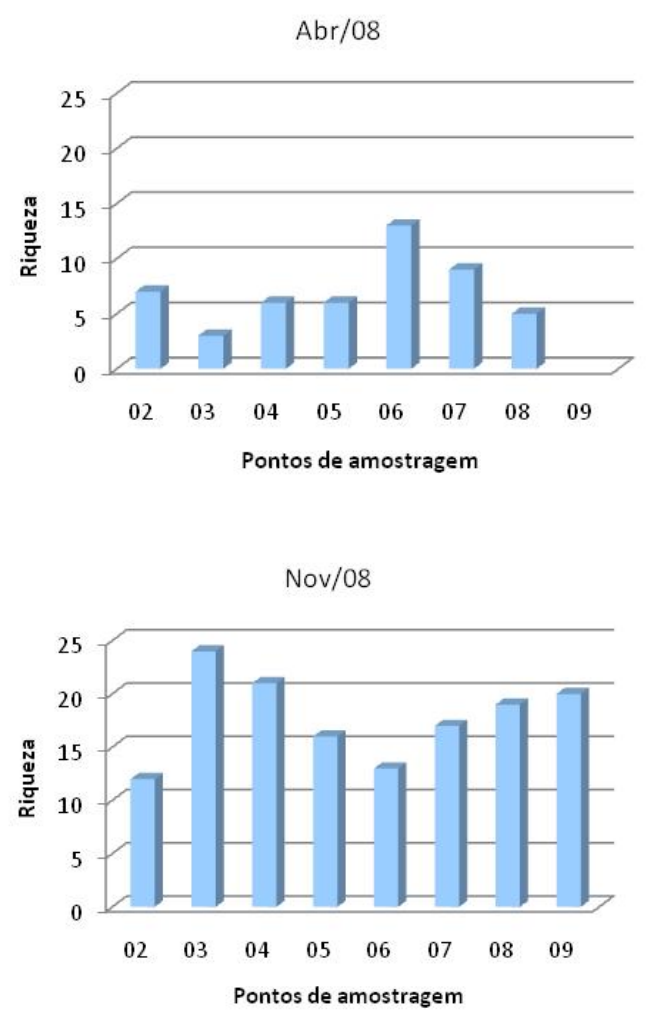

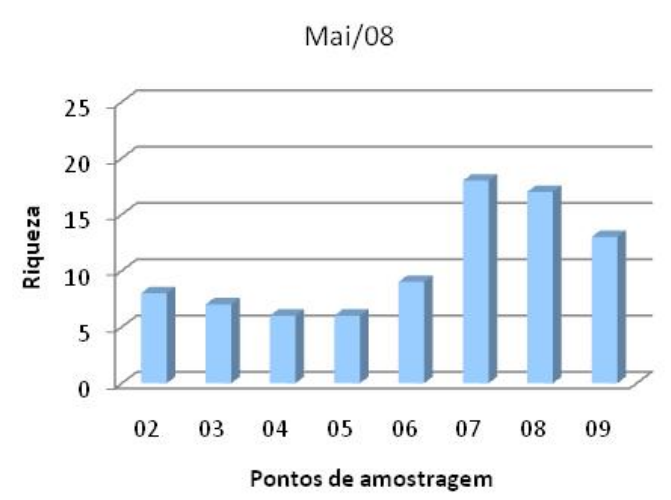

Fev/09

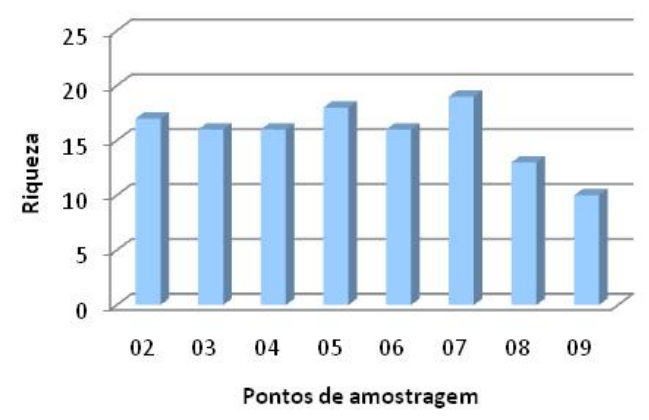

FIGURA 25 - Riqueza total ( $n^{\circ}$ de táxons) nos pontos de amostragem durante 0 período de estudo.

A riqueza total de espécies deve ser analisada juntamente a outros parâmetros quantitativos como valores de densidades, diversidade, abundância e dominância. Carvalho (2003) detectou no reservatório de Itupararanga 194 táxons, no reservatório de Pirapora 204 táxons e no reservatório Billings 154 táxons, todos localizados no estado de São Paulo, e que apresentam comprometimento em termos de qualidade de água como presença de algas tóxicas, contaminações orgânica e inorgânica. Segundo a autora, dois fatores poderiam estar relacionados à riqueza elevada no reservatório de Pirapora, como baixo tempo de residência e elevada quantidade de matéria orgânica.

\subsubsection{2 Índice de diversidade $\left(\mathrm{H}^{\prime}\right)\left(\mathrm{bbits}\right.$ ind $\left.^{-1}\right)$}

Os valores do índice de diversidade variaram entre 1,26 bits.ind ${ }^{-1}$, no ponto 09 em fev/09, e 3,75 bits.ind ${ }^{-1}$, no ponto 04, em nov/08 (TAB. 14 e FIG. 26). 
Em abr/08 a diversidade variou entre 1,40 bits.ind ${ }^{-1}$ no ponto 03 e 3,28 bits.ind ${ }^{-1}$ no ponto 06 . Em mai/08 a diversidade variou entre 2,18 bits.ind $^{-1}$ no ponto 04 e 3,56 bits.ind ${ }^{-1}$ no ponto 08. No mês de nov/08, a diversidade variou entre 1,59 bits.ind $^{-1}$ no ponto 06 e 3,75 bits.ind $^{-1}$ no ponto 04 . E, em fev/09 a diversidade variou entre 1,26 bits.ind ${ }^{-1}$ no ponto 09 e 3,27 bits.ind ${ }^{-1}$ nos pontos 02 e 03.

TABELA 14 - Valores de diversidade média, máxima, mínima, desvio padrão e coeficiente de variação nos meses de amostragem

\begin{tabular}{ccccc}
\hline & abr/08 & mai/08 & nov/08 & fev/09 \\
\hline Média & 2,35 & 2,78 & 3,12 & 2,55 \\
Máx. & 3,28 & 3,56 & 3,75 & 3,27 \\
Mín. & 1,40 & 2,18 & 1,59 & 1,26 \\
Desvio Padrão & 0,58 & 0,49 & 0,80 & 0,67 \\
Coef. Var. (\%) & 24,7 & 17,5 & 25,8 & 26,1 \\
\hline
\end{tabular}

Abr/08

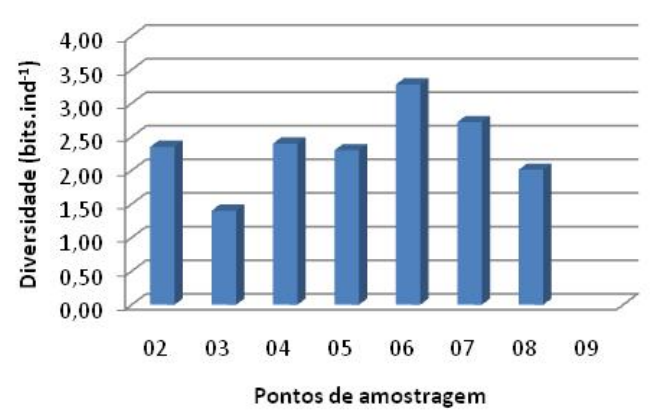

Nov/08

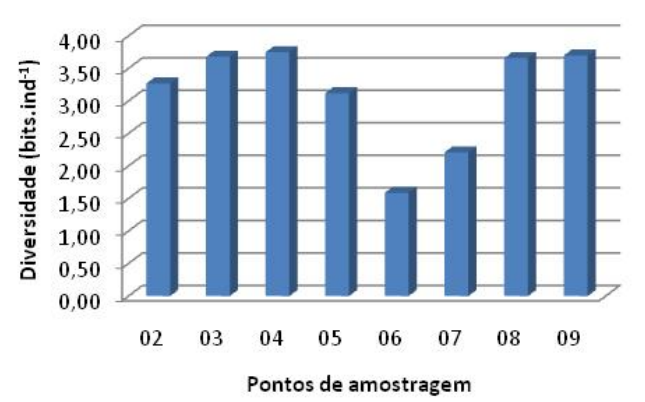

Mai/08

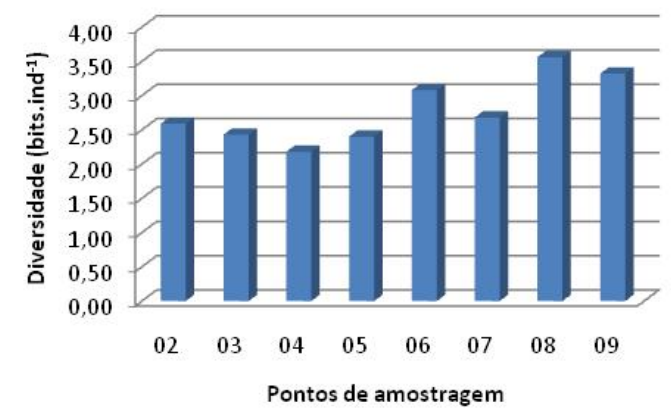

Fev/09

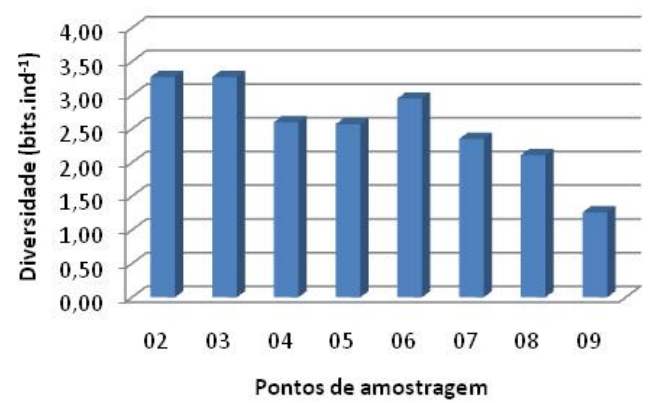

FIGURA 26 - Diversidade (bits.ind ${ }^{-1}$ ) nos pontos de amostragem durante o período de estudo. 
Segundo Marques (2006), a diversidade biológica é um conceito multidimensional e não pode ser reduzido a um único número. Entende-se por diversidade de espécies a interação entre seus dois componentes básicos: a riqueza específica que e o número total de espécies presentes, e a equitabilidade, que se relaciona com a abundância relativa de espécies e grau de dominância.

O valor mínimo de diversidade ocorre quando todos os indivíduos pertencem à mesma espécie e o máximo quando cada indivíduo pertence a uma espécie diferente (ACIESP, 1997).

Os maiores valores de diversidade ocorreram em abr/08 e mai/08 e os menores em nov/08 e fev/08, que podem ser contrastados inversamento aos valores do índice de dominância.

Segundo Nogueira (1999), valores mais baixos de diversidade específica na represa Samambaia (GO), aconteceram devido à dominância de alguma espécie.

Os menores valores de diversidade específica encontrados por Marques (2006) no ponto LIM3, na represa da Usina Hidrelétrica Lajeado (TO), em agosto e outubro, poderiam estar associados à presença de Cylindrospermopsis raciborskii que foi considerada espécie dominante neste ponto.

Para Trindade (2007), a diversidade pode ser entendida como expressão do conteúdo de informação de cada espécie para a comunidade como um todo e, equitabilidade, expressão de como a biomassa se distribui entre as espécies, são importantes descritores da comunidade fitoplanctônica, os maiores valores de equitabilidade refletem a ausência de dominância de poucas espécies.

\subsubsection{3 Índice de equitabilidade (E')}

Os valores do índice de equitabilidade variaram entre 0,38 , no ponto 09 em fev/09, e 0,97, no ponto 06, em mai/08 (TAB. 15 e FIG. 27).

Em abr/08 a equitabilidade variou entre 0,84 no ponto 02 e 0,93 no ponto 04. Em mai/08 a equitabilidade variou entre 0,64 no ponto 07 e 0,97 no ponto 06 . No mês de nov/08, a equitabilidade variou entre 0,43 no ponto $06 \mathrm{e}$ 
0,91 no ponto 02 . E, em fev/09 a equitabilidade variou entre 0,38 no ponto 09 e 0,82 no ponto 03 .

TABELA 15 - Valores de equitabilidade média, máxima, mínima, desvio padrão e coeficiente de variação nos meses de amostragem

\begin{tabular}{ccccc}
\hline & abr/08 & mai/08 & nov/08 & fev/09 \\
\hline Média & 0,88 & 0,86 & 0,75 & 0,64 \\
Máx. & 0,93 & 0,97 & 0,91 & 0,82 \\
Mín. & 0,84 & 0,64 & 0,43 & 0,38 \\
Desvio Padrão & 0,03 & 0,10 & 0,17 & 0,15 \\
Coef. Var. (\%) & 3,3 & 11,4 & 23,0 & 22,8 \\
\hline
\end{tabular}

O índice de equitabilidade reflete o grau de organização da comunidade, a variação percentual de seus componentes, e o distanciamento entre comunidades com espécies equitativamente representadas. $\mathrm{Na}$ interpretação deste índice, o valor mínimo é zero, significando uma equitabilidade baixa, e o máximo é um, representando uma equitabilidade alta (Marques, 2006).

De modo geral, a equitabilidade ou equitatividade é a relação entre a diversidade observada ( $\mathrm{H}$ ou $\left.\mathrm{H}^{\prime}\right)$ e a diversidade máxima, situando-se estes valores entre 0 e 1 (Rosso, 1996).

Portanto, a equitabilidade de uma comunidade especifica a distribuição uniforme ou não das espécies. Quanto mais próximo de 1 o valor da equitabilidade se aproxima, mais uniforme é a distribuição dos indivíduos.

Ao longo do período de estudo, os índices de equitabilidade mantiveram-se altos, sempre acima de 0,6, o que significa que apesar de existirem espécies abundantes a distribuição dos organismos se manteve uniforme. 
Abr/08

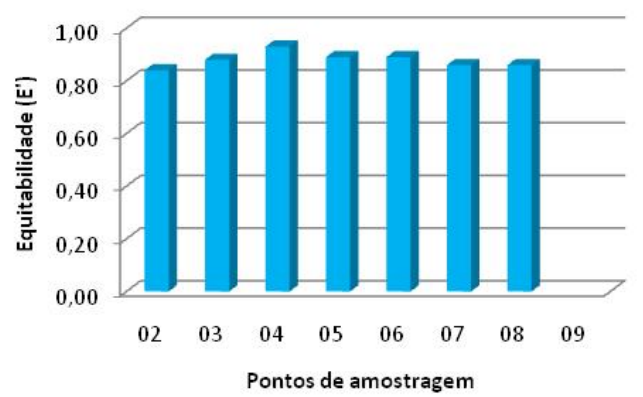

Nov/08

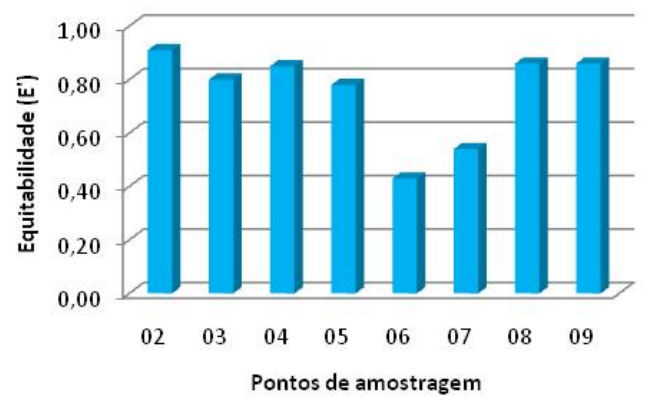

Mai/08

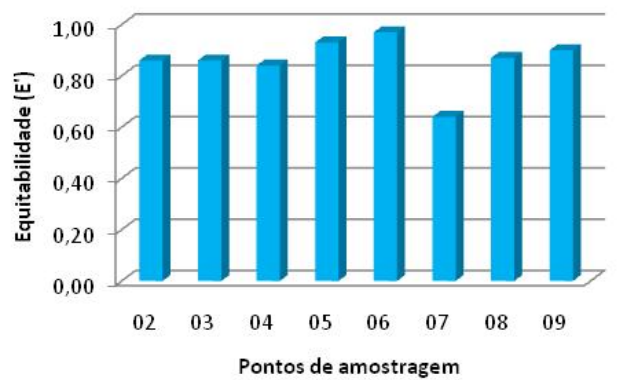

Fev/09

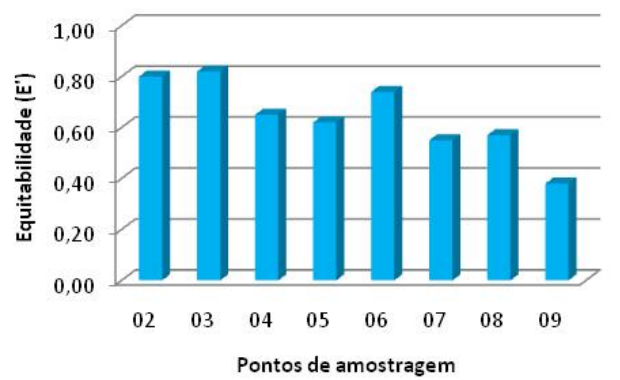

FIGURA 27 - Equitabilidade (E') nos pontos de amostragem durante o período de estudo.

\subsubsection{4 Índice de dominância (DS'):}

Durante o período de estudo os índices de dominância mantiveram-se baixos. O valor máximo registrado foi de 0,66 em fev/09, no ponto 09, e o mínimo de 0,09 em nov/08, no ponto 08 (TAB. 16 e FIG. 28).

Em abr/08 a dominância variou entre 0,11 no ponto 06 e 0,40 no ponto 03. Em mai/08 a dominância variou entre 0,10 no ponto 06 e 0,28 no ponto 07 . No mês de nov/08, a dominância variou entre 0,09 no ponto 04 e 0,58 no ponto 06 . E, em fev/09 a dominância variou entre 0,13 no ponto 03 e 0,66 no ponto 09 . 
TABELA 16 - Valores de dominância média, máxima, mínima, desvio padrão e coeficiente de variação nos meses de amostragem

\begin{tabular}{ccccc}
\hline & abr/08 & mai/08 & nov/08 & fev/09 \\
\hline Média & 0,23 & 0,18 & 0,20 & 0,29 \\
Máx. & 0,40 & 0,28 & 0,58 & 0,66 \\
Mín. & 0,11 & 0,10 & 0,09 & 0,13 \\
Desvio Padrão & 0,09 & 0,07 & 0,18 & 0,17 \\
Coef. Var. (\%) & 38,3 & 39,4 & 89,9 & 58,1 \\
\hline
\end{tabular}

Os maiores valores de dominância, acima de 0,40, ocorreram no período quente e chuvoso, e os menores no período frio e seco. Os valores de dominância para o Lago das Garças, estudado por Lopes (2007), mostraram-se mais baixos no verão e outono, e mais altos na primavera e inverno. Altos índices de dominância encontrados na primavera e inverno devem-se á dominância de Cylindrospermopsis raciborskii e a floração de Chroococcus minutus respectivamente, o que refletiu nos baixos índices de diversidade e equitabilidade.

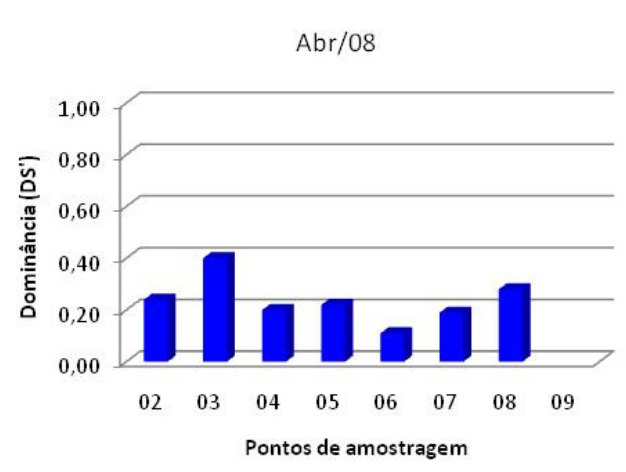

Nov/08

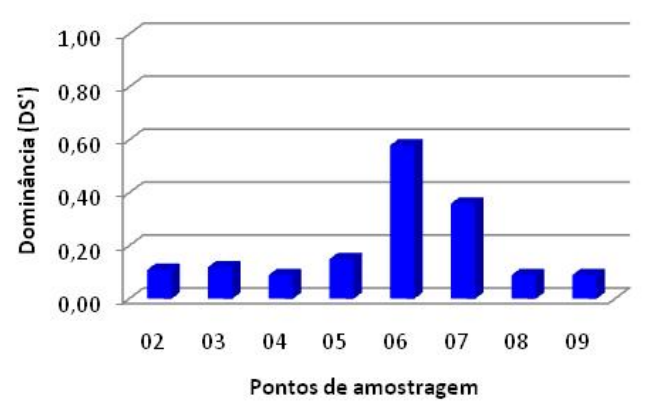

Mai/08

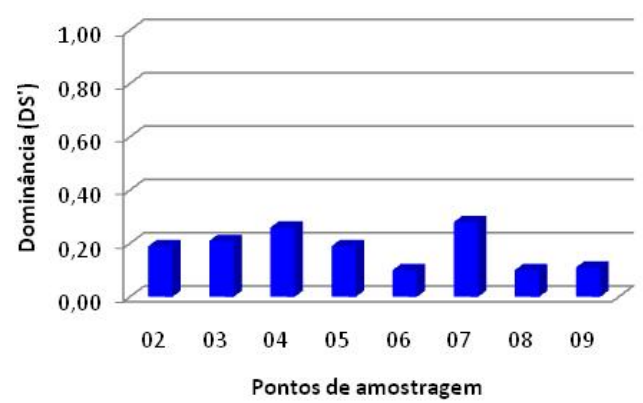

Fev/09

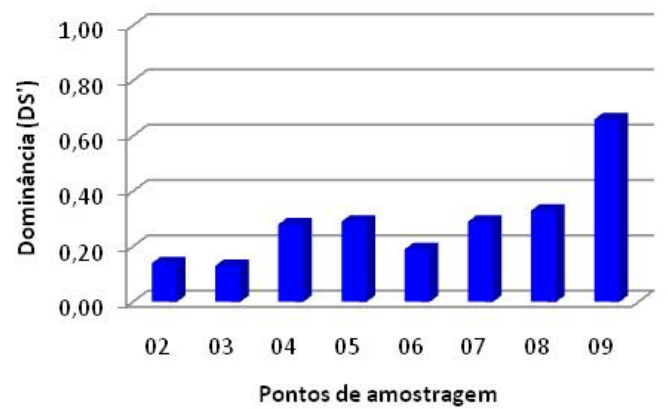

FIGURA 28 - Dominância (DS') nos pontos de amostragem durante o período de estudo. 


\subsubsection{Freqüência de ocorrência (F) (\%)}

Na TAB. 17 está apresentada a listagem dos táxons identificados, sua frequência de ocorrência e as espécies classificadas como abundantes e dominantes.

TABELA 17 - Lista geral de táxons identificados, sua frequência de ocorrência (Freq.), classificação (Clas.: $\mathrm{R}=$ raro; $\mathrm{CM}=$ comum; $\mathrm{CT}=$ constante), espécies abundantes $\left({ }^{*}\right)$ nos meses de estudo

\begin{tabular}{|c|c|c|c|c|c|c|c|c|}
\hline \multirow[b]{2}{*}{ Táxons } & \multicolumn{2}{|c|}{ abr/08 } & \multicolumn{2}{|c|}{ mai/08 } & \multicolumn{2}{|c|}{ nov/08 } & \multicolumn{2}{|c|}{ fev/09 } \\
\hline & $\begin{array}{l}\text { Freq. } \\
(\%)\end{array}$ & Clas. & $\begin{array}{l}\text { Freq. } \\
(\%)\end{array}$ & Clas. & $\begin{array}{l}\text { Freq. } \\
(\%)\end{array}$ & Clas. & $\begin{array}{l}\text { Freq. } \\
(\%)\end{array}$ & Clas. \\
\hline \multicolumn{9}{|l|}{$\begin{array}{l}\text { Classe BACILLARIOPHYCEAE } \\
\text { Ordem Centrales }\end{array}$} \\
\hline Aulacoseira sp. & 43 & $\mathrm{CM}^{*}$ & 63 & $C T^{*}$ & 13 & $\mathrm{R}^{*}$ & - & \\
\hline Cyclotella sp. & 100 & $C T^{*}$ & 50 & $\mathrm{CM}$ & 25 & CM & 50 & $\mathrm{CM}^{*}$ \\
\hline Diatomácea cêntrica & - & & 63 & $\mathrm{CT}$ & 25 & $\mathrm{CM}$ & - & \\
\hline \multicolumn{9}{|l|}{ Ordem Penales } \\
\hline Amphora sp. & - & & 25 & $\mathrm{CM}$ & 38 & CM & 13 & $\mathrm{R}$ \\
\hline Encyonema sp. & - & & - & & 13 & $\mathrm{R}$ & 25 & $\mathrm{CM}$ \\
\hline Fragillaria sp. & - & & - & & 50 & $\mathrm{CM}$ & 38 & $\mathrm{CM}$ \\
\hline Melosira sp. & - & & - & & - & & - & \\
\hline Navicula sp. & 14 & $\mathrm{R}$ & 13 & $\mathrm{R}$ & 38 & $\mathrm{CM}$ & 25 & $\mathrm{CM}$ \\
\hline Synedra sp. & - & & 50 & $\mathrm{CM}^{*}$ & 13 & $\mathrm{R}$ & 13 & $\mathrm{R}$ \\
\hline Pennales sp.1 & 14 & $\mathrm{R}$ & - & & 38 & $\mathrm{CM}$ & 13 & $\mathrm{R}$ \\
\hline \multicolumn{9}{|l|}{$\begin{array}{l}\text { Classe CHLOROPHYCEAE } \\
\text { Ordem Chlorococcales }\end{array}$} \\
\hline Ankistrodesmus bernardii & - & & - & & 13 & $\mathrm{R}$ & - & \\
\hline Botryococcus braunii & 14 & $\mathrm{R}$ & - & & 13 & $\mathrm{R}$ & - & \\
\hline Chlorella vulgaris & 29 & $\mathrm{CM}^{*}$ & 13 & $\mathrm{R}$ & 75 & $C T^{*}$ & 63 & $C T^{*}$ \\
\hline Chlorococcum sp. & 43 & CM & 50 & $\mathrm{CM}$ & 50 & $\mathrm{CM}$ & - & \\
\hline Closteriospsis sp. & 14 & $\mathrm{R}$ & 63 & $\mathrm{CT}^{*}$ & 13 & $\mathrm{R}$ & - & \\
\hline Coelastrum cf. microporum & - & & - & & - & & 13 & $\mathrm{R}$ \\
\hline $\begin{array}{l}\text { Coelastrum reticulatum } \\
\text { Dictyosphaerium }\end{array}$ & 57 & CT & 13 & $\mathrm{R}$ & 75 & CT & 13 & $\mathrm{R}$ \\
\hline ehrenbergianum & 29 & $\mathrm{CM}$ & - & & 13 & $\mathrm{R}$ & - & \\
\hline Elakatothrix gelatinosa & 100 & CT & 38 & $\mathrm{CM}$ & 63 & CT & 63 & CT \\
\hline Elakatothrix gelifacta & 14 & $\mathrm{R}$ & - & & - & & 38 & $\mathrm{CM}$ \\
\hline cf. Eremosphaera & 29 & $\mathrm{CM}$ & - & & - & & 50 & $\mathrm{CM}$ \\
\hline Eutetramorus fottii & 100 & $\mathrm{CT}^{*}$ & 100 & $\mathrm{CT}^{*}$ & 63 & $\mathrm{CT}^{*}$ & 88 & $\mathrm{CT}^{*}$ \\
\hline Eutetramorus globosus & 71 & CT & 63 & $\mathrm{CT}$ & 63 & CT & 38 & $\mathrm{CM}$ \\
\hline
\end{tabular}


Continuação da TABELA 17- Lista geral de táxons identificados, sua frequência de ocorrência (Freq.), classificação (Clas.: $\mathrm{R}=$ raro; $\mathrm{CM}=$ comum; $\mathrm{CT}=$ constante), espécies abundantes $\left(^{*}\right)$ nos meses de estudo

\begin{tabular}{|c|c|c|c|c|c|c|c|c|}
\hline Golenkinia radiata & - & & - & & - & & 13 & $\mathrm{R}$ \\
\hline Kirchneriella aperta & 29 & CM & - & & - & & - & \\
\hline Kirchneriella contorta & - & & 13 & $\mathrm{R}$ & - & & - & \\
\hline cf. Kirchneriella & - & & - & & 25 & $\mathrm{CM}$ & - & \\
\hline Monoraphidium dybowskii & 71 & CT & - & & 50 & $\mathrm{CM}^{*}$ & 38 & $\mathrm{CM}$ \\
\hline Monoraphidium irregulare & 14 & $\mathrm{R}$ & 38 & $\mathrm{CM}$ & - & & 13 & $\mathrm{R}$ \\
\hline Monoraphidium sp.2 & 29 & $\mathrm{CM}$ & 25 & $\mathrm{CM}^{*}$ & 38 & $\mathrm{CM}$ & 38 & $\mathrm{CM}^{*}$ \\
\hline Monoraphidium sp.3 & - & & 13 & $\mathrm{R}$ & 25 & CM & 25 & $\mathrm{CM}^{*}$ \\
\hline Nephrocytium schilleri & - & & 13 & $\mathrm{R}$ & 13 & $\mathrm{R}$ & - & \\
\hline Oocystis lacustris & 14 & $\mathrm{R}$ & 50 & $\mathrm{CM}$ & 25 & $\mathrm{CM}$ & - & \\
\hline Quadrigula closteroides & 14 & $\mathrm{R}$ & 13 & $\mathrm{R}$ & 13 & $\mathrm{R}$ & 25 & $\mathrm{CM}$ \\
\hline Radiococcus cf. bavaricus & 57 & CT & - & & - & & - & \\
\hline Radiococcus planktonicus & 14 & $\mathrm{R}$ & 50 & CM & 75 & CT & 75 & CT \\
\hline Scenedesmus sp. & - & & - & & - & & 13 & $\mathrm{R}$ \\
\hline Selenastrum gracile & - & & 13 & $\mathrm{R}$ & - & & - & \\
\hline Sphaerocystis schroeteri & 14 & $\mathrm{R}$ & 50 & $\mathrm{CM}$ & 63 & CT & - & \\
\hline Ordem Volvocales & & & & & & & & \\
\hline Chlamydomonas sp. & - & & - & & 13 & $\mathrm{R}$ & - & \\
\hline Volvox cf. aureus & 29 & CM & 25 & CM & 25 & CM & 25 & $\mathrm{CM}$ \\
\hline \multicolumn{9}{|l|}{$\begin{array}{c}\text { Classe CHRYSOPHYCEAE } \\
\text { Ordem Ochromonadales }\end{array}$} \\
\hline Dinobryon bavaricum & - & & - & & 13 & $\mathrm{R}$ & 13 & $\mathrm{R}$ \\
\hline Mallomonas sp.1 & - & & 88 & $\mathrm{CT}^{*}$ & 38 & $\mathrm{CM}$ & 13 & $\mathrm{R}$ \\
\hline Mallomonas sp.2 & 29 & CM & - & & - & & - & \\
\hline Mallomonas sp.3 & 29 & CM & 88 & CT & 25 & $\mathrm{CM}$ & 13 & $\mathrm{R}$ \\
\hline Mallomonas sp.4 & - & & 25 & $\mathrm{CM}$ & 13 & $\mathrm{R}$ & 13 & $\mathrm{R}$ \\
\hline Synura sp. & 29 & $\mathrm{CM}$ & 50 & CM & 25 & CM & 13 & $\mathrm{R}$ \\
\hline \multicolumn{9}{|l|}{$\begin{array}{l}\text { Classe CRYPTOPHYCEAE } \\
\text { Ordem Cryptomonadales }\end{array}$} \\
\hline Cryptomonas brasiliensis & 14 & $\mathrm{R}$ & 38 & $\mathrm{CM}^{*}$ & 38 & $\mathrm{CM}$ & - & \\
\hline Cryptomonas marsonii & 14 & $\mathrm{R}^{*}$ & 63 & $\mathrm{CT}^{*}$ & 38 & $\mathrm{CM}^{*}$ & 25 & $\mathrm{CM}$ \\
\hline \multicolumn{9}{|l|}{$\begin{array}{c}\text { Classe CYANOPHYCEAE } \\
\text { Ordem Choroococcales }\end{array}$} \\
\hline Aphanocapsa delicatissima & 14 & $\mathrm{R}$ & - & & 38 & $\mathrm{CM}$ & - & \\
\hline Aphanocapsa elachista & 29 & $\mathrm{CM}$ & 25 & CM & 88 & CT & 13 & $\mathrm{R}$ \\
\hline Aphanocapsa sp.1 & 43 & $\mathrm{CM}$ & 25 & CM & - & & - & \\
\hline Chroococcus minimus & 43 & CM & 38 & $\mathrm{CM}$ & 88 & CT & 75 & $\mathrm{CT}^{*}$ \\
\hline Chroococcus sp.1 & 71 & $\mathrm{CT}^{*}$ & 38 & $\mathrm{CM}^{*}$ & 13 & $\mathrm{R}^{*}$ & 75 & $\mathrm{CT}^{*}$ \\
\hline Chroococcus sp.2 & - & & 13 & $R^{*}$ & - & & 25 & $\mathrm{CM}$ \\
\hline Cyanodictyon sp. & - & & 13 & $\mathrm{R}$ & 13 & $\mathrm{R}$ & 50 & $\mathrm{CM}$ \\
\hline Epigloeosphaera sp. & - & & 50 & $\mathrm{CM}$ & 38 & $\mathrm{CM}$ & 75 & CT \\
\hline Merismopedia glauca & - & & 38 & $\mathrm{CM}^{*}$ & 38 & $\mathrm{CM}^{*}$ & - & \\
\hline
\end{tabular}


Continuação da TABELA 17- Lista geral de táxons identificados, sua frequência de ocorrência (Freq.), classificação (Clas.: $\mathrm{R}=$ raro; $\mathrm{CM}=$ comum; $\mathrm{CT}=$ constante), espécies abundantes $\left(^{*}\right)$ nos meses de estudo

\begin{tabular}{|c|c|c|c|c|c|c|c|c|}
\hline Merismopedia tenuissima & 14 & $\mathrm{R}$ & - & & 13 & $\mathrm{R}$ & - & \\
\hline Microcystis aeruginosa & 71 & CT & 63 & CT & 38 & CM & - & \\
\hline Microcystis protocystis & 43 & $\mathrm{CM}^{*}$ & 38 & $\mathrm{CM}$ & - & & - & \\
\hline Myxobaktron sp. & 14 & $\mathrm{R}$ & - & & 13 & $\mathrm{R}$ & 25 & $\mathrm{CM}^{*}$ \\
\hline Rabdoderma cf. sancti pauli & 14 & $\mathrm{R}$ & - & & - & & 13 & $\mathrm{R}^{*}$ \\
\hline Synechocystis sp. & - & & 13 & $\mathrm{R}^{*}$ & 13 & $\mathrm{R}$ & - & \\
\hline \multicolumn{9}{|l|}{ Ordem Nostocales } \\
\hline Anabaena circinalis & 43 & CM & 25 & $\mathrm{CM}$ & - & & - & \\
\hline Anabaena spiroides & 86 & CT & 63 & CT & 13 & $\mathrm{R}$ & - & \\
\hline Anabaena sp.1 & 57 & CT & 38 & $\mathrm{CM}$ & - & & - & \\
\hline Anabaena sp.2 & 29 & $\mathrm{CM}$ & 50 & $\mathrm{CM}$ & - & & - & \\
\hline \multicolumn{9}{|l|}{ Ordem Oscillatoriales } \\
\hline Gleiterinema sp. & - & & - & & 13 & $\mathrm{R}$ & - & \\
\hline Oscillatoria cf. lacustris & - & & - & & 13 & $\mathrm{R}$ & - & \\
\hline Pseudanabaena moniliformis & - & & 13 & $\mathrm{R}$ & 38 & $\mathrm{CM}$ & - & \\
\hline Pseudanabaena mucicola & - & & 13 & $\mathrm{R}$ & - & & - & \\
\hline Pseudoanabaena sp.1 & - & & - & & 13 & $\mathrm{R}$ & 13 & $\mathrm{R}$ \\
\hline \multicolumn{9}{|l|}{$\begin{array}{l}\text { Classe DINOPHYCEAE } \\
\text { Ordem Peridiniales }\end{array}$} \\
\hline Peridinium cf. cunnigtonii & 71 & $\mathrm{CT}$ & 100 & CT & 50 & $\mathrm{CM}$ & 50 & CM \\
\hline Peridinium cf. pusillum & 29 & $\mathrm{CM}$ & 13 & $\mathrm{R}$ & 38 & $\mathrm{CM}^{*}$ & 25 & $\mathrm{CM}$ \\
\hline Peridinium cf. volzii & 100 & $\mathrm{CT}^{*}$ & 88 & $\mathrm{CT}^{*}$ & 100 & CT & 100 & $\mathrm{CT}^{*}$ \\
\hline \multicolumn{9}{|l|}{$\begin{array}{l}\text { Classe EUGLENOPHYCEAE } \\
\text { Ordem Euglenales }\end{array}$} \\
\hline Euglena sp.1 & 43 & CM & 38 & $\mathrm{CM}$ & 50 & $\mathrm{CM}$ & 13 & $\mathrm{R}$ \\
\hline Euglena sp.2 & 14 & $\mathrm{R}$ & 13 & $\mathrm{R}$ & - & & - & \\
\hline Lepocinclis sp. & 57 & CT & 38 & CM & 13 & $\mathrm{R}$ & 25 & CM \\
\hline Trachelomonas armata & 14 & $\mathrm{R}$ & - & & - & & - & \\
\hline Trachelomonas cf. bacillifera & - & & - & & - & & 13 & $\mathrm{R}$ \\
\hline Trachelomonas rotunda & - & & - & & 25 & $\mathrm{CM}$ & 25 & $\mathrm{CM}$ \\
\hline $\begin{array}{l}\text { Trachelomonas volvocina } \\
\text { Trachelomonas cf. }\end{array}$ & 14 & $\mathrm{R}$ & 13 & $\mathrm{R}$ & 38 & $\mathrm{CM}$ & 25 & $\mathrm{CM}$ \\
\hline volvocinopsis & - & & 25 & $\mathrm{CM}$ & 25 & CM & 38 & CM \\
\hline \multicolumn{9}{|l|}{$\begin{array}{l}\text { Classe ZYGNEMAPHYCEAE } \\
\text { Ordem Desmidiales }\end{array}$} \\
\hline Micrasterias cf. laticeps & - & & - & & - & & 13 & $\mathrm{R}$ \\
\hline Staurastrum sp.1 & 86 & CT & 75 & CT & 75 & CT & 38 & $\mathrm{CM}$ \\
\hline Staurastrum sp.2 & 14 & $\mathrm{R}$ & - & & - & & - & \\
\hline Staurastrum sp.3 & - & & 13 & $\mathrm{R}$ & - & & 13 & $\mathrm{R}$ \\
\hline Staurastrum sp.4 & - & & - & & 63 & CT & - & \\
\hline Staurodesmus sp. & - & & - & & - & & 13 & $\mathrm{R}$ \\
\hline Desmidia sp.1 & - & & - & & - & & 25 & CM \\
\hline
\end{tabular}


Continuação da TABELA 17- Lista geral de táxons identificados, sua frequência de ocorrência (Freq.), classificação (Clas.: $\mathrm{R}=$ raro; $\mathrm{CM}=$ comum; $\mathrm{CT}$ = constante), espécies abundantes $\left(^{*}\right)$ nos meses de estudo

\section{Ordem Zygnematales}

Mougeotia sp.

Não identificados

táxon não identificado

Colônia

$14 \mathrm{R}$

$57 \mathrm{CT}^{*}$ $14 \mathrm{R}$

Durante todo o período de estudo, 55 espécies (59\%) foram classificadas como raras, 32 espécies (34\%) como comuns e 7 espécies como constantes $(7 \%)$. Destacaram-se como espécies constantes: Peridinium cf. cunnigtonii, Peridinium cf. volzii, Chroococcus minimus, Staurastrum sp.1, Eutetramorus fottii, Eutetramorus globosus e Elakatothrix gelatinosa.

$\mathrm{Na}$ amostra de abr/08, 28\% como constantes, 33\% das espécies foram classificadas como comuns, e $39 \%$ como raras. Destacaram-se como espécies constantes: Cyclotella sp., Coelastrum reticulatum, Elakatothrix gelatinosa, Eutetramorus fottii, Eutetramorus globosus, Monoraphidium dybowskii, Radiococcus cf. bavaricus, Staurastrum sp.1, Chroococcus sp.1, Microcystis aeruginosa, Anabaena spiroides, Anabaena sp.1, Peridinium cf. cunnigtonii, Peridinium cf. volzii, Lepocinclis sp. e táxon não identificado.

$\mathrm{Na}$ amostra de mai/08, 22\% como constantes, $48 \%$ das espécies foram classificadas como comuns, e $29 \%$ como raras. Destacaram-se como espécies constantes: Aulacoseira sp., Diatomácea cêntrica, Closteriospsis sp., Eutetramorus fottii, Eutetramorus globosus, Staurastrum sp.1, Mallomonas sp.1, Mallomonas sp.3, Cryptomonas marsonii, Microcystis aeruginosa, Anabaena spiroides, Peridinium cf. cunnigtonii, Peridinium cf. volzii.

Na amostra de nov $/ 08,19 \%$ como constantes, $47 \%$ das espécies foram classificadas como comuns, e $34 \%$ como raras. Destacaram-se como espécies constantes: Chlorella vulgaris, Coelastrum reticulatum, Elakatothrix gelatinosa, Eutetramorus fottii, Eutetramorus globosus, Radiococcus planktonicus, Sphaerocystis schroeteri, Staurastrum sp.1, Staurastrum sp.4, Aphanocapsa elachista, Chroococcus minimus, Peridinium cf. volzii. 
Na amostra de fev/09, 16\% como constantes, $44 \%$ das espécies foram classificadas como comuns, e $40 \%$ como raras. Destacaram-se como espécies constantes: Chlorella vulgaris, Elakatothrix gelatinosa, Eutetramorus fottii, Radiococcus planktonicus, Chroococcus minimus, Chroococcus sp.1, Epigloeosphaera sp., Peridinium cf. volzii e táxon não identificado.

\subsubsection{Espécies dominantes e abundantes}

De acordo com o critério de Lobo e Leigthon (1986), não houve espécies dominantes no período analisado, visto que nenhuma espécie atingiu densidades maiores que $50 \%$ da densidade total da amostra.

Já as espécies abundantes, aquelas cujas densidades superam a densidade média de cada amostra (TAB. 17), ocorreram em todos os meses de amostragem.

Em abr/08, 9 espécies foram consideradas abundantes: Aulacoseira sp., Cyclotella sp., Chlorella vulgaris, Eutetramorus fottii, Cryptomonas marsonii, Chroococcus sp.1, Microcystis protocystis, Peridinium cf. volzii e táxon não identificado.

Em mai/08, 13 espécies foram consideradas abundantes: Aulacoseira sp., Synedra sp., Closteriospsis sp., Eutetramorus fottii, Monoraphidium sp. 2, Mallomonas sp.1, Cryptomonas brasiliensis, Cryptomonas marsonii, Chroococcus sp.1, Chroococcus sp. 2, Merismopedia glauca, Synechocystis sp. e Peridinium cf. volzii.

Em nov/08, 9 espécies foram consideradas abundantes: Aulacoseira $\mathrm{sp}$, Chlorella vulgaris, Eutetramorus fottii, Monoraphidium dybowskii, Cryptomonas marsonii, Chroococcus sp.1, Merismopedia glauca, Peridinium cf. pusillum e táxon não identificado.

Em fev/09, 11 espécies foram consideradas abundantes: Cyclotella sp., Chlorella vulgaris, Eutetramorus fottii, Monoraphidium sp.2, Monoraphidium sp.3, Chroococcus minimus, Chroococcus sp.1, Myxobaktron sp., Rabdoderma cf. sancti pauli, Peridinium cf. volzii e táxon não identificado. 
O gênero Peridinium, um dinoflagelado, ocorreu como abundante durante os meses de amostragem, bem como constante em diversos momentos, e como uma das descritoras da comunidade.

O maior conhecimento sobre dinoflagelados está nos ambientes marinhos, onde existe maior quantidade de espécies, mas em águas doces são cosmopolitas. O gênero Peridinium foi pouco estudado no Brasil, sendo raras as espécies identificadas e, sem exceção, em trabalhos florísticos mais abrangentes (Bicudo e Menezes, 2005).

Apesar da importância de Dinophyta em muitas águas doces, muito pouco é conhecido sobre os fatores que influenciam sua ocorrência (Grigorszky et al. 2003). Gêneros como Ceratium, Peridinium e Peridiniopsis são citados como aparentemente cosmopolitas, preferindo águas duras com alta concentração de cálcio e tolerando uma ampla variação de condições ambientais. Muitos dinoflagelados são encontrados em corpos d'água bem oxigenados, pois evitam sistemas eutróficos que sofrem depreciação periódica de oxigênio (Cardoso e Torgan, 2007). Segundo estes autores, o tipo de habitat (lagoa aberta, lagoa fechada, banhado e canal) influenciou significativamente a riqueza, densidade e diversidade de dinoflagelados, e a densidade também foi significativamente influenciada pelo hidroperíodo (águas altas e águas baixas). Fatores como $\mathrm{pH}$ e temperatura da água foram as variáveis abióticas que mais influenciaram a estrutura da comunidade de dinoflagelados no referido estudo.

No presente estudo, Aulacoseira sp. e Cyclotella sp. ocorreram como abundantes e, por vezes, como contantes, bem como foram descritoras da comunidade. Estes gêneros, ambos da ordem Centrales, apesar da diferenças morfológicas e fisiológicas, constam como adaptadas ao crescimento em ambientes com correnteza e turbidez (Costa, 2007). Espécies como Aulacoseira granulata e Aulacoseira pseudogranulata pertencem ao grupo funcional $P$ (diatomáceas de ambientes eutróficos) e Cyclotella meneghiniana ao grupo funcional $R$ (diatomáceas de ambientes mesotróficos em circulação), respectivamente, segundo Reynolds et al. (2002) apud Nishimura (2008). 


\subsection{Aplicação de índices de qualidade}

\subsection{1 Índice de Estado Trófico (IET)}

Para os cálculos do IET foram utilizados apenas os valores obtidos para o fósforo total (PT), já que medidas de clorofila a não estavam disponíveis.

Os valores de transparência ao Disco de Secchi não foram utlizados, já que a CETESB não considera, normalmente, na estimativa de Estado Trófico, o cálculo do índice de transparência, pois esta é afetada pela elevada turbidez decorrente de material em suspensão, comum em reservatórios e rios do estado de São Paulo (Lamparelli, 2004).

Os resultados referentes ao índice de estado trófico (IET) dos pontos de amostragem no período de estudo estão apresentados na TAB. 18 e FIG. 29.

TABELA 18 - Valores do Índice de Estado Trófico nos pontos de amostragem durante o período de estudo

\begin{tabular}{crccc}
\hline & \multicolumn{4}{c}{ IET (PT) - Classificação } \\
\hline Pontos & abr/08 & mai/08 & nov/08 & fev/09 \\
\hline 02 & 42 - oligotrófico & 61 - eutrófico & 40 - oligotrófico & 40 - oligotrófico \\
03 & 43 - oligotrófico & 55 - eutrófico & 40 - oligotrófico & 40 - oligotrófico \\
04 & 44 - oligotrófico & 51 -mesotrófico & 40 - oligotrófico & 40 - oligotrófico \\
05 & 42 - oligotrófico & 51 -mesotrófico & 40 - oligotrófico & 40 - oligotrófico \\
06 & 46 -mesotrófico & 40 - oligotrófico & 40 - oligotrófico & 40 - oligotrófico \\
07 & 46 -mesotrófico & 51 -mesotrófico & 40 - oligotrófico & 40 - oligotrófico \\
08 & 50 -mesotrófico & 53 -mesotrófico & 40 - oligotrófico & 40 - oligotrófico \\
09 & -- & 52 -mesotrófico & 40 - oligotrófico & 40 - oligotrófico \\
\hline
\end{tabular}


IET - abr/08

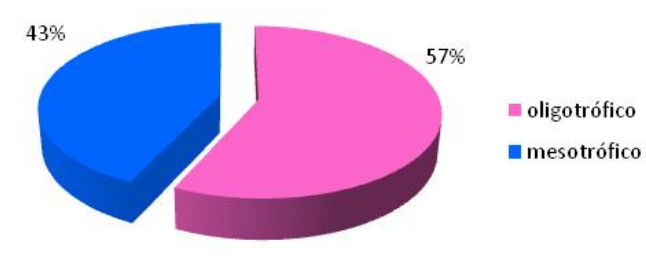

IET - nov/08

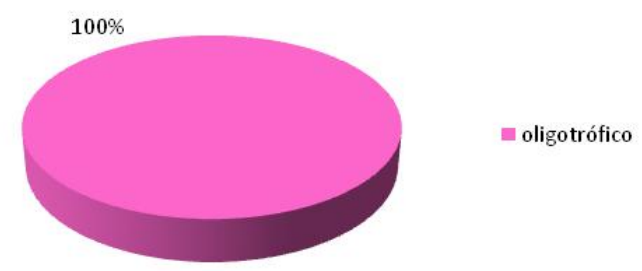

IET - mai/08

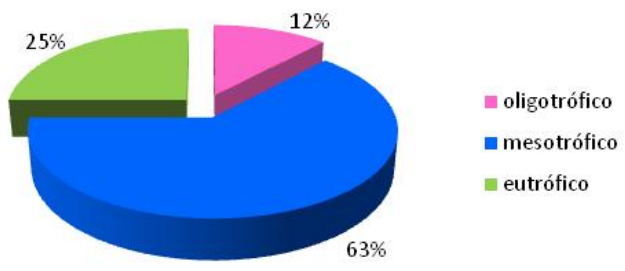

IET - fev/09

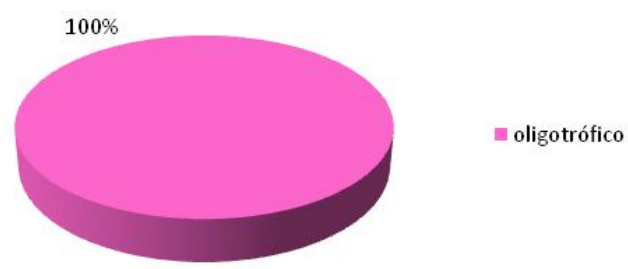

FIGURA 29 - Porcentagens do IET, calculadas com base nos valores de fósforo total, nos meses de amostragem.

No mês de abr/08 os pontos 02, 03, 04 e 05 foram classificados em oligotróficos, enquanto os pontos 06,07 e 08 foram classificadaos como mesotróficos, e o ponto 09 não foi amostrado.

Em mai/08 os pontos 02 e 03 apresentaram níveis mais elevados de fósforo total, denotando uma piora na qualidade da água, fato que levou à classificação destes pontos como eutróficos. Neste mês, apenas o ponto 06 foi classificado como oligotrófico, pois todo o restante, os pontos $04,07,08$ e 09 foram classificados como mesotróficos.

Em nov/08 e fev/09 houve diminuição na quantidade de fósforo total disponível na água, refletido nos índices de estado trófico, nos quais todos os pontos foram classificados como oligotróficos.

Segundo Mercante e Tucci-Moura (1999), a aplicação destes índices deve ser feita com cautela e devem ser utilizados apenas como um indicador do potencial do estado trófico, devendo-se considerar ainda a dinâmica temporal e espacial das variáveis físicas, químicas e biológicas dos sistema aquático, os diferentes compartimentos de cada sistema, principalmente em relação ao 
conteúdo de nitrogênio e fósforo e aos aspectos regionais de cada bacia hidrográfica.

\subsection{2 Índice da Comunidade Fitoplanctônica (ICF)}

O Índice da Comunidade Fitoplanctônica classifica a qualidade da água por meio de descritores da comunidade como proporção entre os grande grupos que compõem o fitoplâncton, a densidade de organismos, e o Índice de Estado Trófico (IET). Uma avaliação dos grandes grupos ou ordens já pode ser suficiente para se ter uma idéia de como o manancial se comporta em termos de qualidade da água ou futuros problemas em relação ao seu uso. Entretanto, nesta avaliação, quando houver dominância de organismos que podem provocar problemas para a saúde humana, a identificação em nível de espécie se torna necessária (CETESB, 2006).

Os resultados referentes ao índice da comunidade fitoplanctônica (ICF) dos pontos de amostragem no período de estudo estão apresentados na TAB. 19.

TABELA 19 - Valores do Índice da Comunidade Fitoplanctônica nos pontos de amostragem durante o período de estudo

\begin{tabular}{|c|c|c|c|c|}
\hline \multirow[b]{2}{*}{ Pontos } & \multicolumn{4}{|c|}{ ICF - Classificação } \\
\hline & abr/08 & mai/08 & nov/08 & fev/09 \\
\hline 02 & 42 - ótima & 61 - regular & 40 - ótima & 40 - ótima \\
\hline 03 & 43 - ótima & $55-$ boa & 40 - ótima & 40 - ótima \\
\hline 04 & 44 - ótima & 51 - ótima & 40 - ótima & 40 - ótima \\
\hline 05 & 42 - ótima & 51 - ótima & 40 - ótima & 40 - ótima \\
\hline 06 & 46 - ótima & 40 - ótima & 40 - ótima & 40 - ótima \\
\hline 07 & 46 - ótima & 51 - ótima & 40 - ótima & 40 - ótima/boa \\
\hline 08 & 50 - ótima & $53-$ boa & 40 - ótima & 40 - ótima \\
\hline 09 & -- & 52 - ótima & 40 - ótima & 40 - ótima \\
\hline
\end{tabular}

Os pontos de amostragem das represas Paraibuna e Paraitinga apresentaram qualidade ótima a regular, segundo o índice da comunidade fitolpanctônica (ICF) calculado com o IET. A qualidade regular apenas foi obtida 
para o ponto 02 no mês de maio, devido ao alto valor do IET (calculado pelas concentrações de fósforo total). Com qualidade boa apresentaram-se os pontos 03 (maio), 08 (maio) e 07 (fevereiro). Todos os demais pontos apresentaram qualidade ótima.

O ponto 02 (maio), apresentou alto valor de IET, classificando-o com qualidade regular. Porém, se considerados os fatores densidade total (113 org. $\mathrm{mL}^{-1}$ ), e predominância de Bacillariophyceae (Diatomáceas), a qualidade das águas seria classificada como boa.

O ponto 07 na amostragem de fev/09 apresentou a mais alta densidade fitoplanctônica durante o período de estudo (4.360 org. $\mathrm{mL}^{-1}$ ), fato que o coloca na qualidade do boa quanto à densidade de organismos, porém, quanto ao valor do IET, a qualidade da água neste ponto classifica-se como ótima, devido ao baixo teor de fósforo.

Considerando que o grupo Cyanophyceae apresentou a maior contribuição de densidade no mês de fev/09 (FIG. 23), cabe salientar a necessidade de atenção ao surgimento de florações destes organismos, neste ponto, principalmente porque os organismos desta classe apresentam potencial de produção de toxinas.

\subsection{Análise Estatística}

Inicialmente foi realizada a Análise de Componentes Principais (ACP) entre as variáveis físicas e químicas (temperatura da água, turbidez, transparência, condutividade elétrica, oxigênio dissolvido, $\mathrm{pH}$, sólidos dissolvidos totais, nitrato, cloreto, sulfato). Aquelas que apresentaram os menores valores de correlação com os eixos fatoriais foram excluídas, com o objetivo de aumentar a variância explicada pelos dados.

$\mathrm{Na} \mathrm{ACP}$, as unidades amostrais que se acomodam próximas ao vetor de uma determinada variável possuem altos valores ou concentrações desta variável. À medida que a unidade amostral se afasta no sentido contrário ao vetor, diminuem as oportunidades de serem encontrados altos valores da variável naquela unidade amostral. Os eixos 1 e 2 representam gradientes ambientais teóricos extraídos dos dados abióticos. O primeiro eixo é o mais importante ao 
explicar a dispersão das unidades amostrais, seguido pelo segundo eixo e, assim, sucessivamente (Fonseca, 2005).

Os dois primeiros eixos da Análise de Componentes Principais explicaram $63,00 \%$ da variação dos dados, sendo $35,81 \%$ no primeiro eixo e, $27,18 \%$ no segundo eixo (TAB. 20 e FIG. 30).

As unidades amostrais foram separadas da seguinte forma: o lado negativo do eixo 1 agrupou os meses de Maio e Novembro, associados aos maiores valores de $\mathrm{pH}$, turbidez, sulfato e nitrato, já no lado positivo foram agrupados os meses de Abril e Fevereiro, associados aos maiores valores de temperatura da água, transparência e cloreto. A condutividade apresentou, por sua vez, altas concentrações nos meses de Abril, Maio e Fevereiro.

No eixo 2, o lado positivo reuniu a maioria dos pontos de amostragem do mês de Novembro e três pontos do mês de Maio, com os maiores valores de $\mathrm{pH}$ e sulfato, e os alguns pontos dos meses de Fevereiro e Abril com os maiores valores de transparência e cloreto. Já o lado negativo do eixo foi associado ao maiores valores de turbidez e condutividade na maioria dos pontos de Maio.

TABELA 20 - Coeficientes de correlação de Pearson e Kendall entre as variáveis físicas e químicas da água e os dois primeiros eixos de ordenação para o período de estudo $(\mathrm{N}=31)$

\begin{tabular}{lccc}
\hline \multirow{2}{*}{ Variável } & \multicolumn{2}{c}{ Componentes Principais } \\
\cline { 2 - 4 } & Abreviações & Eixo 1 & Eixo 2 \\
\hline Temperatura da água & TAg & $\mathbf{0 , 8 6 5}$ & $-0,283$ \\
Transparência & Transp & 0,486 & $\mathbf{0 , 7 4 5}$ \\
Turbidez & Turb & $\mathbf{- 0 , 5 8 3}$ & $\mathbf{- 0 , 6 4 6}$ \\
Condutividade elétrica & Cond & 0,124 & $\mathbf{- 0 , 8 0 0}$ \\
pH & pH & $-\mathbf{0 , 6 7 7}$ & 0,458 \\
Cloreto & Clo & 0,417 & $\mathbf{0 , 6 9 1}$ \\
Sulfato & Sul & $\mathbf{- 0 , 6 2 0}$ & 0,351 \\
Nitrato & Nit & $\mathbf{- 0 , 8 6 9}$ & 0,077 \\
\hline Total de Explicabilidade: & & $\mathbf{3 5 , 8 1 \%}$ & $\mathbf{2 7 , 1 8 \%}$ \\
\hline
\end{tabular}




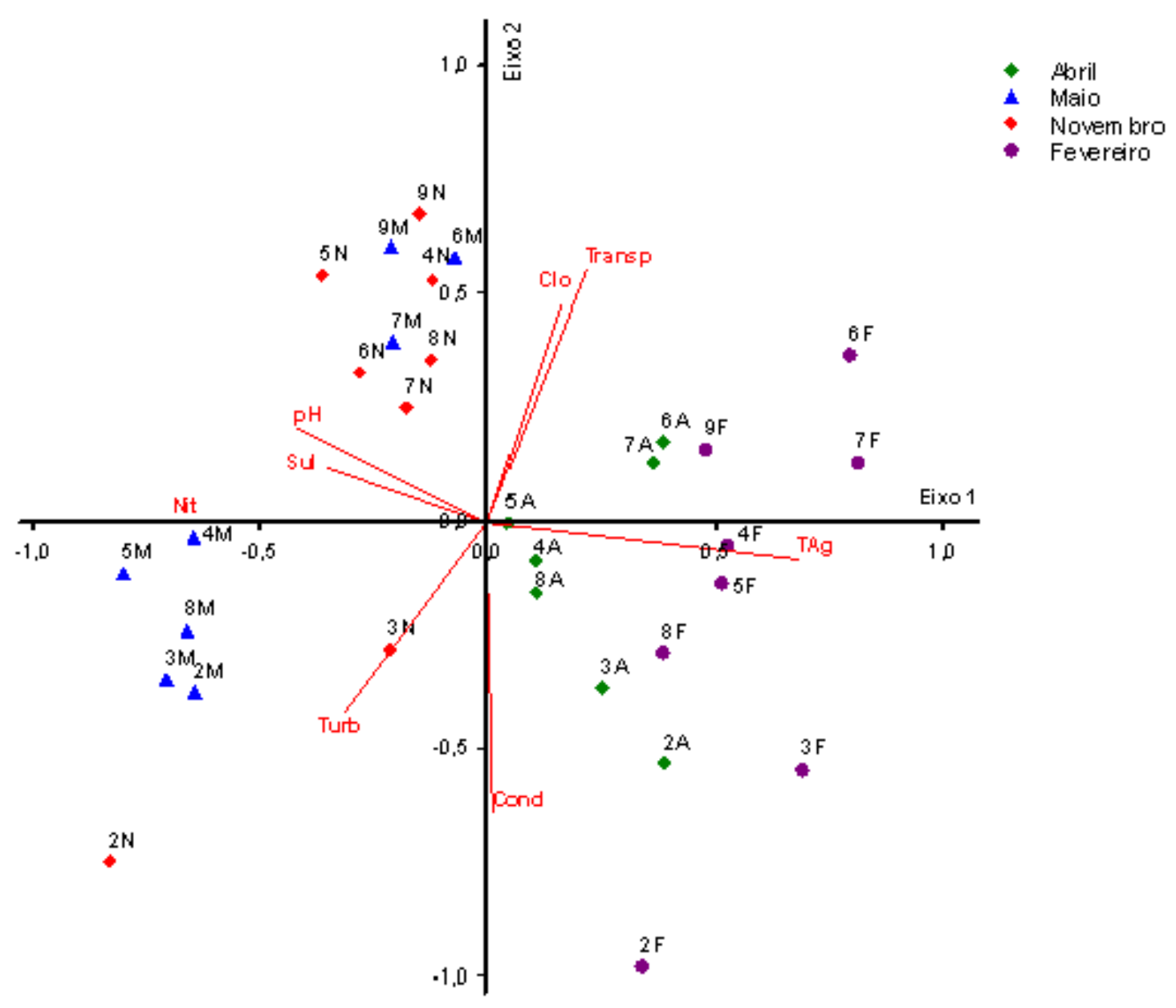

FIGURA 30 - Ordenação biplot, por ACP, das unidades amostrais (pontos de amostragem e meses) e das variáveis físicas e químicas analisadas. As unidades amostrais foram identificadas de acordo com o mês de coleta Abril/08 (A), Maio/08 (M), Novembro/08 (N) e Fevereiro/09 (F). Os números localizados antes das unidades amostrais referem-se ao ponto de amostragem (02 ao 09). As variáveis abióticas utilizadas foram temperatura da água (TAg), transparência (Transp), turbidez (Turb), condutividade elétrica (Cond), $\mathrm{pH}$, cloreto (Clo), sulfato (Sul) e nitrato (Nit).

A análise de componentes principais da matriz de correlação das espécies descritoras da comunidade fitoplanctônica e os pontos e meses de amostragem encontram-se na TAB. 21 e FIG. 31.

Os dois primeiros eixos da Análise de Componentes Principais para as espécies descritoras explicaram $57,31 \%$ da variação dos dados, sendo $37,95 \%$ no primeiro eixo e, 19,36\% no segundo eixo (TAB. 21). 
O lado negativo do eixo 1 agrupou os meses de Novembro e Fevereiro às todas as espécies descritoras da comunidade, as quais apresentaram as maiores densidades nestes meses de amostragem. A maioria dos pontos de amostragem do mês de Novembro, estiveram associados às maiores densidades de Aphanocapsa elachista, Merismopdeia glauca, Peridinium cf. pusillum, Eutetramorus fottii, Monoraphidium dybowskii, Monopraphidium sp.2, Monopraphidium sp. 3, Chlorella vulgaris e táxon não identificado, já o mês de Fevereiro demonstrou associação com as maiores densidades de Chroococcus minimus, Rhabdoderma cf. sancti-pauli, Radiococcus planktonicus e Monopraphidium sp.1.

TABELA 21 - Coeficientes de correlação de Pearson e Kendall entre as espécies descritoras da comunidade fitoplanctônica e os dois primeiros eixos de ordenação para o período de estudo $(\mathrm{N}=31)$

\begin{tabular}{|c|c|c|c|}
\hline \multirow{2}{*}{ Variável } & \multicolumn{3}{|c|}{ Componentes Principais } \\
\hline & Abreviações & Eixo 1 & Eixo 2 \\
\hline Chlorella vulgaris & C.vul & $-0,794$ & 0,068 \\
\hline Monoraphidium sp.3 & Mon3 & $-0,625$ & 0,114 \\
\hline Monoraphidium dybowskii & M.dyb & $-0,584$ & 0,150 \\
\hline Monopraphidium sp.1 & Mon1 & $-0,351$ & $-0,545$ \\
\hline Monoraphidium sp.2 & Mon2 & $-0,575$ & 0,155 \\
\hline Radiococcus planktonicus & R.plan & $-0,435$ & $-0,510$ \\
\hline Eutetramorus fottii & E.fot & $-0,742$ & 0,118 \\
\hline Chroococcus minimus & C.min & $-0,706$ & $-0,574$ \\
\hline Chroococcus sp.1 & Chro1 & 0,072 & 0,663 \\
\hline Rhabdoderma cf. sancti pauli & R.san & $-0,456$ & $-0,461$ \\
\hline Aphanocapsa elachista & A.ela & $-0,430$ & 0,600 \\
\hline Merismopedia glauca & M.gla & $-0,573$ & 0,636 \\
\hline Peridinium cf. pusillum & P.pus & $-0,725$ & 0,436 \\
\hline Táxon não identificado & táxon & $-0,803$ & $-0,034$ \\
\hline Total de Explicabilidade: & & $37,95 \%$ & $19,36 \%$ \\
\hline
\end{tabular}




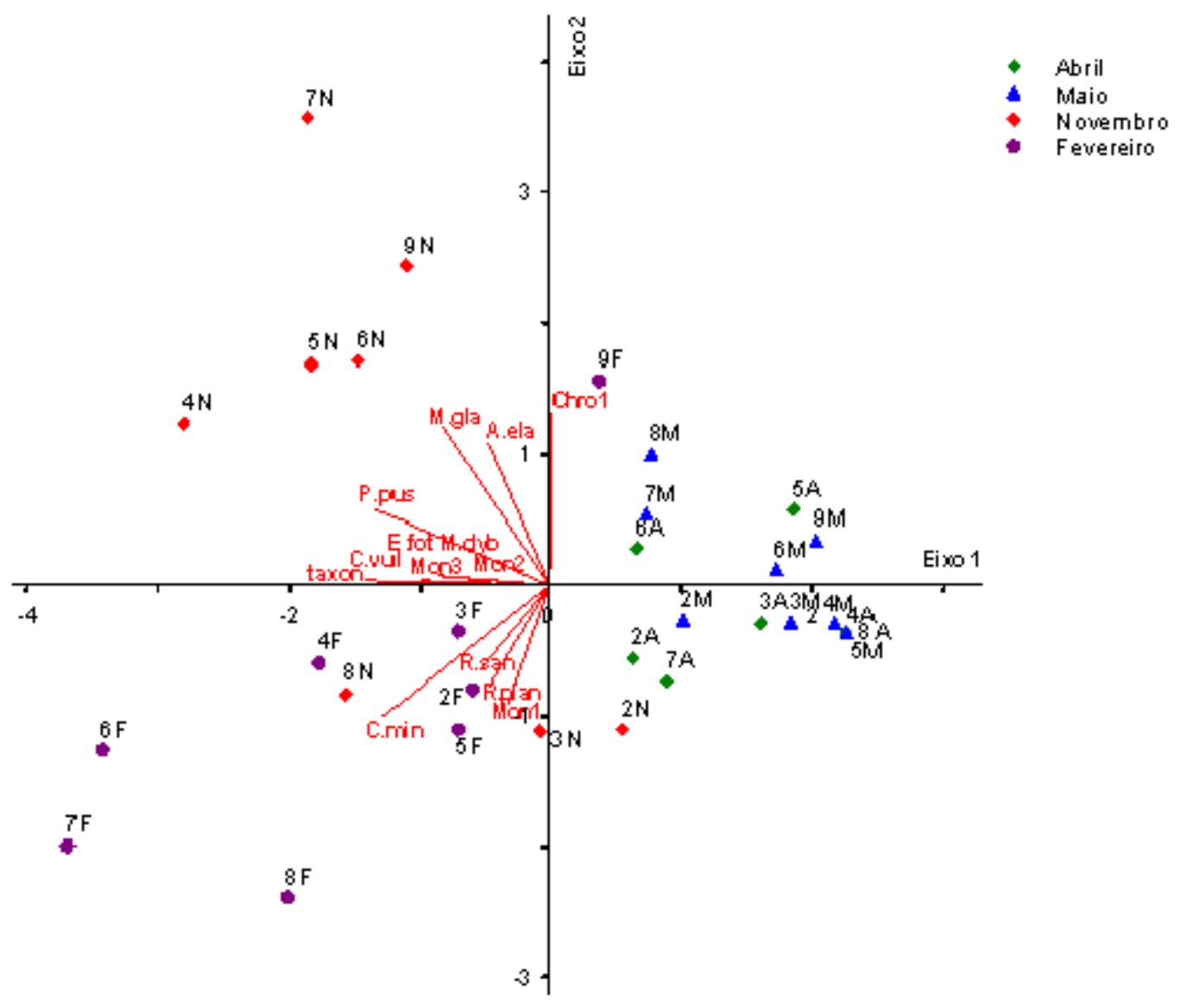

FIGURA 31 - Ordenação biplot, por ACP, das unidades amostrais (pontos de amostragem e meses) e das espécies descritoras. As unidades amostrais foram identificadas de acordo com 0 mês de coleta Abril/08 (A), Maio/08 (M), Novembro/08 (N) e Fevereiro/09 (F). Os números localizados antes das unidades amostrais referem-se ao ponto de amostragem (02 ao 09). As espécies descritoras utilizadas e suas respectivas abreviações estão apresentadas na TAB. 22.

\subsection{Análise dos resultados por pontos de amostragem}

As represas Paraibuna e Paraitinga somam a extensão de $224 \mathrm{~km}^{2}$, por onde foram distribuídos, inicialmente, os nove pontos de amostragem deste estudo, com o intuito de demonstrar os aspectos hidrobiológicos característicos daquele ambiente.

Estes pontos apresentam características variadas no que tange ao seu entorno e recebimento de contribuição orgânica de rios ou ribeirões afluentes das 
represas. Por este motivo, elaborou-se a análise dos dados por pontos de amostragem.

Os pontos foram descritos com limites geográficos, características do entorno, afluentes contribuintes e imagem do local.

É constante a presença da silvicultura de eucaliptos às margens das represas, destinado basicamente ao abastecimento das indústrias de celulose. Embora seja de conhecimento que os fertilizantes aplicados nas lavouras existentes dentro da área da bacia hidrográfica contribuem para a poluição das águas e a eutrofização (Straškraba e Tundisi, 2000), é controverso e escasso o estudo sobre os efeitos e impactos ambientais causados por plantações de eucaliptos (Vianna et al., 2009).

Parâmetros como temperatura do ar e da água, pH e concentração de fosfato mostraram-se praticamente constantes, ou dentro dos limites considerados normais, durante todo o período de estudo. As temperaturas seguiram os padrões do período, mais baixas nos meses de abril e maio de 2008 e, mais elevadas nos período chuvoso, novembro de 2008 e fevereiro de 2009.

$\mathrm{O}$ pH manteve-se entre 6,0 e 8,58, apresentando uma queda para 5,57 apenas no ponto $02 \mathrm{em}$ abr/08.

Os níveis de fluoreto apresentaram baixa variação entre os pontos de amostragem e os meses de coleta, apresentando valor mínimo de 0,030 mg. $\mathrm{L}^{-1} \mathrm{e}$ máximo de $0,050 \mathrm{mg} \cdot \mathrm{L}^{-1}$, com média de 0,04 $\pm 0,005 \mathrm{mg} \cdot \mathrm{L}^{-1}$ cumprido $\mathrm{o}$ estabelecido na resolução CONAMA 357/05 para águas doces de classe $2(1,4$ $\left.\mathrm{mg} \cdot \mathrm{L}^{-1}\right)$.

\subsubsection{Ponto de amostragem 01}

O ponto de amostragem 01 localiza-se no extremo leste da represa Paraitinga, próximo à Ponte dos Mineiros, recebendo maior contribuição de volume de água diretamente do Rio Paraitinga.

Desde a primeira coleta a passagem para alcançar este ponto encontrava-se com grande massa de macrófita aquática, pertencente ao gênero Salvinea sp. (FIG. 32 e FIG. 33). Motivo pelo qual ocorreu coleta de amostras somente em abril de 2008. Nas datas das demais coletas, a massa de Salvinea 
sp. havia se intensificado, impedindo a passagem da embarcação e a coleta das amostras de água e fitoplâncton neste ponto de amostragem.

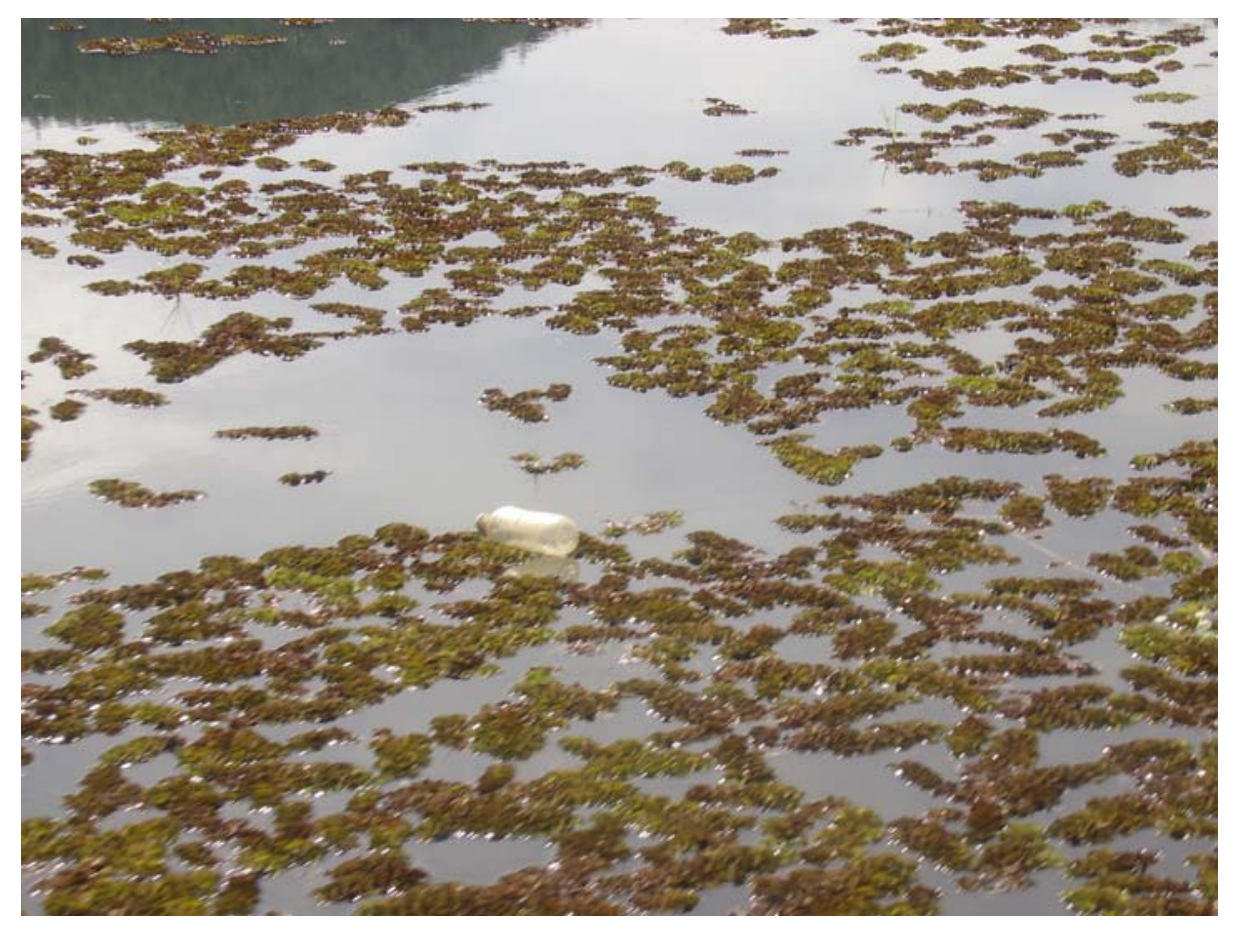

FIGURA 32 - Massa de macrófitas aquáticas na represa Paraitinga.

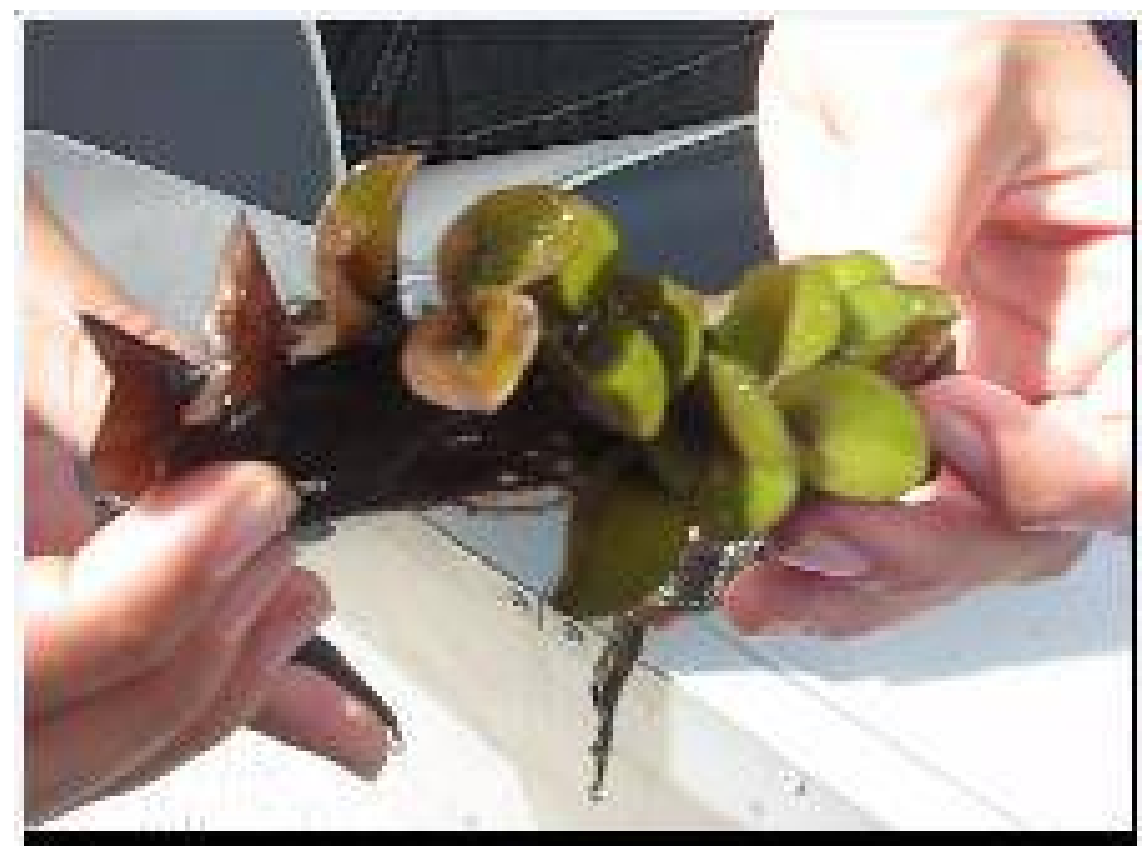

FIGURA 33 - Detalhe Salvinea sp. da represa Paraitinga.

O gênero Salvinia (Michell) Adans é atualmente considerado como uma das plantas daninhas aquáticas mais importantes, sendo classificado como uma macrófita aquática livre e flutuante pertencente à família Salviniaceae. É muito 
comum em água doce e sob condições favoráveis é rapidamente disseminado principalmente por propagação vegetativa, o que o faz colonizar extensas superfícies de água em tempo reduzido (Peixoto et al., 2005).

As macrófitas são importantes fontes de energia e de matéria para as cadeias alimentares em ecossistemas aquáticos e, além disso, promovem outros benefícios em regiões de baixíssima ação antrópica, como: propiciar abrigo para reprodução e proteção de organismos aquáticos e pássaros, retirar o excesso de substâncias tóxicas da água, promover a heterogeneidade espacial e temporal no corpo hídrico que favorece a biodiversidade biológica e de outros organismos aquáticos, além de proteger as margens dos corpos hídricos contra o processo erosivo (AGEVAP, 2007). É útil para purificação e oxigenação da água, mas sua decomposição diminui o oxigênio dissolvido (Martins et al., 2004).

Porém, outros fatores, prejudiciais, são decorrentes da presença em massa das macrófitas num ambiente aquático.

Segundo Julien et al. (2002), tapetes de Salvinea impedem o acesso e utilização das vias navegáveis para fins comerciais e de recreação, além de degradar a harmonia paisagística local. Águas sob tapetes de Salvinea tem uma menor concentração de oxigênio (devido à reduzida superfície da água disponível para oxigenação, a inibição da fotossíntese por plantas submersas, e consumo de oxigênio dissolvido pela decomposição), níveis elevados de dióxido de carbono, altas concentrações de sulfeto de hidrogênio, $\mathrm{pH}$ mais baixo, e temperaturas mais elevadas.

Impactos econômicos estão relacionados à perdas de áreas alagadiças cultiváveis, dificuldades para a geração de energia elétrica devido à tomada das grades de proteção anteriores à turbina, além de aumentar a suscetibilidade de um ambiente ao desenvolvimento de vetores de doenças, devido ao aumento do acúmulo de lixo.

A alteração das características de uma região, devido à ação do homem, provoca fortes modificações nos corpos hídricos. Assim sendo, algumas populações de macrófitas são favorecidas e passam a desenvolver densas colonizações em detrimento de outras espécies.

As alterações que mais tem contribuído para essas modificações nas comunidades de macrófitas são a eutrofização da água, as alterações do regime hídrico de cursos d'água com construções de barragens, o desvio de água para 
irrigação, assoreamento e outras, bem como a introdução de macrófitas e peixes exóticos (AGEVAP, 2007).

Martins et al. ( 2004), concluíram que a movimentação das águas do rio causada por barcos, fez com que Salvinia auriculata se acumulasse nas margens e se desenvolvesse melhor devido ao acúmulo de matéria orgânica dissolvida. Assim, esta espécie variou na quantidade em relação à ação antrópica, como também, em relação às mudanças em função do processo de sucessão natural.

Segundo Julien (2002), Salvinia é uma planta perene, sem periodicidade sazonal, embora as mudanças no crescimento podem estar relacionadas às variações sazonais, tais como mudanças na temperatura. $\mathrm{O}$ autor destaca que Salvinia está bem adaptada ao crescimento quando os nutrientes se tornam escassos na água, podendo capturá-los rapidamente quando se tornam disponíveis. Em níveis baixos de nitrogênio, suas folhas se tornam maiores, suas raízes mais longas, e a ramificação do rizoma fica reduzida. A temperatura ótima de crescimento é de $30^{\circ} \mathrm{C}$, e não ocorre crescimento em temperaturas inferiores a $10^{\circ} \mathrm{C}$ e acima de $40{ }^{\circ} \mathrm{C}$. Massas de Salvinia podem crescer em corpos d'água com condutividade variando entre $100 \mu \mathrm{S} . \mathrm{cm}^{-1}$ a $1.400 \mu \mathrm{S} . \mathrm{cm}^{-1}$, e o pH ótimo para o crescimento é 6,0 .

Conforme relatório da Associação Pró-Gestão das Águas da Bacia Hidrográfica do Rio Paraíba do Sul (AGEVAP, 2007) é oportuno destacar que o problema de proliferação de macrófitas tem sido observado em diversos reservatórios na bacia do rio Paraíba do Sul, entre os quais se destacam: os reservatórios de Paraibuna e Paraitinga, Santa Branca, Jaguari, Funil, Santana e de Vigário no Complexo Hidrelétrico de Lajes/Paraíba do Sul pertencentes à Light Energia, CESP e FURNAS; os reservatórios da usinas hidrelétricas Glória e Nova Maurício de propriedade da empresa Valesul Alumínio, nas bacias dos rios Muriaé e Pomba; e, a represa Dr. João Penido da CESAMA, em Juiz de Fora, na bacia do rio Paraibuna (AGEVAP, 2007).

No ponto de amostragem 01, apesar da criação de gado e equinos no entorno, a carga orgânica advinda deste tipo de atividade não se mostrou como importante contribuidora para o enriquecimento do corpo d'água. O Rio Paraitinga, corpo receptor de carga orgânica poluidora de São Luiz do Paraitinga, recebe o esgoto de origem doméstica deste município, porém esta carga é $84 \%$ 
tratada pela SABESP (CETESB, 2006), fator essencial para evitar o aporte excessivo de nutrientes na água e a deteriorização de sua qualidade.

Apesar de Salvinia não apresentar variação sazonal o aumento da temperatura no período chuvoso parece ter sido uma importante contribuição para o aumento de sua densidade populacional. Pode-se verificar que este ponto de amostragem apresentou baixas concentrações de nutrientes como nitrato e fostato (TAB. 22) e pH próximo a 6,0. Estes organismos demonstram adaptações favoráveis ao seu desenvolvimento em condições escassez de nutrientes, fato que pode ter ocorrido neste local de estudo. Porém, outros fatores como ocorrência, direção e velocidade do vento e vazão da água, entre outros, não abordados neste trabalho, influenciam na reprodução das macrófitas. 
TABELA 22 - Parâmetros físicos e químicos e valores medidos no ponto de amostragem $01 \mathrm{em}$ abril de 2008

\begin{tabular}{lc}
\hline \multicolumn{1}{c}{ Parâmetros } & Valores \\
\hline Temperatura da água & $24,5^{\circ} \mathrm{C}$ \\
$\mathrm{pH}$ & 6,85 \\
$\mathrm{OD}$ & $7,47 \mathrm{mg} \cdot \mathrm{L}^{-1}$ \\
Condutividade elétrica & $0,029 \mathrm{mS} . \mathrm{cm}^{-1}$ \\
Turbidez & $1,08 \mathrm{NTU}$ \\
Transparência & $3,3 \mathrm{~m}$ \\
Sólidos Totais Dissolvidos & $50,0 \mathrm{mg} \cdot \mathrm{L}^{-1}$ \\
Nitrato & $0,11 \mathrm{mg} \cdot \mathrm{L}^{-1}$ \\
Fosfato & $<\mathrm{LD}$ \\
Sulfato & $0,49 \mathrm{mg} \cdot \mathrm{L}^{-1}$ \\
Cloreto & $1,39 \mathrm{mg} \cdot \mathrm{L}^{-1}$ \\
$\mathrm{Fluoreto}$ & $0,04 \mathrm{mg} \cdot \mathrm{L}^{-1}$ \\
$\mathrm{Al}$ & $0,0582 \mathrm{mg} \cdot \mathrm{L}^{-1}$ \\
Ba & $<0,001 \mathrm{mg} \cdot \mathrm{L}^{-1}$ \\
$\mathrm{Fe}$ & $0,1280 \mathrm{mg} \cdot \mathrm{L}^{-1}$ \\
$\mathrm{Mn}$ & $<0,002 \mathrm{mg} \cdot \mathrm{L}^{-1}$ \\
$\mathrm{P}$ & $0,0287 \mathrm{mg} \cdot \mathrm{L}^{-1}$ \\
$\mathrm{~Pb}$ & $0,0024 \mathrm{mg} \cdot \mathrm{L}^{-1}$ \\
$\mathrm{Zn}$ & $0,0069 \mathrm{mg} \cdot \mathrm{L}^{-1}$ \\
\hline
\end{tabular}

Conforme explica Moura (2009), o manejo integrado das macrófitas aquáticas, que emprega combinações de métodos físico (remoção mecânica), químico (aplicação de herbicidas) e biológico (controle por animais herbívoros), apresenta-se como a forma mais eficaz de controle. Entretanto, é necessário que se combata as fontes eutrofizadoras dos recursos hídricos.

A utilização de métodos biológicos no controle destas plantas daninhas certamente é o menos impactante, mas deve ser realizado de forma criteriosa, para que não se incorra em erros graves como a introdução de espécies exóticas, que muitas vezes competem por recursos com os organismos endêmicos e não têm predadores naturais. A introdução de espécies exóticas é apontada como 
uma das principais causas de perda da biodiversidade, juntamente com a destruição de habitats e a exploração dos recursos naturais (Moura, 2009).

\subsubsection{Ponto de amostragem 02}

O ponto de amostragem 02 localiza-se à leste da represa Paraitinga, próximo à Fazenda Ponte Alta, recebendo maior contribuição de volume de água diretamente do Rio Paraitinga. A fazenda, localizada às margens da represa, possui áreas de reflorestamento de eucaliptos e de pastagens (FIG. 34 e FIG. 35).

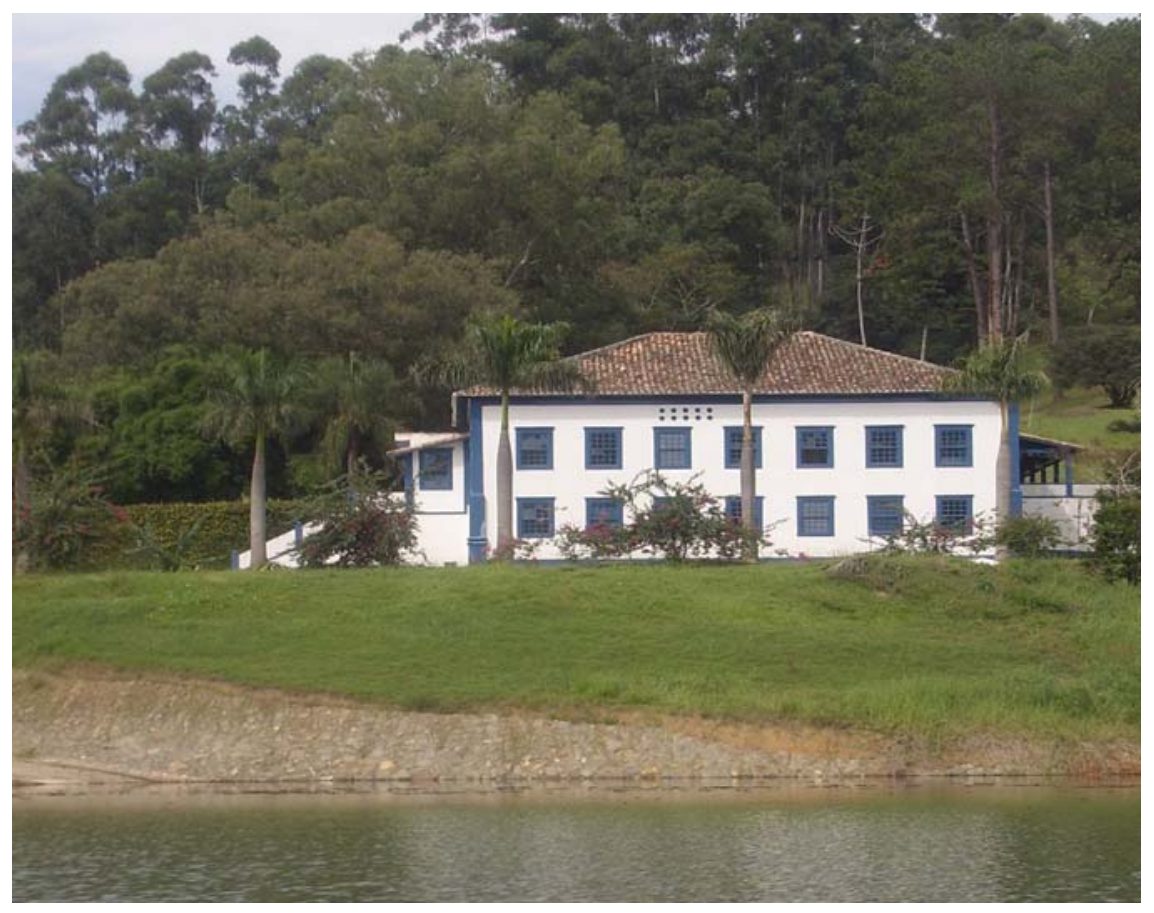

FIGURA 34 - Fazenda Ponte Alta localizada próxima ao ponto de amostragem 02. 


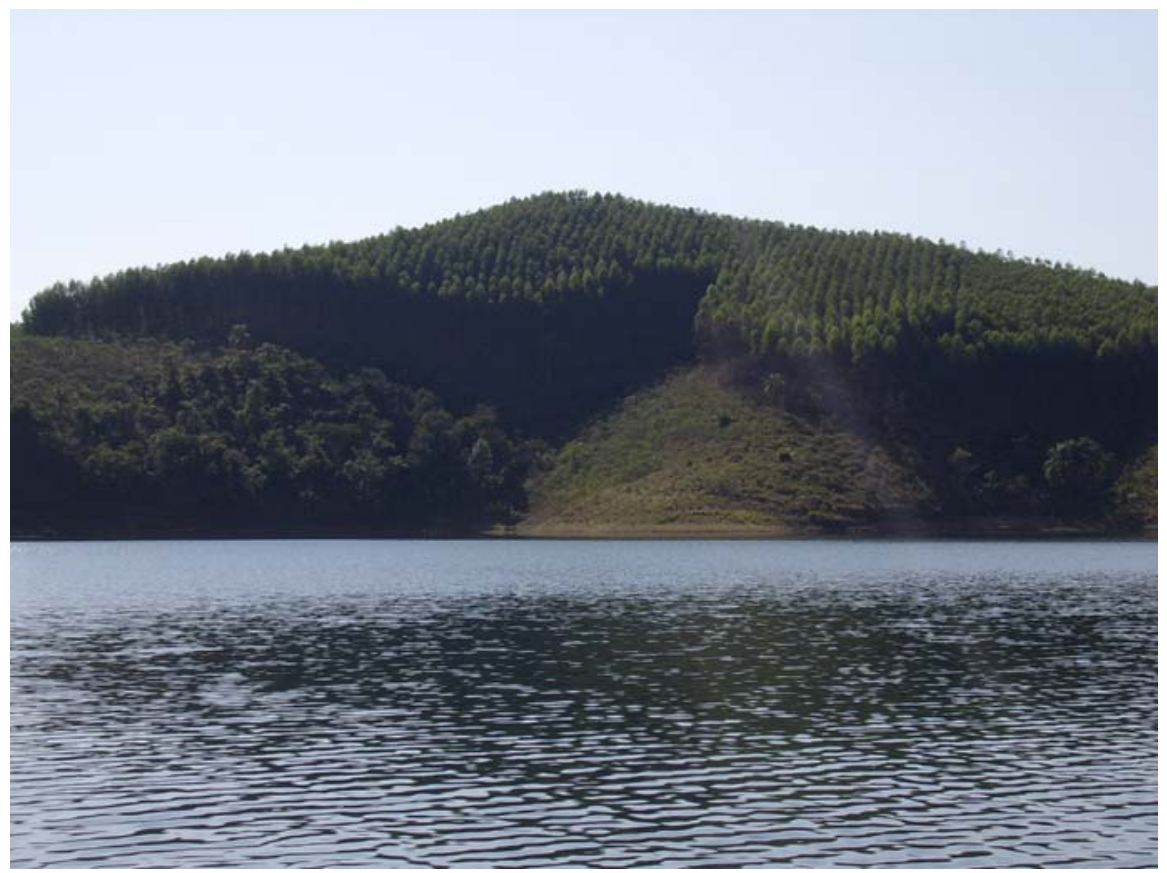

FIGURA 35 - Área de reflorestamento de eucaliptos localizada próxima ao ponto de amostragem 02.

Neste ponto, apesar da existência de monocultura de eucaliptos e pastagens no entorno, a carga orgânica advinda destas atividades não se mostrou importante contribuidora para o enriquecimento do corpo d'agua deste local, verificados pelos mais baixos níveis de densidade fitoplanctônica (TAB. 23 e FIG. 36), principalmente no período de seca e frio, e níveis maiores no período chuvoso e quente, o que significa uma variação sazonal natural desta comunidade conforme monstram diversos estudos (Fonseca e Bicudo, 2008; Vercellino e Bicudo, 2006; Coquemala, 2005).

TABELA 23 - Valor médio, máximo e mínimo, desvio padrão e coeficiente de variação da densidade fitoplanctônica (org. $\mathrm{mL}^{-1}$ ) no ponto 02 durante o período de estudo

\begin{tabular}{lr}
\hline Média & 267 \\
Máximo & 371 \\
Mínimo & 113 \\
DP & 123,50 \\
Coef. Var. (\%) & 46,31 \\
\hline
\end{tabular}




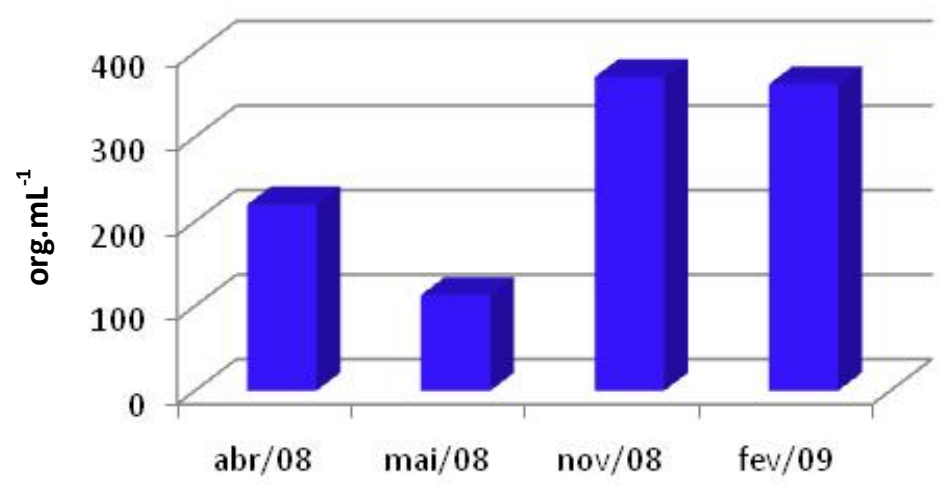

FIGURA 36 - Densidades totais da comunidade fitoplanctônica (org. $\mathrm{mL}^{-1}$ ) no ponto de amostragem 02.

A composição da comunidade fitoplanctônica esteve constituída por 8 classes. As classes mais representativas foram Chlorophyceae, que apresentou maior riqueza, contribuindo com $31 \%$ do total, seguida por Cyanophyceae com 23\% e Bacillariophyceae com 14\%, como apresentado na FIG. 37.

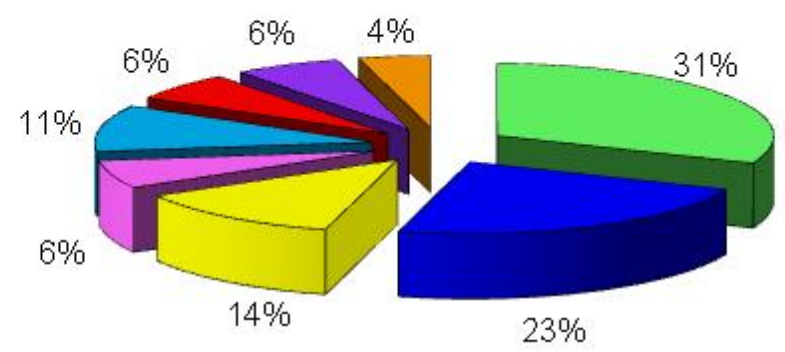

\begin{tabular}{|c|c|}
\hline 口CHLOROPHYCEAE & DCYANOPHYCEAE \\
\hline 口BACILLARIOPHYCEAE & 口ZYGNEMAPHYCEAE \\
\hline 口EUGLENOPHYCEAE & 口CHRYSOPHYCEAE \\
\hline 口DINOPHYCEAE & 口CRYPTOPHYCEAE \\
\hline
\end{tabular}

FIGURA 37 - Composição da comunidade fitoplanctônica, do ponto de amostragem 02 , durante o período de estudo.

Ocorreu aumento da turbidez, e consequente diminuição da transparência (FIG. 38), no período chuvoso, fatores ocasionados pela turbulência da coluna de água. Os valores de OD mostraram-se menores no período chuvoso 
(FIG. 39), fato esperado devido à dimimuição da solubilidade deste gás quando ocorre elevação da temperatura atmosférica (Esteves, 1998).

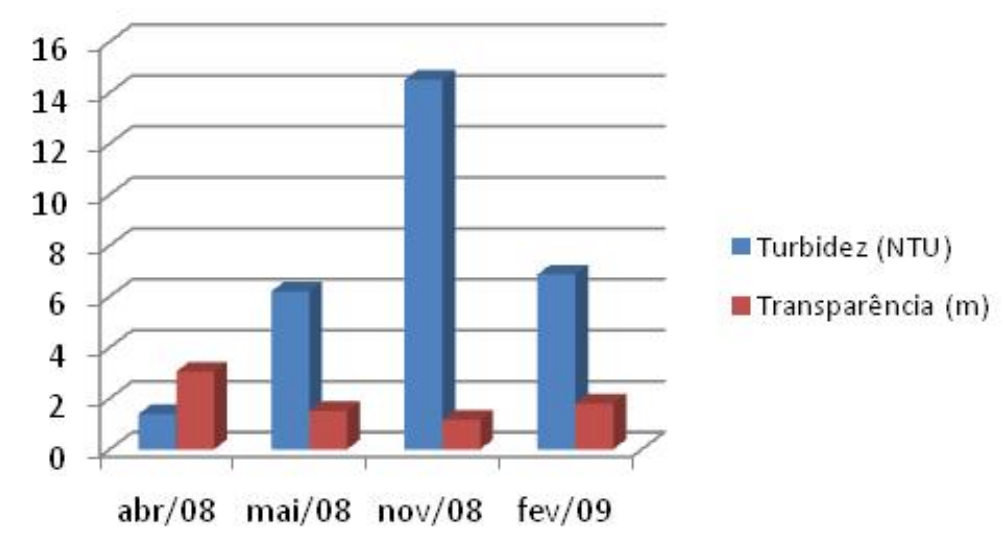

FIGURA 38 - Valores de turbidez (NTU) e transparência (m) no ponto de amostragem 02.

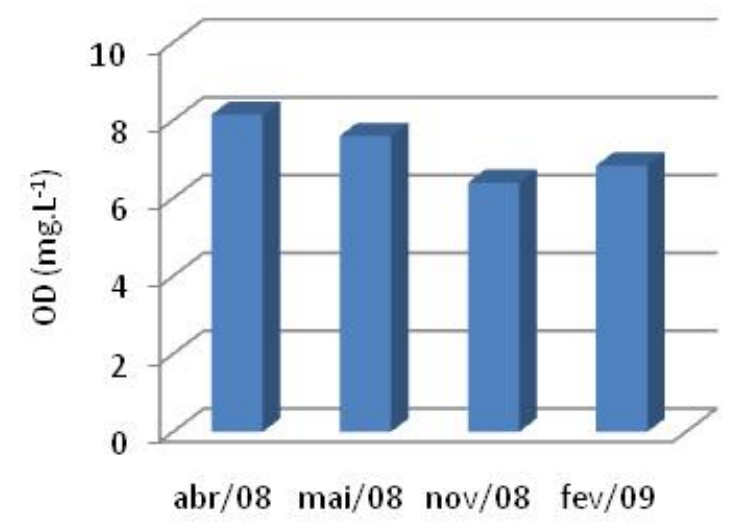

FIGURA 39 - Valores de oxigênio dissolvido $\left(\mathrm{mg}^{\mathrm{L}} \mathrm{L}^{-1}\right)$ no ponto de amostragem 02.

Compostos de nitrogênio, como nitrito e nitrato, constituem um dos mais importantes fatores limitantes à vida dos microrganismos de água doce (Branco, 1986). Os valores de nitrato, neste ponto, estiveram abaixo de 0,55 $\mathrm{mg} \cdot \mathrm{L}^{-1}$, apresentando apenas um aumento, de cerca 2 vezes, no mês de nov/08, atingindo 1,0 mg. $\mathrm{L}^{-1}$ (FIG. 40).

Valores semelhantes, menores que $1,0 \mathrm{mg} \cdot \mathrm{L}^{-1}$, foram encontrados por Vercellino e Bicudo (2006) num lago oligotrófico tropical. 
Vollenweider (1968) apud Esteves (1998) classificou lagos europeus contendo até $1 \mathrm{mg} \cdot \mathrm{L}^{-1}$ de nitrato como oligotróficos, de 1 a $5 \mathrm{mg} \cdot \mathrm{L}^{-1}$, mesotróficos e, de 5 a $50 \mathrm{mg} \cdot \mathrm{L}^{-1}$, como eutróficos.

O cloreto apresenta também influência nas características dos ecossistemas aquáticos naturais, por provocarem alterações na pressão osmótica em células de microrganismos (CESTESB, 2009), geralmente são responsáveis pelo gosto salgado da água e podem interferir, pelo aumento da salinidade, na concentração de oxigênio dissolvido em água (Branco, 1986; Piveli e Kato, 2006). Esgotos domésticos são importantes fontes de cloretos, onde os valores deste parâmetro ultrapassam 15 mg.L-1.

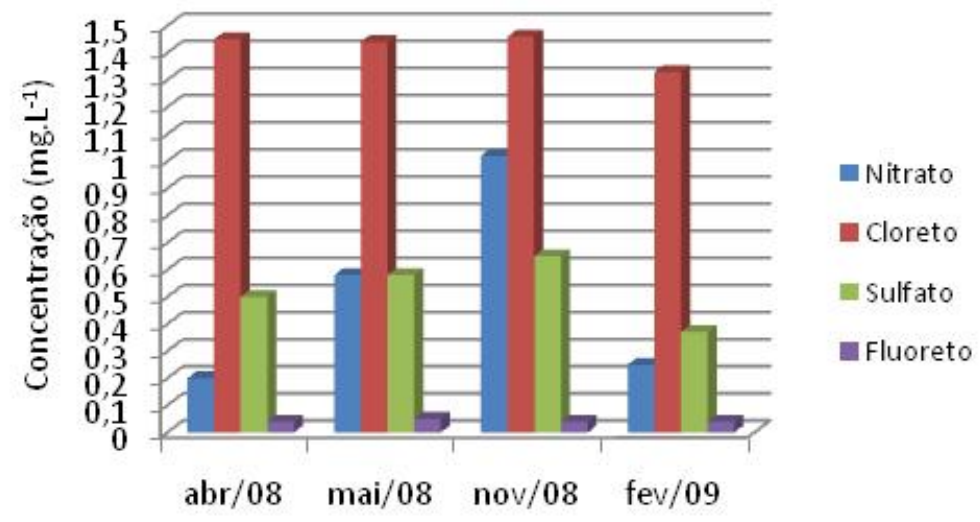

FIGURA 40 - Concentração de nitrato, cloreto, sulfato e fluoreto (mg.L $\left.{ }^{-1}\right)$ no ponto de amostragem 02.

As concentrações de cloreto, sulfato e fluoreto apresentaram pouca variação de amplitude entre os meses amostrados (FIG. 40).

Frações de sólidos voláteis mostraram valores acima das frações de sólidos fixos durante os meses de abr/08, mai/08 e nov/08 (FIG. 41). Apenas em fev/09 a porção fixa mostrou valores acima da porção volátil. 


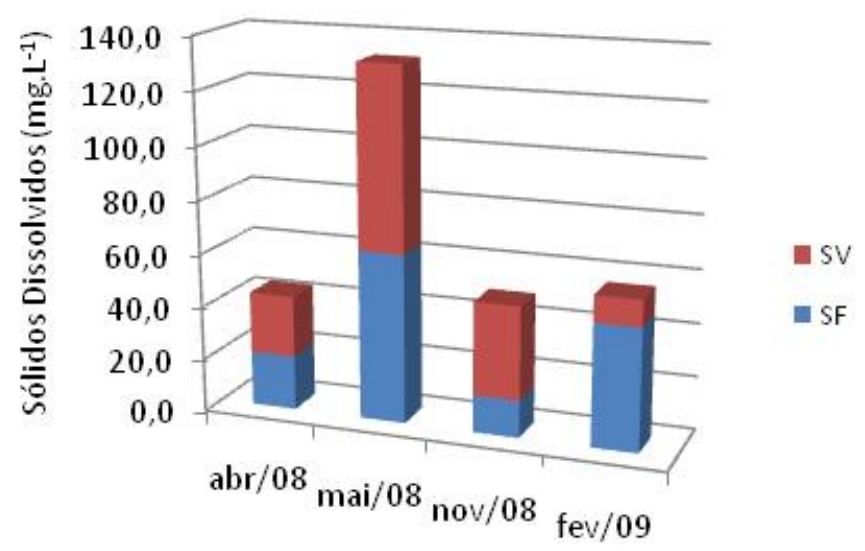

FIGURA 41 - Valores de série de sólidos dissolvidos, sólidos voláteis (SV) e sólidos fixos (SF) (mg. $\left.\mathrm{L}^{-1}\right)$ no ponto de amostragem 02.

As classificações referentes ao índice de estado trófico (IET), calculado segundo as concentrações de fósforo total, para o ponto de amostragem 02 , durante o período de estudo estão apresentadas na FIG. 42.

No mês de abr/08, nov/08 e fev/09 este ponto foi classificado como oligotrófico, enquanto que no mês de mai/08 foi classificado como eutrófico.

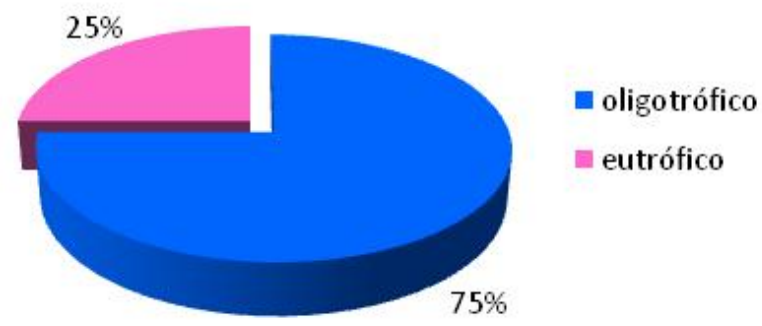

FIGURA 42 - Proporção das classificações do Índice de Estado Trófico (IET), no ponto de amostragem 02 , durante o período de estudo.

\subsubsection{Ponto de amostragem 03}

O ponto de amostragem 03 localiza-se ao norte da represa Paraitinga, próximo ao município de Redenção da Serra, recebendo contribuição de volume de água do Ribeirão Palmital, Ribeirão dos Afonsos e do Rio Paraitinga. Às margens deste ponto, encontram-se áreas de reflorestamento de eucaliptos (FIG. 43). 


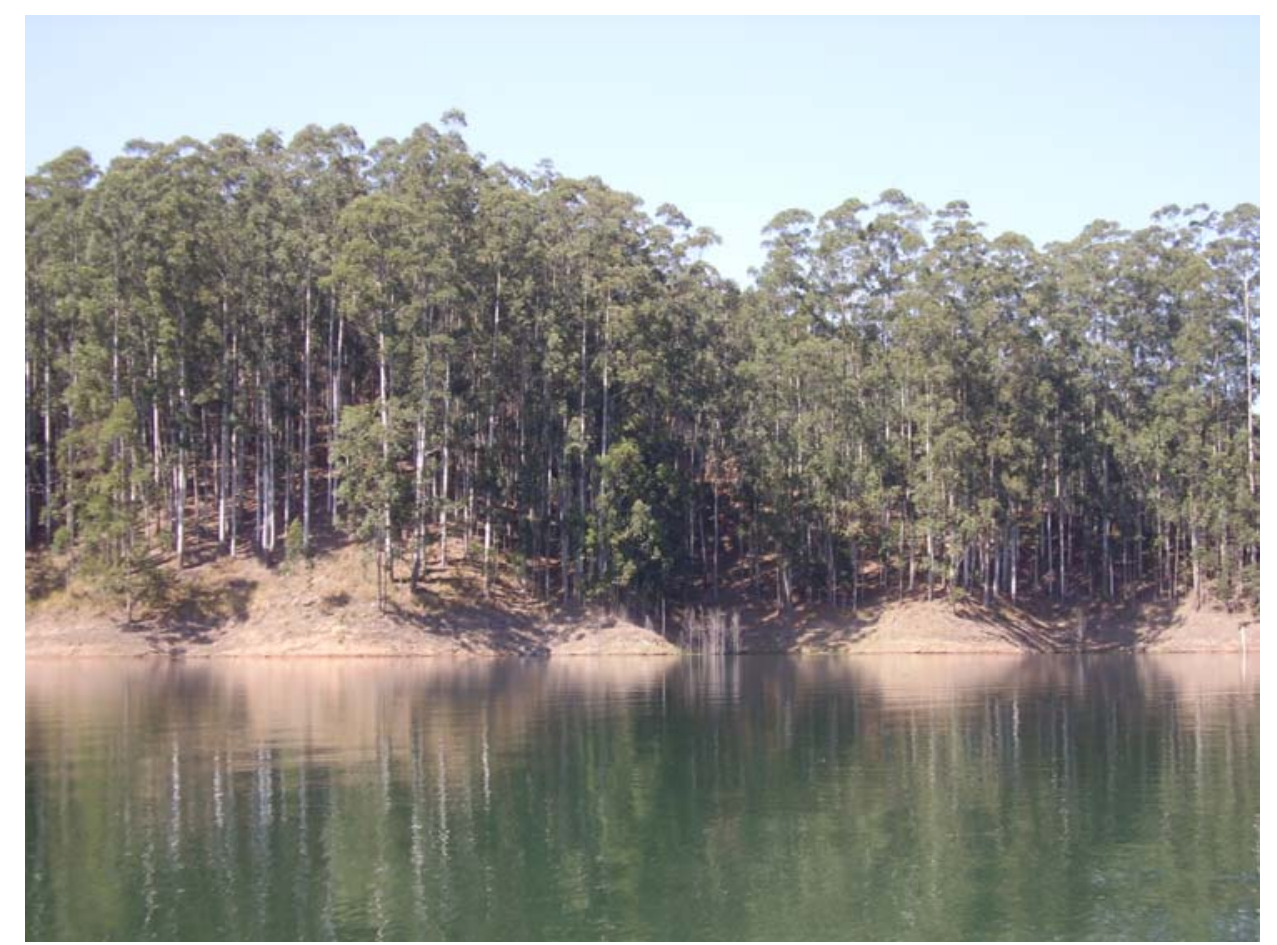

FIGURA 43 - Área de reflorestamento de eucaliptos localizada próxima ao ponto de amostragem 03.

Neste ponto, ocorreram níveis baixos de densidade fitoplanctônica, porém acima dos valores encontrados do ponto 02 (exceto no mês de abr/08). Como esperado, ocorreu aumento na densidade fitoplanctônica no período chuvoso e mais quente (nov/08 e fev/09) juntamente com o decréscimo do OD (TAB. 24, FIG.44 e FIG. 45).

Este ponto recebe maior contribuição orgânica, provavelmente advinda do Rio Paraitinga, por ser este o corpo receptor da carga poluidora do município de São Luiz do Paraitinga.

TABELA 24 - Valor médio, máximo e mínimo, desvio padrão e coeficiente de variação da densidade fitoplanctônica (org. $\mathrm{mL}^{-1}$ ) no ponto 03 durante o período de estudo

\begin{tabular}{lr}
\hline Média & 291 \\
Máximo & 538 \\
Mínimo & 101 \\
DP & 188,24 \\
Coef. Var. (\%) & 64,68 \\
\hline
\end{tabular}




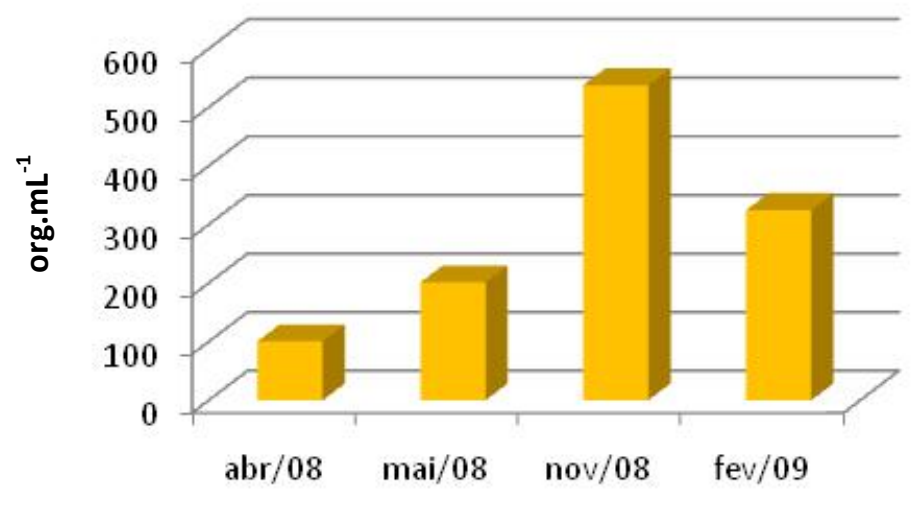

FIGURA 44 - Densidades totais da comunidade fitoplanctônica (org. $\mathrm{mL}^{-1}$ ) no ponto de amostragem 03.

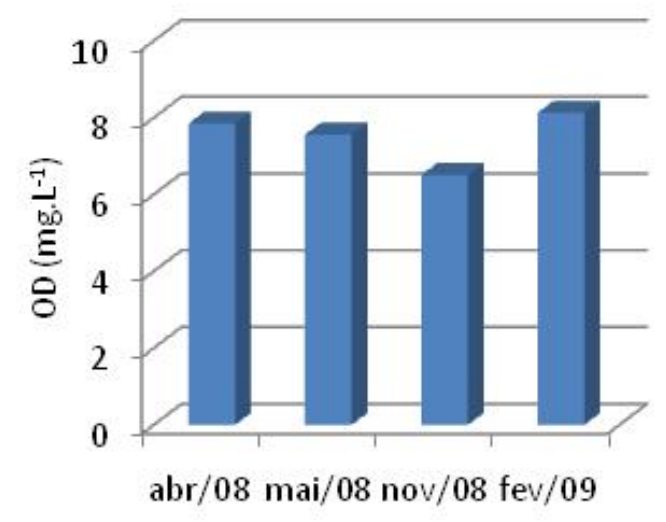

FIGURA 45 - Valores de oxigênio dissolvido $\left(\mathrm{mg}^{\mathrm{L}} \mathrm{L}^{-1}\right)$ no ponto de amostragem 03.

A composição da comunidade fitoplanctônica esteve constituída por 7 classes. As classes mais representativas foram Chlorophyceae, que apresentou maior riqueza, contribuindo com $34 \%$ do total, seguida por Cyanophyceae com $27 \%$ e Bacillariophyceae com 13\%, como apresentado na FIG. 46. Neste ponto não houve ocorrência de organismos da classe Cryptophyceae. 


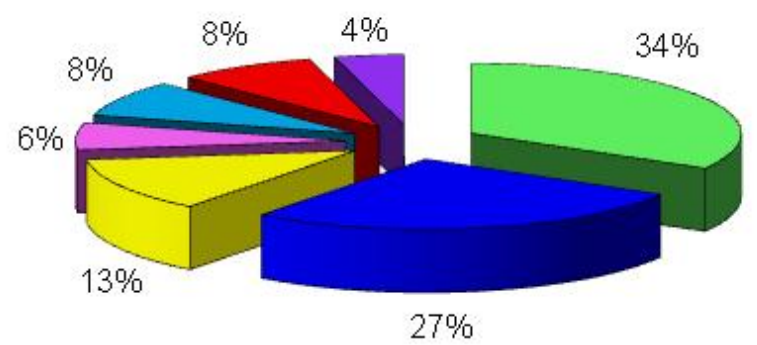

\begin{tabular}{|c|c|}
\hline 口CHLOROPHYCEAE & -CYANOPHYCEAE \\
\hline 口BACILLARIOPHYCEAE & 口ZYGNEMAPHYCEAE \\
\hline 口EUGLENOPHYCEAE & 口CHRYSOPHYCEAE \\
\hline 口DINOPHYCEAE & \\
\hline
\end{tabular}

FIGURA 46 - Composição da comunidade fitoplanctônica, do ponto de amostragem 03 , durante o período de estudo.

Houve um pronunciado aumento da turbidez no mês de mai/08 acompanhado pelo aumento nos níveis de sólidos dissolvidos totais (FIG 47 e FIG. 48).

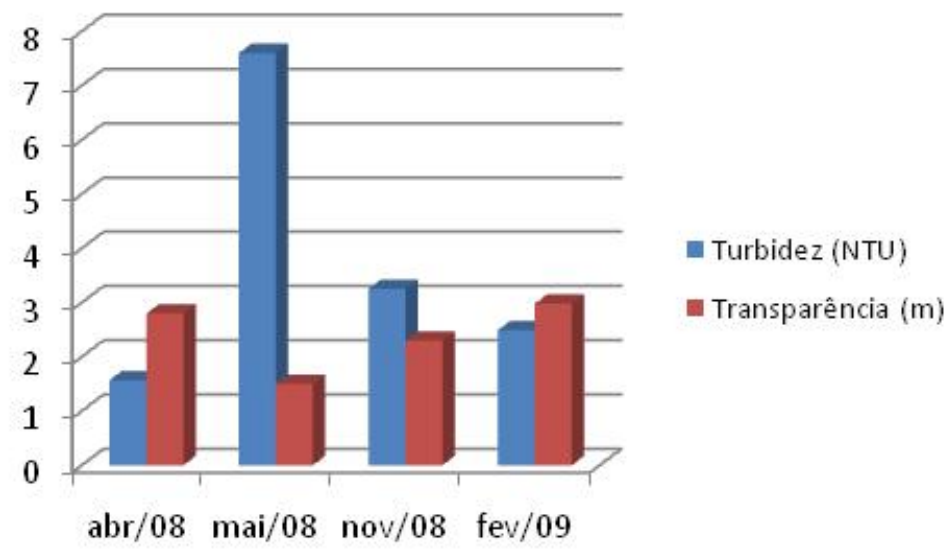

FIGURA 47 - Valores de turbidez (NTU) e transparência (m) no ponto de amostragem 03.

Frações de sólidos voláteis mostraram valores acima das frações de sólidos fixos durante os meses de mai/08 e fev/09 (FIG. 48). Em abr/08 e nov/08 a porção fixa mostrou valores acima da porção volátil. 


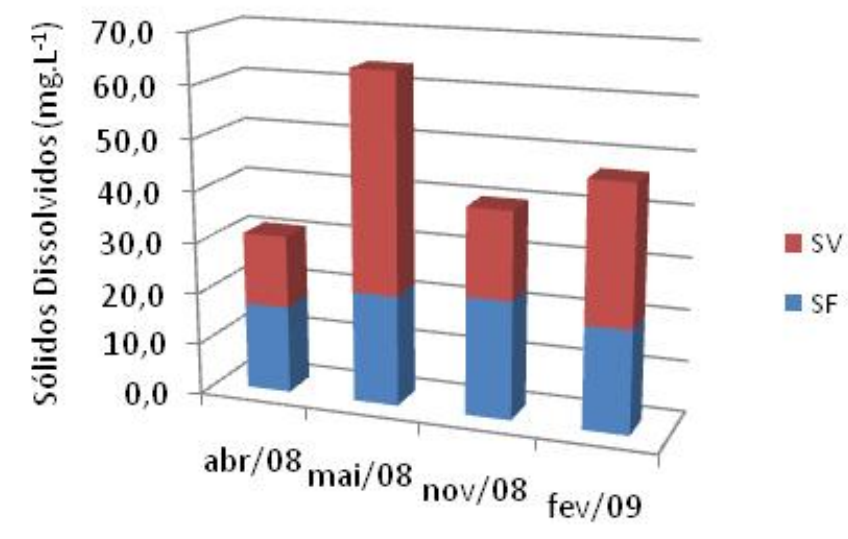

FIGURA 48 - Valores de série de sólidos dissolvidos, sólidos voláteis (SV) e sólidos fixos (SF) (mg. $\left.\mathrm{L}^{-1}\right)$ no ponto de amostragem 03.

O nitrato apresentou, em mai/08, um acréscimo de aproximadamente quatro vezes o valor obtido no mês de abr/08 (FIG. 49). Este acréscimo não perdurou durante os próximos meses de amostragem, decrescendo para 0,47 $\mathrm{mg} \cdot \mathrm{L}^{-1} \mathrm{em}$ nov/08 e para $0,07 \mathrm{em}$ fev/09, podendo representar a assimilação deste composto pelo fitoplâncton que apresentou crescimento nestes meses.

As concentrações de cloreto, sulfato e fluoreto apresentaram pouca variação de amplitude entre os meses amostrados (FIG. 49).

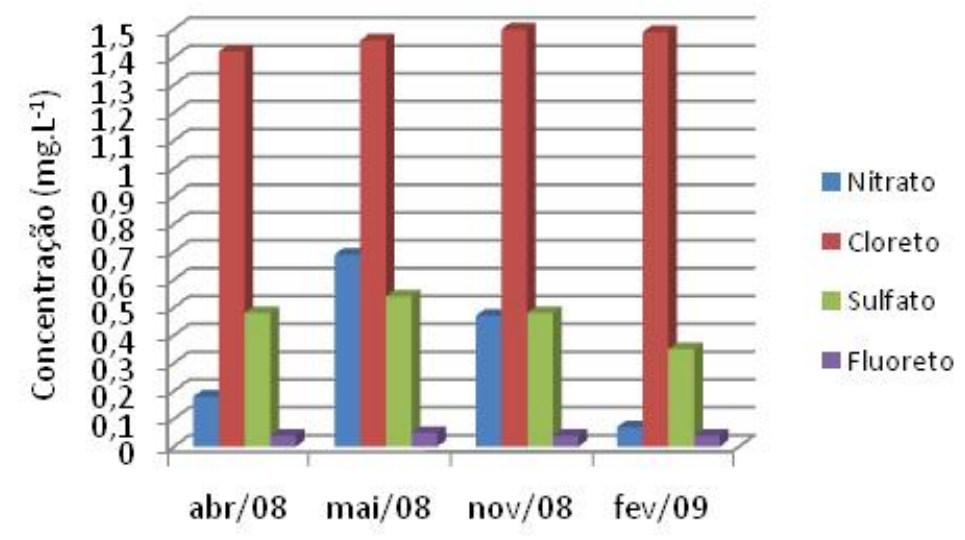

FIGURA 49 - Concentração de nitrato, cloreto, sulfato e fluoreto $\left(\mathrm{mg} \cdot \mathrm{L}^{-1}\right)$ no ponto de amostragem 03. 
As classificações referentes ao índice de estado trófico (IET), calculado segundo as concentrações de fósforo total, para o ponto de amostragem 03 , durante o período de estudo estão apresentadas na FIG. 50.

Da mesma forma que o ponto 02, no mês de abr/08, nov/08 e fev/09 o ponto 03 foi classificado como oligotrófico, enquanto que no mês de mai/08 foi classificado como eutrófico.

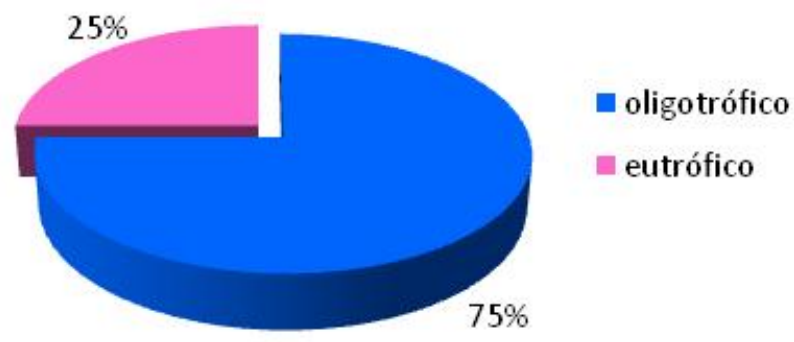

FIGURA 50 - Proporção das classificações do Índice de Estado Trófico (IET), no ponto de amostragem 03 , durante o período de estudo.

\subsubsection{Ponto de amostragem 04}

O ponto de amostragem 04 localiza-se na represa Paraibuna, ao sul do ponto 05, próximo à barragem da hidrelétrica da CESP, recebendo contribuição de volume de água do Rio Paraibuna. Algumas fazendas e pontos de erosão estão localizados próximos a este ponto (FIG. 51). 


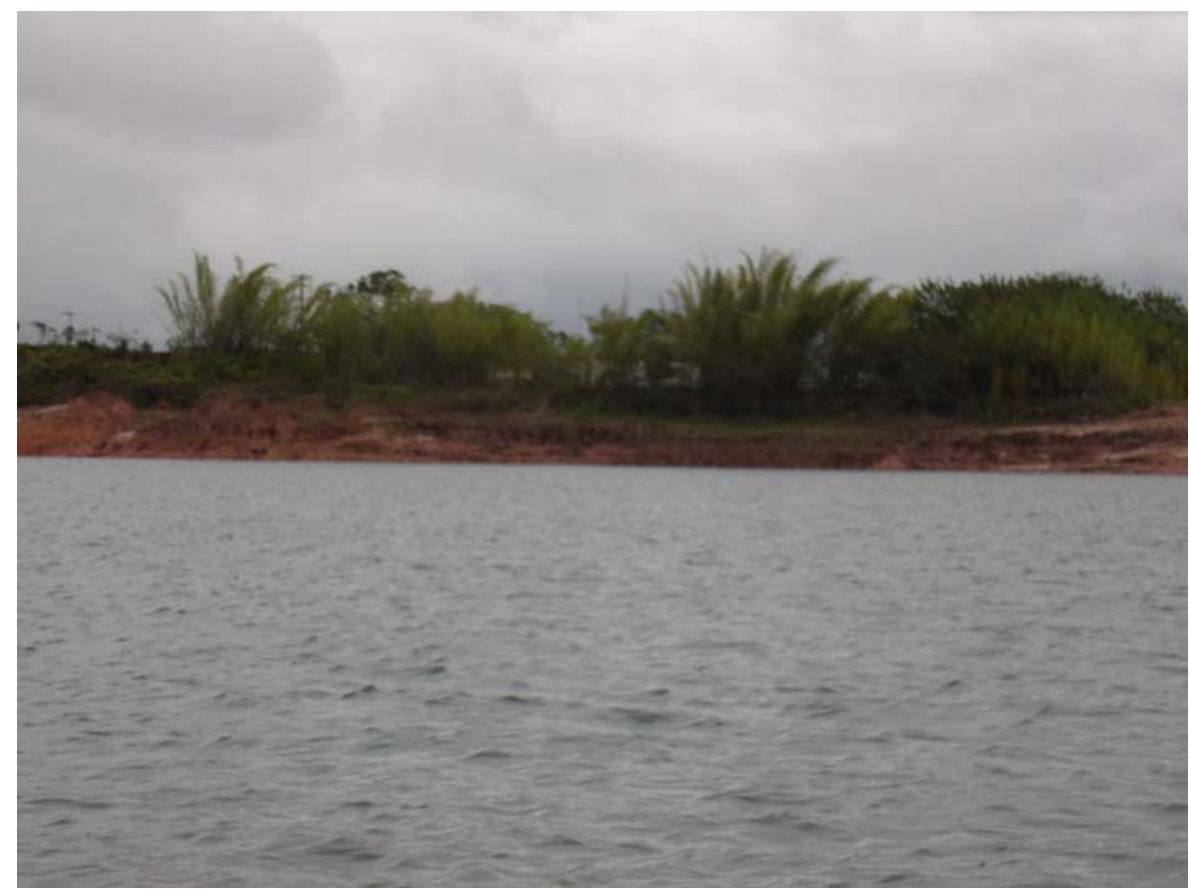

FIGURA 51 - Área com erosão localizada próxima ao ponto de amostragem 04.

Neste ponto, ocorreu grande variação de amplitude nas densidades fitopanctônicas que subiram de 40 org. $\mathrm{mL}^{-1}$, em mai/08 para 862 org.mL $\mathrm{m}^{-1}$, em nov/08. Este fato provavelmente ocorreu devido ao aumento da temperatura da água e as condições para a reprodução destes organismos, conseqüentemente houve um pequeno decréscimo nos valores de OD, devido ao consumo deste elemento pelos organismos (TAB. 25, FIG.52 e FIG. 53).

Este ponto recebe contribuição orgânica, advinda do Rio Paraibuna, por ser este o corpo receptor da carga poluidora dos municípios de Natividade da Serra, Paraibuna e Redenção da Serra.

TABELA 25 - Valor médio, máximo e mínimo, desvio padrão e coeficiente de variação da densidade fitoplanctônica (org. $\mathrm{mL}^{-1}$ ) no ponto 04 durante o período de estudo

\begin{tabular}{lr}
\hline Média & 383 \\
Máximo & 862 \\
Mínimo & 40 \\
DP & 381,65 \\
Coef. Var. (\%) & 99,72 \\
\hline
\end{tabular}




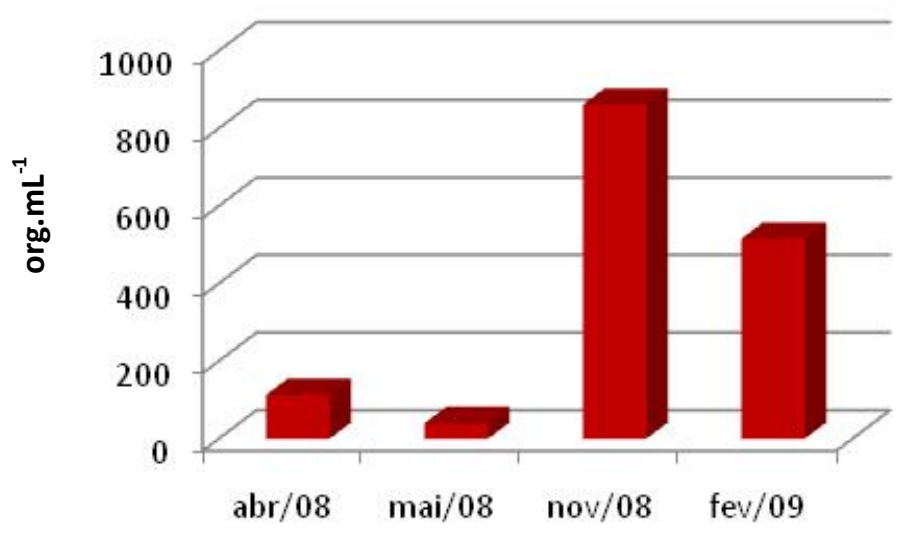

FIGURA 52 - Densidades totais da comunidade fitoplanctônica (org. $\mathrm{mL}^{-1}$ ) no ponto de amostragem 04.

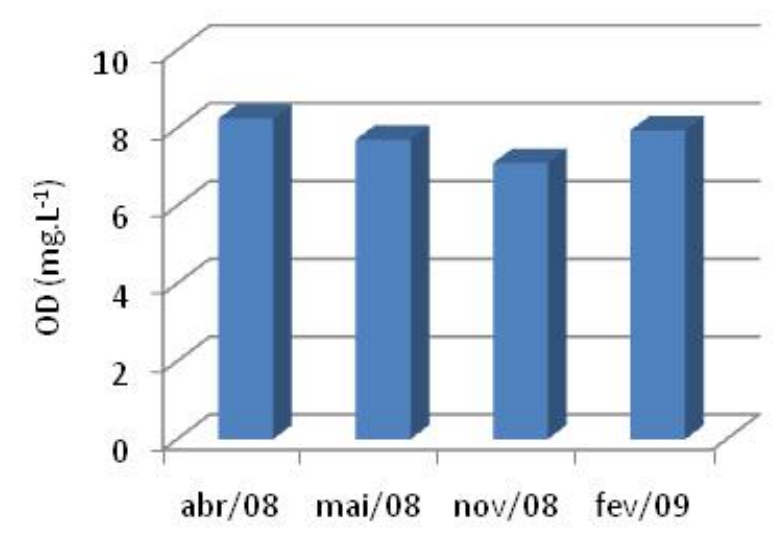

FIGURA 53 - Valores de oxigênio dissolvido $\left(\mathrm{mg} \cdot \mathrm{L}^{-1}\right)$ no ponto de amostragem 04.

A composição da comunidade fitoplanctônica esteve constituída por 8 classes. As classes mais representativas foram Chlorophyceae, que apresentou maior riqueza, contribuindo com 31\% do total, seguida por Cyanophyceae com $27 \%$ e Bacillariophyceae e Chrysophyceae com 10\%, como apresentado na FIG. 54. 


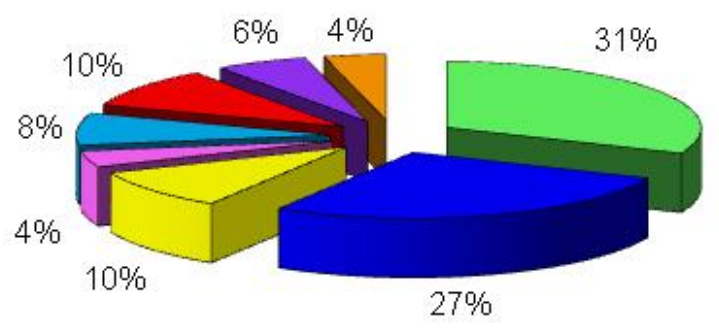

\begin{tabular}{|c|c|}
\hline 口CHLOROPHYCEAE & -CYANOPHYCEAE \\
\hline 口BACILLARIOPHYCEAE & 口ZYGNEMAPHYCEAE \\
\hline 口EUGLENOPHYCEAE & 口CHRYSOPHYCEAE \\
\hline QDINOPHYCEAE & 口CRYPTOPHYCEAE \\
\hline
\end{tabular}

FIGURA 54 - Composição da comunidade fitoplanctônica, do ponto de amostragem 04, durante o período de estudo.

Assim como no ponto 03, ocorreu pronunciado aumento da turbidez no mês de mai/08 acompanhado pelos maiores valores de sólidos dissolvidos totais em abr/08 e mai/08 (FIG. 55 e FIG. 56).

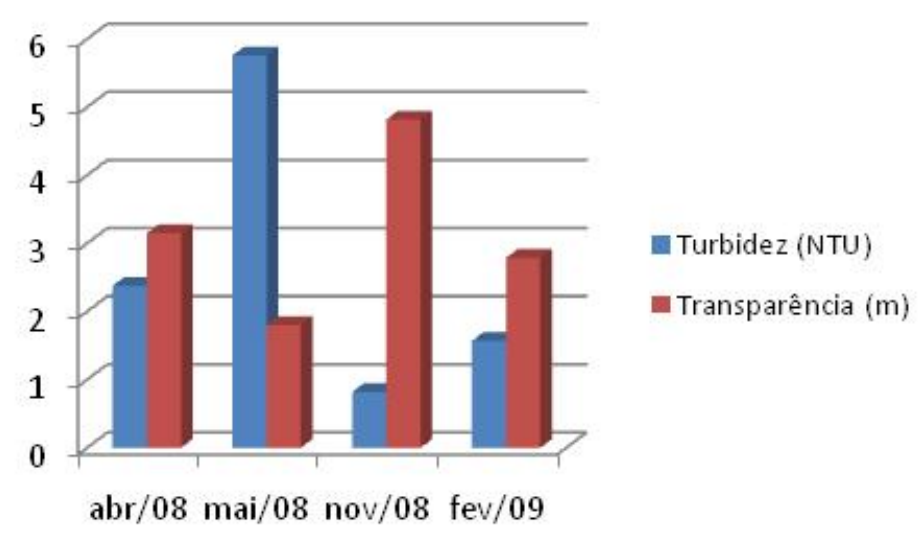

FIGURA 55 - Valores de turbidez (NTU) e transparência $(m)$ no ponto de amostragem 04.

Frações de sólidos voláteis mostraram valores acima das frações de sólidos fixos durante os meses de abr/08 e nov/08 (FIG. 56). No mês de abr/08 ocorreram elevados valores das porções voláteis. 


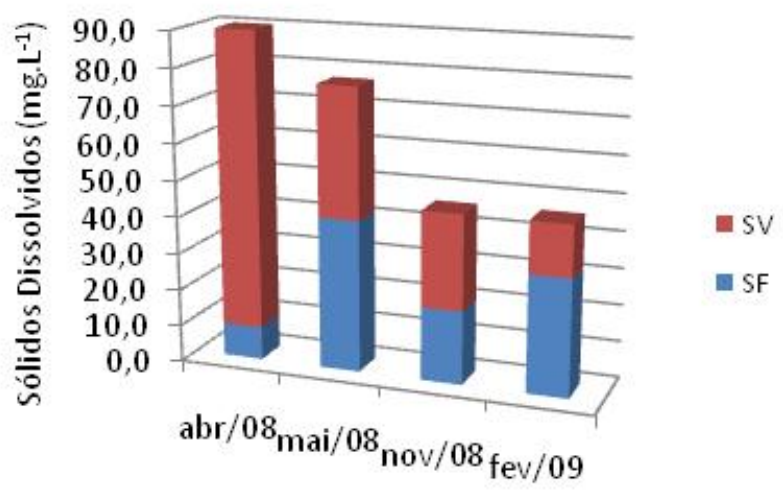

FIGURA 56 - Valores de série de sólidos dissolvidos, sólidos voláteis (SV) e sólidos fixos (SF) (mg. $\left.\mathrm{L}^{-1}\right)$ no ponto de amostragem 04.

O nitrato apresentou, mesma tendência do ponto 03, no qual ocorreu um acréscimo nos valores do mês de mai/08, 0,68 mg. $\mathrm{L}^{-1}$, em relação aos outros meses, decrescendo para $0,58 \mathrm{mg} \cdot \mathrm{L}^{-1} \mathrm{em}$ nov/08 e para $0,20 \mathrm{mg} \cdot \mathrm{L}^{-1} \mathrm{em}$ fev/09 (FIG. 57).

As concentrações de sulfato e fluoreto apresentaram pouca variação de amplitude entre os meses amostrados. Já as concentrações de cloreto demostraram aumento gradual, neste ponto, durante o período de estudo (FIG. 57)

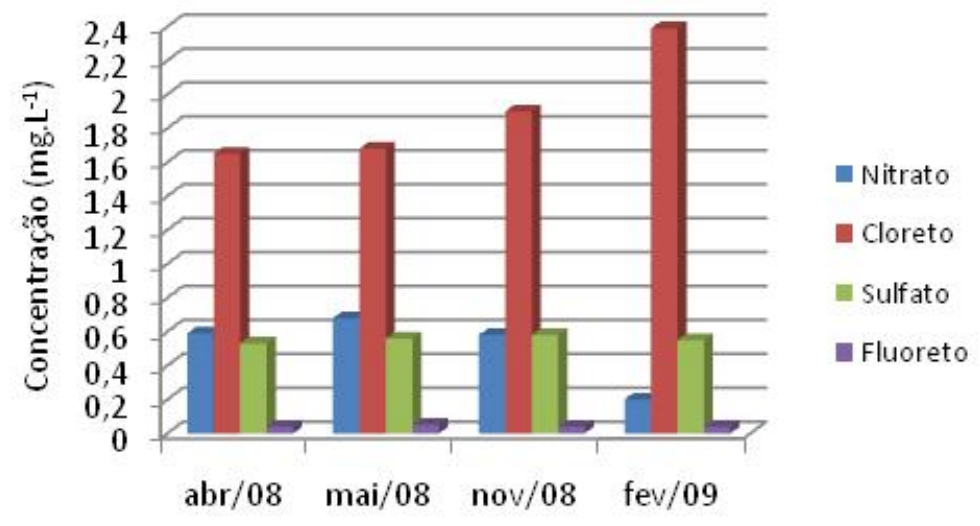

FIGURA 57 - Concentração de nitrato, cloreto, sulfato e fluoreto $\left(\mathrm{mg} \cdot \mathrm{L}^{-1}\right)$ no ponto de amostragem 04.

As classificações referentes ao índice de estado trófico (IET), calculado segundo as concentrações de fósforo total, para o ponto de amostragem 04, durante o período de estudo estão apresentadas na FIG. 58. 
Semelhante aos pontos 02 e 03, no mês de abr/08, nov/08 e fev/09 o ponto 04 foi classificado como oligotrófico, enquanto que no mês de mai/08 foi classificado como mesotrófico.

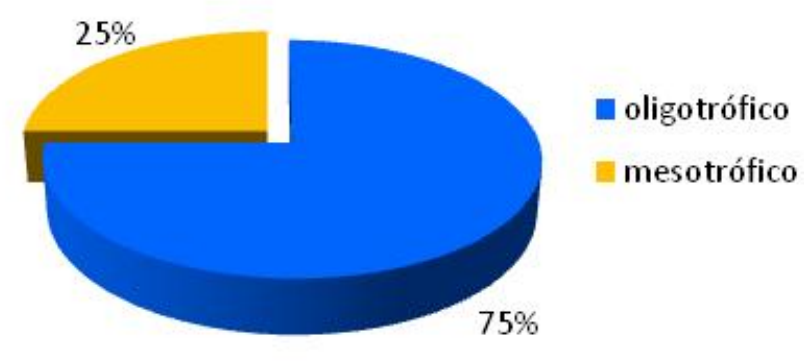

FIGURA 58 - Proporção das classificações do Índice de Estado Trófico (IET), no ponto de amostragem 04, durante o período de estudo.

\subsubsection{Ponto de amostragem 05}

O ponto de amostragem 05 localiza-se na represa Paraibuna, à noroeste do ponto 04, junto à barragem da hidrelétrica da CESP, próximo ao equipamento de tomada de água da usina. Recebe, também, contribuição de volume de água do Rio Paraibuna (FIG. 59). 


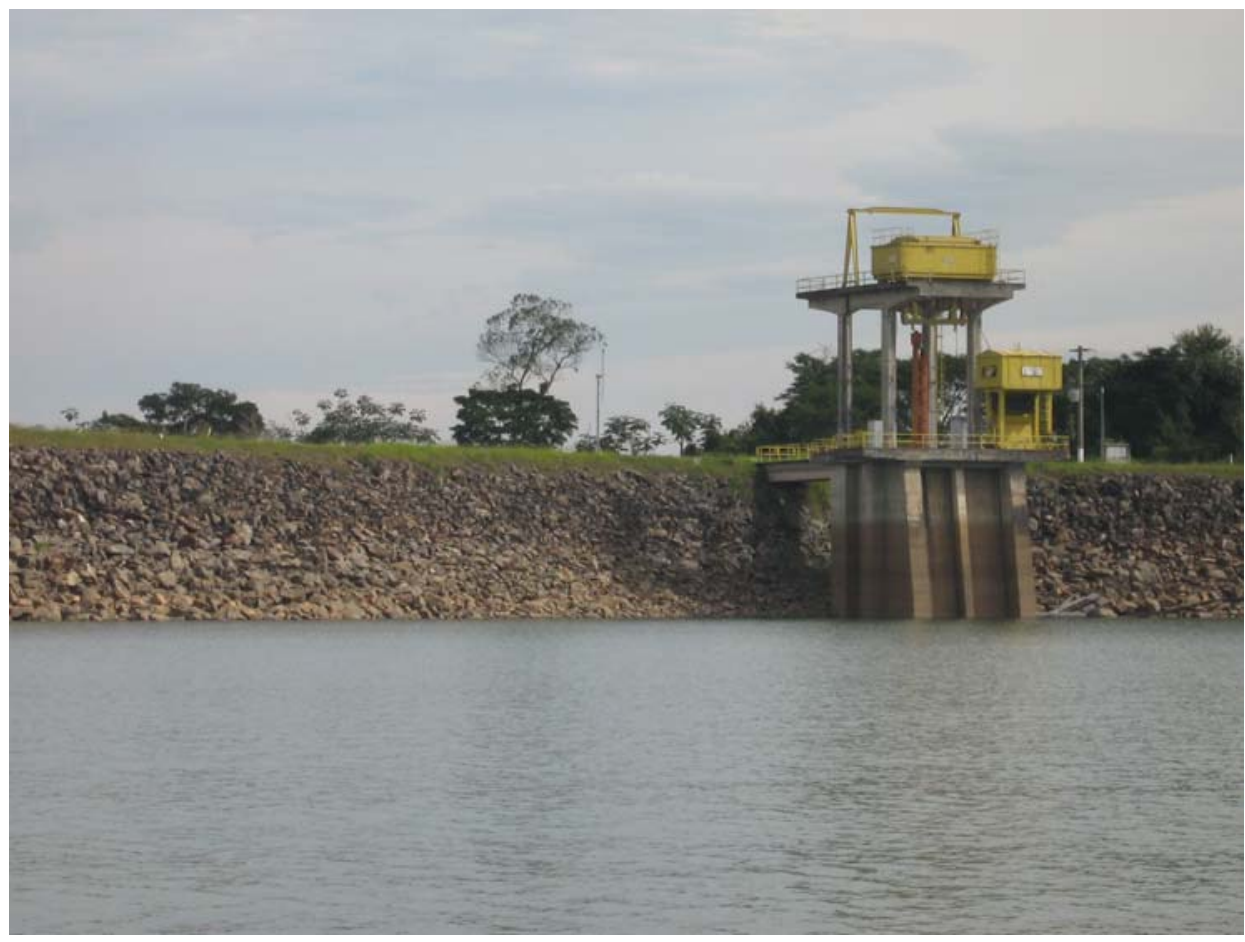

FIGURA 59 - Barragem e equipamento de tomada de água da UHE Paraibuna.

Neste ponto, ocorreram níveis baixos de densidade fitoplanctônica. Assim como no ponto 04, o valor mais baixo de densidade fitoplanctôncia ocorreu no mês de mai/08, com 79 org. $\mathrm{mL}^{-1}$, e o valor mais alto ocorreu no mês de nov/08, com 582 org. $\mathrm{mL}^{-1} 1$, relação inversamente proporcional aos valores de OD (TAB. 26, FIG. 60 e FIG. 61).

Este ponto recebe maior contribuição orgânica, advinda do Rio Paraibuna, por ser este o corpo receptor da carga poluidora dos municípios de Natividade da Serra, Paraibuna e Redenção da Serra.

TABELA 26 - Valor médio, máximo e mínimo, desvio padrão e coeficiente de variação da densidade fitoplanctônica (org. $\mathrm{mL}^{-1}$ ) no ponto 05 durante o período de estudo

\begin{tabular}{lr}
\hline Média & 335 \\
Máximo & 582 \\
Mínimo & 79 \\
DP & 215,93 \\
Coef. Var. (\%) & 107,24 \\
\hline
\end{tabular}




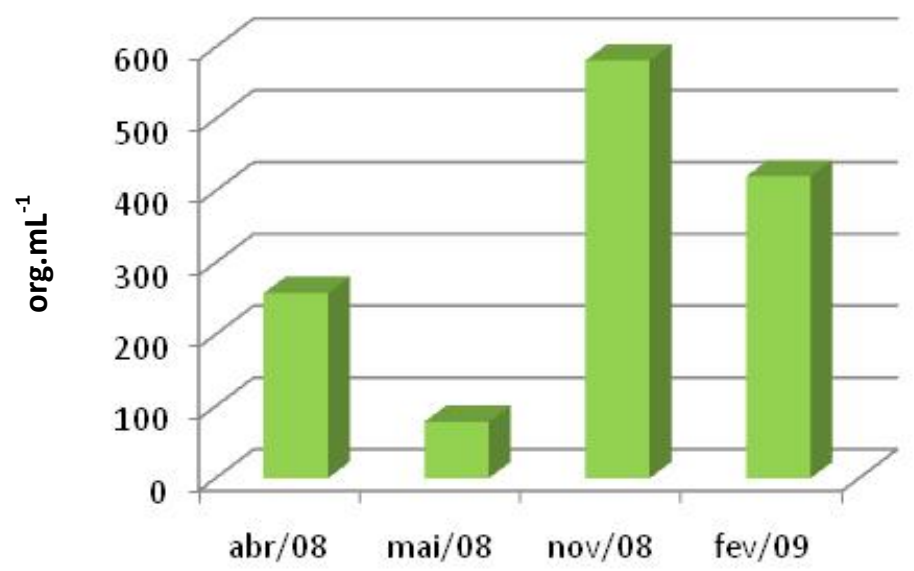

FIGURA 60 - Densidades totais da comunidade fitoplanctônica (org. $\mathrm{mL}^{-1}$ ) no ponto de amostragem 05.

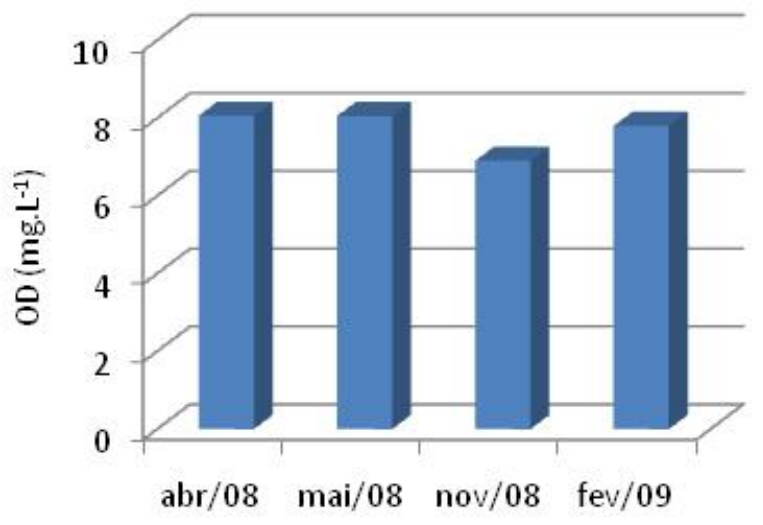

FIGURA 61 - Valores de oxigênio dissolvido $\left(\mathrm{mg} \cdot \mathrm{L}^{-1}\right)$ no ponto de amostragem 05.

Assim como no ponto 03, ocorreu pronunciado aumento da turbidez no mês de mai/08 acompanhado pelos maiores valores de sólidos dissolvidos totais no mesmo mês (FIG. 62 e FIG. 63). 


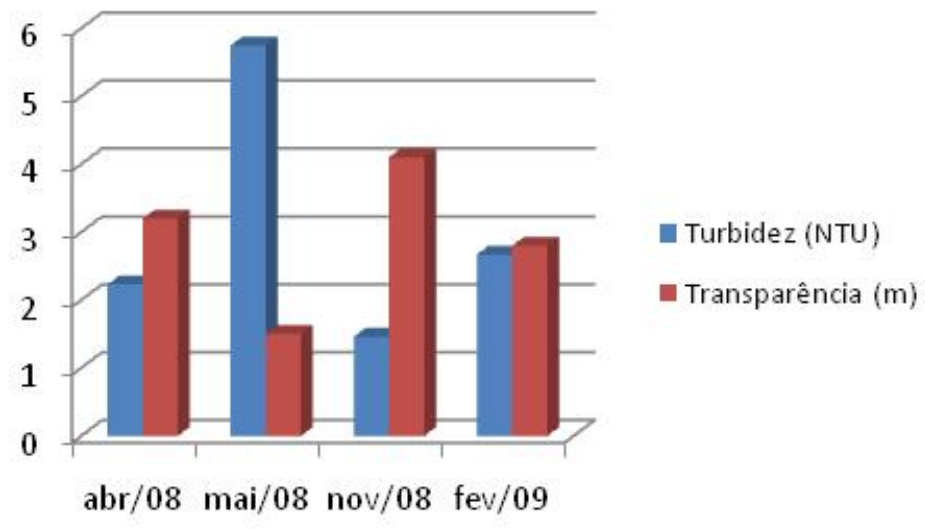

FIGURA 62 - Valores de turbidez (NTU) e transparência $(m)$ no ponto de amostragem 05.

Frações de sólidos voláteis mostraram valores acima das frações de sólidos fixos durante os meses de abr/08 e mai/08 (FIG. 63). Em nov/08 e fev/09 a porção fixa mostrou valores acima da porção volátil. Em mai/08 ocorreu um pico nos valores de sólidos dissolvidos totais, cerca de 10 vezes os valores obtidos nos outros meses. Um pico isolado no mês de mai/08 não foi observado nos pontos 04 e 08, localizados próximos ao ponto 05, porém estes pontos no mês de abril apresentaram valores mais altos comparados aos outros meses de amostragem.

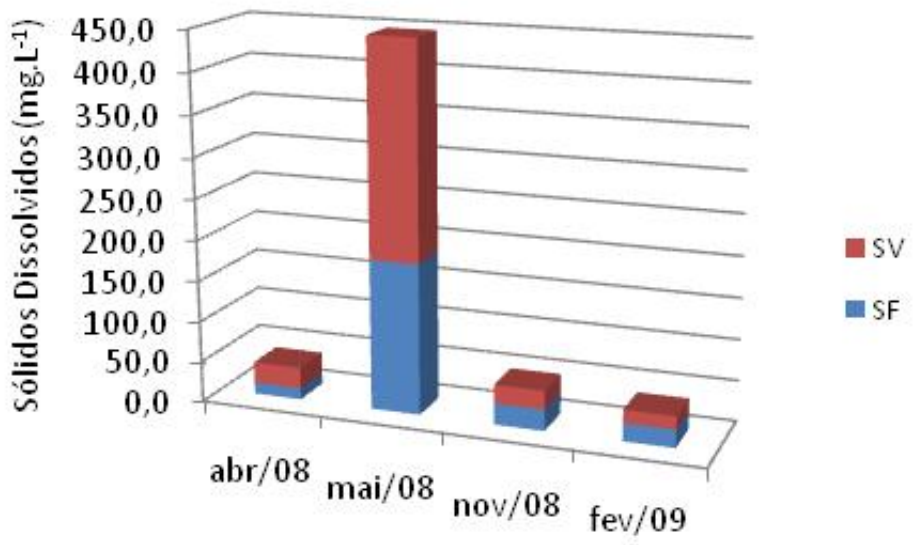

FIGURA 63 - Valores de série de sólidos dissolvidos, sólidos voláteis (SV) e sólidos fixos (SF) (mg. $\left.\mathrm{L}^{-1}\right)$ no ponto de amostragem 05. 
A composição da comunidade fitoplanctônica esteve constituída por 8 classes. As classes mais representativas foram Chlorophyceae, que apresentou maior riqueza, contribuindo com 34\% do total, seguida por Cyanophyceae com $34 \%$ e Bacillariophyceae, Zygnemaphyceae e Euglenophyceae com 7\%, como apresentado na FIG. 64.

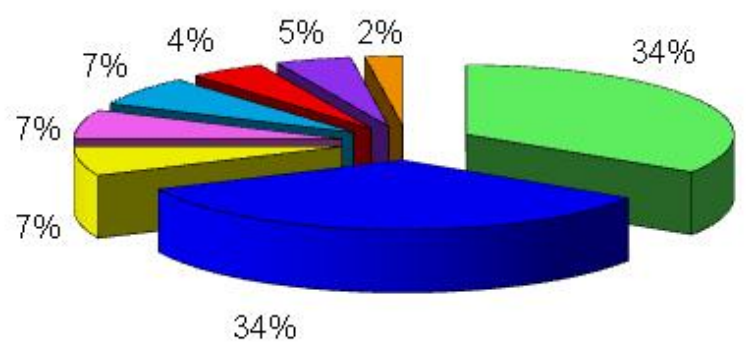

\begin{tabular}{|c|c|}
\hline 口CHLOROPHYCEAE & -CYANOPHYCEAE \\
\hline 口BACILLARIOPHYCEAE & 口ZYGNEMAPHYCEAE \\
\hline 口EUGLENOPHYCEAE & 口CHRYSOPHYCEAE \\
\hline QDINOPHYCEAE & 口CRYPTOPHYCEAE \\
\hline
\end{tabular}

FIGURA 64 - Composição da comunidade fitoplanctônica, do ponto de amostragem 05, durante o período de estudo.

O nitrato apresentou um acréscimo nos valores do mês de nov/08, 0,91 $\mathrm{mg} \cdot \mathrm{L}^{-1}$, em relação aos outros meses (abr/08, 0,50 mg. $\mathrm{L}^{-1}$, mai/08, 0,64 mg. $\mathrm{L}^{-1}$ ) decrescendo para 0,10 mg.L ${ }^{-1}$ em fev/09 (FIG. 65).

As concentrações de sulfato e fluoreto apresentaram pouca variação de amplitude entre os meses amostrados. Já as concentrações de cloreto demostraram aumento no mês de nov/08 e leve queda em fev/09 (FIG. 65). 


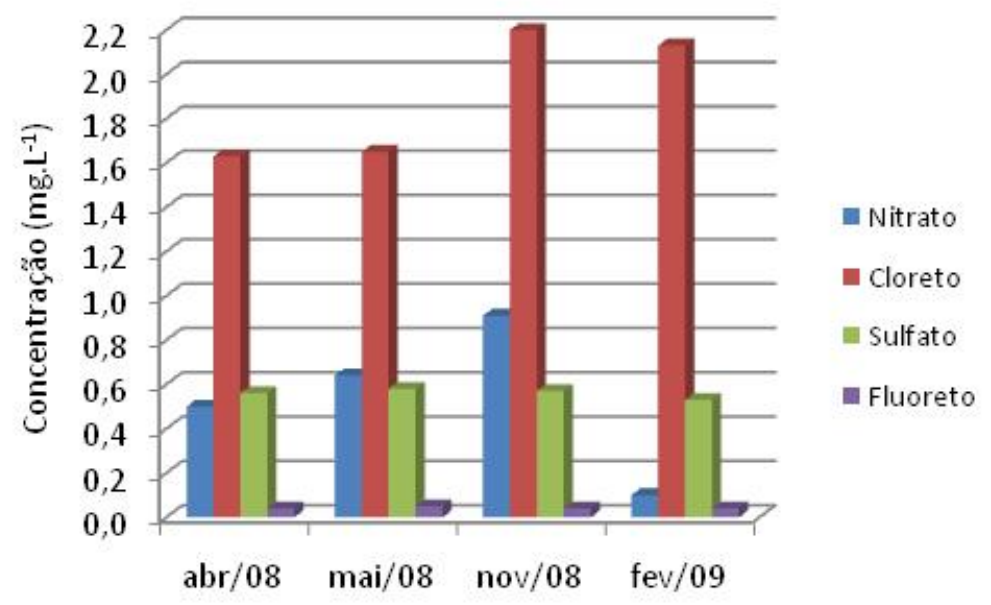

FIGURA 65- Concentração de nitrato, cloreto, sulfato e fluoreto $\left(\mathrm{mg}^{-\mathrm{L}^{-1}}\right)$ no ponto de amostragem 05.

As classificações referentes ao índice de estado trófico (IET), calculado segundo as concentrações de fósforo total, para o ponto de amostragem 05 , durante o período de estudo estão apresentadas na FIG. 66.

Da mesma forma que o ponto 04 , no mês de abr/08, nov/08 e fev/09 o ponto 05 foi classificado como oligotrófico, enquanto que no mês de mai/08 foi classificado como mesotrófico.

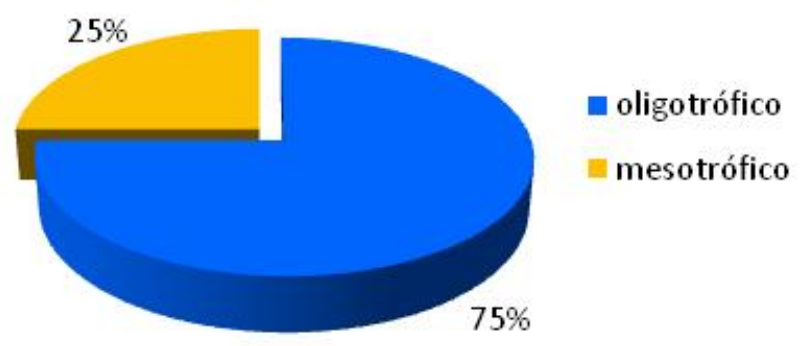

FIGURA 66 - Proporção das classificações do Índice de Estado Trófico (IET), no ponto de amostragem 05 , durante o período de estudo. 


\subsubsection{Ponto de amostragem 06}

O ponto de amostragem 06 localiza-se à leste da represa Paraibuna, próximo à estação da balsa de Natividade da Serra, recebendo maior contribuição de volume de água diretamente do Ribeirão Manso e do Ribeirão do Peixe que, neste local, faz a junção com o Rio Paraibuna. A balsa de travessia entre os municípios de Paraibuna e Natividade da Serra transporta pessoas e automóveis, operando de hora em hora. Praticamente é inexistente mata ciliar no entorno deste ponto de amostragem, como apresentado nas FIG. 67 e FIG. 68.

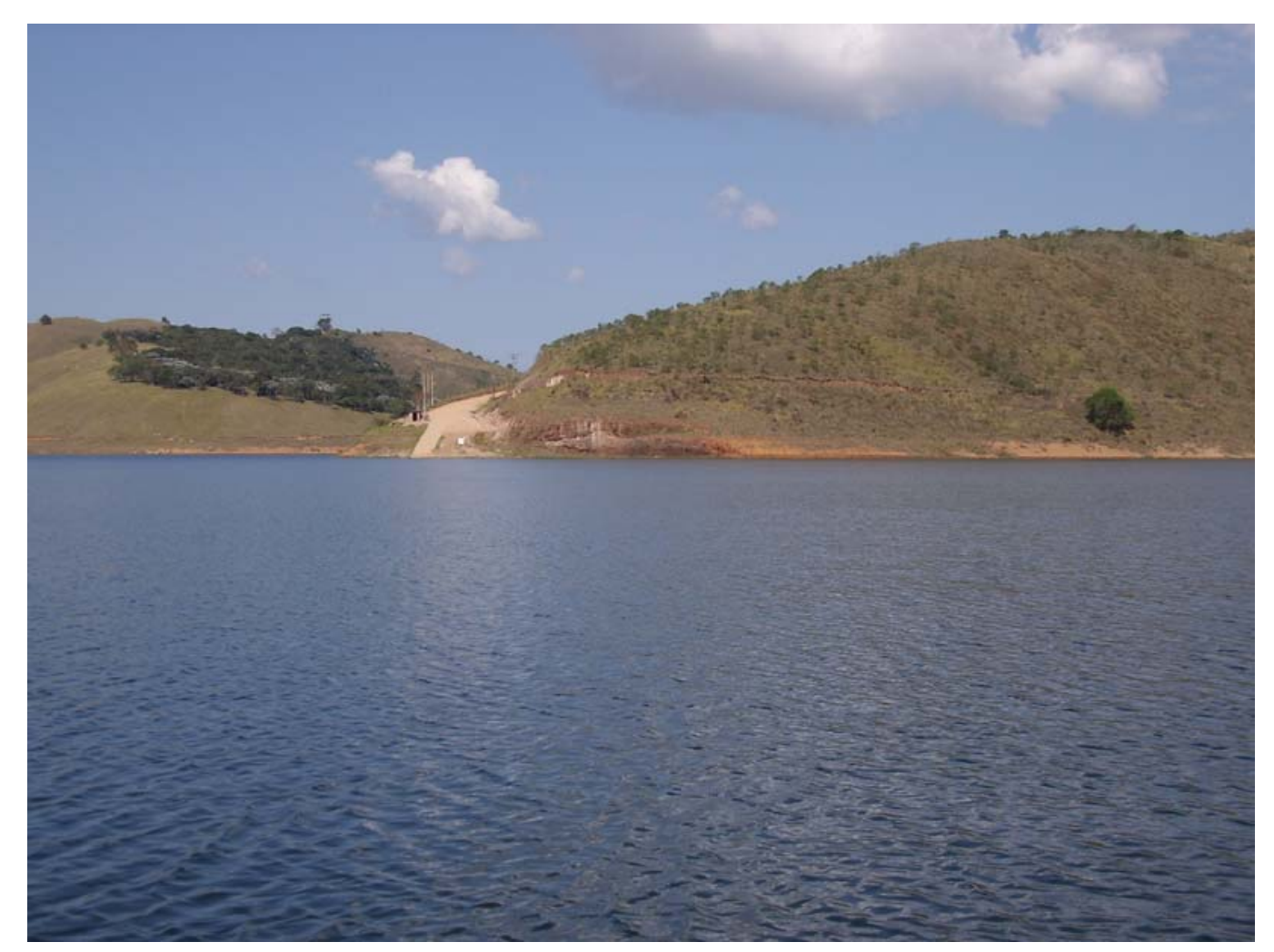

FIGURA 67 - Área próxima ao ponto de amostragem 06, inexistência de mata ciliar. 


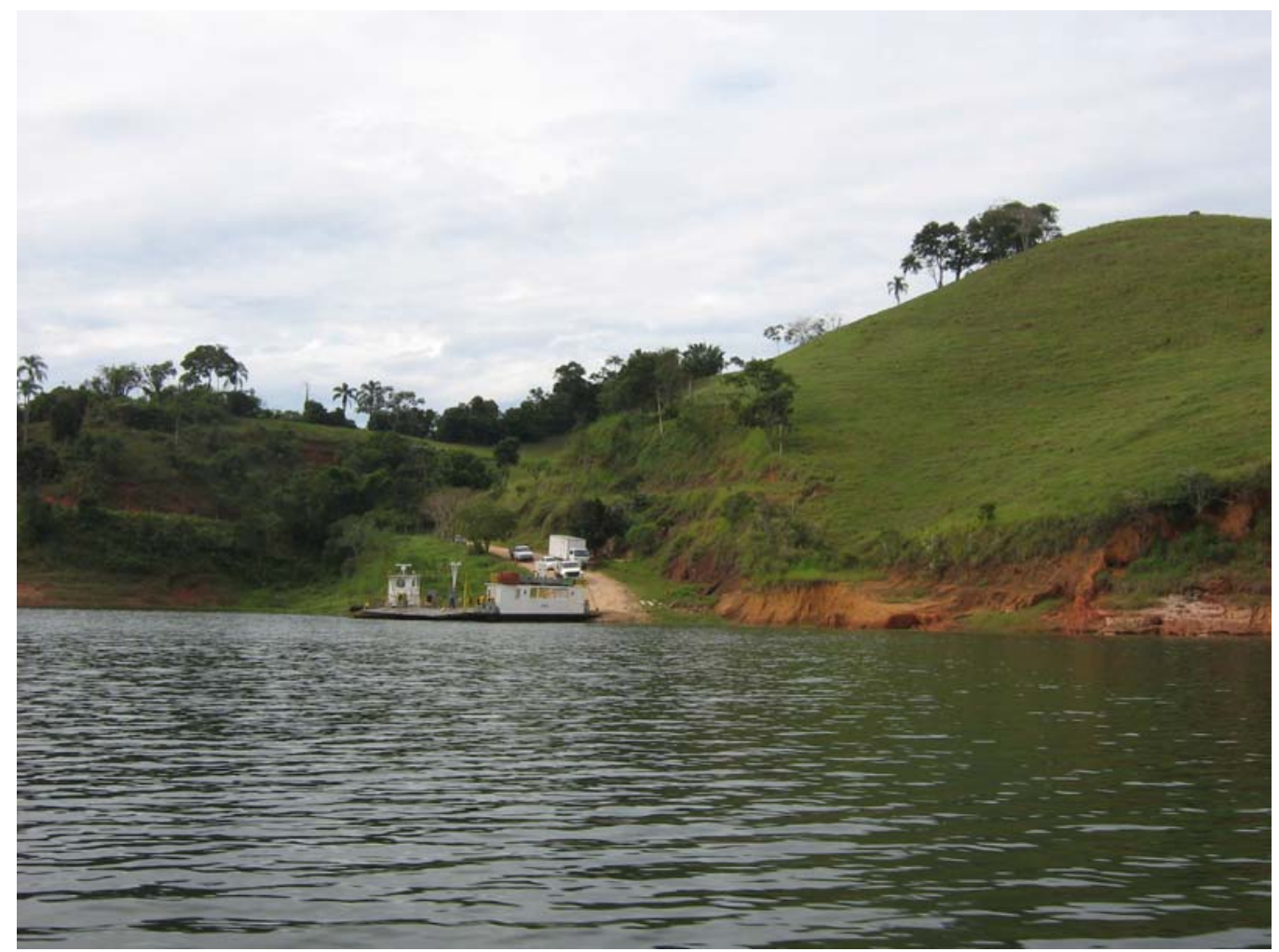

FIGURA 68 - Área próxima ao ponto de amostragem 06, balsa de travessia entre Paraibuna e Natividade da Serra.

Neste ponto, ocorreram níveis baixos de densidade fitoplanctônica, nos meses de abr/08 e mai/08, com aumento de até 40 vezes, nos meses de nov/08 e fev/09, época da primavera/verão, com temperaturas mais elevadas, fato esperado para a densidade fitoplanctônica (TAB. 27 e FIG. 69) no período chuvoso e mais quente, porém não verificou-se o decréscimo de OD (FIG. 70), nem a tendência de aumento da turbidez e diminuição da transparência (FIG. 71).

Este ponto recebe maior contribuição orgânica, provavelmente advinda do Rio Paraitinga, por ser este o corpo receptor da carga poluidora do município de São Luiz do Paraitinga.

TABELA 27 - Valor médio, máximo e mínimo, desvio padrão e coeficiente de variação da densidade fitoplanctônica (org. $\mathrm{mL}^{-1}$ ) no ponto 06 durante o período de estudo

\begin{tabular}{lr}
\hline Média & 803 \\
Máximo & 1849 \\
Mínimo & 38 \\
DP & 860,78 \\
Coef. Var. (\%) & 107,24 \\
\hline
\end{tabular}




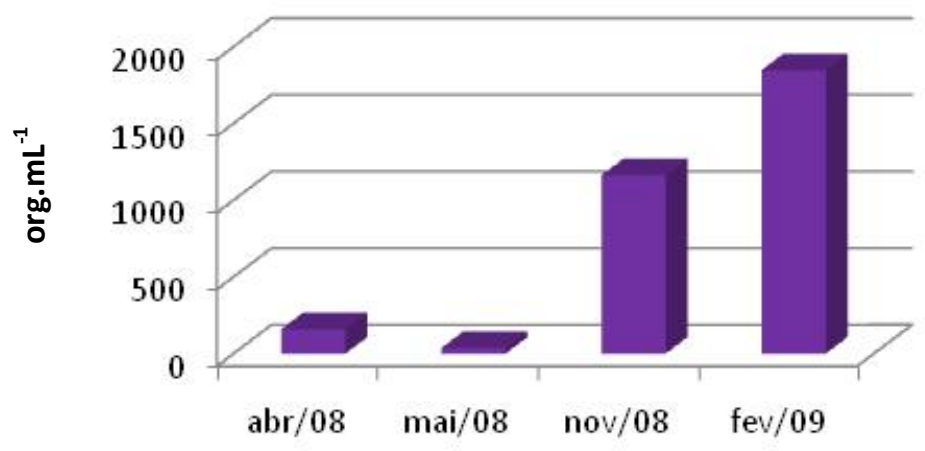

FIGURA 69 - Densidades totais da comunidade fitoplanctônica (org. $\mathrm{mL}^{-1}$ ) no ponto de amostragem 06 .

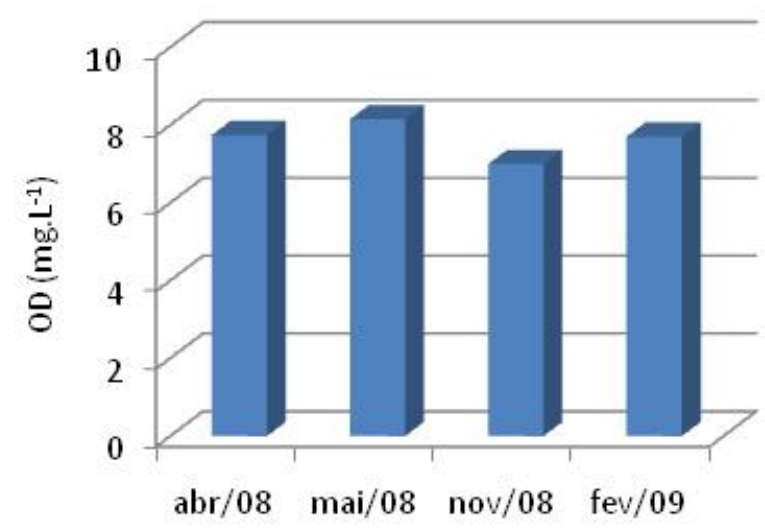

FIGURA 70 - Valores de oxigênio dissolvido $\left(\mathrm{mg} \cdot \mathrm{L}^{-1}\right)$ no ponto de amostragem 06.

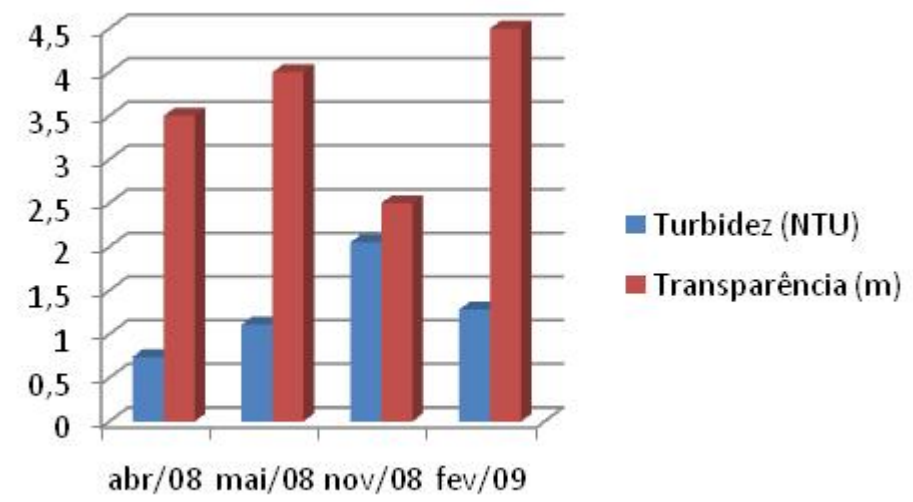

FIGURA 71 - Valores de turbidez (NTU) e transparência (m) no ponto de amostragem 06. 
A composição da comunidade fitoplanctônica esteve constituída por 8 classes. As classes mais representativas foram Chlorophyceae, que apresentou maior riqueza, contribuindo com 33\% do total, seguida por Cyanophyceae com $27 \%$ e Bacillariophyceae e Euglenophyceae com 10\%, como apresentado na FIG. 72.

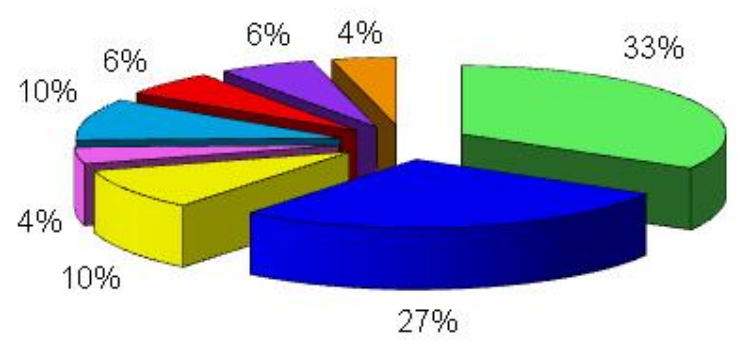

\begin{tabular}{|c|c|}
\hline 口CHLOROPHYCEAE & -CYANOPHYCEAE \\
\hline 口BACILLARIOPHYCEAE & 口ZYGNEMAPHYCEAE \\
\hline 口EUGLENOPHYCEAE & 口CHRYSOPHYCEAE \\
\hline 口DINOPHYCEAE & 口CRYPTOPHYCEAE \\
\hline
\end{tabular}

FIGURA 72 - Composição da comunidade fitoplanctônica, do ponto de amostragem 06 , durante o período de estudo.

Frações de sólidos voláteis mostraram valores acima das frações de sólidos fixos durante os meses de abr/08, mai/08 e fev/09 (FIG. 73). Em nov/08 a porção fixa mostrou valores acima da porção volátil.

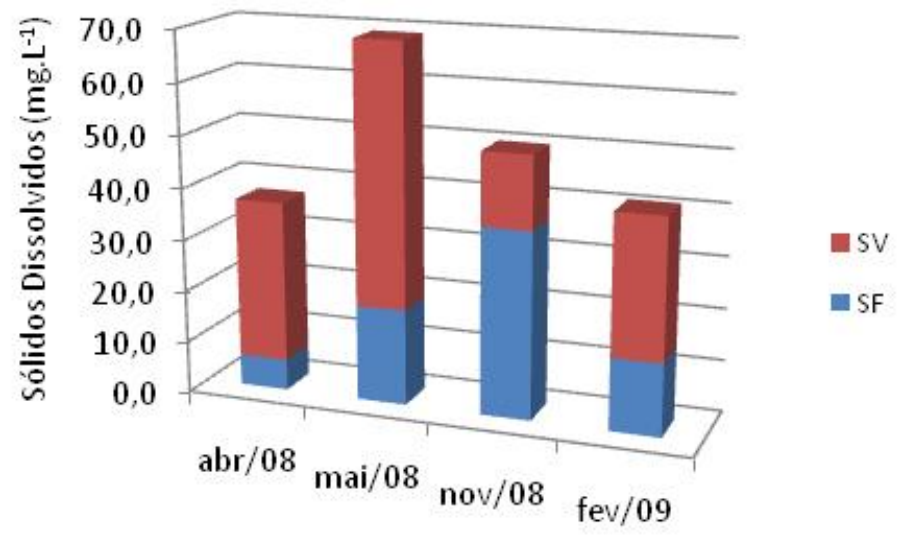

FIGURA 73 - Valores de série de sólidos dissolvidos, sólidos voláteis (SV) e sólidos fixos (SF) (mg. $\left.\mathrm{L}^{-1}\right)$ no ponto de amostragem 06. 
O nitrato apresentou um acréscimo nos valores do mês de nov/08, 0,48 $\mathrm{mg} \cdot \mathrm{L}^{-1}$, em relação aos outros meses (abr/08, 0,29 mg. $\mathrm{L}^{-1}$, mai/08, 0,32 mg. $\mathrm{L}^{-1}$ ) decrescendo para 0,23 mg.L-1 em fev/09 (FIG. 74).

As concentrações de sulfato e fluoreto apresentaram pouca variação de amplitude entre os meses amostrados. Já as concentrações de cloreto demostraram aumento gradual, neste ponto, durante o período de estudo (FIG. 74).

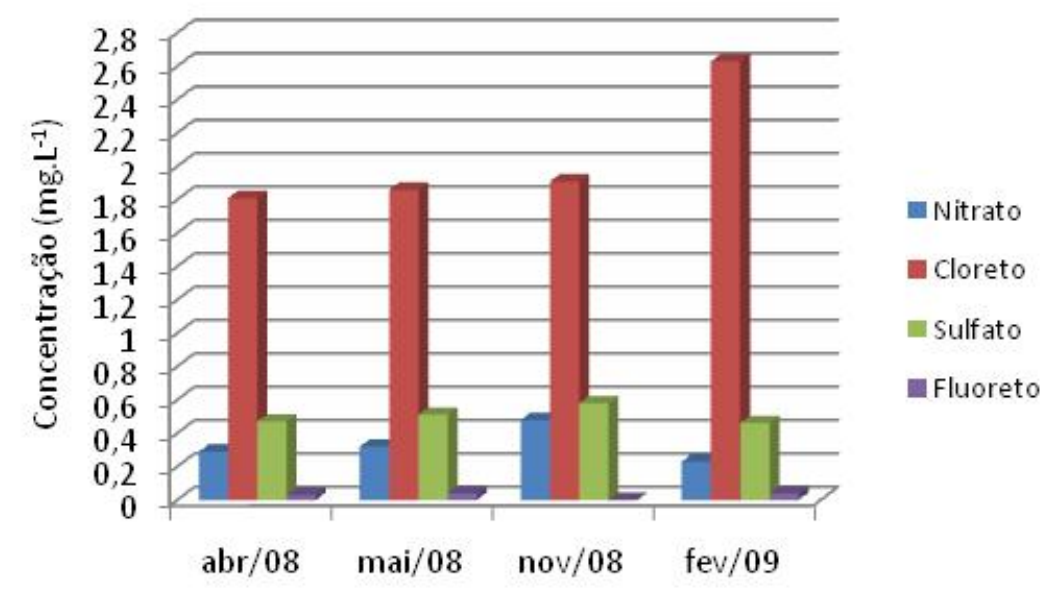

FIGURA 74 - Concentração de nitrato, cloreto, sulfato e fluoreto (mg. $\mathrm{L}^{-1}$ ) no ponto de amostragem 06.

As classificações referentes ao índice de estado trófico (IET), calculado segundo as concentrações de fósforo total, para o ponto de amostragem 06 , durante o período de estudo estão apresentadas na FIG. 75.

O mês de abr/08, foi o único período no qual o ponto 06 foi classificado como mesotrófico, enquanto que nos meses de mai/08, nov/08 e fev/09 o ponto foi classificado como oligotrófico.

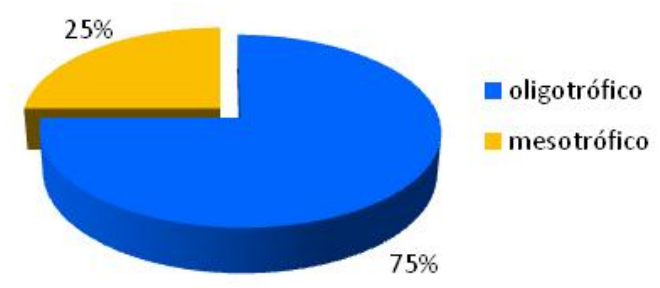

FIGURA 75 - Proporção das classificações do Índice de Estado Trófico (IET), no ponto de amostragem 06, durante o período de estudo. 


\subsubsection{Ponto de amostragem 07}

O ponto de amostragem 07 localiza-se, na Represa Paraibuna, ao norte do ponto de amostragem 06. Localiza-se também próximo à estação da balsa de Natividade da Serra, e recebe maior contribuição de volume de água diretamente do Ribeirão Manso, do Ribeirão Selado e do Ribeirão do Peixe que, neste local, faz a junção com o Rio Paraibuna. No entorno deste ponto observouse a presença de pastagens e atividade pecuária (FIG. 76).

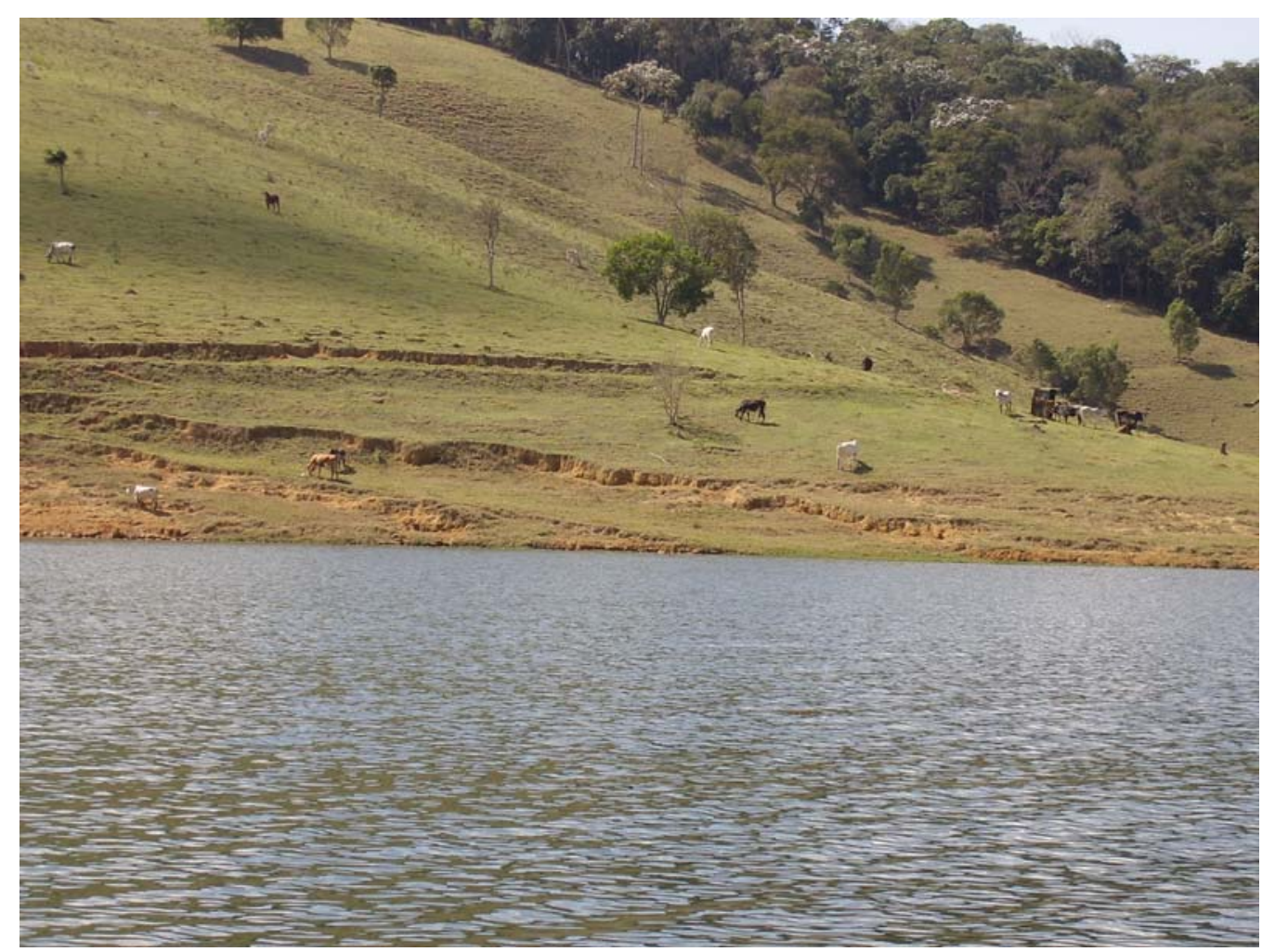

FIGURA 76 - Área próxima ao ponto de amostragem 07, com pastagens e gado.

Neste ponto, ocorreu aumento na densidade fitoplanctônica, durante os meses de estudo. Houve aumento de até 30 vezes, entre os meses de abr/08 e fev/09. As temperaturas mais elevadas, dos meses mais quentes e chuvosos influencia a densidade fitoplanctônica (TAB. 28 e FIG.77), porém não verificou-se o decréscimo de OD (FIG. 78), nem a tendência de aumento da turbidez e diminuição da transparência, observada apenas no mês de nov/08 (FIG. 79).

Este ponto, assim como o ponto 06, recebe maior contribuição orgânica, advinda do Rio Paraitinga, por ser este o corpo receptor da carga orgânica poluidora do município de São Luiz do Paraitinga. 
TABELA 28 - Valor médio, máximo e mínimo, desvio padrão e coeficiente de variação da densidade fitoplanctônica (org. $\mathrm{mL}^{-1}$ ) no ponto 07 durante o período de estudo

\begin{tabular}{lr}
\hline Média & 1993 \\
Máximo & 4360 \\
Mínimo & 129 \\
DP & 2033,72 \\
Coef. Var. (\%) & 102,06 \\
\hline
\end{tabular}

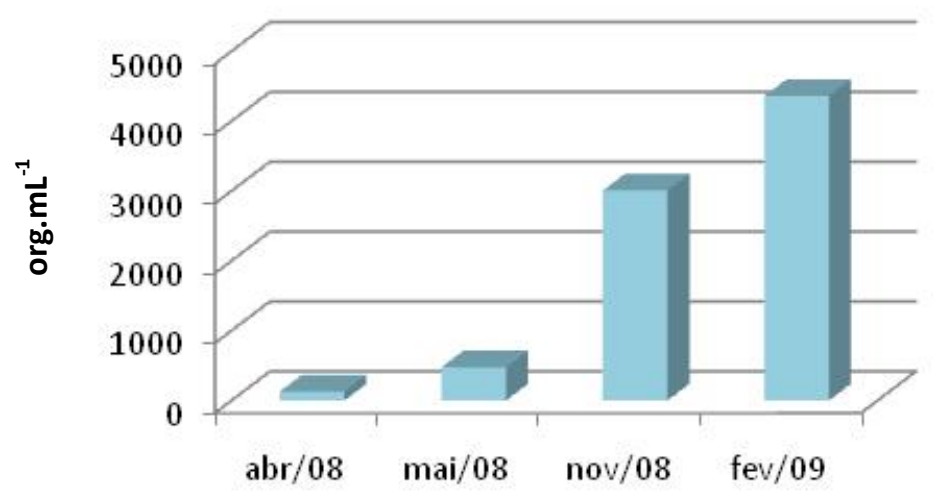

FIGURA 77 - Densidades totais da comunidade fitoplanctônica (org. $\mathrm{mL}^{-1}$ ) no ponto de amostragem 07.

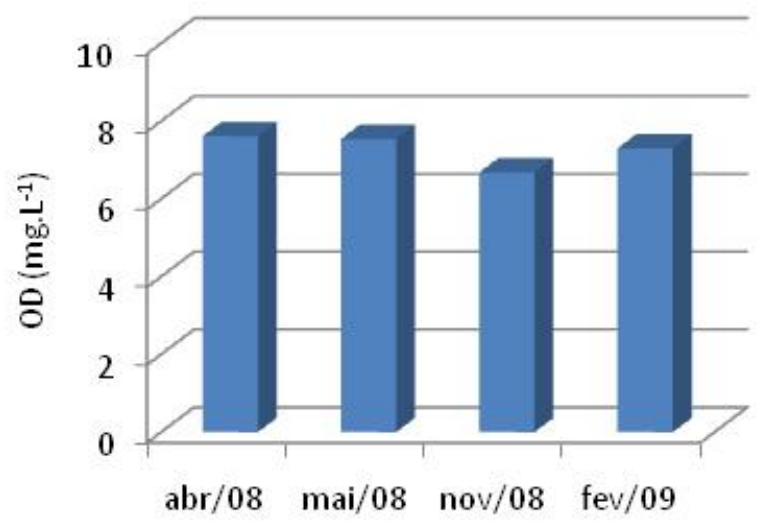

FIGURA 78 - Valores de oxigênio dissolvido $\left(\mathrm{mg} \cdot \mathrm{L}^{-1}\right)$ no ponto de amostragem 07. 


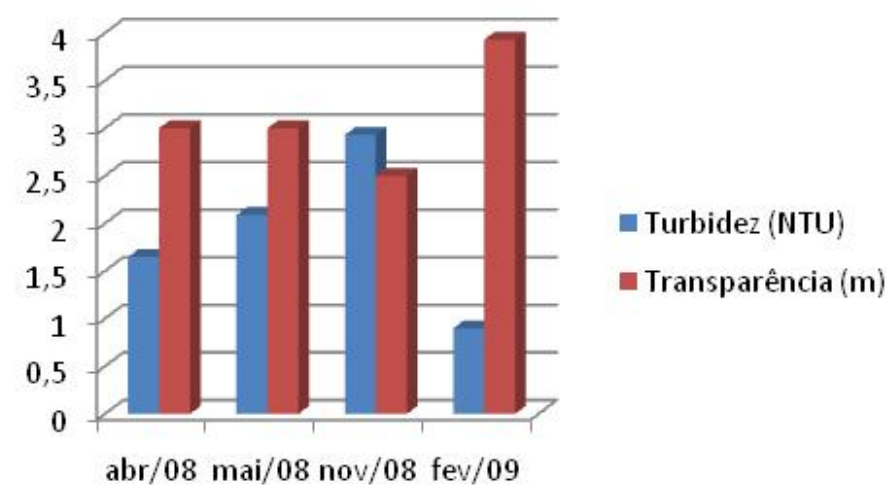

FIGURA 79 - Valores de turbidez (NTU) e transparência (m) no ponto de amostragem 07.

A composição da comunidade fitoplanctônica esteve constituída por 8 classes. As classes mais representativas foram Chlorophyceae, que apresentou maior riqueza, contribuindo com $33 \%$ do total, seguida por Cyanophyceae com 18\% e Bacillariophyceae com 15\%, como apresentado na FIG. 80.

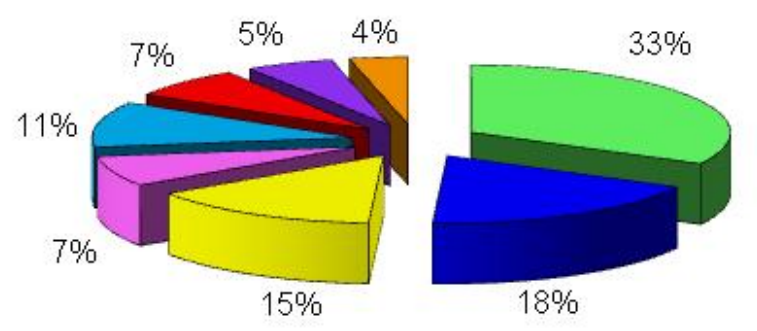

\begin{tabular}{|c|c|}
\hline 口CHLOROPHYCEAE & -CYANOPHYCEAE \\
\hline 口BACILLARIOPHYCEAE & 口ZYGNEMAPHYCEAE \\
\hline 口EUGLENOPHYCEAE & 口CHRYSOPHYCEAE \\
\hline 口DINOPHYCEAE & 口CRYPTOPHYCEAE \\
\hline
\end{tabular}

FIGURA 80 - Composição da comunidade fitoplanctônica, do ponto de amostragem 07 , durante o período de estudo.

Frações de sólidos voláteis mostraram valores acima das frações de sólidos fixos durante os meses de abr/08, mai/08 e nov/08 (FIG. 81). Apenas em fev/09 as porções fixa e volátil contribuiram com proporções idênticas para o valor dos sólidos dissolvidos totais. 


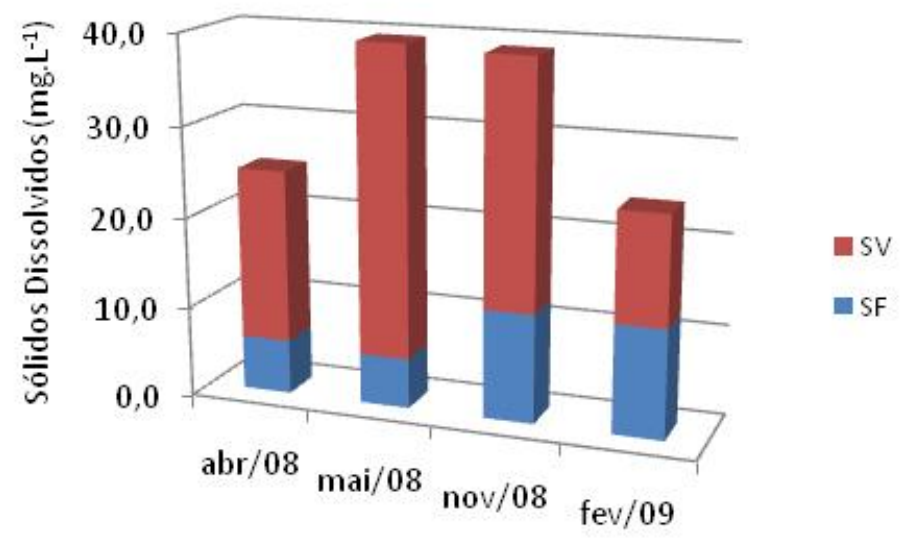

FIGURA 81 - Valores de série de sólidos dissolvidos, sólidos voláteis (SV) e sólidos fixos (SF) (mg. $\left.\mathrm{L}^{-1}\right)$ no ponto de amostragem 07.

O nitrato apresentou um acréscimo nos valores dos meses de mai/08 e nov/08, em relação aos meses de abr/08 e fev/09 (FIG. 82).

As concentrações de sulfato e fluoreto apresentaram pouca variação de amplitude entre os meses amostrados. Já as concentrações de cloreto demonstraram aumento gradual, neste ponto, durante o período de estudo (FIG. 82).

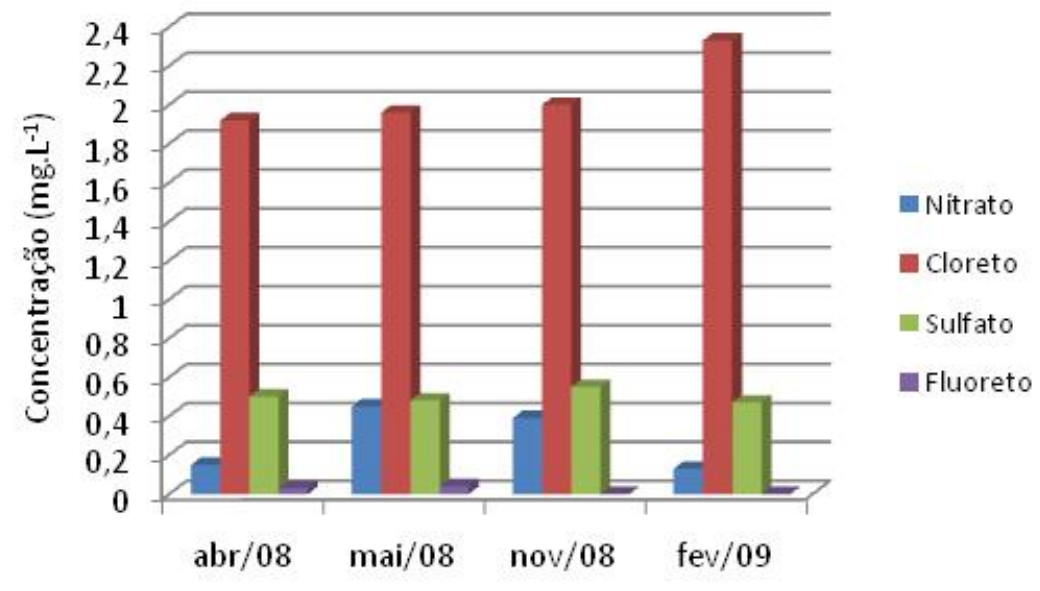

FIGURA 82 - Concentração de nitrato, cloreto, sulfato e fluoreto $\left(\mathrm{mg} \cdot \mathrm{L}^{-1}\right)$ no ponto de amostragem 07.

As classificações referentes ao índice de estado trófico (IET), calculado segundo as concentrações de fósforo total, para o ponto de amostragem 07 , durante o período de estudo estão apresentadas na FIG. 83. 
Este ponto apresentou classificação mesotrófica em abr/08 e mai/08 e oligotrófica em nov/08 e fev/09.

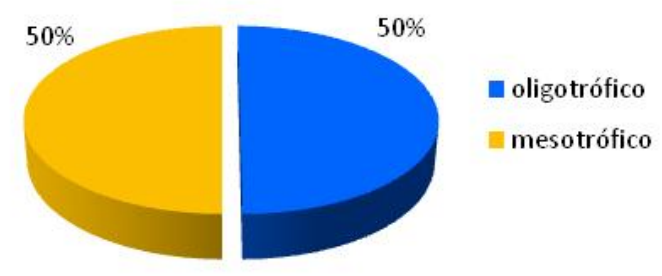

FIGURA 83 - Proporção das classificações do Índice de Estado Trófico (IET), no ponto de amostragem 07 , durante o período de estudo.

\subsubsection{Ponto de amostragem 08}

O ponto de amostragem 08 localiza-se na interligação da represa Paraibuna com a represa Paraitinga, próximo à estação da balsa que trafega entre Paraibuna e Natividade da Serra, e recebe maior contribuição de volume de água diretamente do Rio Paraibuna e do Rio Lourenço Velho. Neste ponto, a CESP mantém um porto para entrada e saída de suas embarcações nas represas. No entorno deste ponto observou-se a presença de público banhista e pescadores. (FIG. 84 e FIG. 85). 


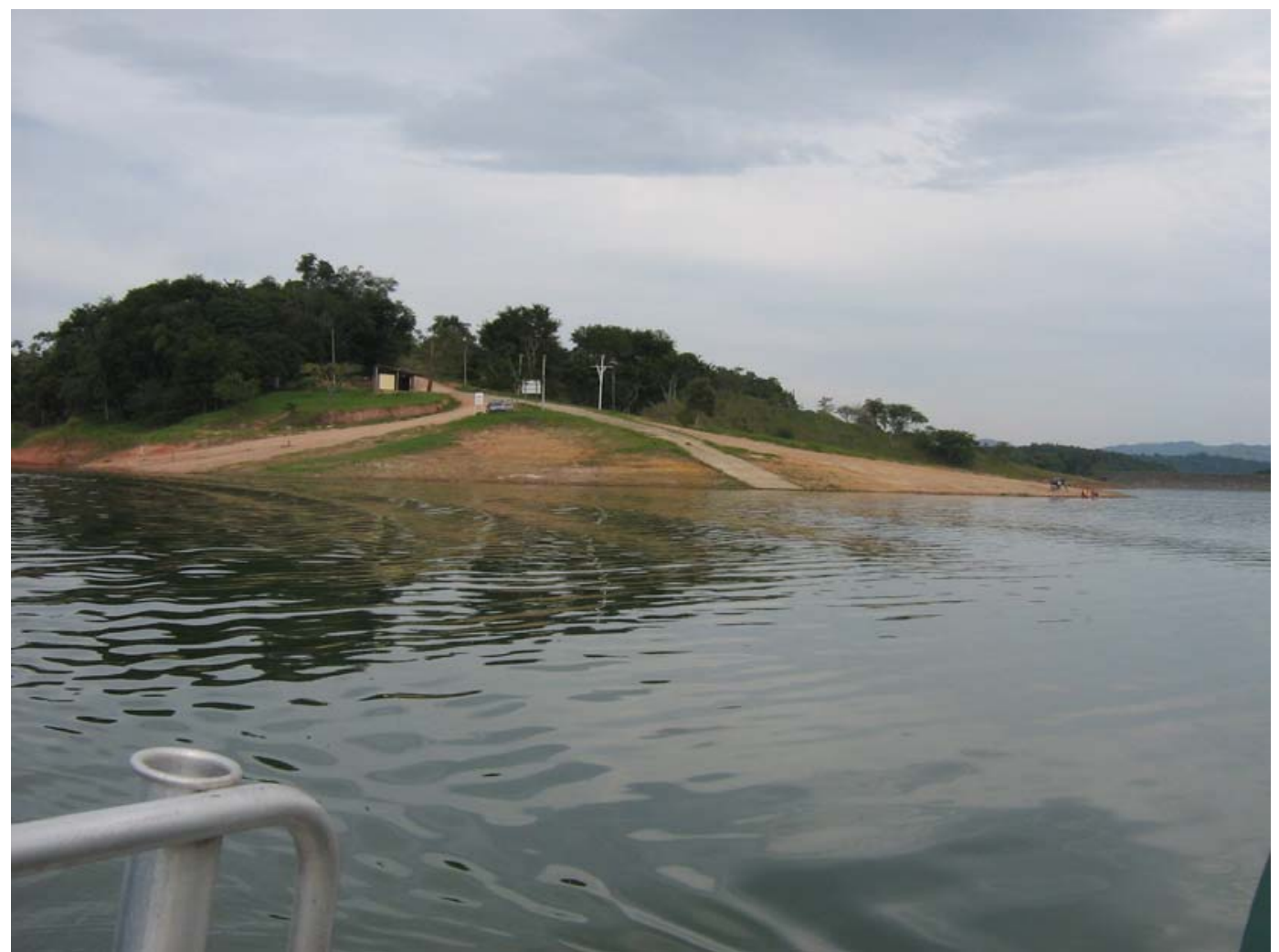

FIGURA 84 - Área próxima ao ponto de amostragem 08, porto da CESP, estação a balsa para Natividade da Serra.

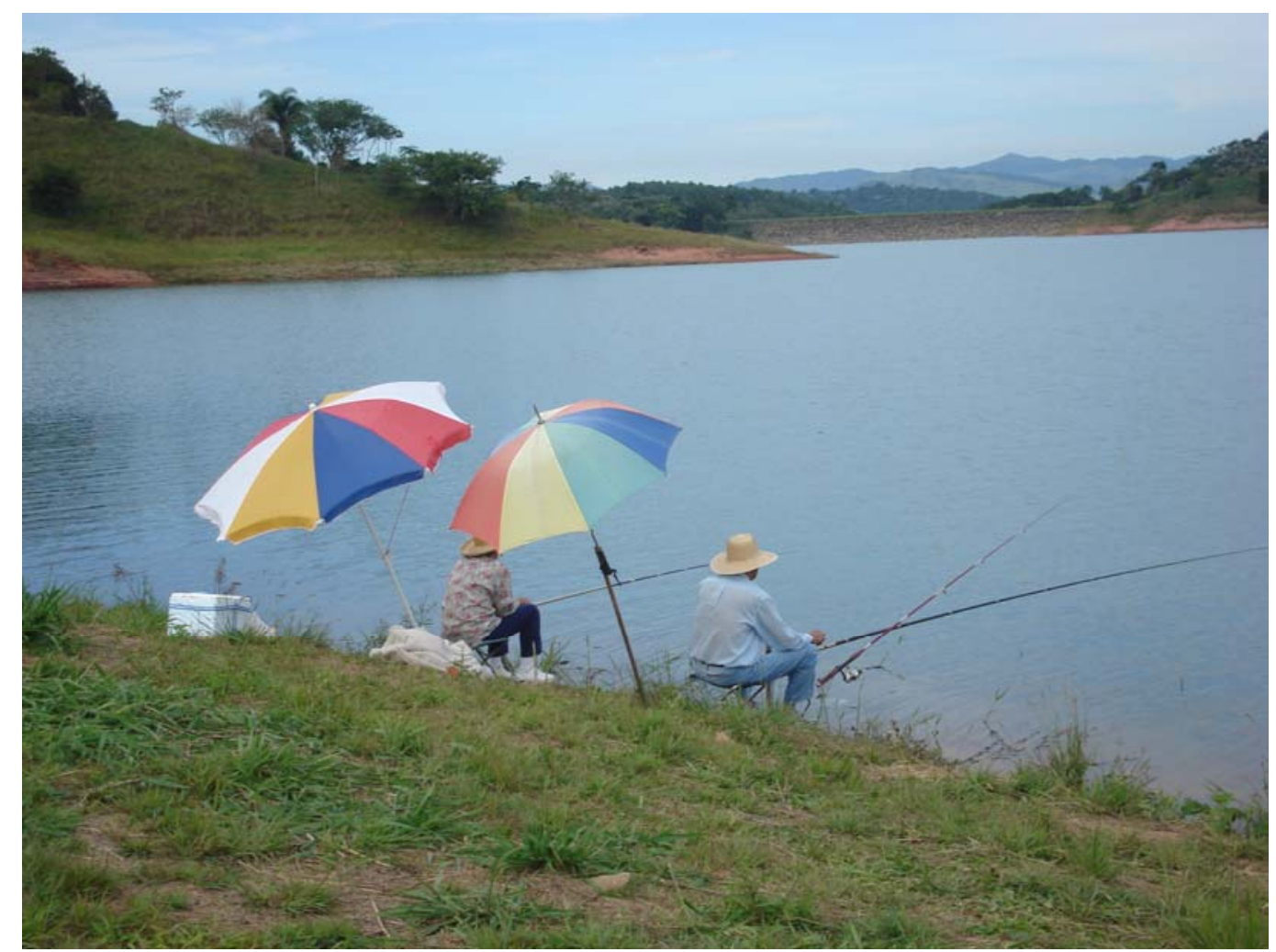

FIGURA 85 - Área próxima ao ponto de amostragem 08, porto da CESP, presença de pescadores. 
Neste ponto, ocorreu progressivo aumento na densidade fitoplanctônica, durante os meses de estudo. As temperaturas mais elevadas, dos meses mais quentes e chuvosos influencia a densidade fitoplanctônica, juntamente com leve decréscimo dos valores de OD (TAB. 29, FIG. 86 e FIG. 87).

Este ponto, assim como o ponto 06, recebe maior contribuição orgânica, advinda do Rio Paraitinga e Rio Paraibuna, por ser estes os corpos receptores da carga orgânica poluidora dos municípios de São Luiz do Paraitinga e Paraibuna, respectivamente.

TABELA 29 - Valor médio, máximo e mínimo, desvio padrão e coeficiente de variação da densidade fitoplanctônica (org. $\mathrm{mL}^{-1}$ ) no ponto 08 durante o período de estudo

\begin{tabular}{lr}
\hline Média & 659 \\
Máximo & 1818 \\
Mínimo & 47 \\
DP & 801,57 \\
Coef. Var. (\%) & 121,67 \\
\hline
\end{tabular}

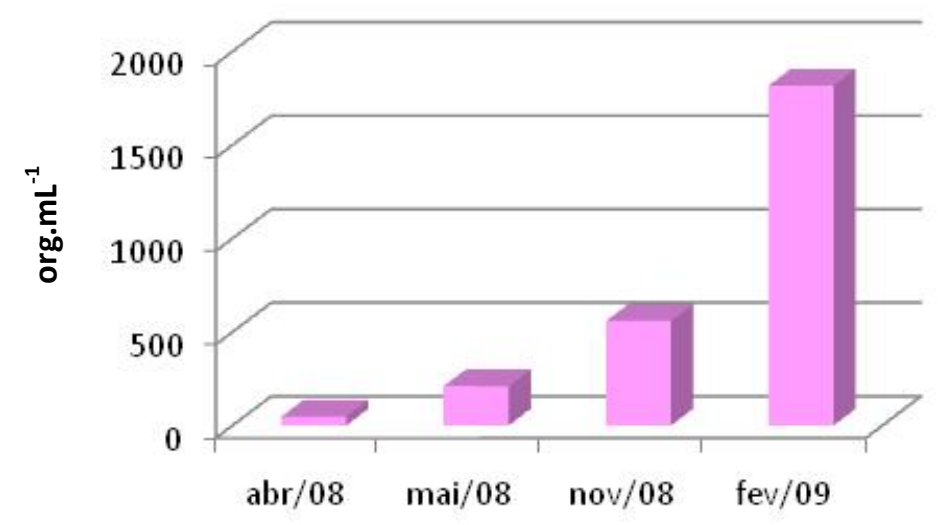

FIGURA 86 - Densidades totais da comunidade fitoplanctônica (org. $\mathrm{mL}^{-1}$ ) no ponto de amostragem 08. 


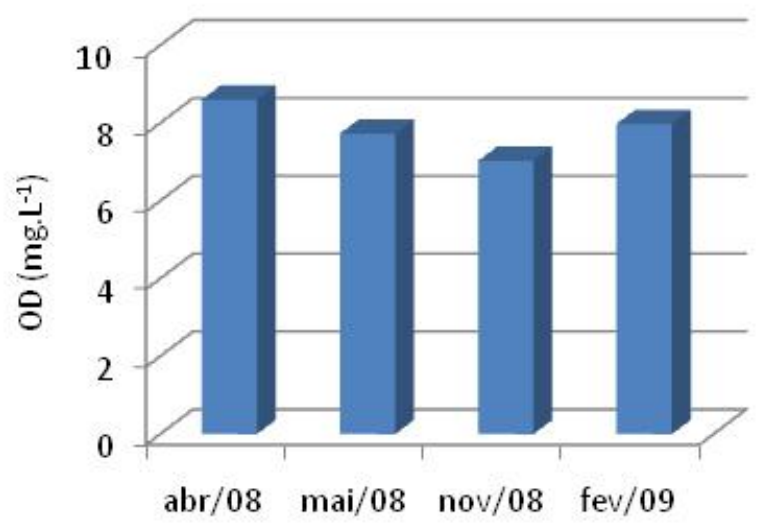

FIGURA 87 - Valores de oxigênio dissolvido $\left(\mathrm{mg}^{\mathrm{L}} \mathrm{L}^{-1}\right)$ no ponto de amostragem 08.

A composição da comunidade fitoplanctônica esteve constituída por 7 classes. As classes mais representativas foram Chlorophyceae, que apresentou maior riqueza, contribuindo com 39\% do total, seguida por Cyanophyceae com $29 \%$ e Bacillariophyceae com 16\%, como apresentado na FIG. 88.
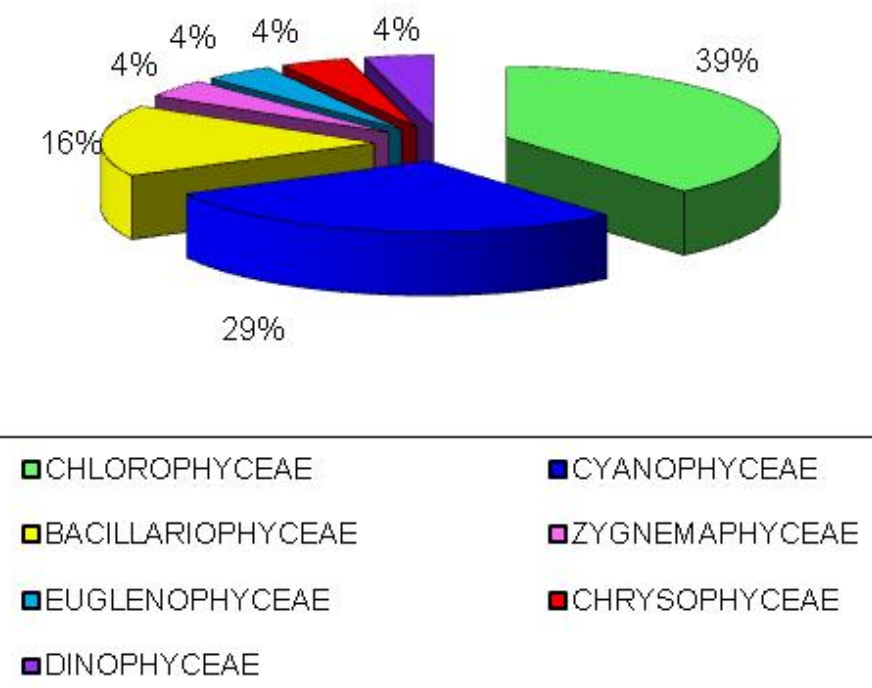

-DINOPHYCEAE

- CYANOPHYCEAE

口ZYGNEMAPHYCEAE

口CHRYSOPHYCEAE

FIGURA 88 - Composição da comunidade fitoplanctônica, do ponto de amostragem 08 , durante o período de estudo.

Em mai/08, ocorreu pronunciado aumento da turbidez, acompanhado pelos maiores valores de sólidos dissolvidos totais (FIG. 89 e FIG. 90), relação não observada no mês de fev/09. 


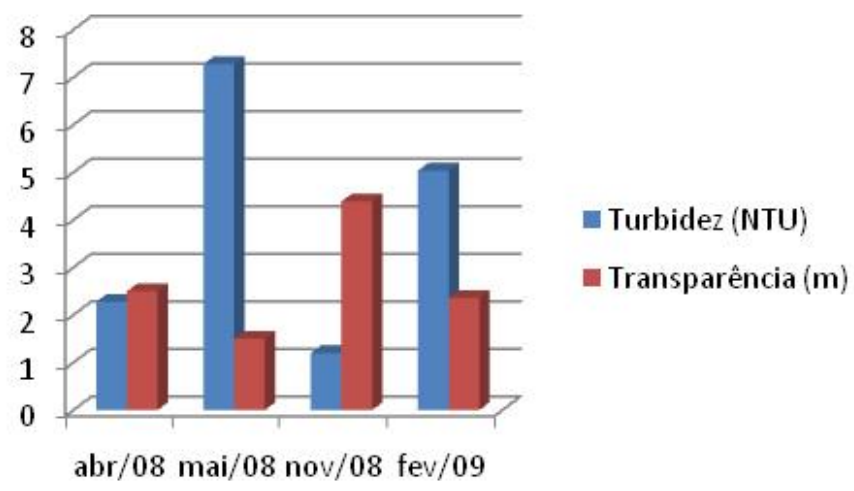

FIGURA 89 - Valores de turbidez (NTU) e transparência $(m)$ no ponto de amostragem 08.

Frações de sólidos voláteis mostraram valores acima das frações de sólidos fixos durante os quatro meses de amostragem, abr/08, mai/08, nov/08 e fev/09 (FIG. 90). Neste ponto, semelhante ao ocorrido nos pontos 02, 03, 05 e 06, mai/08 apresentou valores mais elevados de sólidos dissolvidos totais, com maior contribuição da porção volátil.

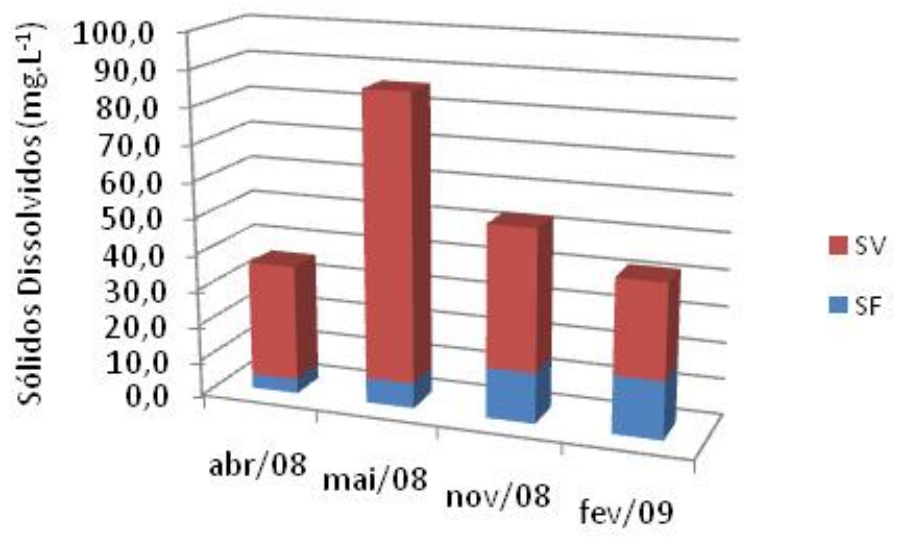

FIGURA 90 - Valores de série de sólidos dissolvidos, sólidos voláteis (SV) e sólidos fixos (SF) (mg. $\mathrm{L}^{-1}$ ) no ponto de amostragem 08.

O nitrato apresentou um acréscimo nos valores do mês de mai/08, 0,65 $\mathrm{mg} \cdot \mathrm{L}^{-1}$, em relação ao mês de abr/08, 0,44 mg. $\mathrm{L}^{-1}$, e decréscimo em nov/08, 0,48 mg. $\mathrm{L}^{-1}$ e fev/09 com 0,18 mg. $\mathrm{L}^{-1}$ (FIG. 91).

As concentrações de sulfato e fluoreto apresentaram pouca variação de amplitude entre os meses amostrados. Já as concentrações de cloreto 
demostraram aumento gradual, neste ponto, durante o período de estudo (FIG. 91).

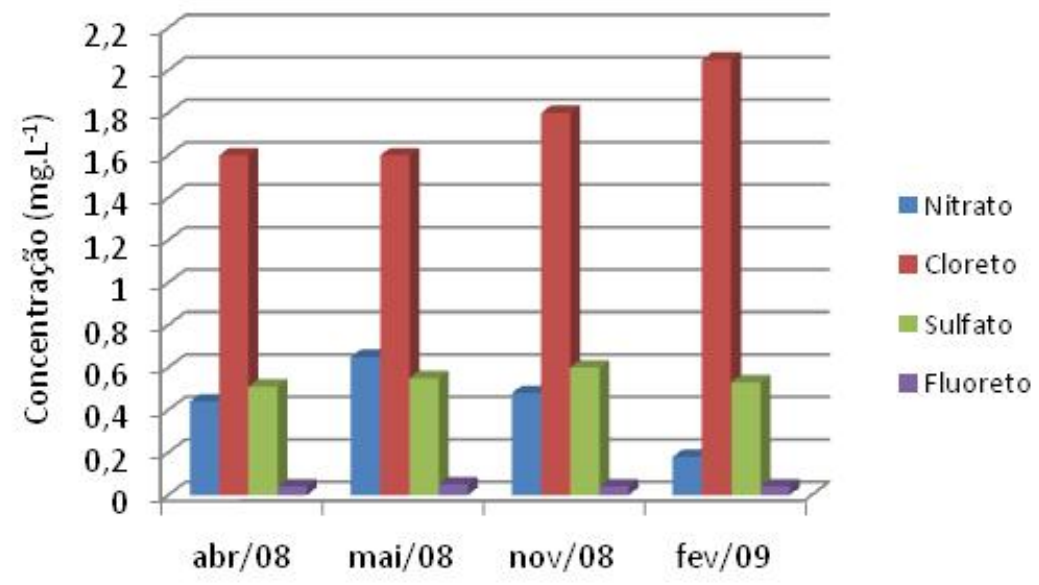

FIGURA 91 - Concentração de nitrato, cloreto, sulfato e fluoreto (mg. $\mathrm{L}^{-1}$ ) no ponto de amostragem 08.

As classificações referentes ao índice de estado trófico (IET), calculado segundo as concentrações de fósforo total, para o ponto de amostragem 08 , durante o período de estudo estão apresentadas na FIG. 92.

Da mesma forma que o ponto 07 , este ponto apresentou classificação mesotrófica em abr/08 e mai/08 e oligotrófica em nov/08 e fev/09.

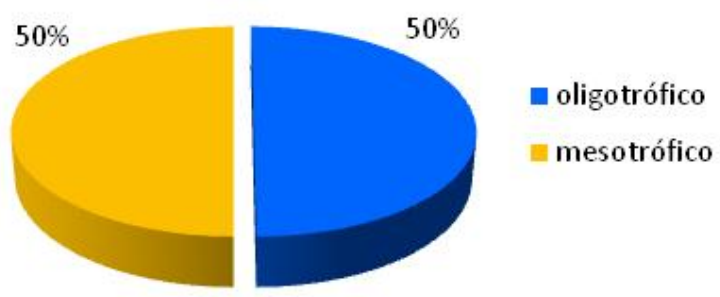

FIGURA 92 - Proporção das classificações do Índice de Estado Trófico (IET), no ponto de amostragem 08, durante o período de estudo.

\subsubsection{Ponto de amostragem 09}

O ponto de amostragem 09 localiza-se no extremo sul da represa Paraibuna, e recebe maior contribuição de volume de água diretamente do Rio 
Negro, Rio Pardo e do Rio Lourenço Velho. No entorno deste ponto observou-se áreas com mata ciliar escassa. (FIG. 93).

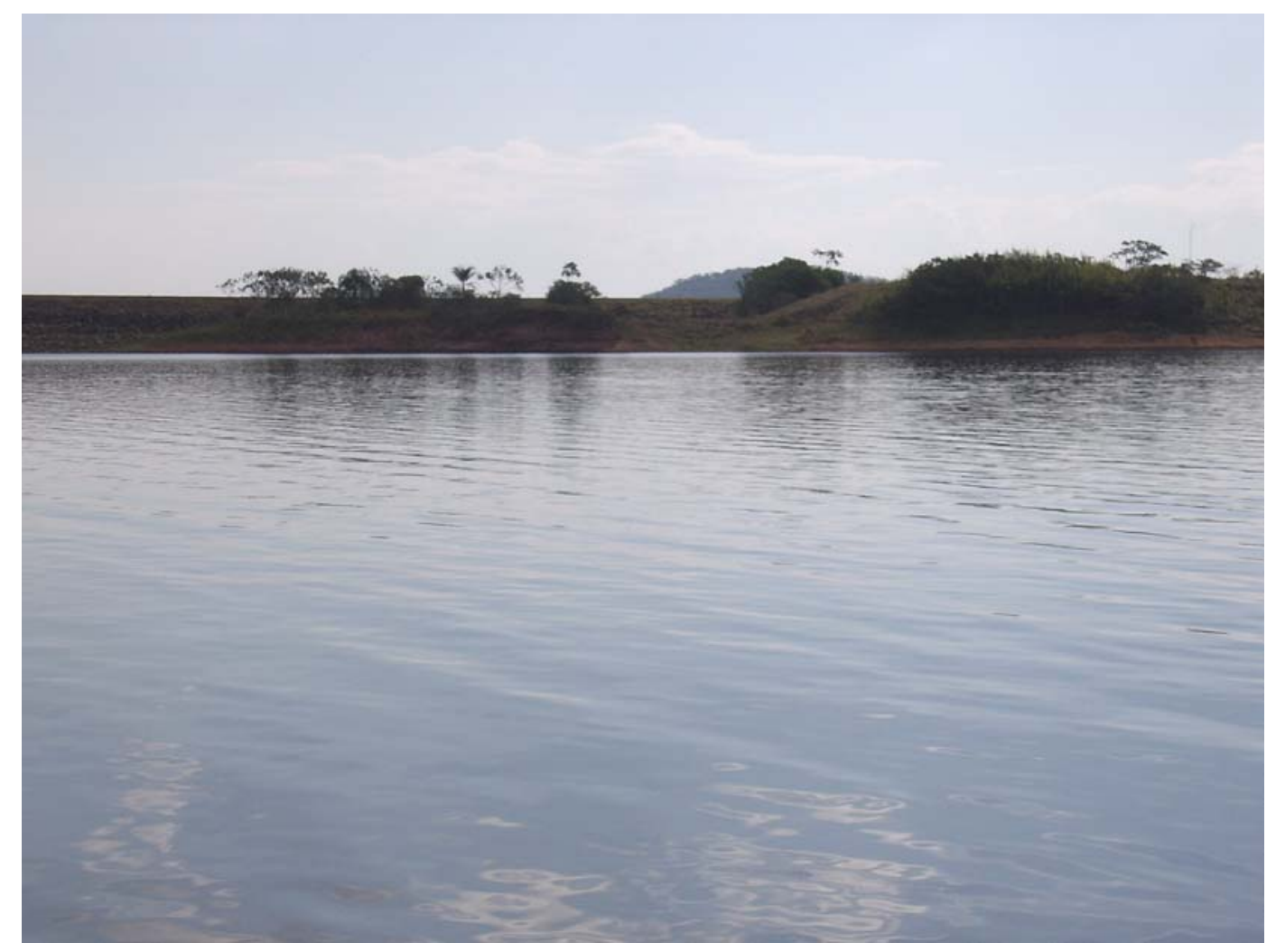

FIGURA 93 - Área próxima ao ponto de amostragem 09, escassez de mata ciliar.

No mês de Abril não houve coleta neste ponto de amostragem devido a problemas técnicos, por este motivo, gráficos e tabelas não apresentam dados relativos a este mês.

Neste ponto, ocorreu aumento na densidade fitoplanctônica, durante os meses de estudo. As temperaturas mais elevadas, dos meses mais quentes e chuvosos influenciou a densidade fitoplanctônica (TAB. 30 e FIG.94), porém não verificou-se o decréscimo de OD (FIG. 95), nem a tendência de aumento da turbidez e diminuição da transparência. (FIG. 96). 
TABELA 30 - Valor médio, máximo e mínimo, desvio padrão e coeficiente de variação da densidade fitoplanctônica (org. $\mathrm{mL}^{-1}$ ) no ponto 09 durante o período de estudo

\begin{tabular}{lr}
\hline Média & 596 \\
Máximo & 846 \\
Mínimo & 145 \\
DP & 391,81 \\
Coef. Var. (\%) & 65,71 \\
\hline
\end{tabular}

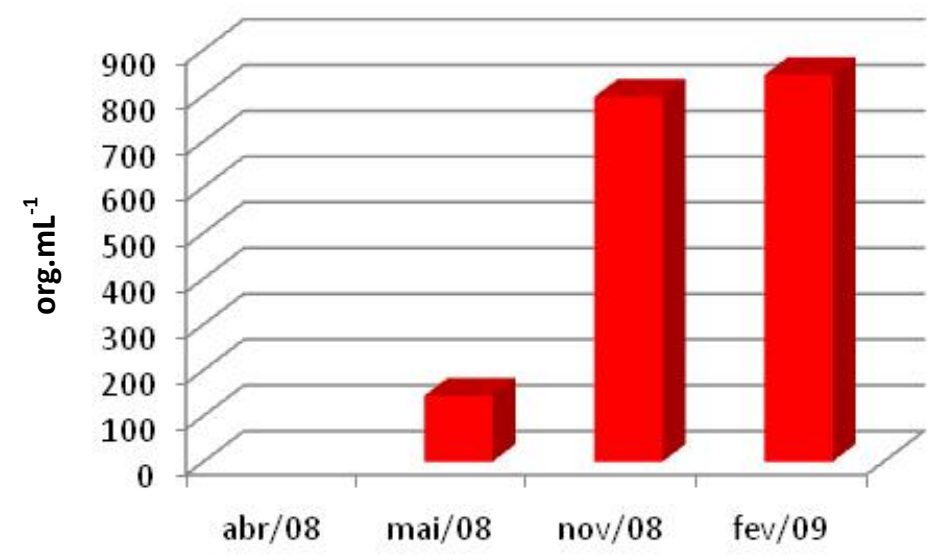

FIGURA 94 - Densidades totais da comunidade fitoplanctônica (org. $\mathrm{mL}^{-1}$ ) no ponto de amostragem 09.

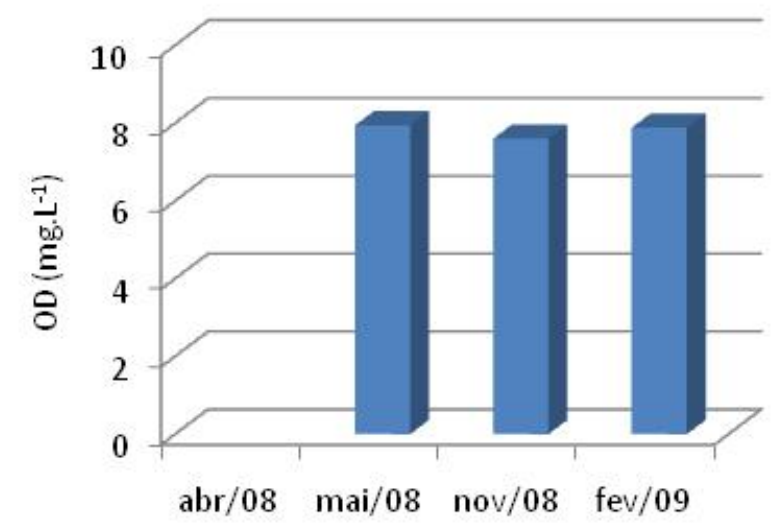

FIGURA 95 - Valores de oxigênio dissolvido $\left(\mathrm{mg} \cdot \mathrm{L}^{-1}\right)$ no ponto de amostragem 09. 


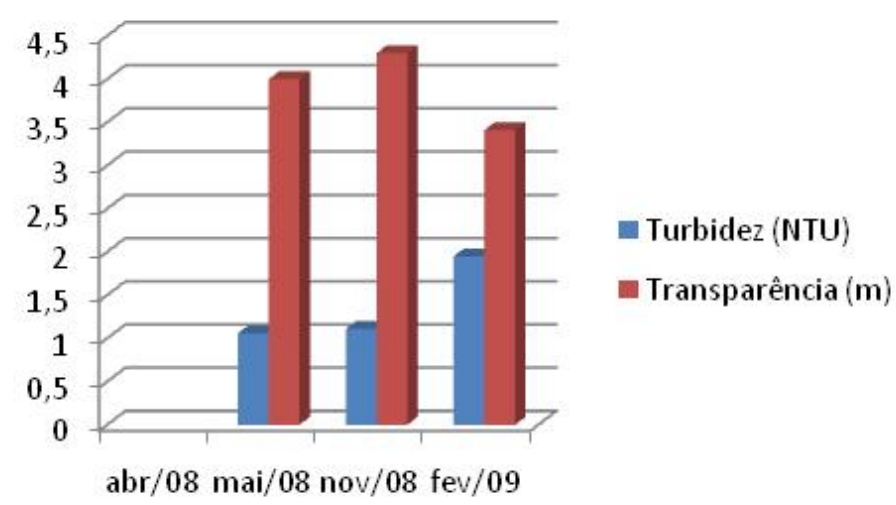

FIGURA 96 - Valores de turbidez (NTU) e transparência $(m)$ no ponto de amostragem 09.

A composição da comunidade fitoplanctônica esteve constituída por 8 classes. As classes mais representativas foram Chlorophyceae, que apresentou maior riqueza, contribuindo com $30 \%$ do total, seguida por Cyanophyceae com 22\% e Bacillariophyceae com 15\%, como apresentado na FIG. 97.

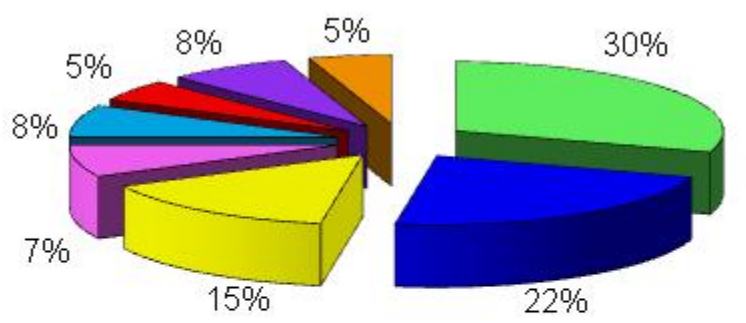

\begin{tabular}{|c|c|}
\hline 口CHLOROPHYCEAE & DCYANOPHYCEAE \\
\hline 口BACILLARIOPHYCEAE & 口ZYGNEMAPHYCEAE \\
\hline 口EUGLENOPHYCEAE & 口CHRYSOPHYCEAE \\
\hline 口DINOPHYCEAE & 口CRYPTOPHYCEAE \\
\hline
\end{tabular}

FIGURA 97 - Composição da comunidade fitoplanctônica, do ponto de amostragem 09, durante o período de estudo.

Frações de sólidos voláteis mostraram valores acima das frações de sólidos fixos durante o mês de mai/08 (FIG. 98). Em nov/08 e fev/09 a porção fixa mostrou valores acima da porção volátil. 


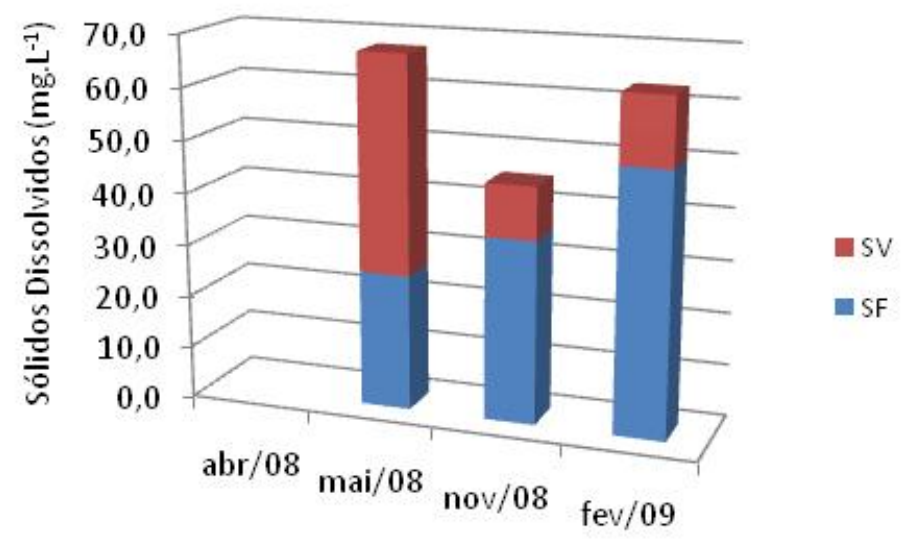

FIGURA 98 - Valores de série de sólidos dissolvidos, sólidos voláteis (SV) e sólidos fixos (SF) (mg. $\left.\mathrm{L}^{-1}\right)$ no ponto de amostragem 09.

As concentrações de nitrato, sulfato e fluoreto apresentaram pouca variação de amplitude, neste ponto, durante os meses amostrados. Já as concentrações de cloreto demostraram aumento gradual, durante o período de estudo (FIG. 99).

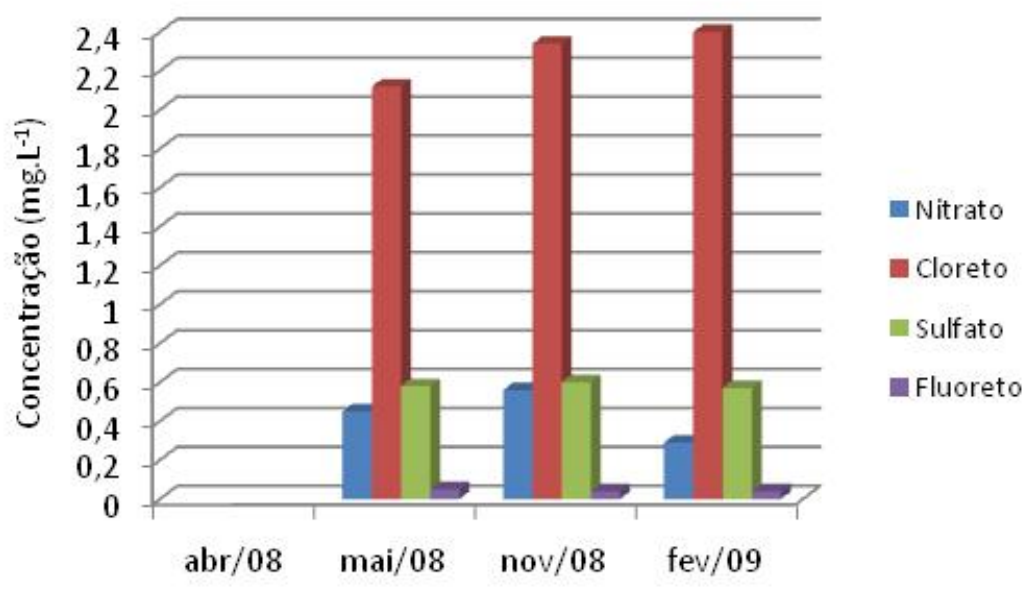

FIGURA 99 - Concentração de nitrato, cloreto, sulfato e fluoreto $\left(\mathrm{mg} \cdot \mathrm{L}^{-1}\right)$ no ponto de amostragem 09.

As classificações referentes ao índice de estado trófico (IET), calculado segundo as concentrções de fósforo total, para o ponto de amostragem 09, durante o período de estudo estão apresentadas na FIG. 100.

No mês de abr/08, não houve amostragem para este ponto. No mês de mai/08 foi o único período no qual o ponto 09 foi classificado como mesotrófico, 
enquanto que nos meses de nov/08 e fev/09 o ponto foi classificado como oligotrófico.

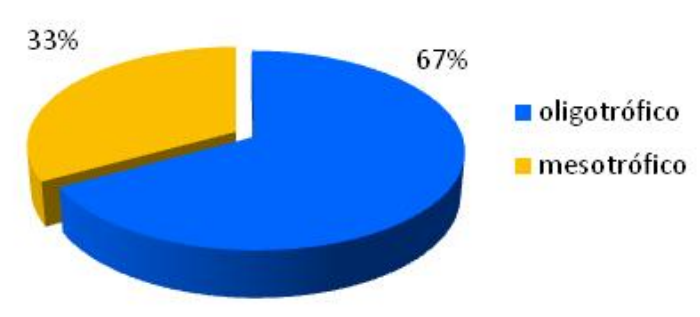

FIGURA 100 - Proporção das classificações do Índice de Estado Trófico (IET), no ponto de amostragem 09, durante o período de estudo. 


\section{CONCLUSÕES}

A partir dos resultados obtidos no presente trabalho pode-se concluir que:

1. A comunidade fitoplanctônica das represas Paraibuna e Paraitinga, esteve constituída de 92 táxons, distribuídos em dez classes, na qual Chlorophyceae foi a mais representativa, resultado também registrado na literatura, para diversos sistemas aquáticos.

2. Verificou-se sazonalidade na densidade fitoplanctônica, que aumentou no período chuvoso e quente, fato associado à sazonalidade natural em ecossistemas aquáticos, já que as concentrações de nutrientes mantiveram-se constantemente baixas.

3. Não foi observada forte variação sazonal na composição desta comunidade.

4. Não houve espécies dominantes, ou seja, a distribuição das espécies na comunidade esteve uniforme, demonstrada pelos altos valores dos índices de diversidade e equitabilidade e baixos valores do índice de dominância.

5. A classe Cyanobacteria, foi a maior contribuidora na porcentagem de espécies descritoras, baseadas na densidade, fato que merece atenção pois, como indicado na literatura, esta classe possui gêneros potencialmente tóxicos, como Anabaena sp., Microcystis sp., Pseudoanabaena sp. e Synechocystis sp. A presença destes gêneros, ainda que em baixas densidades, indicam a necessidade de monitoramento das águas das represas estudadas e o correto manejo, para que estes organismos não se tornem problemáticos tanto para o funcionamento da usina hidrelétrica, quanto para a saúde pública, já que as represas são utilizadas para recreação (banho e pesca) e dessedentação de animais.

6. Na maior parte do tempo e dos pontos de amostragem, de acordo com o índice de estado trófico, as represas foram consideradas oligotróficas. 
7. As baixas concentrações dos metais e elementos-traço encontradas nas represas estudadas demonstraram que, atualmente, não há comprometimento quanto à contribuição destes elementos.

8. Dos 22 metais e elementos-traço estudados apenas o Fe, Al e P apresentaramse, em algum momento, acima dos limites estabelecidos na legislação CONAMA $357 / 05$.

9. Sendo o fósforo um dos principais fatores limitantes para a produtividade de águas continentais, deve-se observar e monitorar a presença deste elemento nas represas, para que não se torne fator de eutrofização, já que nas amostragens de abril e maio de 2008 este elemento ultrapassou os valores estabelecidos na legislação supra citada.

10. As concentrações de ânions cloreto, fluoreto, nitrato e fosfato encontraram-se, ao longo do período de estudo, sempre abaixo dos limites estabelecidos pela resolução CONAMA 357/05.

11. Altos valores de oxigênio dissolvido e transparência, baixos valores de condutividade, turbidez, fosfato, nitrato, $\mathrm{pH}$ próximo à neutralidade e predomínio de clorofíceas indicam que as represas estudadas ainda mantêm características de ambiente aquático preservado. Porém, a existência de áreas de agropecuária no entorno merecem atenção no que tange ao seu correto manejo para que não se tornem fatores prejudiciais à qualidade daquelas águas.

12. Quanto ao possível uso dessas represas para o abastecimento público, devese observar, além dos parâmetros dispostos na resolução CONAMA 357/05, todas as diretrizes dispostas na portaria 518/04 do Ministério da Saúde, relativas ao controle e vigilância da qualidade de água para consumo humano, como padrões microbiológicos (coliformes fecais, totais e termotolerantes), padróes de radioatividade, quantificação de cianobactérias e análises de cianotoxinas. 
APÊNDICE A - Registro fotográfico do procedimento de coleta em campo.

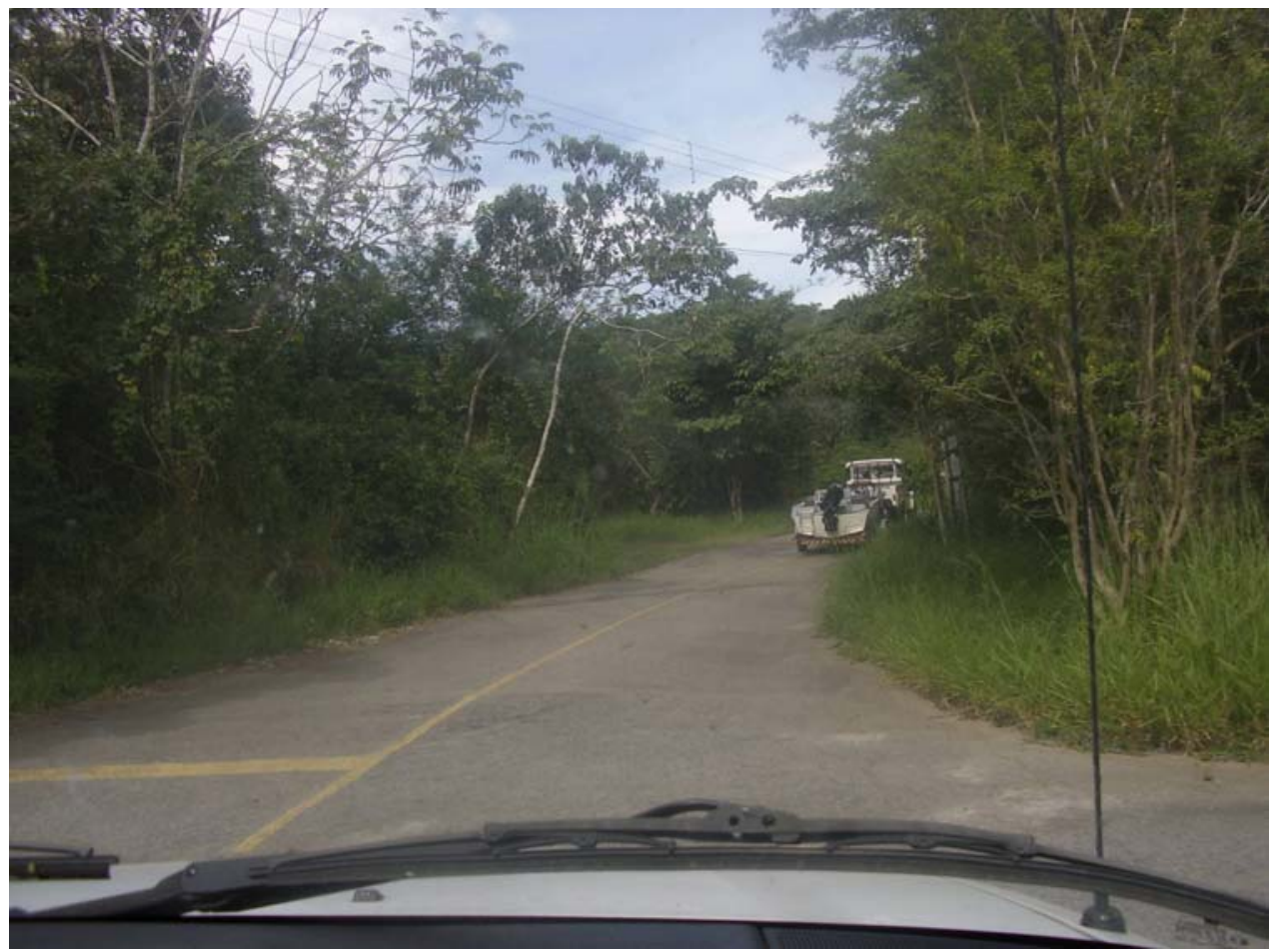

Foto 1 - Estrada para o porto de embarque da CESP nas represas Paraibuna e Paraitinga.

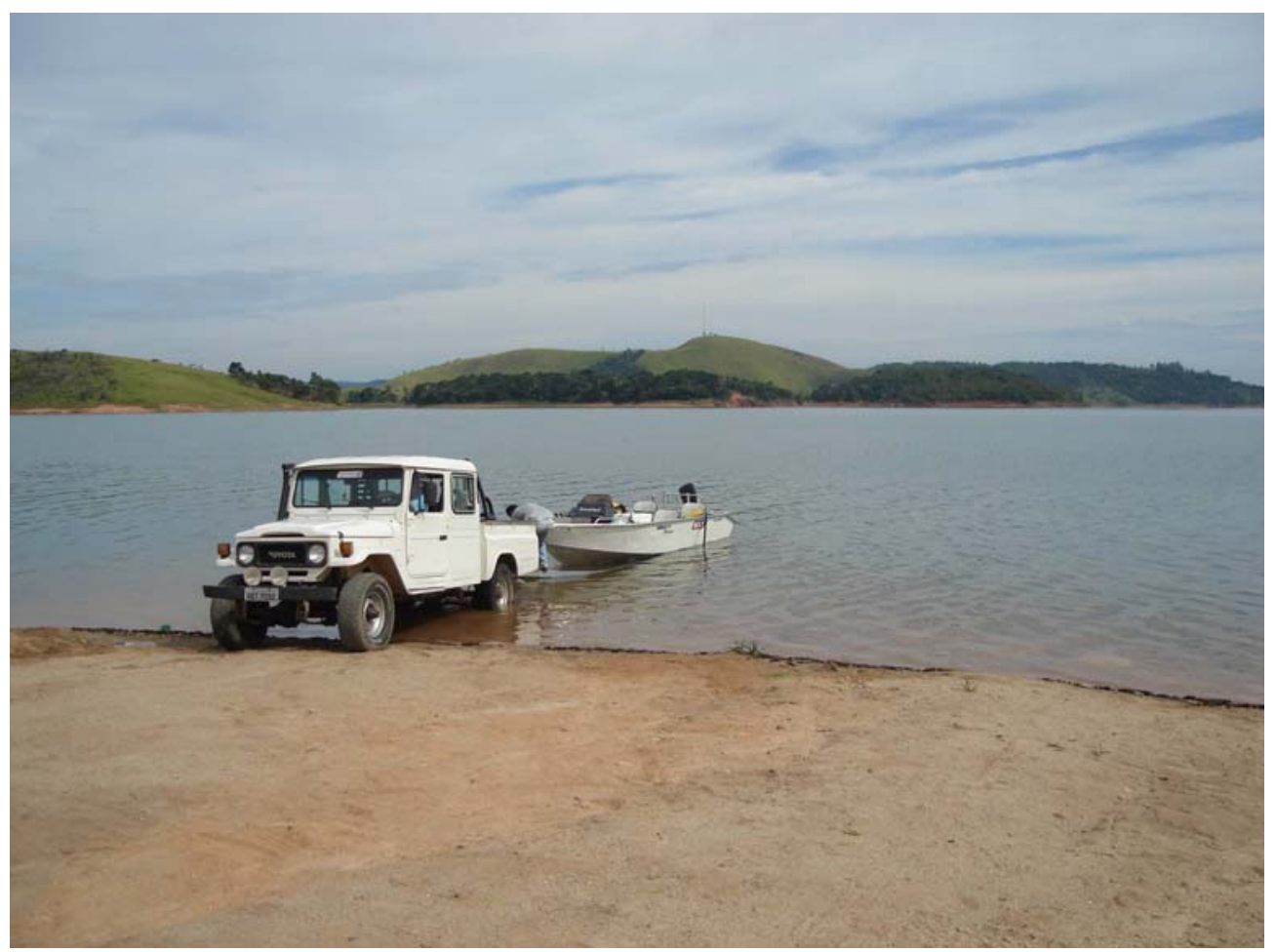

Foto 2 - Colocação da embarcação a motor na represa Paraibuna. 


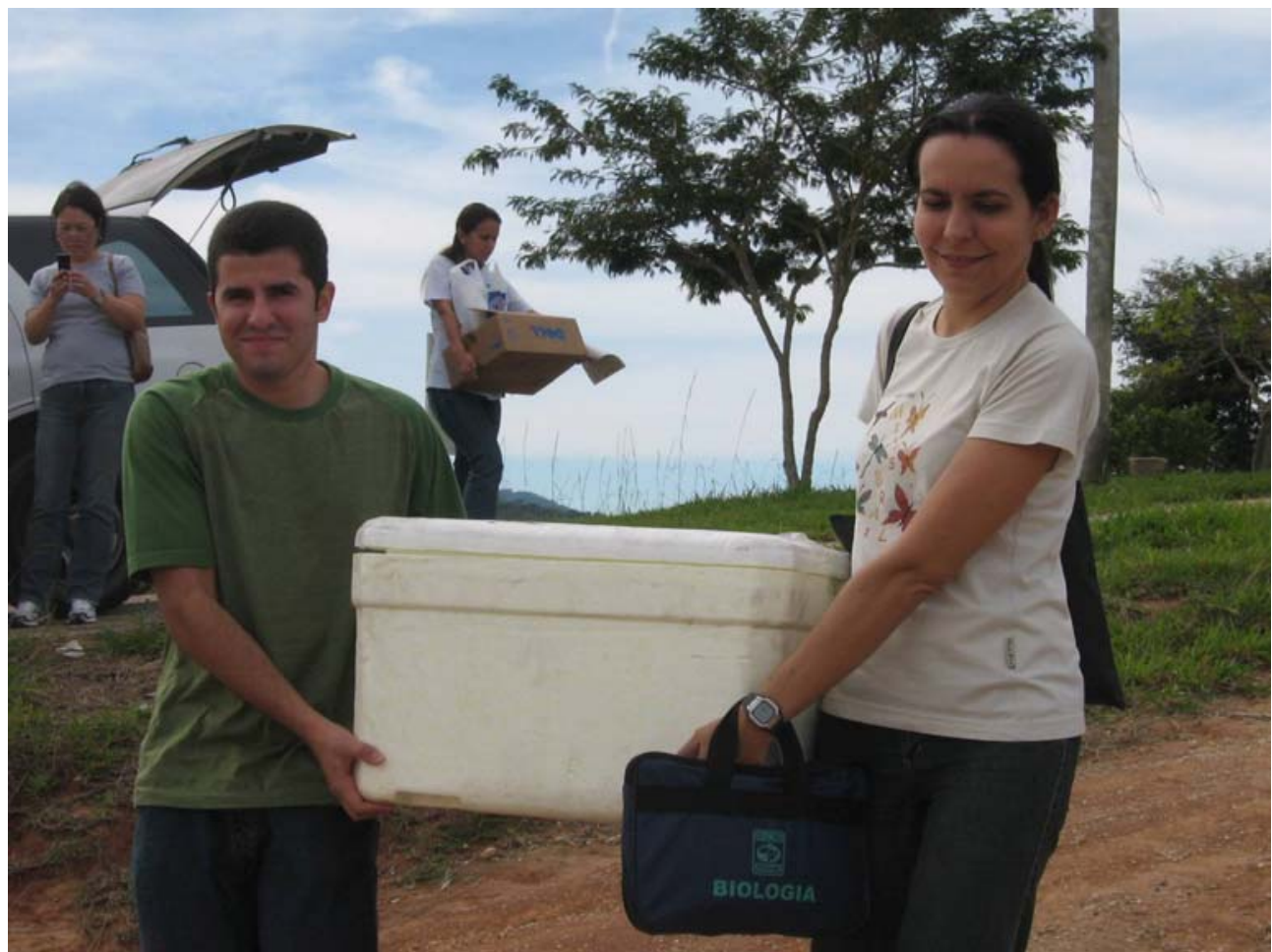

Foto 3 - Embarque dos materiais de coleta e análise.

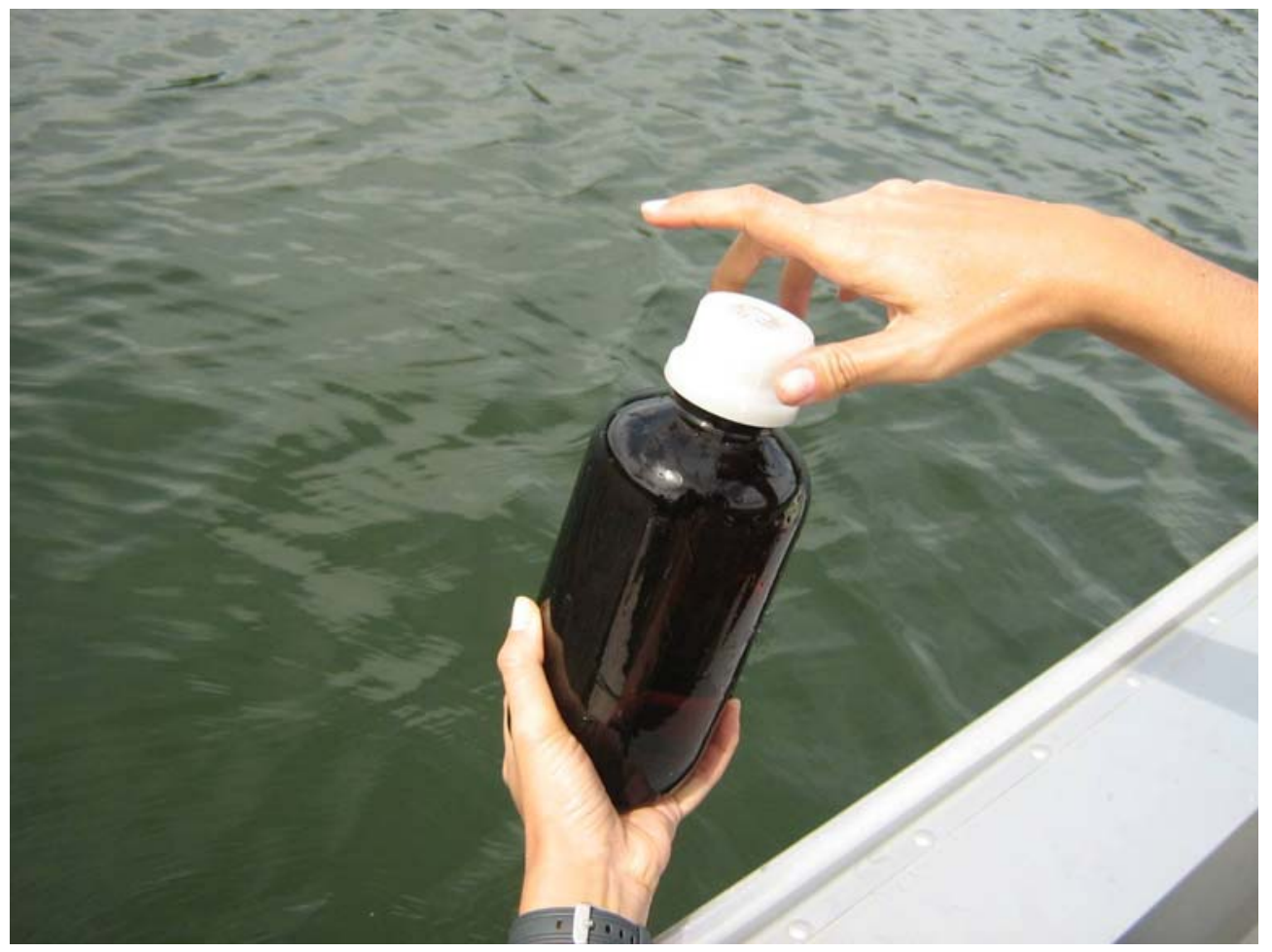

Foto 4 - Coleta da água, em frasco de vidro âmbar, para as análises físicoquímicas. 


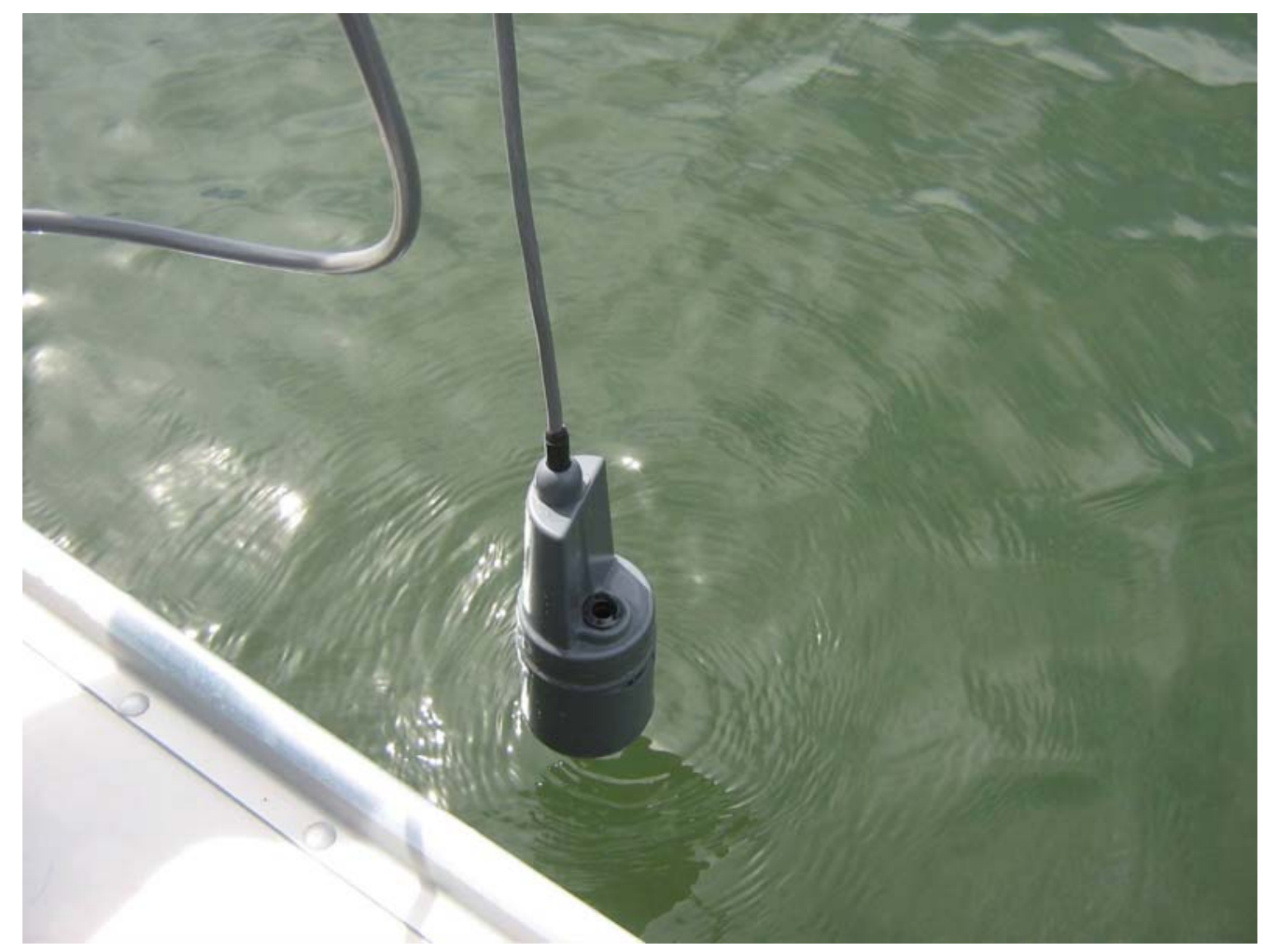

Foto 5 - Obtenção de dados com sonda multiparamétrica Horiba U-10.

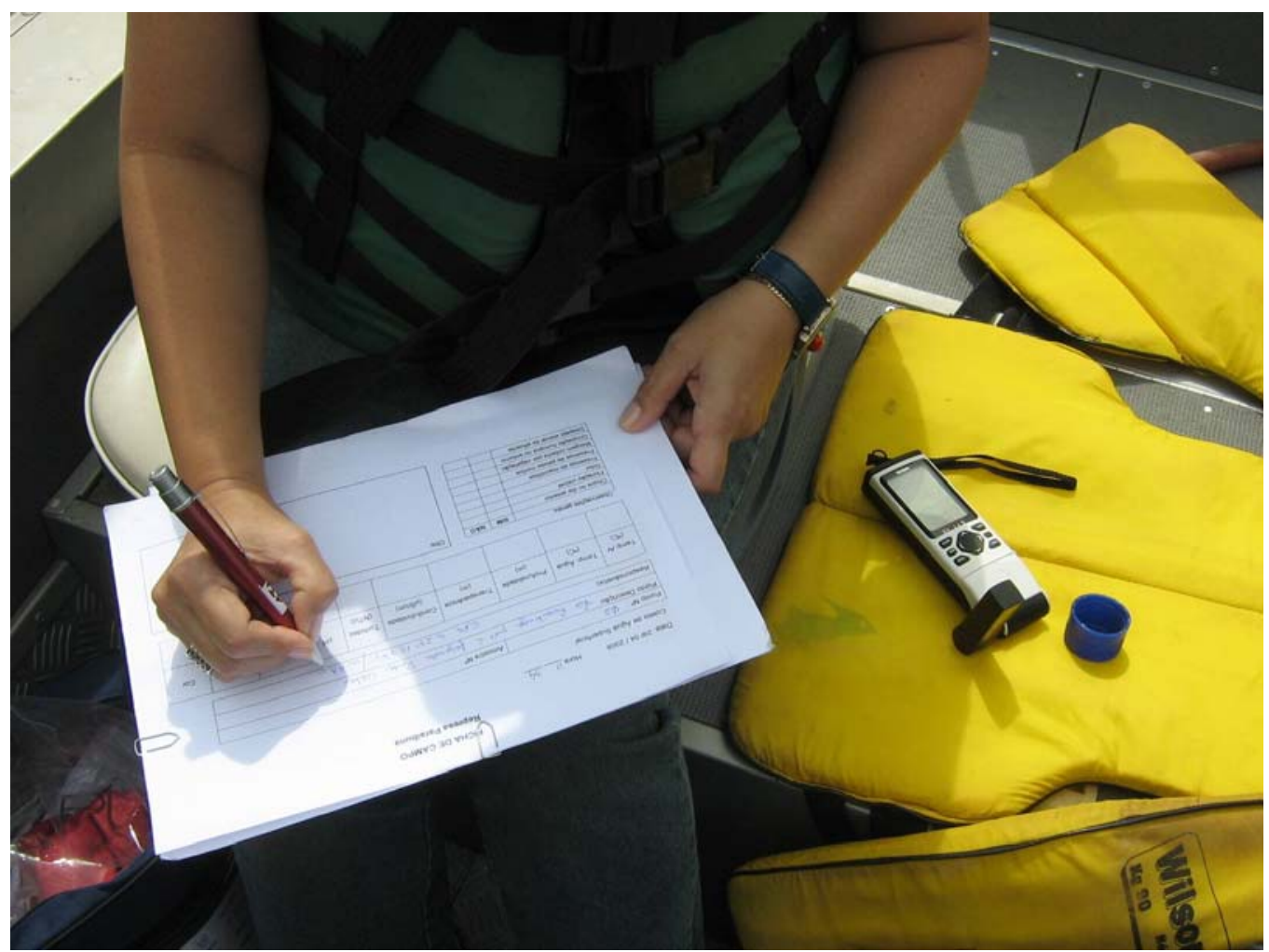

Foto 6 - Anotação dos dados obtidos, com sonda Horiba U-10 e GPS, em ficha de campo. 


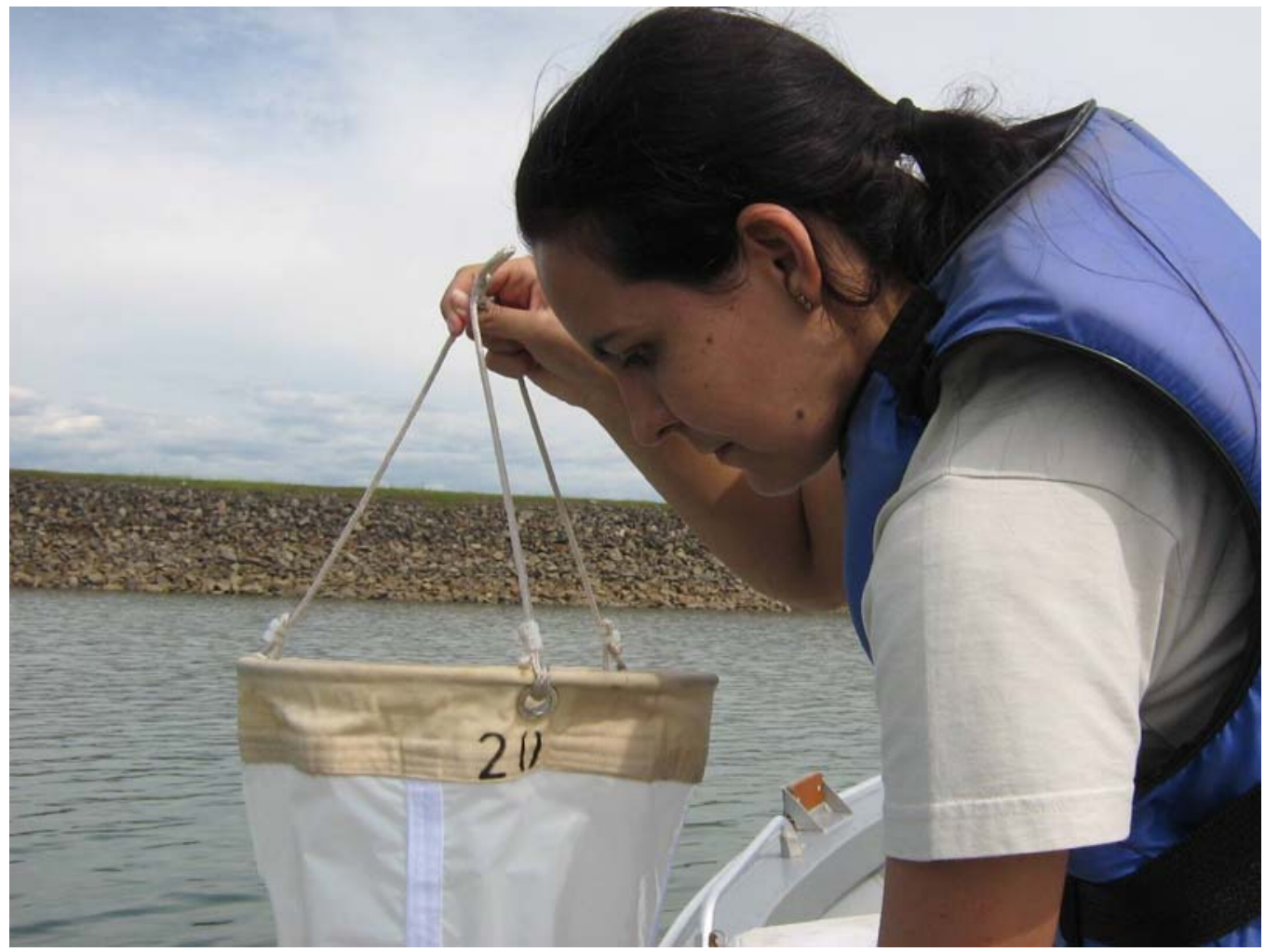

Foto 7 - Coleta do fitoplâncton, com rede de plâncton de $20 \mu \mathrm{m}$.

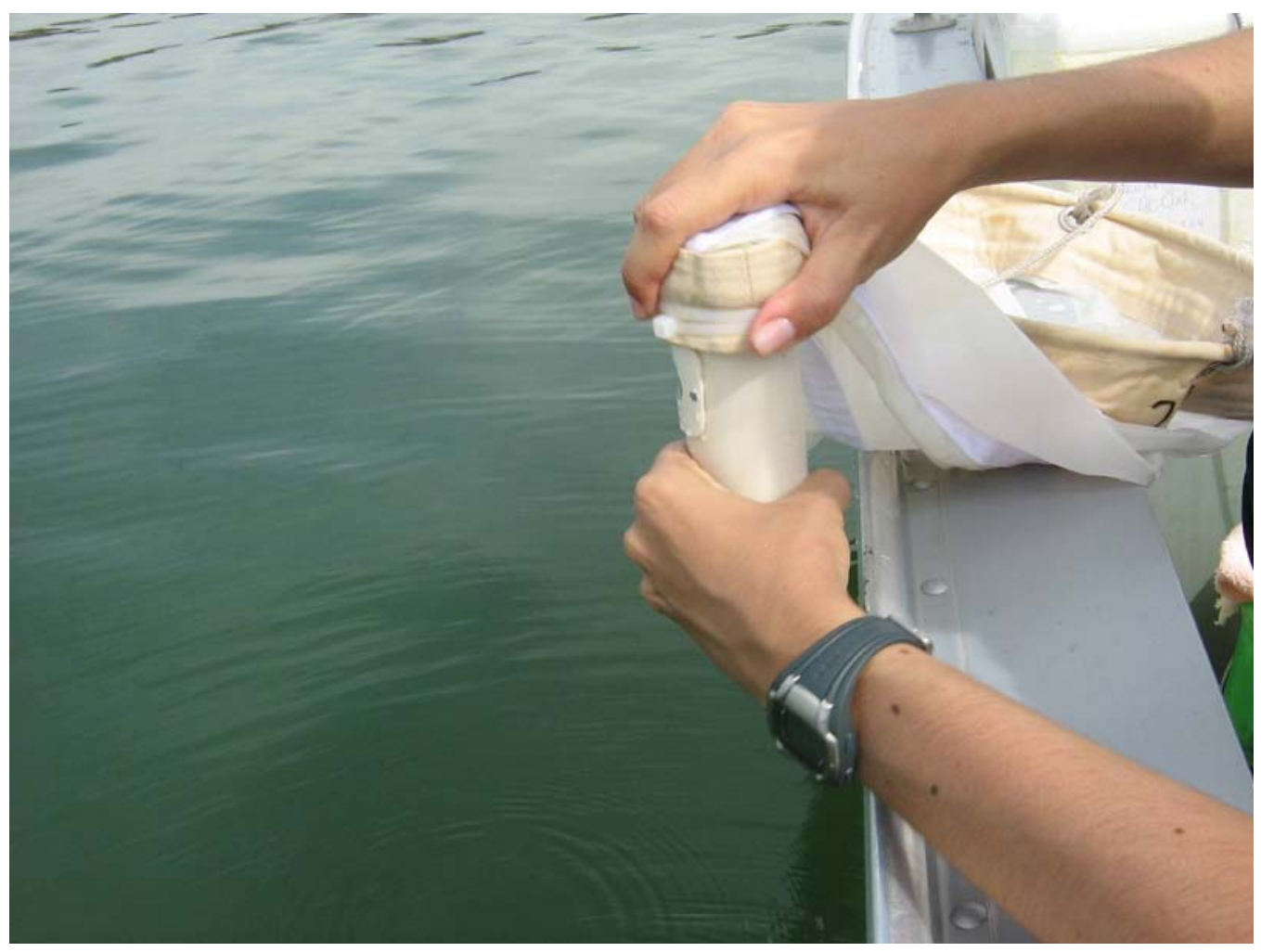

Foto 8 - Coleta do material planctônico retido na rede. 


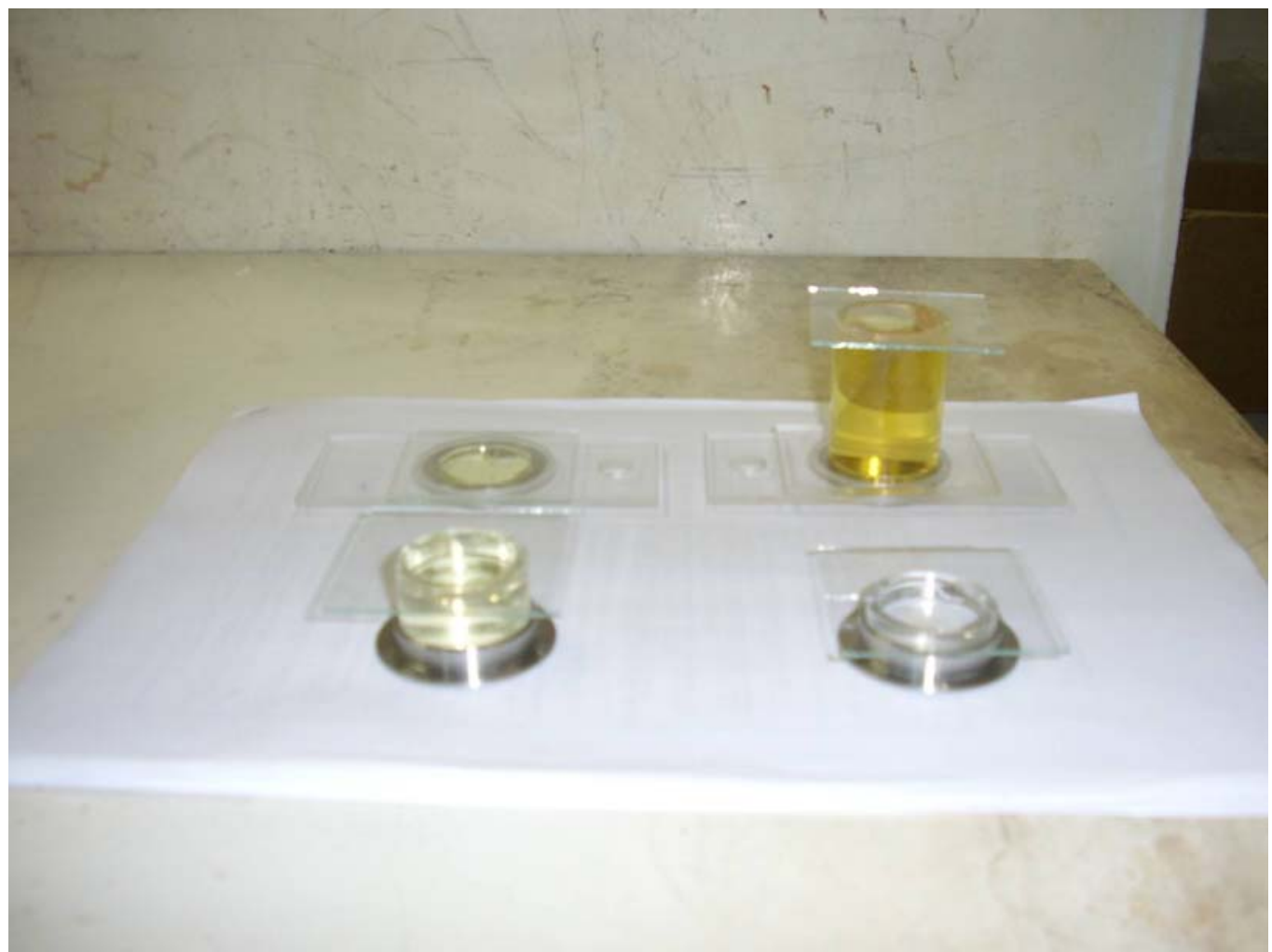

Foto 9 - Sedimentação das amostras quantitativas de fitoplâncton em câmaras de Utermöhl.

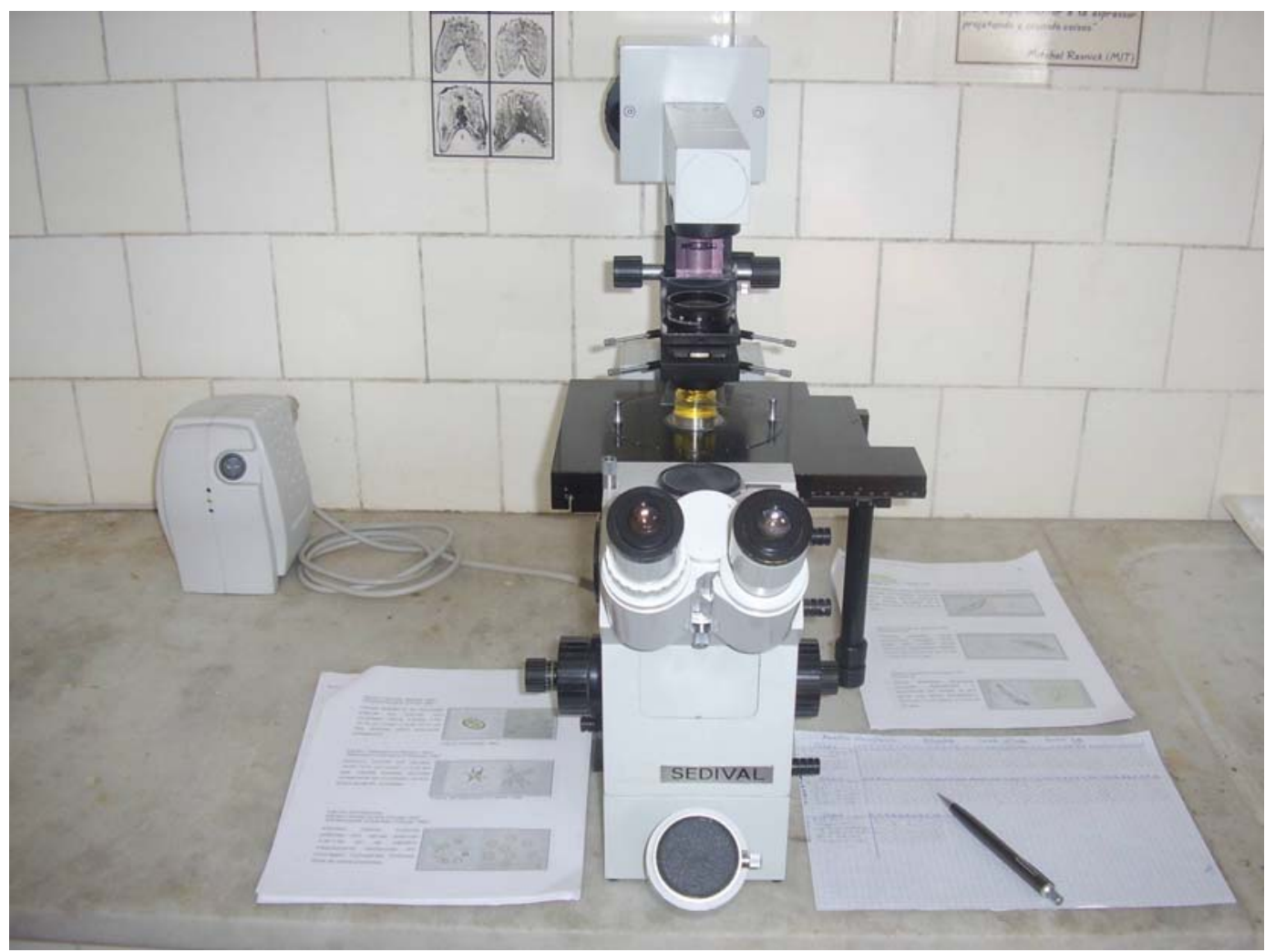

Foto 10 - Microscópio invertido para análise quantitativa. 

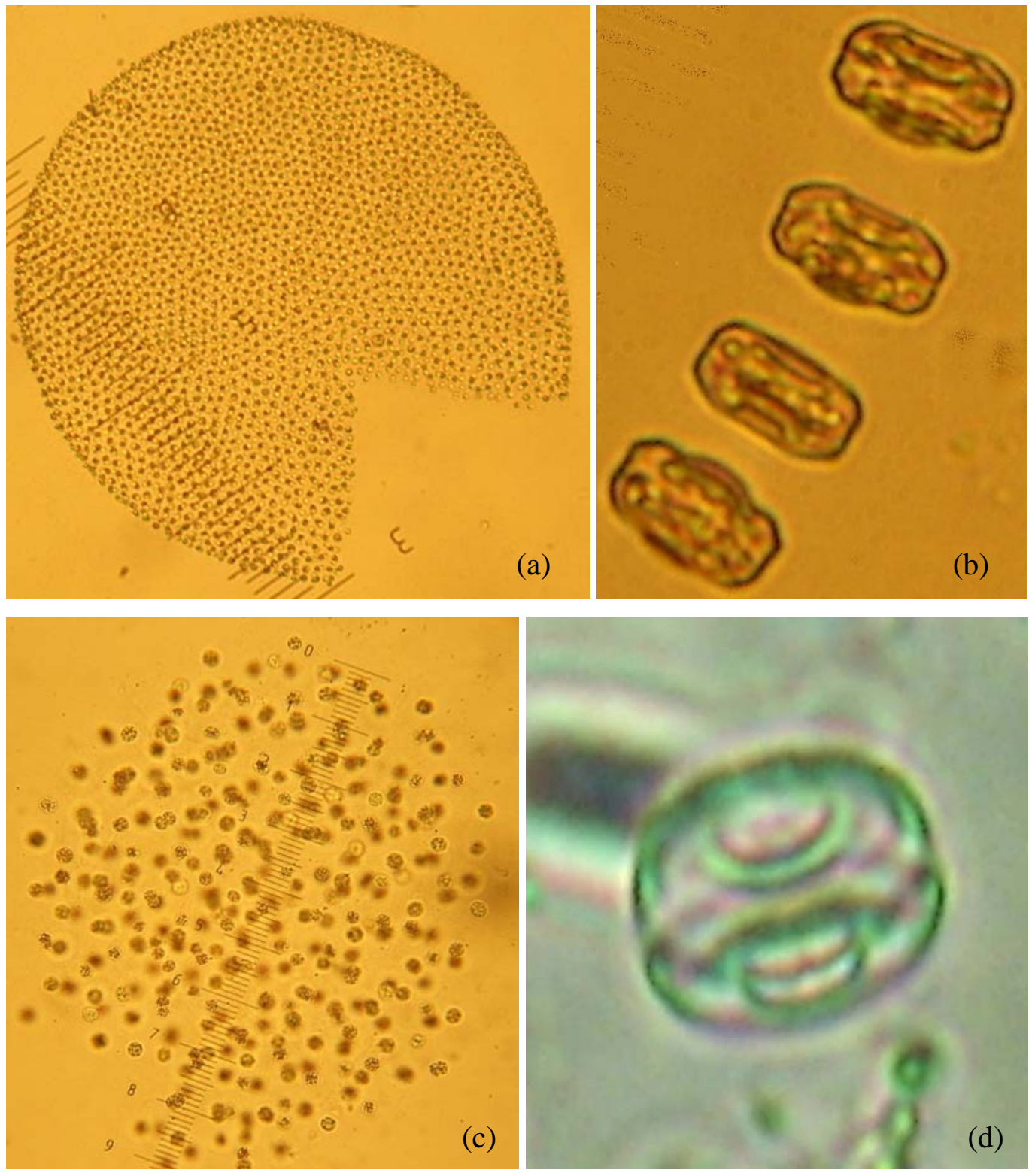

Foto 11 - Alguns dos exemplares fitoplanctônicos, encontrados nas represas estudadas, observados ao microscópio óptico. Fotos sem escala. (a) Volvox cf. aureus; (b) diatomácea cêntrica; (c) Microcystis aeruginosa; (d) Cyclotella sp. 
APÊNDICE B - Listagem dos táxons inventariados.

Divisão: BACILLARIOPHYTA

\section{Classe: BACILLARIOPHYCEAE}

\section{Ordem: PENALES}

Fragillaria sp.

Frústulas lineares a lanceolada com extremidades arredondadas. Medidas: $5,0 \mu \mathrm{m}$ largura $\times$ 62,5-65,0 $\mu \mathrm{m}$ comprimento.

Synedra sp.

Frústulas lineares alongadas apresentando área mediana mais larga que os ápices, os quais são levemente capitados.

Navicula $\mathrm{sp}$.

Células solitárias com formato lanceolado, com extremidades capitadas. Medidas: $36,0 \mu \mathrm{m}$ comprimento $\times 7,5 \mu \mathrm{m}$ largura.

Encyonema sp.

Frústulas solitárias de formato semi-elíptico. Medidas: 28,5-37,0 $\mu \mathrm{m}$ largura x 10,0-17,5 $\mu \mathrm{m}$ comprimento.

Amphora sp.

Frústulas solitárias de formato semi-elíptico, com margem ventral quase reta e margem dorsal convexa, com extremidades afiladas. Medidas: 25,0 $\mu \mathrm{m}$ largura x $77,5 \mu \mathrm{m}$ comprimento.

Melosira sp.

Frústulas cilíndricas unidas formando filamentos unisseriados sem espinhos nas margens. Medidas: 12,0-13,0 $\mu \mathrm{m}$ de diâmetro.

\section{Penales sp. 1}

Frústulas alongadas, com ápices retos. Medidas: 160,0 $\mu \mathrm{m}$ comprimento x $10,0 \mu \mathrm{m}$ largura. 


\section{Ordem: CENTRALES}

\section{Aulacoseira sp.}

Frústulas cilíndricas em geral encaixadas uma sob a outra formando duplas unidas por espinhos de ligação inconspícuos. Medidas: 22,5-36,0 $\mu \mathrm{m}$ de comprimento e 5,0-7,0 $\mu \mathrm{m}$ de diâmetro.

\section{Cyclotella sp.}

Frústulas cilíndricas solitárias, apresentando na área central aréola isolada circundada por estrias. Medidas: 12,5-20,0 $\mu \mathrm{m}$ de diâmetro e 10,0-16,0 $\mu \mathrm{m}$ de altura.

Diatomácea cêntrica

Frústulas circulares apresentando, na área central, aréola isolada circundada por estrias. Geralmente dispostas em grupos de 4 células próximas. Medidas: 7,5 $\mu \mathrm{m}$ de diâmetro e 5,0 $\mu \mathrm{m}$ de altura.

\section{Divisão: CHLOROPHYTA}

\section{Classe: CHLOROPHYCEAE}

\section{Ordem: CHLOROCOCALES}

Ankistrodesmus bernardii Komárek

Colônias alongadas formadas por células fusiformes. Medidas: células 1,25-2,0 $\mu \mathrm{m}$ largura $\times 35,0-40,0 \mu \mathrm{m}$ comprimento.

Botryococcus braunii Kützing

Colônias globosas formadas por células ovóides em numerosos grupos. Medidas: células 5,0-6,5 $\mu \mathrm{m}$ de largura $\times$ 7,0-12,0 $\mu \mathrm{m}$ comprimento.

Dictyosphaerium ehrenbergianum Nägeli

Colônias ovais formadas por cachos de 3-4 células oblongas. Medidas células: $3,0-7,2 \mu \mathrm{m}$ comprimento $\times 5,0-8,5 \mu \mathrm{m}$ de largura.

Coelastrum cf. microporum Nägeli

Colônias esféricas formada por células esféricas, espaços intercelulares pequenos. Medidas: células 7,2-11,0 $\mu \mathrm{m}$ diâmetro. 
Coelastrum reticulatum (Dangeard) Senn

Colônias esféricas formada por células esféricas, espaços intercelulares grandes. Colônias em autoesporulação. Medidas: células 2,0-7,0 $\mu \mathrm{m}$ diâmetro.

Chlorella vulgaris Beijerinck

Células esféricas. Medidas: 5,0-10,0 $\mu \mathrm{m}$ diâmetro.

\section{Chlorococcum sp.}

Células esféricas. Medidas: 12,5-15,0 $\mu \mathrm{m}$ diâmetro.

Quadrigula closterioides (Bohlin) Printz

Células fusiformes dispostas em feixes paralelos ao eixo longitudinal.

Medidas: $12,5-20 \mu \mathrm{m}$ comprimento $\times 2,0-4,0 \mu \mathrm{m}$ de largura.

Kirchneriella aperta Teiling

Colônias esféricas formadas por células lunadas com ápices arredondados. Medidas: células 5,0-6,0 $\mu \mathrm{m}$ comprimento x 2,5-3,0 $\mu \mathrm{m}$ de largura.

Kirchneriella contorta (Schmidle) Bohlin

Colônias esféricas formadas por células lunadas com ápices arredondados. Medidas: células 6,0-10,0 $\mu \mathrm{m}$ comprimento x 2,0 $\mu \mathrm{m}$ de largura.

Cf. Kirchneriella

Colônias esféricas formadas por células lunadas com ápices pontiagudos. Medidas: células 5,0-8,0 $\mu \mathrm{m}$ comprimento x 1,5-2,0 $\mu \mathrm{m}$ de largura.

Closteriopsis sp.

Células fusiformes arcuadas, isoladas. Medidas: 18,0-30,0 $\mu \mathrm{m}$ comprimento $\times 2,5-6,0 \mu \mathrm{m}$ de largura.

Monoraphidium dybowskii (Woloszynka) Hindak e Komarková-Legnerová

Células fusiformes, alongadas e isoladas. Medidas: 12,5-15,0 $\mu \mathrm{m}$ comprimento $\times 2,5-5,0 \mu \mathrm{m}$ de largura. 
Monoraphidium sp. 2

Células fusiformes, alongadas e isoladas. Medidas: 15,0-22,5 $\mu \mathrm{m}$ comprimento $\times 2,5-3,0 \mu \mathrm{m}$ largura.

Monoraphidium sp. 3

Células isoladas, reniformes com ápices redondos. Medidas: 12,0-12,5 $\mu \mathrm{m}$ comprimento $\times 2,5 \mu \mathrm{m}$ largura.

Monoraphidium irregulare (G. M. Smith) Kormaková-Legnerová

Células isoladas fusiformes levemente helicoidais. Medidas: 40,0-60,0 $\mu \mathrm{m}$ comprimento x 2,5-3,0 $\mu \mathrm{m}$ largura.

Sphaerocystis schroeteri Chodat

Colônias esféricas, células esféricas distribuídas ao longo da mucilagem firme e homogênea. Presença de colônias filhas. Medidas: células 3,8-6,0 $\mu \mathrm{m}$ diâmetro.

Eutetramorus fottii (Hindak) Komárek

Colônia esféricas formadas células esféricas, dispostas em 2 planos. Medidas: células 5,0 $\mu \mathrm{m}$ diâmetro.

Eutetramorus globosus Walton

Colônia esféricas formadas células esféricas, dispostas em 2 planos. Medidas: células 7,0-10,0 $\mu \mathrm{m}$ diâmetro.

Golenkinia radiata Chodat

Células esféricas isoladas com setas diversas. Medidas: células 10,0-15,0 $\mu \mathrm{m}$ de diâmetro, com setas medindo 20,0-40,0 $\mu \mathrm{m}$ de comprimento.

Radiococcus cf. bavaricus (Skuja) Komárek

Colônias arredondadas formadas por células esféricas agrupadas. Medidas: células 2,0-3,0 $\mu \mathrm{m}$ diâmetro.

Radiococcus planktonicus Lund

Colônias arredondadas formadas por células esféricas agrupadas. Medidas: células 3,0-6,0 $\mu \mathrm{m}$ diâmetro; colônias até 250,0 $\mu \mathrm{m}$ diâmetro. 
Cf. Eremosphaera

Células isoladas, esféricas, com mucilagem firme e homogênea. Medidas: 12,5-17,5 $\mu \mathrm{m}$ diâmetro.

Oocystis lacustris Chodat

Colônias elípticas com mucilagem hialina formadas por células elípticas. Medidas: células 7,5 $\mu \mathrm{m}$ comprimento x 5,5 $\mu \mathrm{m}$ largura.

Nephrocytium schilleri (Kammerer) Comas

Colônias arredondadas formadas por células reniformes com ápices arredondados. Medidas: células 10,0-15,0 $\mu \mathrm{m}$ comprimento x 2,5-7,0 $\mu \mathrm{m}$ largura.

Selenastrum gracile Reinsch

Células lunadas formando grupos. Medidas: células 3,0-5,0 $\mu \mathrm{m}$ diâmetro, 10,0-16,5 $\mu \mathrm{m}$ distância entre os ápices.

Elakatothrix gelatinosa Wille

Células fusiformes dispostas em duplas no eixo transversal. Medidas:

células 10,0-12,0 $\mu \mathrm{m}$ comprimento x 2,5-3,5 $\mu \mathrm{m}$ largura

Elakatothrix gelifacta (Chod.) Hind.

Células fusiformes isoladas com constrição na porção mediana. Medidas: células 17,5-20,0 $\mu \mathrm{m}$ comprimento x 2,5-3,0 $\mu \mathrm{m}$ largura.

Scenedesmus sp.

Cenóbios planos de 2 células, dispostas paralelamente ao eixo longitudinal. Células oblongas. Medidas: células 6,0-7,5 $\mu \mathrm{m}$ comprimento x 3,0 $\mu \mathrm{m}$ largura.

\section{Ordem: VOLVOCALES}

Volvox cf. aureus Ehrenberg

Colônias esféricas formadas por muitas células dispostas na periferia da mucilagem, distantes umas das outras. Medidas: células 4,0-5,0 diâmetro. 
Chlamydomonas sp.

Células esféricas, pólo anterior com papila, 2 flagelos de igual tamanho. Medidas: células 7,5-10,0 $\mu \mathrm{m}$ diâmetro.

\section{Classe: ZYGNEMAPHYCEAE \\ Ordem: DESMIDIALES}

\section{Staurastrum sp.1}

Semicélulas subtriangulares, com 7 processos longos de ápices trifurcados. Parede celular denticulada tanto nos processos quanto nas semicélulas. Medidas: largura do istmo 7,5 $\mu \mathrm{m}$; células com processo 185,0 $\mu \mathrm{m}$ largura x 35,0-39,0 $\mu \mathrm{m}$ comprimento.

\section{Staurastrum sp.2}

Semicélulas subtriangulares, com 6 processos longos de ápices trifurcados. Parede celular denticulada tanto nos processos quanto nas semicélulas. Medidas: largura do istmo 7,5 $\mu \mathrm{m}$; células com processo 184,0 $\mu \mathrm{m}$ largura $\times 35,0-38,5 \mu \mathrm{m}$ comprimento.

\section{Staurastrum sp.3}

Semicélulas semicirculares, com 6 processos de ápices bifurcados. Parede celular lisa tanto nos processos quanto nas semicélulas. Medidas: largura do istmo 10,0-12,0 $\mu \mathrm{m}$; células com processo $31,5 \mu \mathrm{m}$ largura $\times 25,0 \mu \mathrm{m}$ comprimento.

\section{Staurastrum sp. 4}

Semicélulas subtriangulares, com 9 processos longos de ápices trifurcados. Parede celular denticulada tanto nos processos quanto nas semicélulas. Medidas: largura do istmo 8,0 $\mu \mathrm{m}$; células com processo 172,5 $\mu \mathrm{m}$ largura $\mathrm{x} 35,0 \mu \mathrm{m}$ comprimento.

Staurodesmus sp.

Semicélulas elípticas, ângulos apicais com um espinho curto, subtriangulares, com 9 processos longos de ápices trifurcados. Parede celular 
denticulada tanto nos processos quanto nas semicélulas. Medidas: largura do istmo $12,5 \mu \mathrm{m}$; células $16,5 \mu \mathrm{m}$ largura $\times 31,0 \mu \mathrm{m}$ comprimento.

Micrasterias cf. laticeps Nordstedt

Semicélulas trilobadas, margem superior convexa, constrição do istmo profunda. Medidas: largura do istmo 18,5 $\mu \mathrm{m}$; células 203,5 $\mu \mathrm{m}$ largura x 165,0 $\mu \mathrm{m}$ comprimento.

Desmídia sp. 1

Semicélulas semicirculares, com 6 processos. Parede celular lisa tanto nos processos quanto nas semicélulas. Medidas: largura do istmo $10,0 \mu \mathrm{m}$; células com processo $78,0 \mu \mathrm{m}$ largura $\times 64,0 \mu \mathrm{m}$ comprimento.

\section{Ordem: ZYGNEMATALES}

Mougeotia sp.

Filamentos cilíndricos não ramificados. Medidas: filamento $31,5-45,0 \mu \mathrm{m}$ comprimento x 3,0-3,5 $\mu \mathrm{m}$ largura.

\section{Divisão: CHRYSOPHYTA \\ Classe: CHRYSOPHYCEAE \\ Ordem: OCHROMONADALES}

Dinobryon bavaricum Imhof

Colônias ramificadas formadas por lóricas cilíndricas com pólo posterior afilado com margens alargando-se em direção ao pólo anterior; margens laterais discretamente onduladas. Medidas: 42,0-50,0 $\mu \mathrm{m}$ comprimento x 8,5-10,0 $\mu \mathrm{m}$ largura.

Mallomonas sp. 1

Células elipsóides, pólo anterior arredondado afilando-se levemente em direção ao pólo posterior, setas distribuídas por toda a célula, parede com escamas. Medidas: 32,5-35,0 $\mu \mathrm{m}$ comprimento x 12,0-20,0 $\mu \mathrm{m}$ largura. 
Mallomonas sp. 2

Células ovóides, pólo posterior arredondado e anterior acuminado, setas curtas distribuídas no pólo anterior da célula, parede com escamas. Medidas: 15,5-18,0 $\mu \mathrm{m}$ comprimento x 9,5 $\mu \mathrm{m}$ largura.

Mallomonas sp. 3

Células ovaladas, pólo posterior arredondado e pólo anterior levemente acuminado, setas distribuídas no pólo anterior da célula, parede com escamas. Medidas: $12,5-13,0 \mu \mathrm{m}$ comprimento x 7,0-9,5 $\mu \mathrm{m}$ largura.

Mallomonas sp. 4

Células ovaladas, pólos levemente acuminados, setas distribuídas por toda a célula, parede com escamas discóides. Medidas: 31,0 $\mu \mathrm{m}$ comprimento $\times 16,0$ $\mu \mathrm{m}$ largura.

\section{Synura sp.1}

Colônias globosas formadas por células ovadas unidas entre si, no centro da colônia, por pedúnculos da própria célula. Medidas: 12,5 $\mu \mathrm{m}$ comprimento $\mathrm{x}$ $10,0 \mu \mathrm{m}$ largura.

\section{Divisão: CHRYPTOPHYTA}

Classe: CHRYPTOPHYCEAE

Ordem: CHYPTOMONADALES

Cryptomonas brasiliensis Castro, C. Bic \& D. Bic.

Célula obovadas, pólo anterior afilado. Medidas: 7,0-7,5 $\mu \mathrm{m}$ largura x 10,0 $\mu \mathrm{m}$ comprimento.

Cryptomonas marsonii Ehrenberg

Célula obovadas, pólo anterior afilado levemente curvado. Medidas: 8,5$10,0 \mu \mathrm{m}$ largura $\times 13,0 \mu \mathrm{m}$ comprimento.

\section{Divisão: CYANOPHYTA/CYANOBACTERIA}

\section{Classe: CYANOPHYCEAE}

\section{Ordem: CHROOCOCCALES}


Chroococcus minimus (Keissler) Lemmermann

Colônias formadas por diversas células esféricas sem aerótopos. Medidas: células 1,5-2,5 $\mu \mathrm{m}$ diâmetro.

Chroococcus sp.1

Colônias formadas por 2-4 células esféricas sem aerótopos. Medidas: células 2,5-3,0 $\mu \mathrm{m}$ diâmetro.

\section{Chroococcus sp.2}

Colônias formadas por 2-4 células esféricas sem aerótopos. Medidas:

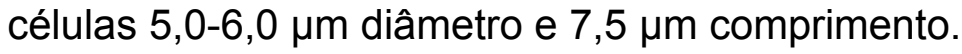

Cyanodictyon sp.

Colônias esféricas formadas por células cilíndricas. Medidas: células 1,5-

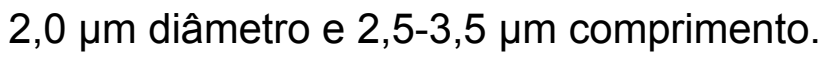

Epigloeosphaera sp.

Colônias esféricas formadas por células cilíndricas. Medidas: células 1,0 $\mu \mathrm{m}$ diâmetro e 1,5-2,0 $\mu \mathrm{m}$ comprimento.

Aphanocapsa sp.1

Colônias globosas formadas por células esféricas sem aerótopos. Medidas: células 4,0-5,0 $\mu \mathrm{m}$ diâmetro.

Aphanocapsa elachista W. \& G. S. West

Colônias ovais alongadas formadas por células esféricas sem aerótopos. Medidas: células 1,5-2,5 $\mu \mathrm{m}$ diâmetro.

Aphanocapsa delicatissima W. \& G. S. West

Colônias irregulares formadas por células esféricas sem aerótopos. Medidas: células 0,5-1,0 $\mu \mathrm{m}$ diâmetro.

Merismopedia glauca (Ehrenberg) Kützing

Colônias tabulares formadas por células esféricas ou oblongas, sem

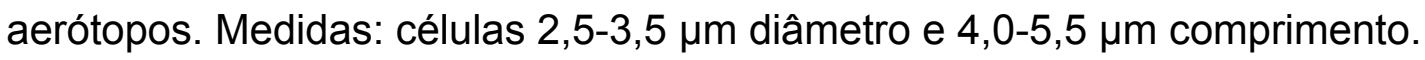


Merismopedia tenuissima Lemmermann

Colônias tabulares formadas por células esféricas, sem aerótopos.

Medidas: células 1,5-2,5 $\mu \mathrm{m}$ diâmetro.

Synechocystis sp. Sauvageau

Células esféricas solitárias. Medidas: 2,5-4,5 $\mu \mathrm{m}$ diâmetro.

Microcystis aeruginosa Kützing

Colônias esféricas clatradas formadas por células esféricas com aerótopos densamente agregadas. Medidas: células 2,5-6,5 um diâmetro.

Microcystis protocystis

Colônias esféricas não clatradas formadas por células esféricas com aerótopos frouxamente agregadas. Medidas: células 4,5-6,5 $\mu \mathrm{m}$ diâmetro.

Rhabdoderma cf. sancti-pauli Azevedo, Sant'anna, Senna, Komárek \& Komárková

Colônias alongadas formadas por células cilíndricas com ápices arredondados levemente arcuadas. Medidas: células 2,0-3,5 $\mu \mathrm{m}$ comprimento $\mathrm{x}$ 1,0-1,5 $\mu \mathrm{m}$ largura.

Myxobaktron sp.

Células isoladas alongadas e afiladas nas extremidades, sem aerótopos. Medidas: 4,8-11,0 $\mu \mathrm{m}$ comprimento x 0,5-1,0 $\mu \mathrm{m}$ largura.

\section{Ordem: NOSTOCALES}

Anabaena sp.1

Tricomas solitários curtos compostos de células esféricas. Medidas: células 3,0-4,5 $\mu \mathrm{m}$ diâmetro. Não foi observada na população a presença de heterocitos ou acinetos.

Anabaena sp.2

Tricomas solitários retos compostos de células arredondadas. Medidas: células 3,5-5,0 $\mu \mathrm{m}$ diâmetro e 4,0-5,5 $\mu \mathrm{m}$ comprimento Não foi observada na população a presença de heterocitos ou acinetos. 
Anabaena spiroides Klebahn

Tricomas solitários espiralados compostos de células esféricas. Medidas: células 3,5-5,0 $\mu \mathrm{m}$ diâmetro. Não foi observada na população a presença de heterocitos ou acinetos.

Anabaena circinalis Rabenhorst

Tricomas solitários espiralados irregularmente compostos de células esféricas. Medidas: células 6,5-7,5 $\mu$ m diâmetro. Não foi observada na população a presença de heterocitos ou acinetos.

\section{Ordem: OSCILLATORIALALES}

Pseudoanabaena mucicola Huber-Pestalozzi \& Naumann

Tricomas curtos, retos, formados por células cilíndricas e arredondadas nos ápices unidas por mucilagem. Encontrada freqüentemente na mucilagem de outras algas como Microcystis aeruginosa. Medidas: células 1,5 $\mu \mathrm{m}$ diâmetro e 2,0-2,5 $\mu \mathrm{m}$ comprimento.

Pseudoanabaena moniliformis Komárek \& Kling

Tricomas curtos, retos, formados por células unidas por mucilagem. Medidas: células 2,0-3,0 um diâmetro e 4,0-5,5 um comprimento.

Pseudoanabaena sp.1

Tricomas curtos, retos, formados por células cilíndricas com aerótopos. Medidas: células 3,5 $\mu \mathrm{m}$ diâmetro e 5-7,5 $\mu \mathrm{m}$ comprimento.

Oscillatoria cf. lacustris (Klebs) Geitler

Tricomas formados por diversas células mais largas do que longas, células

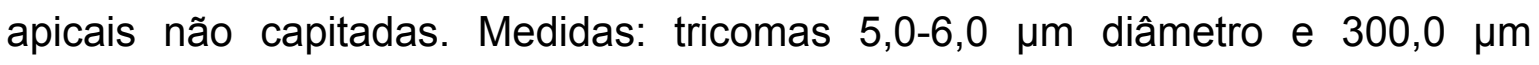
comprimento.

Gleiterinema sp.

Tricomas solitários retos formados por células alongadas com grânulos. Medidas: células 2,0 diâmetro x 4,5-5,0 $\mu \mathrm{m}$ de comprimento. 


\section{Divisão: DYNOPHYTA}

\section{Classe: DINOPHYCEAE}

Ordem: PERIDINIALES

Peridinium cf. cunnigtonii (Lemmermann) Lemmermann emend. Lefevre

Células ovaladas ou piriformes. Medidas: células 35,5-40,0 $\mu \mathrm{m}$ largurax $39,5-45,0$ um comprimento.

Peridinium cf. volzii Lemmermann

Células esféricas com placas de ornamentação reticulada. Medidas: células 42,0-50,0 um diâmetro.

Peridinium cf. pusilium (Penard) Lemmermann

Células ovaladas alongadas. Medidas: células 17,0-20,0 $\mu \mathrm{m}$ largura x 17,523,0 $\mu \mathrm{m}$ comprimento.

Divisão: EUGLENOPHYTA

Classe: EUGLENOPHYCEAE

Ordem: EUGLENALES

Euglena sp. 1

Células fusiformes alongadas com ápices arredondados pouco pontiagudos. Medidas: 10,0-15 $\mu \mathrm{m}$ largura x 37,5-45,0 $\mu \mathrm{m}$ comprimento.

\section{Euglena sp. 2}

Células elípticas com ápices arredondados pouco pontiagudos. Medidas: 9,0-13,5 $\mu \mathrm{m}$ largura $\times 22,0-32,0 \mu \mathrm{m}$ comprimento

Lepocinclis sp.

Células elípticas com ápices anterior arredondado e posterior acuminado. Medidas: 19,5-40,5 um comprimento x 12,0-26,0 $\mu \mathrm{m}$ largura.

Trachelomonas armata (Ehr.) Stein

Lórica oval com espinhos cônicos espalhados e mais concentrados nos pólos, parede celular pontuada. Medidas: 35,0-40,5 $\mu \mathrm{m}$ comprimento x 28,0-30,0 $\mu \mathrm{m}$ largura. 
Trachelomonas cf. bacilifera Playfair

Lórica elíptica com espinhos cônicos espalhados e mais concentrados nos pólos, parede celular pontuada. Medidas: 35,0-40,5 $\mu \mathrm{m}$ comprimento x 28,0-30,0 $\mu \mathrm{m}$ largura.

Trachelomonas cf. rotunda Swirenko

Lórica redonda, parede com pequenas pontuações, sem espessamento na abertura. Medidas: 12,0-18,0 $\mu \mathrm{m}$ diâmetro.

Trachelomonas volvocina Ehrenberg

Lóricas esféricas, parede celular lisa, com dois cloroplastos. Medidas: 13,017,0 um diâmetro.

Trachelomonas cf. volvocinopsis Ehrenberg

Lóricas esféricas, parede celular lisa, com vários cloroplastos discóides. Medidas: 15,5-19,0 um diâmetro. 


\section{REFERÊNCIAS BIBLIOGRÁFICAS}

1. ACIESP. Academia de Ciências do Estado de São Paulo. Glossário de Ecologia. 2 ed. São Paulo: ACIESP, n. 103, 1997.

2. AGEVAP. Associação pró-gestão das águas da bacia hidrográfica do Rio Paraíba do Sul. Relatório final PSR-018-RO - Plano de Recursos Hídricos da Bacia do Rio Paraíba do Sul - Resumo. 2007.

3. AGEVAP. Associação pró-gestão das águas da bacia hidrográfica do Rio Paraíba do Sul. Plano de Recursos Hídricos da Bacia do Rio Paraíba do Sul Resumo. Publicação: Janeiro/2007. Disponível em: <http://ceivap.org.br/gestao_1_1.php>. Acesso em: 02 de jul. 2008.

4. ALVES-DA-SILVA, S. M.; LAITANO, M. C. Euglenaceae pigmentadas do Banhado do Jacaré, em um Parque de Proteção Ambiental, Triunfo, Rio Grande do Sul, Brasil. Iheringia, sér. Bot., v. 28, p. 95-106, 1994.

5. ANAGNOSTIDIS, K.; KOMÁREK, J. Modern approach to the classification system of cyanophytes, 3: Oscillatoriales. Algological Studies, v. 50, n. 53, p. 327-472.1988.

6. ANAGNOSTIDIS, K.; KOMÁREK, J. Modern approach to the classification system of cyanophytes, 5: Stigonematales. Algological Studies, v. 59, p. 1-53. 1990.

7. APHA. American Public Health Association, AWWA American Water Works Association, WEF Water Environmental Federation. Standard Methods for the Examination of water and Wastewater. $20^{\text {th }}$ ed. Washington: American Public Health Association, 2005.

8. BARBOSA, F. A. R.; PADISÁK, J.; ESPÍNDOLA, E. L. G.; BORICS, G.; ROCHA $O$. The cascading reservoir continuum concept (CRCC) and its application to the river Tietê-basin, São Paulo State, Brazil. In: TUNDISI, J. G.; STRASKRABRA, M. Theoretical Reservoir Ecology and its applications. São Carlos. Rio de Janeiro: International Institute of Ecology ; Brazilian Academy of Sciences. 1999.

9. BARBOSA, J. E. L. Dinâmica do fitoplâncton e condicionantes limnológicos nas escalas de tempo (nictmeral/sazonal) e de espaço (horizontal/vertical) no açude Taperoá II: trópico semi-árido nordestino. 2002. Tese (Doutorado) - Universidade Federal de São Carlos. São Paulo.

10. BEGON, M.; HARPER, J. L.; TOWNSEND, C. R. Ecology: Individuals, Populations and Communites. 2 ed. Inglaterra: Blackwell Sci. Publ. Oxford, 1990. 
11. BEYRUTH, Z. Comunidade fitoplanctônica da represa Guarapiranga: 1991-1992, Aspectos ecológicos, sanitários e subsídios para a reabilitação da qualidade ambiental. 1996. Tese (Doutorado) - Universidade de São Paulo, São Paulo.

12. BICUDO, C. E. M.; MENEZES, M. Gêneros de Algas de Águas Continentais do Brasil - Chave para Identificação e Descrições. 2 ed. São Carlos, SP: Rima, 2005.

13. BITTENCOURT-OliveIRA, M. C.; MOURA, A. N.; OlIVEIRA, M. C. Geitlerinema species (Oscillatoriales, Cyanobacteria) revealed by cellular morphology, ultrastructure, and DNA sequencing. J. Phycol., v. 45, p. 716-725, 2009.

14. BOURRELLY $P$. Les algues d'eau douce: initiation à la systemátigue, 2: les algues jaunes et brunes, les Chrysophycées, Phéophycées, Xantophycées et Diatomomées. Paris: Éditions N. Boubée; 1981. v.2.

15. BOURRELLY P. Les algues d'eau douce: initiation à la systemátique, 3: les algues blenes et rouges, les Eugléniens, Peridiniens, et Cryptomonadinas. Paris: Éditions N. Boubée; 1985. v.3.

16. BRANCO, S. M. Hidrobiologia aplicada à Engenharia Sanitária. 3 ed. São Paulo: CETESB. ASCETESB, 1986.

17. BRANDIMARTE, A. L. Macrofauna bentônica da zona litoral da represa de Paraibuna (SP): a influência de diferentes ecossistemas terrestres perimetrais. 1991. Dissertação (Mestrado) - Universidade de São Paulo. São Paulo.

18. BRASIL. Lei Federal n. $^{\circ}$ 9.433. Brasília, DF. 1997. Disponível em: <http://www.planalto.gov.br/ccivil_03/Leis/L9433.htm>. Acesso em: 06 dez. 2009.

19. BRASIL. MINISTÉRIO DA SAÚDE. Portaria n. ${ }^{\circ}$ 518. Brasília, DF. 2004. Disponível em: <http://www.cidades.gov.br/secretariasnacionais/saneamentoambiental/legislacao/portaria/port518.pdf>. Acesso em: 01 fev. 2006.

20. BRASIL. CONSELHO NACIONAL DO MEIO AMBIENTE. Resolução $\boldsymbol{n}^{\circ} 357$. Brasília, DF. 2005. Disponível em: <http://www.mma.gov.br/port/conama/res/res05/res35705.pdf>. Acesso em: 20 jul. 2009.

21. BRASIL. CONSELHO NACIONAL DO MEIO AMBIENTE. Resolução $\boldsymbol{n}^{\circ} 397$. Brasília, DF. 2008. Disponível em: <http://www.mma.gov.br/port/conama/res/res05/res35705.pdf>. Acesso em: 02 out. 2009.

22. CABIANCA, M. A. A. Represa de paraibuna : aspectos do zooplâncton. 1991. Dissertação (Mestrado) - Universidade de São Paulo. São Paulo. 
23. CARDOSO, L. S.; TORGAN, L. C. Dinoflagelados em diversos habitats e hidroperíodos na zona costeira do sul do Brasil. Acta bot. bras., v. 21, n. 2, p. 411-419, 2007.

24. CARMICHAEL, W. W. Freshwater cyanobacteria (blue-green algae) toxins. In: OWSBY, C. L. e ODELL, G. V. (eds.). Natural toxins: characterization, pharmacology and therapeutics pergamon press, p. 3-16, 1989.

25. CARMICHAEL, W. W. Health effects of toxin-producing cyanobacteria: The CyanoHABs. Human and Ecological Risk Assessment, v. 75, p. 1393-1407, 2001.

26. CARVALHO, M. C. Comunidade Fitoplanctônica como instrumento de biomonitoramento de reservatórios no estado de São Paulo. 2003. Tese (Doutorado) - Universidade de São Paulo, São Paulo.

27. CARVALHO, L. R.; SANT'ANNA, C. L.; GEMELGO, M. C. P.; AZEVEDO, M. T. P. Cyanobacterial occurrence and detection of microcystin by planar chromatography in surface water of Billings and Guarapiranga Reservoirs, SP, Brazil. Revista Brasil. Bot., v.30, n.1, p.141-148, 2007.

28. CATANI, D. B.; HUGO, F. N.; CYPRIANO, S.; SOUSA, M. L. R.; CURY, J. A. Relação entre níveis de fluoreto na água de abastecimento público e fluorose dental. Revista Saúde Pública 41(5): 732-739. 2007.

29. CESP. Usina Hidrelétrica Paraibuna. Disponível em: <http://www.cesp.com.br>. Acesso em 02 jul. 2008.

30. CETESB - Companhia de Tecnologia de Saneamento Ambiental. Fitoplâncton de água doce. Métodos qualitativo e quantitativo (Método de Ensaio. 2005. Disponível em: < http://www.bmn.com.br/plan-leg/ma/estsp/decis/cetesb42-06.pdf>. Acesso em: 28 mar. 2008.

31. CETESB - Companhia de Tecnologia de Saneamento Ambiental. Decisão de Diretoria $n^{\circ}$ 232/2006/E. São Paulo: CETESB, 2006. (Norma Técnica L5.303).

32. CETESB - Companhia de Tecnologia de Saneamento Ambiental. Relatório Qualidade das águas interiores no estado de São Paulo - Índice da Qualidade das águas. $2007 . \quad$ Disponível em: <http://www.cetesb.sp.gov.br/Agua/rios/publicacoes.asp>. "download" - Acesso em: 17 jul. 2008.

33. CETESB - Companhia de Tecnologia de Saneamento Ambiental. Variáveis de qualidade das águas. Disponível em: <http://www.cetesb.sp.gov.br/Agua/rios/variaveis.asp> Acesso em: 08 jul. 2009.

34. CIIAGRO - Centro Integrado de Informações Agrometeorológicas. Disponível em: <http://www.ciiagro.sp.gov.br/>. Acesso em: 11 jul. 2008. 
35. COLE, G. Textbook of limnology. Saint Louis: The C.V. Mosby, 1975.

36. COQUEMALA, V. Variação anual do fitoplâncton no reservatório Passaúna, Paraná. 2005. Dissertação (Mestrado) - Universidade Federal do Paraná, Paraná.

37. CORBI, J. J.; STRIXINO, S. T.; SANTOS, A.; DEL GRANDE, M. Diagnóstico ambiental de metais e organoclorados em córregos adjacentes a áreas de cultivo de cana-de-açúcar (estado de São Paulo, Brasil). Quim. Nova, v. 29, n. 1, p. 6165, 2006.

38. COSTA, A. B. Estrutura da comunidade fitoplanctônica em sistema de áreas alagáveis, na planície de inundação do rio Jaucpiranguinha, Vale do Ribeira de Igaupe - SP. 2007. Dissertação (Mestrado) - Universidade de São Paulo. São Paulo.

39. COTTA, J. A. O.; REZENDE, M. O. O.; PIOVANI, M. R. Avaliação do teor de metais em sedimento do Rio Betari no Parque Estadual Turístico do Alto Ribeira PETAR, São Paulo, Brasil. Química Nova, v. 29, n. 1, p. 40-45. 2006.

40. COTRIM, M. E. B. Avaliação da qualidade da água na bacia hidrográfica do Ribeira de Iguape com vistas ao abastecimento público. 2006. Tese (Doutorado) - Instituto de Pesquisas Energéticas e Nucleares, São Paulo.

41. DIAS, N. W.; MORAES, E. C.; NOVO, E. M. L. M.; ARAI, E.; CATELANI, C. S. Caracterização das Águas da Represa de Paraibuna com o Uso de Dados Hiperespectrais. In: SIMPÓSIO BRASILEIRO DE SENSORIAMENTO REMOTO, 13. (SBSR), 2007, Florianópolis. Anais... São José dos Campos: INPE, 2007. p. 3335-3342. Disponível em: <http://urlib.net/dpi.inpe.br/sbsr@80/2006/11.13.23.48>. Acesso em: 31 jul. 2009.

42. ESPÍNDOLA, E. L. G. Limnologia de Represas: alguns fatores determinantes. São Carlos. 2001.

43. ESTEVES, F. A. Fundamentos de Limnologia. 2.ed. Rio de Janeiro: Interciência, 1998.

44. FERRAGUT, C.; LOPES, M. R. M.; BICUDO, D. C.; BICUDO, C. E. M.; VERCELLINO, I. S. Ficoflórula perifítica e planctônica (exceto Bacillariophyceae) de um reservatório oligotrófico raso (Lago do IAG, São Paulo). Hoehnea, v. 32, n. 2, p. 137-184, 2005.

45. FIGUEIREDO, C. C. Monitoramento da Qualidade da Água de Sete Reservatórios Pertencentes a Furnas Centrais Elétricas S.A. In: $3^{\circ}$ Simpósio de Especialistas em Operação de Centrais Hidrelétricas, 2002, Foz do Iguaçu. Disponível em: <http://www2.itaipu.gov.br/sepoch/>. Acesso em: 24 set. 2009.

46. FONSECA, B. M. Diversidade fitoplanctônica como discriminador ambiental em dois reservatórios rasos com diferentes estados tróficos no 
Parque Estadual das Fontes do Ipiranga, São Paulo, SP. 2005. Tese (Doutorado) - Universidade de São Paulo, São Paulo.

47. FONSECA, B. M.; BICUDO, C. E. M. Phytoplankton seasonal variation in a shallow stratified eutrophic reservoir (Garças Pond, Brazil). Hydrobiologia, v. 600 , p. 267-282, 2008.

48. FOSTER, I. D. L.; CHARLESWORTH, S. M. Heavy Metals in the Hydrological Cycle Trends and Explanation. Hidrological processes, v. 10, p. 227-261, 1996.

49. GENTIL, R. C. Estrutura da comunidade fitoplanctônica de pesqueiros da Região Metropolitana de São Paulo, SP, em dois períodos: primavera e verão. 2007. Tese (Doutorado) - Instituto de Botânica de São Paulo, São Paulo.

50. GIANESELLA-GALVÃO, S. M. F. Limnology of ten reservoirs in Southern Brazil, II: Phytoplankton primary productivity in a reservoir with monomictical characteristics - Paraibuna Reservoir. In: BICUDO, C. E.; TEIXEIRA, C.; TUNDISI, J. G. (Eds.). Algas: a energia do amanhã. São Paulo: Ins. Oceanogr/USP, 1986. p. 199-208.

51. GIANI, A.; FIGUEIREDO, C. C.; ETEROVICK, P. C. Algas planctônicas do reservatório da Pampulha (MG): Euglenophyta, Chrysophyta, Pyrrophyta, Cyanobacteria. Revta brasil. Bot., v. 22, n. 2, p.107-116, 1999.

52. GODOI, E. L. Monitoramento de água superficial densamente poluída - o Córrego Pirajuçara, Região Metropolitana de São Paulo, Brasil. 2008. Dissertação (Mestrado) - Instituto de Pesquisas Energéticas e Nucleares, São Paulo.

53. GRIGORSZKY, I.; BORICS, G.; PADISÁK, J.; TÓTMÉRÉSZ, B.; VASAS, G.; NAGY, S.; BORBÉLY, G. Factors controlling the occurrence of Dinophyta species in Hungary. Hydrobiologia, v. 506-509: 203-207, 2003.

54. HENRY, R.; NUNES, M. A.; MITSUKA, P. M.; LIMA, N.; CASANOVA, S. M. C. Variação espacial e temporal da produtividade primária pelo fitoplâncton na represa de Jurumirim (rio Paranapanema, SP). Rev. Brasil. Biol., v. 58, n. 4, p. 571-590, 1998.

55. HENRY, R.; USHINOHAMA, E.; FERREIRA, R. M. R. Fitoplâncton em três lagoas marginais ao Rio Paranapanema e em sua desembocadura no Reservatório de Jurumirim (São Paulo, Brasil) durante um período prolongado de seca. Revista Brasil. Bot., v. 29, n. 3, p. 399-414, 2006.

56. HORIZONTE GEOGRÁFICO. Dossiê Água e Energia. Disponível em: <www.horizontegeografico.com.br/arquivos/arquivo 20.pdf>. Acesso em: 02 out. 2009.

57. HUSZAR, V. L. M. Fitoplâncton de um lago amazônico impactado por rejeito de bauxita (Lago Batata, Pará, Brasil): estrutura da comunidade, 
flutuações espaciais e temporais. 1994. Tese (Doutorado) - Universidade Federal de São Carlos, São Paulo.

58. IBGE. Instituto Brasileira de Geografia e Estatística. Disponível em: <http://www.ibge.gov.br/cidadesat/topwindow.htm?1>. Acesso em: 30 set. 2009.

59. INPE. Instituto Nacional de Pesquisas Espaciais. Imagem de satélite. Disponível em: $<$ http://www.dgi.inpe.br/CDSR/manage.php?INDICE=CB2BCCD15312620080903 \&DONTSHOW=0>. Acesso em: 02 out. 2009.

60. INSTITUTO H \& H FAUSER. Núcleo de formação ecoprofissional do Instituto $\mathrm{H}$ \& $\mathrm{H}$ Fauser no município de Paraibuna - SP. Disponível em: http://www.ihhf.org.br/ihhf2-br.htm. Acesso em: 23 set 2009.

61. ISA - Instituto Socioambiental. Almanaque Brasil Socioambiental. São Paulo: ISA, 2008.

62. ISHII, I. H. Contribuição ao estudo do ciclo do carbono na Represa de Três Marias, MG. 1987. Dissertação (Mestrado) - Universidade Federal de São Carlos, São Paulo.

63. JULIEN, M. H.; CENTER, T. D.; TIPPING, P. W. Floating Fern (Salvinia). In: VAN DRIESCHE, R., et al. Biological Control of Invasive Plants in the Eastern United States, USDA Forest Service Publication FHTET, 2002. 413 p. Disponível em: <http://www.invasive.org/eastern/biocontrol/2FloatingFern.html>. Acesso em: 13 out. 2009.

64. KOMÁREK, J.; ANAGNOSTIDIS, K. Modern approach to the classification system of cyanophytes, 2: Chroococcales. Algological Studies, v. 43, p. 157226, 1986.

65. KOMÁREK, J.; ANAGNOSTIDIS, K. Modern approach to the classification system of cyanophytes, 4: Nostocales. Algological Studies, v. 56, p. 247-345, 1989.

66. KOMÁREK, J.; ANAGNOSTIDIS, K. Cyanoprokaryota. I. Teil Chroococcales. In: Ettl H, Gärtner G, Heyning H, Möllenhauer D. (Eds). Süßwasserflora von Mitteleuropa. Stuttgart: Gustav Fischer Verlag., v.19/1. 2005.

67. KOMÁREK, J. Cyanobacterial Taxonomy: Current Problems and Prospects for the Integration of Traditional and Molecular Approaches. Algae, v. 21, n. 4, p. 349375, 2006.

68. KRIENITZ, L.; KASPRZAK, P.; KOSCHEL, R. Long term study on influence of eutrofication, restoration and development of phytoplankton communities in Feldberg Haussee (Baltic Lake District, Germany). Hydrobiologia, v. 30, p. 89110, 1996. 
69. KUHLMANN, M. L. Estudo da comunidade de invertebrados bentônicos da zona profunda da represa de paraibuna (SP). 1993. Dissertação (Mestrado) - Universidade de São Paulo. São Paulo.

70. LAMPARELLI, M. C. Graus de trofia em corpos d'água do estado de São Paulo: avaliação dos métodos de monitoramento. São Paulo. 2004. Tese (Doutorado) - Universidade de São Paulo, São Paulo.

71. LEITE, M. A. Análise do aporte, da taxa de sedimentação e da concentração de metais na água, plancton e sedimento do Reservatório de Salto Grande, Americana-SP. 2002. Tese (Doutorado) - Escola de Engenharia de São Carlos, São Paulo.

72. LILIAMTS, T. B. Avaliação da adição de nitrato de amônio para redução de odor ns esgotos de Pereira Barreto - SP: reflexos na qualidade da água do reservatório de Três Irmãos, após dez anos de aplicação. 2007. Tese (Doutorado) - Universidade de São Paulo, São Paulo.

73. LLOYD, M.; GHELARDI, R. J. A table for calculating the equitability component of species diversity. Journal of Ecology, v. 33, p. 217-225, 1964.

74. LOBO, E.; LEIGHTON, G. Estruturas de las fitocenosis planctónicas de los sistemas de desembocaduras de rios y esteros de la zona central de Chile. Revista de Biologia Marinha, v. 22, n. 1, p. 143-170, 1986.

75. LONG, R. R.; MORGAN, L. G. The Potential for Biological Effects of SedimentSorbed Contaminants Tested in the National Status and Trends Program. NOAA Technical Memorandum, No. 5, OMA52, NOAA National Ocean Service, Seattle, 1990.

76. LOPES, A. G. D. Estudo da comunidade fitoplanctônica como bioindicador de poluição em três reservatórios em série do Parque Estadual da Fontes do Ipiranga (PEFI), São Paulo, SP. 2007. Dissertação (Mestrado) Universidade de São Paulo, São Paulo.

77. LUND, J. W. G.; KIPLING, C.; LECREN, E. D. The invert microscope method of estimating algal numbers and the statistical basis of estimations by counting. Hydrobiologia, v. 11, p. 143-170, 1958.

78.MANANCIAIS. De olho nos mananciais. Disponível em: <http://www.mananciais.org.br/site/legislacao/leideprotecao97>. Acesso em: 25 set. 2009.

79. MARQUES, A. K. Análise da diversidade fitoplanctônica no reservatório da usina hidroelétrica Luis Eduardo Magalhães, no médio Tocantins-TO: estrutura da comunidade, flutuações temporais e espaciais. 2006. Dissertação (Mestrado) - Universidade Federal do Tocantins, Tocantins.

80. MARTINS, R. M. S.; IKEDA, A. K.; LOURENÇO, M. H.; SANTOS, L. C.; SILVA, E. A.; ROCHA, N. M. Ocorrência de Salvinia auriculata Aubl. 
(Salviniaceae) em dois pontos da baía do Malheiros, Pantanal de Cáceres-MT, Brasil. In: IV Simpósio sobre recursos naturais e sócio econômico do Pantanal, 2004, Corumbá, MS. SIMPAN ,

81. MATSUZAKI, M. A comunidade fitoplanctônica de um pesqueiro na cidade de São Paulo: aspectos ecológicos e sanitários. 2002. Dissertação (Mestrado) - Universidade de São Paulo. São Paulo.

82. MATSUZAKI, M.; MUCCI, J. L. N.; ROCHA, A. A. Comunidade fitoplanctônica de um pesqueiro na cidade de São Paulo. Revista Saúde Pública, v. 38, n. 5, p. 679- 86, 2004.

83. MERCANTE, C. T.; TUCCI-MOURA, A. Comparação entre os índices de Carlson e de Carlson modificado aplicado a dois ambientes aquáticos subtropicais, São Paulo, SP. Acta Limnológica Brasiliensia, v. 11, p. 1-14, 1999.

84. MILANI, G. M. A contaminação por $\mathrm{Al}, \mathrm{As}, \mathrm{Cr}, \mathrm{Cu}, \mathrm{Pb}, \mathrm{Cd}$, e $\mathrm{Zn}$ na bacia do Taiaçupeba Açu, SP - estudo da biomagnificação dos elementos. 2004. Tese (Doutorado) - Universidade de São Paulo. São Paulo.

85. MARGALEF, R. Limnologia. Barcelona: Omega, 1983.

86. MINILLO, A. Análise da distribuição, densidade e toxicidade de florações de cianobactérias e suas toxinas nos reservatórios do médio e baixo rio Tietê (SP) e relação com as características limnológicas do sistema. 2005. Tese (Doutorado) - Universidade de São Paulo, São Paulo.

87. MOURA, M. A. M.; FRANCO, D. A. S.; MATALLO, M. B. Manejo integrado de macrófitas aquáticas. Biológico, v. 71, n. 1, p. 77-82, 2009.

88. NAKANO, V.; AVILA-CAMPOS, M. J. Metais pesados: um perigo eminente. Disponível em:

$<$ http://www.icb.usp.br/ bmm/bmm dpto/index.php?option=com content\&task=vie w\&id=28\&ltemid=1 >. Acesso em: 19 jun. 2008.

89. NISHIMURA, P. Y. Ecologia da comunidade fitoplanctônica em dois braços da Represa Billings (São Paulo, SP) com diferentes graus de trofia. 2008. Dissertação (Mestrado) - Universidade de São Paulo, São Paulo.

90. NOGUEIRA, I. S.; LEANDRO-RODRIGUES, N. C. Algas planctônicas de um lago artificial do jardim botânico Chico Mendes, Goiânia, Goiás: florística e algumas considerações ecológicas. Revista Brasileira de Biologia, v. 59, n. 3, p. 377-395, 1999.

91. NOGUEIRA, I. S.; NABOUT, J. C.; OLIVEIRA, J. E.; SILVA, K. D. Diversidade (alfa, beta e gama) da comunidade fitoplanctônica de quatro lagos artificiais urbanos do município de Goiânia, Goiás. Hoehnea, v. 35, n. 2, p. 219-233, 2008. 
92. NORDI, C. S. F.; CAVAGLIERE, T. G. W. F.; VIEIRA, A. A. H.; NASCIMENTO, O. R. Efeito caotrópico do íon lítio na permeabilidade da cápsula polissacarídica da microalga Ankistrodesmus gracilis (Reinsch) Korsikov (Chlorophyceae). Acta bot. bras., v. 20, n. 2, p. 449-454, 2006.

93. ODUM, E. P. Ecologia. Rio de Janeiro: Guanabara, 1988.

94. OLIVEIRA, E. M.; KACOWICZ, Z. Relatório da qualidade do meio ambiente - ROMA. Brasília: Minter/SEMA, 1984.

95. OLIVEIRA, R. M. S.; TORNISIELO, V. L. Determinação de resíduos organoclorados no leite bovina na bacia do Cerveiro, Piracicaba, SP. In: VI Encontro de Ecotoxicologia, 2000, p. 95, Anais, Brasil.

96.PARAIBUNA. Investir em Paraibuna. Disponível em: <http://www.paraibuna.sp.gov.br/investir.htm>. Acesso em: 02 jul. 2008.

97. PARANAGUASSU, A. B. et al. Considerações sobre o assoreamento do reservatório Álvaro de Souza Lima (Bariri). In: TUNDISI, J. G. (Ed.) Limnologia e manejo de represas. São Paulo: EESC-USP/CRHEA; Academia de Ciências de São Paulo. p. 61-72, 1988.

98. PARRA, O. O.; BICUDO, C. E. M. Introduccion a la biologia y sistemática de las algas de águas continentales. Ediciones Universidad de Concepción.1996.

99. PAIVA, M. P. Grandes represas do Brasil. Brasília: Editerra, 1982.

100. PELÁEZ-RODRÍGUEZ, M. Avaliação da qualidade da água da Bacia do Alto Jacaré-Guaçu- SP (Ribeirão do Feijão e Ribeirão do Monjolinho) através de variáveis Físicas, Químicas e Biológicas. 2001. Tese (Doutorado) Universidade de São Paulo, São Paulo.

101. PEREIRA, M. O.; CALZA, C.; ANJOS, M. J.; LOPES, R. T.; ARAÚJO, F. G. Metal concentrations in surface sediments of Paraíba do Sul River (Brazil). Journal of Radioanalytical and Nuclear Chemistry, v. 269, n. 3, p. 707-709, 2006.

102. PEIXOTO, P. H. P.; PIMENTA, D. S.; ANTUNES, F. Efeitos do flúor em folhas de plantas aquáticas de Salvinia auriculata. Pesq. Agropec. Bras., Brasília, v. 40, n. 8, p. 727-734, 2005.

103. PIELOU, E. C. The measurement of diversity in different types of biological collections. Journal of Theoretical Biology, v. 13, p. 131-144, 1966.

104. PINTO-COELHO, R. M.; GIANI, A.; MORAIS-Jr, C.A.; CARVALHO-JR, E. R.; BEZERRA-NETO, J. F. The nutritional status of zooplankton in a tropical reservoir: effects of food quality and community structure. Brazilian Journal of Biology, v. 65, n. 2, p. 313-324, 2005. 
105. PIVELI, R. P.; KATO, M. T. Qualidade das Águas e Poluição: Aspectos Físico-Químicos. São Paulo: ABES, 2006 (Ed.)

106. PRIMO, A. R. R. Avaliação da influência do Reservatório do Funil na qualidade da água do Rio Paraíba do Sul. 2006. Dissertação (Mestrado) Universidade de São Paulo. São Paulo.

107. RAMIRES, I.; GREC, R. H. C.; CATTAN, L. MOURA, P. G., LAURIS, J. R. P., BUZALAF, M. A. R. Avaliação da concentração de flúor e do consumo de água mineral. Revista de Saúde Pública, v. 38, n. 3, p. 459-465, 2004.

108. RAVEN, P. H.; EVERT, R. F.; EICHORN, S. E. Biologia Vegetal. Rio de Janeiro, RJ: Guanabara-Koogan. 906 p. 2001.

109. REBOUÇAS, A. C. Água doce no mundo e no Brasil. In: Rebouças, A. C.; Braga, B.; Tundisi, J. G. Águas Doces do Brasil - Capital ecológico, uso e conservação. São Paulo: Escrituras Editora, 1999.

110. REYNOLDS, C. S.; HUSZAR, V.; KRUK, C.; NASEILLI-FLORES, L.; MELO, $S$. Towards funcional classification of the freshwater phytoplankton. Journal of Plankton Research, v. 24, n. 5, p. 417-428, 2002.

111. ROSSO, S. Amostragem, repartição espacial e diversidade/dominância de comunidades de costões rochosos: uma abordagem metodológica. Laboratório de Ecologia Marinha - Universidade de São Paulo. 1996. p. 30.

112. ROUND, F. E. The taxonomy of the Chlorophyta II. British Phycological Journal, v. 6, n. 2, p. 235-264, 1971.

113. ROUND, F. E.; CRAWFORD, R. M.; MANN, D. G. The diatoms: biology and morphology of the genera. Cambridge: University Press. 1990.

114. SANTA BRANCA. Prefeitura Municipal de Santa Branca. Disponível em: <http://www.santabranca.sp.gov.br/dadosgerais.htm >. Acesso em: 23 set. 2009.

115. LIRA, G. A. S. T.; BITTENCOURT-OliVEIRA, M. C.; MOURA, A. N. Caracterização Ecológica da Comunidade Fitoplanctônica em um Reservatório de Abastecimento do Estado de Pernambuco. Revista Brasileira de Biociências, v. 5, supl. 2, p. 219-221, 2007.

116. SANT'ANNA, C. L.; AZEVEDO, M. T. P.; SORMUS, L.. Fitoplâncton do Lago das Garças, Parque Estadual das Fontes do Ipiranga, São Paulo, SP, Brasil: Estudo Taxonômico e aspectos Ecológicos. Hoehnea, v. 16, p. 89-131, 1989.

117. SANT'ANNA, C.L.; AZEVEDO, M.T.P.; AGUJARO, L.F.; CARVALHO, M.C.; CARVALHO, L.R.; SOUZA, R.C.R. Manual ilustrado para identificação e contagem de cianobactérias planctônicas de águas continentais brasileiras. Rio de Janeiro: Interciência; São Paulo: Sociedade Brasileira de Ficologia - SBFIc. 2006. 
118. SANT'ANNA, C.L.; AZEVEDO, M.T.P.; WERNER, R. V.; DOGO, C. R.; RIOS, F. R.; CARVALHO, R. L. Review of toxic Cyanobacteria in Brazil. Algological Studies, v. 126, p. 252-265, 2008.

119. SANTOS, A. Distribuição de metais no reservatório de captação de água superficial Anhumas Américo Brasiliense -SP. 1999. Dissertação (Mestrado) Universidade de São Paulo. São Paulo.

120. SÃO PAULO. SECRETARIA DO MEIO AMBIENTE. Decreto $\boldsymbol{n}$. $^{\mathbf{1}} \mathbf{1 0 . 7 5 5}$. São Paulo, SP. 1977.

121. SETO, L. M. Inter-relação entre a comunidade fitoplanctônica e variáveis ambientais em tanques de piscicultura nos períodos de seca e chuva. 2007. Dissertação (Mestrado) - Universidade Estadual Paulista "Julio de Mesquita Filho", São Paulo.

122. SEVA, O. Estranhas catedrais. Notas sobre o capital hidrelétrico, a natureza e a sociedade. Ciênc. cult., v. 60, n. 3, p. 44-50, 2008. Disponível em $<$ http://www.fem.unicamp.br/ seva/SEVA estranhascatedrais a14v60n3.pdf>.

Acesso em: 24 set. 2009.

123.SHANNON, C. E.; WEAVER, W. The mathematical theory of communication. Urbana: University of Illianois Press; 1963.

124. SHEPHERD, G. J. FITOPAC 1: Manual de Usuário. Departamento de Botânica, Unicamp. Campinas. 1996.

125. SHIMIZU, G. Y.; CARVALHO, M. A. J.; ROMANINI, P. U.; BRANDIMARTE, A. L.; KUHLMANN, M. L.; CABIANCA, M. A. A. Estudo Integrado de ecossistemas terrestres e aquáticos na represa de Paraibuna, SP: Limnologia. In: CONGRESSO BRASILEIRO DE LIMNOLOGIA, 3., 22-26 julho, 1990, Porto Alegre. Resumos... Porto Alegre.

126. SILVA, D. Dinâmica de populações de Microcystis (Cyanobacteria) em pesqueiros da Região Metropolitanta de São Paulo, SP. 2005. Dissertação (Mestrado) - Instituto de Botânica da Secretaria do Meio Ambiente, São Paulo.

127. SIMONSEN, R. The diatom system: ideas on phylogeny. Baccilaria., v.2, p.971.1979.

128. SIMPSON, E. H. Measurement of diversity. Nature, v. 163, p. 668-668, 1949.

129. SLADECEK, V. System of water quality from biological point of view. Archiv für Hydrobiologie, v. 7, p. 1-218, 1973.

130. SOARES, C. R. A. Concentrção de metais pesados em sedimento, água e macrófitas aquáticas em duas represas do município de Viçosa, MG. 2006. Tese (Doutorado) - Universidade Federal de Viços. Minas Gerais. 
131. SOMMER, U.; PADISÁK, J.; REYNOLDS, C. S.; JUHÁSZ-NAG, P. Hutchinson's heritage: the diversity-disturbance relationship in phytoplankton. In: PADISÁK, J., REYNOLDS, C. S.; SOMMER, U. (Eds.). Intermediate disturbance hypothesis in phytoplankton ecology. Belgica: Kluwer Academic Publishers; 1993.

132. SOUSA, W. L. Impacto ambiental de hidrelétricas: uma análise comparativa de duas abordagens. 2000. Dissertação (Mestrado) - Universidade Federal do Rio de Janeiro. Rio de Janeiro.

133. STRAŠKRABA, M.; TUNDISI, J. G. Gerenciamento da qualidade da água de represas. Diretrizes para o gerenciamento de lagos. São Carlos: ILEC/IIE; v.9. 2000.

134. SZAJUBOK, A. L. F. R. O desenvolvimento da comunidade fitoplanctônica na represa Guarapiranga no período de 1994 a 1997. 2000. Dissertação (Mestrado) - Universidade de São Paulo, São Paulo.

135. TANIGUCHI, G. M. Estrutura, variação espacial e temporal da comunidade fitoplanctonica em três lagos do Vale do rio doce, estado de Minas Gerais. 2002. Tese (Doutorado) - Universidade Federal de São Carlos, São Paulo.

136. TOLEDO, Jr. A. P. Informe preliminar sobre os estudos para obtenção de um índice para avaliação do estado trófico de reservatórios de regiões quentes tropicais. São Paulo, Companhia de Tecnologia de Saneamento Ambiental, 12 p. Relatório Interno CETESB, 1990.

137. TRINDADE, T. N. Dinâmica horizontal do fitoplâncton no reservatório de Serra da Mesa (GO) em três períodos climatológicos. 2007. Trabalho de Conclusão de Curso. Bacharelado em Biologia Vegetal. Universidade Federal do Rio de Janeiro, Rio de Janeiro. Disponível em: < http://www.dsr.inpe.br/projetofurnas/doc/DinamicaHorizontalFitoplanctonSM.pdf>.

Acesso em: 02 out. 2009.

138. TUCCI, A. Sucessão da comunidade fitoplanctônica de um reservatório urbano e eutrófico, São Paulo, SP, Brasil. 2002. Tese (Doutorado) Universidade Estadual Paulista, São Paulo.

139. TUCCI, A.; SANT'ANNA, C. L.; GENTIL, R. C.; AZEVEDO, M. T. P. Fitoplâncton do Lago das Garças, São Paulo, SP, Brasil: um reservatório urbano eutrófico. Hoehnea, v. 33, n. 2, p. 147-175, 2006.

140. TUNDISI, J. G. Reservatórios como sistemas complexos: Teoria, aplicações e perspectivas para usos múltiplos. In: HENRY, R. Ecologia de Reservatórios: Estrutura, Função e aspectos sociais. São Paulo: FAPESP-FUNDIBIO, 1999.

141. TUCCI-MOURA, A. N. Estrutura e dinâmica da comunidade fitoplanctônica numa lagoa eutrófica, São Paulo, SP, Brasil, a curtos 
intervalos de tempo: comparação entre épocas de chuva e seca. 1996. Dissertação (Mestrado) - Universidade Estadual Paulista, São Paulo.

142. UTEHRMÖHL, H. Zur Vervolkomnung der quantitative phytoplankton: methodik. Mitteilungen Internationale Vereinigung fur Theoretische und Agenwandte Limnologie, v. 9, p. 1-38, 1958.

143. VIANNA, L. G. G.; SATO, A. M.; NETTO, A. L. C. Expansão do eucalipto no Vale do Rio Paraíba do Sul: subsídios aos estudos hidrológicos de bacias. In: XIII Simpósio Brasileiro de Geografia Física Aplicada, 06-10 julho, 2009, Universidade Federal de Viçosa. Disponível em: <http://www.geo.ufv.br/simposio/simposio/trabalhos/trabalhos_completos/eixo2/00 7.pdf>. Acesso em: 06 nov. 2009.

144. VERCELLINO, I. S.; BICUDO, D. C. Sucessão da comunidade de algas perifíticas em reservatório oligotrófico tropical (São Paulo, Brasil): comparação entre período seco e chuvoso. Revista Brasileira de Botânica, v. 29, n. 3, p. 363-377, 2006.

145. VETTORATO, B. Avaliação da qualidade da água no lago artificial do balneário de Jurerê Internacional, Florianópolis, SC. IN: V Semana de Ensino, Pesquisa e Extensão, 14-17 setembro, 2005, UFSC. Disponível em: <http://www.sepex.ufsc.br/anais 5/trabalhos/776.html>. Acesso em: 19 out. 2009.

146. VOLLENWEIDER, R. A. Moglichkeiten und Grenzen Elementarer Modelle der Stoffbitansz von seen. Arch. Hydrobiol., v. 66, p. 1-36, 1968.

147. XAVIER, M. B. Contribuição ao estudo da variação sazonal do fitoplâncton na Represa Billings, São Paulo, SP. 1979. Dissertação (Mestrado) - Universidade de Sâo Paulo, São Paulo.

148. WARREN, C. E. Biology and water pollution control. W. B. Saunders Company, Philadelphia, 1971.

149. WEBER, C. I. Plankton. In: National Environmental Research Center Office of Research and Development U.S. Environmental Protection Agency Cincinnati (Ed). Biological field and laboratory methods for measuring the quality on surface water and effluents, p.1-17. 1973.

150. WEHR, J. D.; SHEATH, R. G. Freshwater algae of North America Ecology and Classification. USA: Academic Press. 918 p. 2003.

151 WERNER, V.R. Cyanophyceae/Cyanobacteria no sistema de lagoas e lagunas da planície do estado de Rio Grande do Sul, Brasil. 2002. Tese (Doutorado) - Universidade Estadual Paulista, Rio Claro.

152. WETZEL, R.G. Limnologia. Ed. Fundação Calouste Gulbenkian, 1993.

153. WETZEL, R. G. Limnology: lake and river ecosystems. $3^{a}$ ed. San Diego: Academic Press, 2001. 